\title{
Perioperative arginine metabolism in cancer : interorgan studies in mice
}

Citation for published version (APA):

Vissers, Y. L. J. (2008). Perioperative arginine metabolism in cancer : interorgan studies in mice. [Doctoral Thesis, Maastricht University]. Universiteit Maastricht. https://doi.org/10.26481/dis.20080411yv

Document status and date:

Published: 01/01/2008

DOI:

10.26481/dis.20080411yv

Document Version:

Publisher's PDF, also known as Version of record

\section{Please check the document version of this publication:}

- A submitted manuscript is the version of the article upon submission and before peer-review. There can be important differences between the submitted version and the official published version of record.

People interested in the research are advised to contact the author for the final version of the publication, or visit the DOI to the publisher's website.

- The final author version and the galley proof are versions of the publication after peer review.

- The final published version features the final layout of the paper including the volume, issue and page numbers.

Link to publication

\footnotetext{
General rights rights.

- You may freely distribute the URL identifying the publication in the public portal. please follow below link for the End User Agreement:

www.umlib.nl/taverne-license

Take down policy

If you believe that this document breaches copyright please contact us at:

repository@maastrichtuniversity.nl

providing details and we will investigate your claim.
}

Copyright and moral rights for the publications made accessible in the public portal are retained by the authors and/or other copyright owners and it is a condition of accessing publications that users recognise and abide by the legal requirements associated with these

- Users may download and print one copy of any publication from the public portal for the purpose of private study or research.

- You may not further distribute the material or use it for any profit-making activity or commercial gain

If the publication is distributed under the terms of Article $25 \mathrm{fa}$ of the Dutch Copyright Act, indicated by the "Taverne" license above, 


\section{Perioperative arginine metabolism in cancer [interorgan studies in mice]}


omslag jeanscheijen (vierdrie.nl) foto's \& layout jeanscheijen | yvonnevissers druk ISBN datawyseuniversitairepers 978-90-5278-702-2

Cyvonnevissersmaastricht2008 


\section{Perioperative arginine metabolism in cancer [interorgan studies in mice]}

\section{PROEFSCHRIFT}

ter verkrijging van de graad van doctor aan de Universiteit Maastricht, op gezag van de Rector Magnificus, prof. mr. GPMF Mols volgens het besluit van het College van Decanen, in het openbaar te verdedigen op vrijdag 11 april 2008 om 12:00 uur

door

Yvonne Leonie Josephine Vissers 


\section{promotores |}

prof. dr. MF von Meyenfeldt

prof. dr. NEP Deutz (University of Arkansas, VS)

\section{copromotores |}

dr. CHC Dejong

dr. ir. YC Luiking (Numico Research, Wageningen)

\section{beoordelingscommissie}

prof. dr. WH Lamers (voorzitter)

prof. dr. WA Buurman

prof. dr. L Cynober (Hôpital Hôtel-Dieu, Parijs, F)

prof. dr. Ph Lambin

prof. dr. PAM van Leeuwen (Vrije Universiteit, Amsterdam)

De studies in dit proefschrift kwamen mede tot stand door financiële ondersteuning van de Nederlandse Organisatie voor Wetenschappelijk Onderzoek(NWO, ZonMw AGIKO-subsidie 920-03-240), de European Society for Enteral and Parenteral Nutrition (ESPEN, research fellowship 2002) en Novartis Consumer Health. 


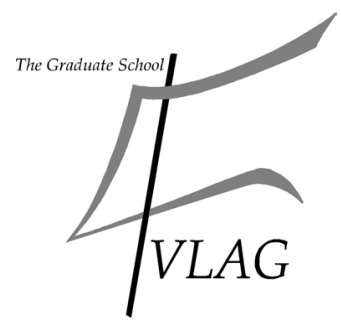

De studies in dit proefschrift werden verricht binnen het Nutrition and Toxicology Research Institute Maastricht (NUTRIM), dat participeert in de onderzoekschool Voeding, Levensmiddelentechnologie, Agrobiotechnologie en Gezondheid (VLAG), geaccrediteerd door de Koninklijke Nederlandse Akademie van Wetenschappen (KNAW). 

aan mijn vader 


\section{contents}

$\begin{array}{lll}\text { partone | } & \text { iniroductionandmethods } \\ \text { chapterone } & \text { | Arginine metabolism in cancer } & 13 \\ \text { chaptertwo } & \begin{array}{l}\text { Plasma arginine concentrations are reduced in } \\ \text { cancer patients: evidence for arginine deficiency? }\end{array} & 31 \\ \text { chapterthree } & \mid \text { Mouse tumour models and tracer methodology } & 41 \\ \text { chapterfour } & \mid \begin{array}{l}\text { Measuring whole-body actin/myosin protein } \\ \text { breakdown in mice using a primed constant stable } \\ \end{array} & \begin{array}{l}\text { isotope infusion protocol } \\ \end{array}\end{array}$

\begin{tabular}{l|l} 
partiwo | & $\begin{array}{l}\text { nen-cagnectice of tumour inhibits the normal postoperativ } \\
\text { response in arginine and NO production in } \\
\text { non-cachectic mice }\end{array}$ \\
chapterfive & $\begin{array}{l}\text { Interorgan synthesis of arginine is downregulated in } \\
\text { tumour-bearing mice undergoing surgical trauma }\end{array}$ \\
chapterseven $\quad$ | $\begin{array}{l}\text { Protein breakdown on whole-body and organ level } \\
\text { in non-cachectic tumour-bearing mice undergoing } \\
\text { surgery }\end{array}$
\end{tabular}

\begin{tabular}{c|l} 
parthree | & cachecticmodel \\
chaptereight & $\begin{array}{l}\text { Surgical stress in cachectic tumour-bearing mice } \\
\text { disturbs arginine metabolism }\end{array}$ \\
chapternine & $\begin{array}{l}\text { Cachectic tumour increases myofibrillar protein } \\
\text { breakdown and attenuates the metabolic response } \\
\text { to surgical trauma in mice }\end{array}$
\end{tabular}




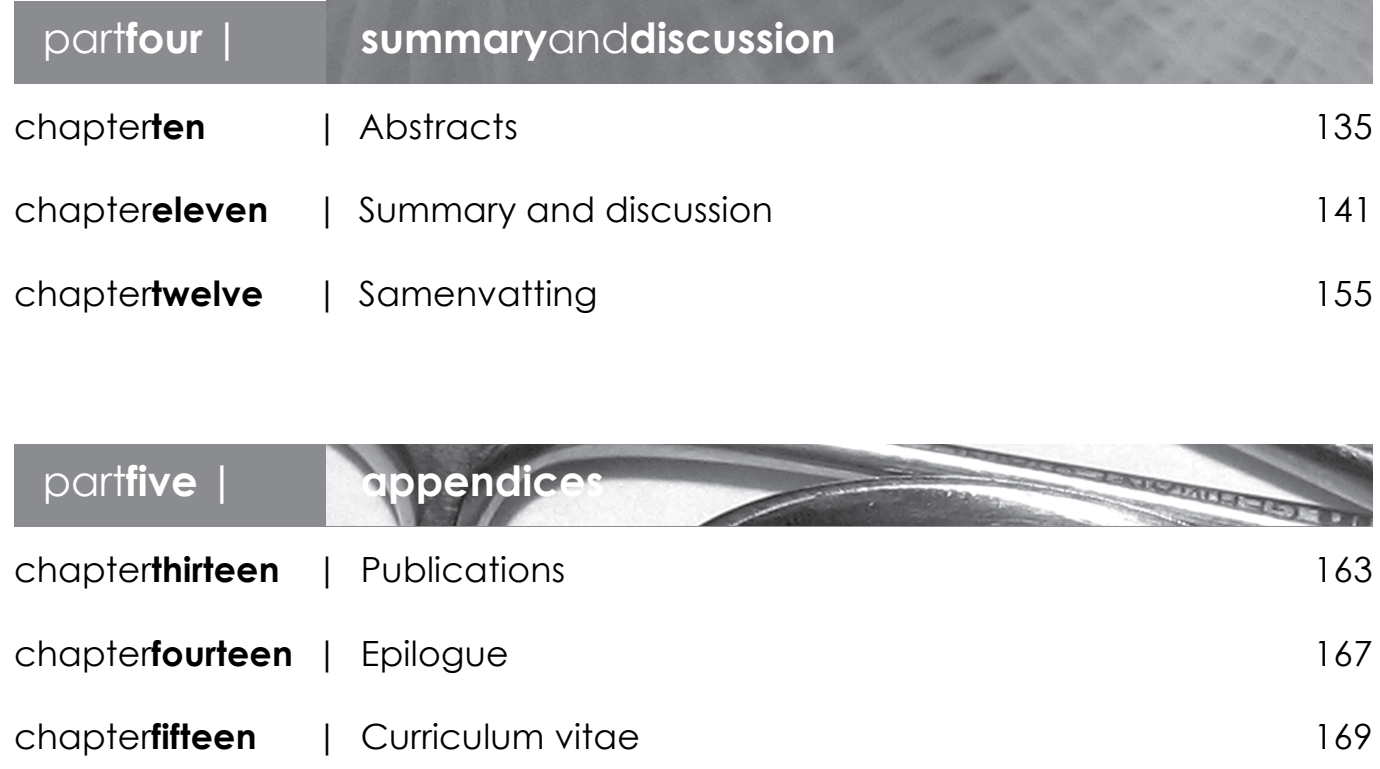





\section{introductionandmethods}

\section{partone}




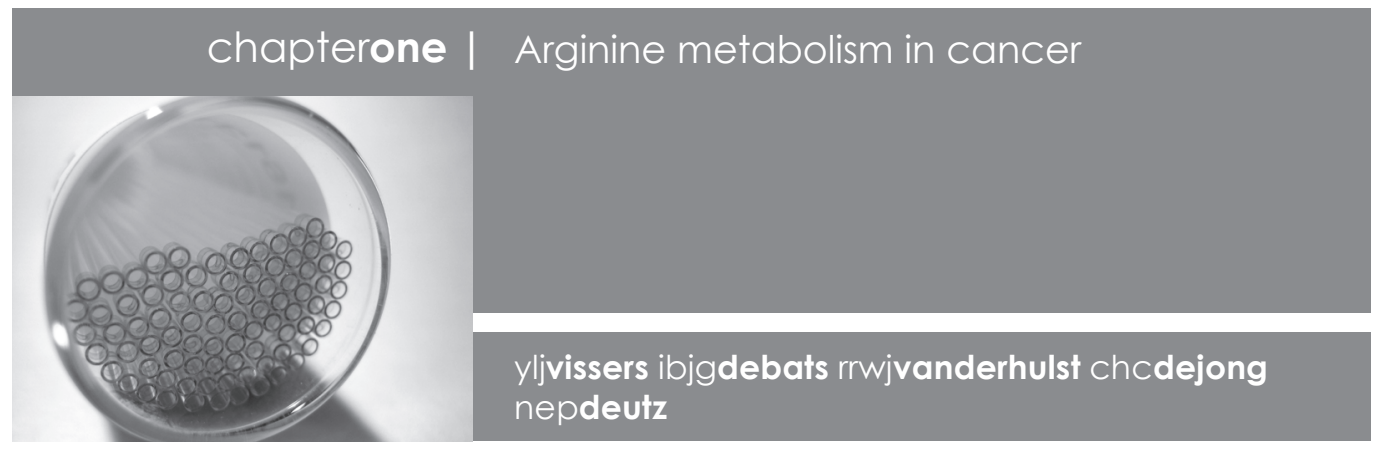

host metabolism |

Cachexia, the syndrome consisting of weight loss, anorexia, adipose tissue loss and skeletal muscle atrophy is associated with several diseases such as cancer, AIDS, chronic heart failure, and COPD. Up to one third of cancer patients die from cachexia rather than from cancer itself 1 , even after surgical removal of the tumour ${ }^{2}$. This suggests that cancer-related alterations in the metabolism of the host are a very important factor in determining mortality. Unfortunately, attempts to reverse cachexia by supplying large amounts of protein or calories have been unsuccessful up to now. Apparently, cachexia differs from simple malnutrition during starvation. The inability of cachectic cancer patients to become anabolic after feeding has led to studies investigating metabolic abnormalities in cancer. So far, no interventional therapy has succeeded in reversing cachexia. However, insight is now emerging that it may be specific amino acid components rather than whole proteins per se that drive the metabolic abnormalities in protein metabolism of cancer patients.

One of the specific amino acids that have been studied in this respect is glutamine, a non-essential amino acid that is released from by muscle and an important fuel for rapidly dividing cells such as intestinal and tumour cells. These studies have led to interventions with glutamine supplementation that resulted in positive effects on intestinal integrity ${ }^{3}$, infectious complications ${ }^{4}$ and length of hospital stay ${ }^{4,5}$ of cancer patients. However, despite these positive effects, glutamine supplementation was not able to reverse weight loss in cancer. One possible explanation is that the effects of glutamine supplementation are indirect and are in fact transmitted by one of its products: the amino acid arginine. Arginine is an amino acid that plays a central role in many pathways besides protein synthesis. This has now redirected our focus towards arginine metabolism in cancer.

\section{arginine metabolism |}

Normal daily intake of arginine is about 5-6 grams ${ }^{6,7}$ and whole-body arginine flux ranges between 15 and 20 grams per day ${ }^{8-10}$. In most mammals, arginine is considered a conditionally essential amino acid ${ }^{8,11-13}$, because the endogenous production of arginine may become insufficient during growth and metabolic stress ${ }^{14,15}$.

Apart from being an essential component of proteins, arginine plays a key role in several other metabolic pathways ${ }^{6,16}$ (figure one). The first is mediated by arginase 
(arginine -> ornithine and urea). Via this route, arginine is a precursor for urea synthesis in the liver ${ }^{8}$ and the kidney ${ }^{17,18}$, and as such plays an important role as a waste nitrogen carrier in the urea cycle. Arginine is also a precursor for synthesis of proline from ornithine ${ }^{19}$. Proline is a precursor in collagen synthesis and therefore important in wound healing.

The second arginine pathway is mediated by arginine/glycine aminodinotransferase. Here, arginine is a precursor in the hepatic and renal synthesis of creatine $6,7,20$, an important constituent for energy metabolism of skeletal muscle ${ }^{16}$. About $10 \%$ of whole-body arginine flux constitutes of creatine synthesis.

The third arginine pathway is mediated via nitric oxide synthase (NOS), yielding stochiometric amounts of citrulline and nitric oxide (NO). Three isoforms of NOS exist: NOS1 (previously named neuronal), NOS2 (previously named inducible) and NOS3 (previously named endothelial). All isoforms appear to be present in nonstimulated conditions, including NOS2 21,22. Microbacterial products and inflammatory cytokines can upregulate NOS2 ${ }^{23}$. It has been reported that NOS3 is downregulated at the same time ${ }^{24}$. This suggests interaction between NOS isoforms, each regulating the expression of the other.

The fourth pathway results in synthesis of agmatine via conversion of arginine by arginine decarboxylase ${ }^{25}$. Arginine decarboxylase activity and agmatine have been found in intestine, liver, kidney and brain, but agmatine's function is poorly understood. It may suppress cellular proliferation via competitive inhibition of polyamine synthesis ${ }^{26}$ and may inhibit NO production via inhibition of NOS ${ }^{27}$.

figureone | fates of arginine

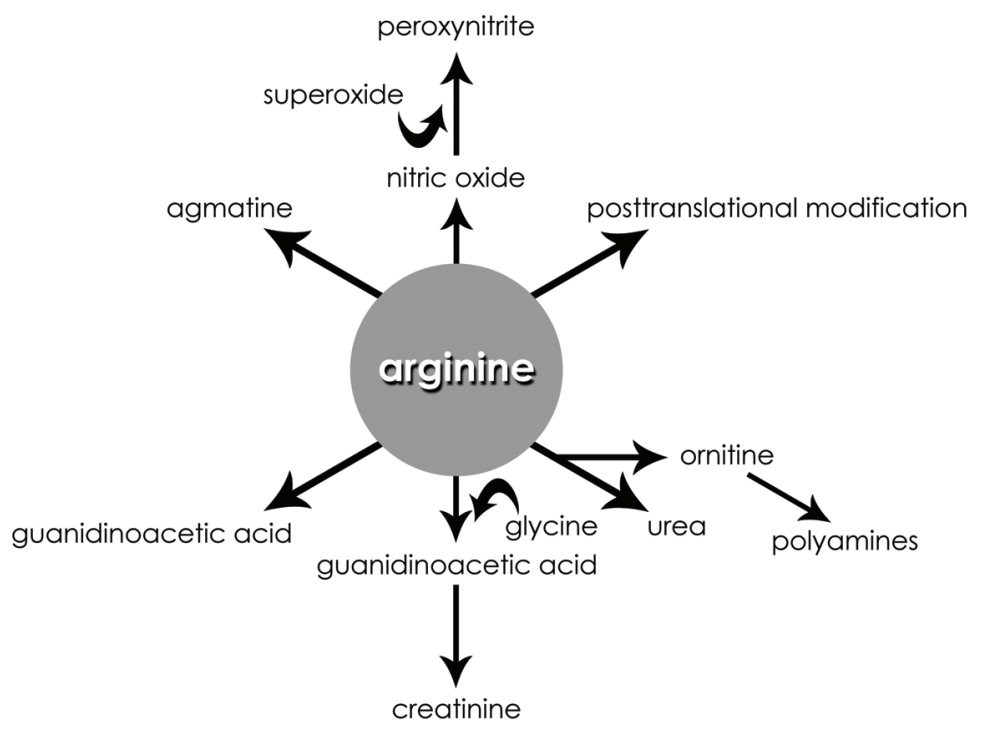


de novo arginine pathway |

Arginine can be generated via nutritional intake, but also via protein breakdown or endogenous synthesis in the de novo arginine pathway, which extends across various organs. In the gut, glutamine is converted to citrulline, which can subsequently be converted to arginine in the kidney. Although contributing for only $10-20 \%$ to total arginine production in healthy circumstances, the de novo arginine pathway may become quantitatively more important for regulation of arginine production in disease.

Muscle is the largest glutamine producer in the body and thus the main endogenous source of glutamine. Glutamine that is taken up by the gut can be converted to citrulline in the proximal part of the small intestine ${ }^{28-32}$. The importance of intestinal citrulline production is illustrated by the fact that arginine becomes an essential amino acid when intestinal citrulline synthesis is inhibited ${ }^{31}$, for example after intestinal resection ${ }^{12}$ and in animals with low rates of intestinal citrulline synthesis, like cats ${ }^{33}$. In man, decreased plasma citrulline levels are related to decreased glutamine concentrations, as observed in nutritional depletion ${ }^{34}$.

Although a correlation between the length of small intestine and net citrulline release is well established ${ }^{35,36}$, the consequences of loss of intestinal length for arginine metabolism are less well known and may differ between animals and humans. Studies in rats subjected to massive small bowel resection have shown that decreased glutamine uptake by the residual bowel ${ }^{36,37}$ was related to decreased intestinal citrulline release ${ }^{36}$ and decreased arterial citrulline concentrations in rats ${ }^{12.36}$ and humans ${ }^{35}$. Since the length of functional bowel appears to be related to intestinal citrulline production, the arterial concentration of citrulline has been suggested to be an indicator of the likelihood to become independent of total parenteral nutrition for patients with short bowel syndrome ${ }^{35}$.

The liver does not take up citrulline in significant quantities ${ }^{18}$ and thus most citrulline synthesised by the bowel bypasses the liver and reaches the systemic circulation ${ }^{14}$. Citrulline can be taken up by the kidney 14,36,38,39, where conversion of citrulline to arginine occurs in the proximal tubules by the enzymes argininosuccinate synthetase and argininesuccinate lyase. Quantitatively, the human kidneys take up about 1.5 gram of citrulline per day from the blood ${ }^{40}$, while arginine release into the blood stream (apart from arginine synthesis resulting from renal protein breakdown) has been reported to be between $2^{40,41}$ and 4 gram $^{8}$ per day in man, illustrating that the kidney is capable of de novo arginine synthesis.

An interesting aspect of the interorgan metabolic relationship between glutamine, citrulline and arginine has been demonstrated by Houdijk et al. ${ }^{42}$ after enterally administered glutamine in rats. They observed a $30 \%$ increase in arterial citrulline and arginine concentrations, as well as a $40 \%$ increase in renal citrulline uptake and arginine release ${ }^{42}$, which might suggest that part of the postulated beneficial effects of glutamine supplementation ${ }^{3,43-49}$ are mediated by intestinal conversion of glutamine to arginine in the de novo arginine pathway ${ }^{50}$. 
arginine transporters |

Arginine is transported across the cellular membrane mainly via system $y+$, mediated by a family of transporters named cationic amino acid transporters (CATs; SLC7A 14). Other amino acids taken up via CATs are lysine and ornithine, and therefore lysine and ornithine are competitive inhibitors for cellular arginine uptake. At present, four genes are known to encode system y+: CAT1, CAT2, CAT3 and CAT4, that differ in tissue distribution. CAT1 is expressed ubiquitously, but absent in hepatocytes. CAT3 is only present in the brain. CAT2 exists in two isoforms: CAT2A and a splice variant with low affinity: CAT2B. The kinetic characteristics for arginine uptake by a cell depend on the isoform of CAT that is present. For this reason, since the liver mainly expresses the low affinity CAT2A hardly any arginine is taken up from the circulation. In addition, the liver contains high levels of the cytosolic enzyme arginase I, which breaks down arginine into urea and ornithine. Therefore, only a small fraction of the large amount of arginine that is produced in the liver is transported into the circulation ${ }^{51}$. So although intracellular arginine flux through the urea cycle (and hence arginine synthesis and breakdown, $350 \mu \mathrm{mol} / \mathrm{kg} / \mathrm{h}$ ) is several-fold greater than total plasma arginine flux (approximately $75 \mu \mathrm{mol} / \mathrm{kg}$ / h), this will not be detected by assessment of whole-body kinetics 13,16,52. As a consequence, net uptake or release of arginine by the liver is not significant 10,16.

NO metabolism |

Arginine is the sole precursor of NO synthesis through the NOS pathway (EC 1.14.13.39) 9,43 . NO currently receives considerable attention in view of its widespread effects, especially in the cardiovascular system ${ }^{53}$, where it functions as a signal molecule in vasodilatation and angiogenesis ${ }^{54}$. Through these same mechanisms $N O$ is involved in wound healing as it indirectly provides the wound area with sufficient oxygen and nutrition. This stimulates fibroblasts to synthesise collagen and keratinocytes to proliferate and in this way NO takes part in building up repair tissue in the wound ${ }^{55}$. $\mathrm{NO}$ is a scavenger of superoxide radicals to form peroxynitrite ${ }^{56,57}$. Because the latter can subsequently decompose to hydroxyl radical and nitrogen dioxide, resulting in nitrate and hydrogen, this can be considered a beneficial mechanism. However, in conditions of reduced arginine availability NOS enzymes produce both superoxide and peroxynitrite ${ }^{58}$, which should probably be regarded as a negative effect. Large amounts of NO, its by-products, or both can exert toxic effects, including mitochondrial dysfunction leading to further impairment in oxygen delivery and extraction ${ }^{59}$. As an example, overproduction of NO has been suggested to result in enterocyte apoptosis or necrosis at the villus tips (suggested to be due to peroxynitrite formation in intestinal villi), inhibition of mitochondrial respiration in enterocytes, and intestinal mucosal barrier dysfunction as evidenced by increases in bacterial translocation 60-63. Therefore, while a limited production of $\mathrm{NO}$ is required for normal function of the organism, excess $\mathrm{NO}$ production should probably be regarded as an adverse effect.

arginine in cancer |

Evidence is accumulating that arginine is of importance in cancer. Various types of cancer affect plasma arginine concentrations. These have been reported to be 
decreased in lung cancer ${ }^{64}$, higher ${ }^{65,66}$ or unchanged ${ }^{67}$ in breast cancer, unchanged ${ }^{66}$ or higher ${ }^{68}$ in gastrointestinal cancer, unchanged in head and neck cancer ${ }^{66}$ and unchanged in oesophageal cancer ${ }^{64}$. Besides, various malignant tumours including lung, colon, prostate and breast carcinoma contain high amounts of arginase 65,69,70, which was initially thought to serve rapid proliferation of tumour cells via polyamine production through conversion of ornithine by ornithine decarboxylase ${ }^{71}$ for review). Later, this was doubted and arginase activity in cancer was put in a different perspective by the observation that tumour-associated macrophages express high arginase activity in the microenvironment of tumours. High arginase activity induces local depletion of arginine with a decreased capacity to produce $\mathrm{NO}{ }^{72}$, leading to suppression of the Th1 response and suppression of lysis of tumour cells by cytotoxic lymphocytes as a consequence ${ }^{73}$. However, it is not known to what extent the accumulation of macrophages in tumours has implications for whole-body arginine metabolism.

NO in cancer |

In addition to high levels of arginase, high levels of all three NOS isoforms have been observed in human tumours. Increased NOS2 levels or expression have been found in tumours of head and neck ${ }^{74,75}$, lung ${ }^{76}$, brain ${ }^{77}$, colon $^{78}$, prostate ${ }^{79,80}$, bladder ${ }^{81}$, thyroid ${ }^{82}$, breast ${ }^{83-85}$ and B-cells ${ }^{86}$. High NOS1 and NOS3 levels or enzymatic expression were demonstrated in thyroid ${ }^{87}$ and brain tumours ${ }^{88}$. Thus, apart from conversion of arginine via arginase activity, tumours have the potential to convert high amounts of arginine via NOS activity. However, in vivo studies investigating this relation between NO metabolism in the tumour and the host, both in animals and patients, are lacking.

consequences of decreased arginine availability for the host 1

In the late 80's, Hibbs showed that $\mathrm{NO}_{2}$ formation from arginine was needed for the host defence against tumours ${ }^{89}$. Later, $\mathrm{NO}$ was proven to be the effector molecule ${ }^{90}$ by which macrophages killed tumour cells ${ }^{91}$.

On basis of the $\mathrm{K}_{\mathrm{m}}$ for NOS $(2-20 \mu \mathrm{M})$, the observed decrease in arginine concentrations in cancer patients should not limit NO production. However, the existence of clusters of signalling proteins that facilitate binding between NOS and membrane transporters of arginine ${ }^{92}$ suggests that arginine transporters may be more important than the $\mathrm{K}_{\mathrm{m}}$ of NOS for regulation of NO production. In contrast to NOS, these membrane transporters of arginine have $K_{m}$ values in the range of physiological arginine concentrations ${ }^{16}$. Therefore, decreases in arginine concentrations may indeed limit NO production and have adverse effects on host defence against tumour cells.

postoperative arginine metabolism in cancer I

Cancer patients undergoing surgical treatment have more postoperative complications ${ }^{93}$ and higher mortality ${ }^{94}$ than patients undergoing surgery for benign disease. Apparently, the host's response to surgery differs between cancer patients and healthy subjects. 
Arginine plays a central role in the host response to surgical trauma, both via NO (produced from arginine in the NOS pathway) and ornithine (produced from arginine in the arginase pathway). NO is the effector molecule of the cytotoxic mechanism of macrophages ${ }^{89}$ and therefore important in the attack against bacterial pathogens. In line with this observation, arginine supplementation increased the postoperative immune response of T cells in patients ${ }^{95}$.

wound healing |

Various phases of wound healing are characterised by changes in arginase and NOS activity in the wound. In the early inflammatory phase, high NOS activity is present, first suggested by increased concentrations of citrulline and nitrite ${ }^{96}$ and later confirmed by upregulation of iNOS 97 in experimental wound models in rats. Wound repair cells, mainly macrophages ${ }^{98}$, but to a lesser extent also fibroblasts, endothelial cells and keratinocytes 99,100 contribute to NO synthesis. The process is probably regulated via IFN and TNF 101 , and depends on the extracellular arginine concentration ${ }^{102,103}$. Conversely, diets deficient in arginine are associated with poor wound healing and poor growth in rats ${ }^{104,105}$. In the later proliferative phase, NO also plays a role. Evidence for this comes from studies with iNOS knock-out mice that displayed delayed wound closure ${ }^{106}$. Besides, arginase activity is present in the wound in the proliferative phase as suggested by increased ornithine concentrations in parallel with decreased arginine concentrations and conversion of labelled arginine to urea ${ }^{96}$. Our group recently found indications of activation of these pathways in human wounds ${ }^{107}$.

\section{supplementation of L-arginine in cancer |}

effects on tumour growth |

Various studies on L-arginine supplementation and tumour growth have been conducted, leading to two opposite hypotheses: that L-arginine either stimulates or inhibits tumour growth. Most animal studies with isonitrogenous control supplements support the latter theory by showing that arginine supplementation, either intravenously of enterally, retarded tumour growth in vivo ${ }^{108-115}$. Only two studies have reported that arginine supplementation enhanced tumour growth in vivo 110,116 , while one did not show changes in growth 117,118.

Up to now, two patient studies investigating the effect of arginine supplementation on tumour growth have been conducted. Park 119 demonstrated that three days of arginine supplementation increased protein synthesis in breast tumours, while Caso ${ }^{120}$ reported no effect on tumour protein synthesis in patients with head and neck carcinoma. However, since these were both studies without supply of amino acids in control groups, this effect may be confounded by less intake of nutrients per se.

effects on immune system |

In tumour-bearing mice, L-arginine was one of the first nutritional supplements that were tested for potential immune stimulating effects ${ }^{121}$. An increased thymic weight and cellularity was observed. Repeated experiments with proper control groups 
confirmed that L-arginine has indeed immune stimulating properties in tumourbearing animals, such as enhanced lymphocyte cytotoxicity ${ }^{122,123}$ and natural killer cell activity ${ }^{123}$.

In breast cancer patients, three days of enteral L-arginine supplementation enhanced cytotoxicity of natural killer and lymphokine activated killer cells ${ }^{124}$, which are thought to be involved in tumour cytotoxicity. Similarly, three days of Larginine supplementation to patients with colorectal cancer increased the activity of tumour infiltrating lymphocytes ${ }^{125}$, which have anti-tumour properties. Patients with breast cancer receiving an enteral diet supplemented with arginine for three days had higher protein synthesis in tumours compared with patients receiving the enteral diet without supplementation 119 . Three days of L-arginine supplementation before each course of chemotherapy was reported to diminish and delay the onset of immunosuppression and to stimulate natural killer and lymphokine activated killer cells ${ }^{126}$. However, because none of these three patient studies included amino acid supplemented control groups, effects may be attributable to administration of nutrients or protein per se.

effects on wound healing |

In rats, $300 \mathrm{mg} / \mathrm{kg}$ of L-arginine per day enhanced wound tensile strength, hydroxyproline concentrations and collagen accumulation. In addition, it decreased neutrophil counts and adhesivity ${ }^{127}$. In NOS2 knock-out mice, NOS2 was shown to be an important mediator of the positive effects of L-arginine supplementation on wound breaking strength and hydroxyproline content ${ }^{128}$. Arbss et al. studied the effects of high arginine plasma levels on early integration of biocompatible mesh grafts in rat abdominal wall. They found enhanced cell accumulation, formation of new vessels, fibroblast proliferation and type III collagen deposition in the L-arginine-supplemented group ${ }^{129}$. In an experimental model for ileitis, ulcer healing was enhanced in rats supplied with diets containing $5 \% \mathrm{~L}$-arginine ${ }^{130}$. Healing of colonic anastomosis in rats on postoperative day 6 was enhanced when rats were fed a L-arginine enriched diet perioperatively ${ }^{131}$.

L-arginine supplementation improved wound breaking strength in mice after abdominal trauma with haemorrhage, demonstrated by increased hydroxyproline deposition in the wound ${ }^{132}$. Only few human studies investigated the effect of L-arginine as single pharmaconutrient on wound healing. Kirk et al. supplied thirty healthy elderly humans with 17 grams of oral L-arginine per day and found improved serum IGF-1, enhanced hydroxyproline and total protein content deposition in subcutaneously placed catheters. However, it did not shorten time to complete epithelialisation of skin defects of $2 \mathrm{~cm}^{2}{ }^{133}$. Barbul et al. ${ }^{134}$ supplied L-arginine to 36 young healthy humans divided in three groups, which received either 17 or 25 grams oral L-arginine or placebo for 2 weeks. Both L-arginine-supplemented groups displayed enhanced hydroxyproline accumulation in subcutaneously placed catheters.

postoperative effects |

Several authors studied the effect of L-arginine on postoperative immune response in cancer patients. Daly et al. compared postoperative enteral supplementation of L-arginine with that of isonitrogenous glycine and concluded that L-arginine 
enhanced peripheral lymphocyte response and increased the number of CD4+ Tcells in gastrointestinal cancer patients ${ }^{95}$. In postoperative head and neck cancer patients fed an enteral diet supplemented with L-arginine, lymphocyte count was increased compared with isocaloric and isonitrogenous control ${ }^{135}$. Also, patients with gastro-intestinal malignancies on a diet supplemented with L-arginine had higher numbers of circulating T-cells on postoperative day 7 compared with an isocaloric and isonitrogenous control diet ${ }^{136}$. In contrast, on the first postoperative day, no effect of pre-operative isocaloric and isonitrogenous enteral arginine supplementation was seen on lymphocyte proliferation or monocyte function in gastro-intestinal cancer patients ${ }^{137}$.

Until now, only one clinical study with L-arginine as monotherapy and isonitrogenous and isocaloric controls has been completed in malnourished head and neck cancer patients undergoing surgery. In 2000, Riso et al. ${ }^{135}$ concluded that a postoperative enteral diet supplemented with L-arginine for four days significantly reduced postoperative infections and length of hospital stay.

\section{summary and conclusion |}

Despite increasing knowledge of the metabolic disturbances of cancer patients, the mechanism of cachexia remains incompletely understood. Since preoperative weight loss adversely affects the outcome of surgery, knowledge of perioperative pathophysiology may provide new possibilities for interventions to optimize recovery of cancer patients.

In the last decade, insight is emerging that it may be specific amino acids rather than whole proteins that drive the metabolic abnormalities in cancer. Because the amino acid arginine plays a role in various pathways that are of importance both in the presence of tumour and after surgery, it may be also involved in perioperative metabolic disturbances of cancer patients. Only limited information is available on in vivo arginine-NO metabolism both in health and in cancer. Goal of the present thesis is therefore to study perioperative arginine metabolism in cancer.

In part one a rationale for studying perioperative arginine metabolism in cancer is provided and methods for experiments are described. In parts two and three the effects of cancer and surgery on arginine metabolism are investigated. Both noncachectic (part two) and cachectic (part three) mice tumour models are used. Since arginine can be produced both from protein breakdown and from endogenous de novo synthesis, these two pathways will be evaluated in both mice models.

\section{references |}

1. Norton JA, Peacock JL, Morrison SD. Cancer cachexia. Crit Rev Oncol Hematol 1987:7(4):289-327.

2. Talamonti MS, Kim SP, Yao KA, et al. Surgical outcomes of patients with gastric carcinoma: the importance of primary tumor location and microvessel invasion. Surgery 2003;134(4):720-7; discussion 727-9.

3. van der Hulst RRWJ, van Kreel BK, von Meyenfeldt MF, et al. Glutamine and the preservation of gut integrity. Lancet 1993;341 (8857):1363-5. 
4. Ziegler TR, Young LS, Benfell K, et al. Clinical and metabolic efficacy of glutaminesupplemented parenteral nutrition after bone marrow transplantation. A randomized, double-blind, controlled study. Ann Intern Med 1992;116(10):821-8.

5. Schloerb PR, Amare M. Total parenteral nutrition with glutamine in bone marrow transplantation and other clinical applications (a randomized, double-blind study). JPEN 1993;17(5):407-13.

6. Heys SD, Gardner E. Nutrients and the surgical patient: current and potential therapeutic applications to clinical practice. J R Coll Surg Edinb 1999;44(5):283-93.

7. Visek WJ. Arginine needs, physiological state and usual diets. A reevaluation. J Nutr 1986;1 16(1):36-46.

8. Cynober L, Le Boucher J, Vasson M-P. Arginine metabolism in mammals. J Nutr Biochem 1995;6:402-403.

9. Castillo L, Sanchez M, Vogt J, et al. Plasma arginine, citrulline, and ornithine kinetics in adults, with observations on nitric oxide synthesis. Am J Physiol 1995;268:E360-E367.

10. Castillo L, Beaumier L, Ajami AM, Young VR. Whole body nitric oxide synthesis in healthy men determined from [15N] arginine-to-[15N]citrulline labeling. Proc Natl Acad Sci U S A 1996;93(21):11460-5.

11. Rose WC. Amino acid requirements of man. Nutr Rev 1976;34:307-309.

12. Wakabayashi Y, Yamada E, Yoshida T, Takahashi N. Effect of intestinal resection and arginine-free diet on rat physiology. Am J Physiol 1995;269:G313-318.

13. Young VR, YU Y-M. Chapter 6. Protein and amino acid metabolism. 2nd ed. Boston: Little, Brown and Company, 1996.

14. Windmueller HG, Spaeth AE. Source and fate of circulating citrulline. Am J Physiol $1981 ; 241(6): E 473-80$.

15. Ardawi MS, Newsholme EA. Glutamine metabolism in lymphocytes of the rat. Biochem J 1983;212(3):835-42.

16. Wu G, Morris SM. Arginine metabolism: nitric oxide and beyond. Biochem J 1998;336:1-17.

17. Levillain O, Hus-Citharel A, Garvi S, et al. Ornithine metabolism in male and female rat kidney: mitochondrial expression of ornithine aminotransferase and arginase II. Am J Physiol Renal Physiol 2004;286(4):F727-38.

18. Bankir L. Urea and the kidney. 5th ed. Philadelphia, USA: W.B. Saunders Company, 1996.

19. Wu G, Knabe DA, Flynn NE, Yan W, Flynn SP. Arginine degradation in developing porcine enterocytes. Am J Physiol 1996;271 (5 Pt 1):G913-9.

20. Perez GO, Epstein M, Rietberg B, Loutzenhiser R. Metabolism of arginine by the isolated perfused rat kidney. Am J Physiol 1978;235:F376-380.

21. Miller MJ, Thompson JH, Zhang XJ, et al. Role of inducible nitric oxide synthase expression and peroxynitrite formation in guinea pig ileitis. Gastroenterology 1995; $109(5): 1475-83$.

22. Hoffman RA, Zhang G, Nussler NC, et al. Constitutive expression of inducible nitric oxide synthase in the mouse ileal mucosa. Am J Physiol 1997;272(2 Pt 1):G383-92.

23. Morris SM, Jr., Billiar TR. New insights into the regulation of inducible nitric oxide synthesis. Am J Physiol 1994;266(6 Pt 1):E829-39. 
24. Chen K, Inoue M, Wasa M, Fukuzawa M, Kamata S, Okada A. Expression of endothelial constitutive nitric oxide synthase mRNA in gastrointestinal mucosa and its downregulation by endotoxin. Life Sci 1997;61 (13):1323-9.

25. Lortie MJ, Novotny WF, Peterson OW, et al. Agmatine, a bioactive metabolite of arginine. Production, degradation, and functional effects in the kidney of the rat. $J$ Clin Invest 1996:97(2):413-20.

26. Satriano J, Isome M, Casero RA, Jr., Thomson SC, Blantz RC. Polyamine transport system mediates agmatine transport in mammalian cells. Am J Physiol Cell Physiol 2001;281 (1):C329-34.

27. Raghavan SA, Dikshit M. Vascular regulation by the L-arginine metabolites, nitric oxide and agmatine. Pharmacol Res 2004;49(5):397-414.

28. Windmueller HG, Spaeth AE. Metabolism of absorbed aspartate, asparagine, and arginine by rat small intestine in vivo. Arch Biochem Biophys 1976;175:670676.

29. Windmueller HG, Spaeth AE. Intestinal metabolism of glutamine and glutamate from the lumen as compared to glutamine from the blood. Arch Biochem Biophys $1975 ; 171: 662-672$.

30. Windmueller HG, Spaeth AE. Identification of ketone bodies and glutamine as the major respiratory fuels in vivo fro postabsorptive rat small intestine. J Biol Chem 1978;253:69-76.

31. Hoogenraad N, Totino N, Elmer H, Wraight C, Alewood P, Johns B. Inhibition of intestinal citrulline synthesis causes severe growth retardation in rats. Am J Physiol 1985;249:G792-799.

32. Vissers YLJ, Debats IBJG, Luiking YC, et al. Pro and con of L-arginine supplementation in disease. Nutr Res Rev 2004;17(2):193-210.

33. Dhanakoti SN, Brosnan JT, Herzberg GR, Brosnan ME. Renal arginine synthesis: studies in vitro and in vivo. Am J Physiol 1990;259(3 Pt 1):E437-42.

34. van der Hulst RRWJ, Deutz NEP, von Meyenfeldt MF, Elbers JMH, Stockbrugger RW, Soeters PB. Decrease of mucosal glutamine concentration in the nutritionally depleted patient. Clin Nutr 1994;13:228-233.

35. Crenn P, Vahedi K, Lavergne-Slove A, Cynober L, Matuchansky C, Messing B. Plasma citrulline: A marker of enterocyte mass in villous atrophy-associated small bowel disease. Gastroenterology 2003;124(5):1210-9.

36. Deutz NEP, Dejong CHC, Athanasas G, Soeters PB. Partial enterectomy in the rat does not diminish muscle glutamine production. Metabolism 1992;41:1343-1350.

37. Klimberg VS, Souba WW, Salloum RM, et al. Intestinal glutamine metabolism after massive small bowel resection. Am J Surg 1990;159:27-33.

38. Dejong CHC, Deutz NEP, Soeters PB. Intestinal glutamine and ammonia metabolism during chronic hyperammonaemia induced by liver insufficiency. Gut 1993;34:1 112 1119.

39. Dejong CHC, Deutz NEP, Soeters PB. Metabolic adaptation of the kidney to hyperammonemia during chronic liver insufficiency in the rat. Hepatology 1993; 18:890-902.

40. Tizianello A, Deferrari G, Garibotto G, Robaudo C, Salvidio G, Saffiotti S. Renal ammoniagenesis in the postprandial period. Contrib Nephrol 1985;47:44-57. 
41. Tizianello A, de Ferrari G, Caribotto G, Gurreri G. Renal metabolism of amino acids and ammonia in subjects with normal renal function and in patients with chronic renal insufficiency. J Clin Invest 1980;65:1162-1173.

42. Houdijk APJ, van Leeuwen PAM, Teerlink T, et al. Glutamine-enriched enteral diet increases renal arginine production. JPEN 1994;18:422-426.

43. Roth E. L-Arginine-nitric oxide metabolism. Glutamine: a new player in this metabolic game. Clin Nutr 1998;17:1-2.

44. Hammarqvist F, Jacks J, Wernerman J. Effects on skeletal muscle amino acids and whole body nitrogen metabolism of total parenteral nutrition following laparoscopic cholecystectomy and given to healthy volunteers. Clin Nutr 1998;17(5):205-10.

45. Scheppach W, Loges C, Bartram P, et al. Effect of free glutamine and alanylglutamine dipeptide on mucosal proliferation of the human ileum and colon. Gastroenterology 1994;107:429-434.

46. Klimberg VS, Salloum RM, Kasper M, et al. Oral glutamine accelerates healing of the small intestine and improves outcome after whole abdominal radiation. Arch Surg 1990;125:1040-1045.

47. Jacobs DO, Evans DA, Mealy K, O'Dwyer ST, Smith RJ, Wilmore DW. Combined effects of glutamine and epidermal growth factor on the rat intestine. Surgery 1988;104:358-364.

48. O'Dwyer ST, Smith RJ, Hwang TL, Wilmore DW. Maintenance of small bowel mucosa with glutamine-enriched parenteral nutrition. JPEN 1989;13:579-585.

49. Hammarqvist F, Wernerman J, Ali R, von der Decken A, Vinnars E. Addition of glutamine to total parenteral nutrition after elective abdominal surgery spares free glutamine in muscle, counteracts the fall in muscle protein synthesis, and improves nitrogen balance. Ann Surg 1989;209:455-461.

50. Houdijk APJ, Rijnsburger ER, Jansen J, et al. Randomised trial of glutamine-enriched enteral nutrition on infectious morbidity in patients with multiple trauma. Lancet 1998;352:772-776.

51. White MF. The transport of cationic amino acids across the plasma membrane of mammalian cells. Biochim Biophys Acta 1985;822(3-4):355-74.

52. Dejong CHC, Welters CFM, Deutz NEP, Heineman E, Soeters PB. Renal arginine metabolism in fasted rats with subacute short bowel syndrome. Clin Sci 1998:95:409418.

53. Guarner C, Soriano G, Tomas A, et al. Increased serum nitrite and nitrate levels in patients with cirrhosis: relationship to endotoxemia. Hepatology 1993;18:1 139-11 43.

54. Lee PC, Salyapongse AN, Bragdon GA, et al. Impaired wound healing and angiogenesis in eNOS-deficient mice. Am J Physiol 1999;277(4 P† 2):H1600-8.

55. Xia W, Szomor Z, Wang Y, Murrell GA. Nitric oxide enhances collagen synthesis in cultured human tendon cells. J Orthop Res 2006;24(2):159-72.

56. Southan GJ, Szabo C. Selective pharmalogical inhibition of distinct nitric oxide synthase isoforms. Biochem Pharmacol 1996;51:383-394.

57. Titheradge MA. Nitric oxide in septic shock. Biochim Biophys Acta 1999;1411(23):437-55. 
58. Xia Y, Dawson VL, Dawson TM, Snyder SH, Zweier JL. Nitric oxide synthase generates superoxide and nitric oxide in arginine-depleted cells leading to peroxynitrite-mediated cellular injury. Proc Natl Acad Sci U S A 1996:93(13):67704.

59. Preiser JC, Berre PJ, Van Gossum A, et al. Metabolic effects of arginine addition to the enteral feeding of critically ill patients. JPEN 2001;25(4):182-7.

60. Mishima S, XU D, LU Q, Deitch EA. The relationships among nitric oxide production, bacterial translocation, and intestinal injury after endotoxin challenge in vivo. $J$ Trauma 1998;44(1):175-82.

61. Dickinson E, Tuncer R, Nadler E, et al. NOX, a novel nitric oxide scavenger, reduces bacterial translocation in rats after endotoxin challenge. Am J Physiol 1999;277/6 P† 1):G1281-7.

62. Morin MJ, Unno N, Hodin RA, Fink MP. Differential expression of inducible nitric oxide synthase messenger RNA along the longitudinal and crypt-villus axes of the intestine in endotoxemic rats. Crit Care Med 1998;26(7):1258-64.

63. Oudenhoven IM, Klaasen HL, Lapre JA, Weerkamp AH, Van der Meer R. Nitric oxide-derived urinary nitrate as a marker of intestinal bacterial translocation in rats. Gastroenterology 1994;107(1):47-53.

64. Naini AB, Dickerson JW, Brown MM. Preoperative and postoperative levels of plasma protein and amino acid in esophageal and lung cancer patients. Cancer 1988;62(2):355-60.

65. Park KG, Heys SD, Harris $\mathrm{Cl}$, et al. Arginine metabolism in benign and malignant disease of breast and colon: evidence for possible inhibition of tumor-infiltrating macrophages. Nutrition 1991;7(3):185-8.

66. Kubota A, Meguid MM, Hitch DC. Amino acid profiles correlate diagnostically with organ site in three kinds of malignant tumors. Cancer 1992;69(9):2343-8.

67. Minet-Quinard R, Van Praagh I, Kwiatkowski F, et al. Pre- and postoperative aminoacidemia in breast cancer: a study vs. matched healthy subjects. Cancer Invest 2004;22(2):203-10.

68. Glass RE, Goode AW, Houghton BJ, Rowell LW. Plasma arginine in cancer of the gastrointestinal tract: effect of surgical treatment. Gut 1986;27(7):844-8.

69. Keskinege A, Elgun S, Yilmaz E. Possible implications of arginase and diamine oxidase in prostatic carcinoma. Cancer Detect Prev 2001;25(1):76-9.

70. Suer Gokmen S, Yoruk Y, Cakir E, Yorulmaz F, Gulen S. Arginase and ornithine, as markers in human non-small cell lung carcinoma. Cancer Biochem Biophys 1999;17(12):125-31.

71. Thomas T, Thomas TJ. Polyamine metabolism and cancer. J Cell Mol Med 2003;7(2):1 13-26.

72. Chang Cl, Liao JC, Kuo L. Macrophage arginase promotes tumor cell growth and suppresses nitric oxide-mediated tumor cytotoxicity. Cancer Res 2001;61 (3):1 100-6.

73. Rodriguez PC, Quiceno DG, Zabaleta J, et al. Arginase I production in the tumor microenvironment by mature myeloid cells inhibits T-cell receptor expression and antigen-specific T-cell responses. Cancer Res 2004;64(16):5839-49. 
74. Gallo O, Schiavone N, Papucci L, et al. Down-regulation of nitric oxide synthase2 and cyclooxygenase-2 pathways by p53 in squamous cell carcinoma. Am J Pathol 2003; 163(2):723-32.

75. Jayasurya A, Dheen ST, Yap WM, Tan NG, Ng YK, Bay BH. Inducible nitric oxide synthase and bcl-2 expression in nasopharyngeal cancer: correlation with outcome of patients after radiotherapy. Int J Radiat Oncol Biol Phys 2003;56(3):837-45.

76. Lee TW, Chen GG, Xu H, et al. Differential expression of inducible nitric oxide synthase and peroxisome proliferator-activated receptor gamma in non-small cell lung carcinoma. Eur J Cancer 2003;39(9):1296-301.

77. Kato S, Esumi H, Hirano A, Kato M, Asayama K, Ohama E. Immunohistochemical expression of inducible nitric oxide synthase (iNOS) in human brain tumors: relationships of iNOS to superoxide dismutase (SOD) proteins (SOD1 and SOD2), Ki67 antigen (MIB-1) and p53 protein. Acta Neuropathol (Berl) 2003;105(4):333-40.

78. Cianchi F, Cortesini C, Fantappie $O$, et al. Inducible nitric oxide synthase expression in human colorectal cancer: correlation with tumor angiogenesis. Am J Pathol 2003;162(3):793-801.

79. Wang J, Torbenson M, Wang Q, Ro JY, Becich M. Expression of inducible nitric oxide synthase in paired neoplastic and non-neoplastic primary prostate cell cultures and prostatectomy specimen. Urol Oncol 2003;21 (2):117-22.

80. Baltaci S, Orhan D, Gogus C, Turkolmez K, Tulunay O, Gogus O. Inducible nitric oxide synthase expression in benign prostatic hyperplasia, low- and high-grade prostatic intraepithelial neoplasia and prostatic carcinoma. BJU Int 2001;88(1):1003.

81. Wolf H, Haeckel C, Roessner A. Inducible nitric oxide synthase expression in human urinary bladder cancer. Virchows Arch 2000;437(6):662-6.

82. Choe W, Kim S, Hwang TS, Lee SS. Expression of inducible nitric oxide synthase in thyroid neoplasms: Immunohistochemical and molecular analysis. Pathol Int 2003;53(7):434-9.

83. Vakkala M, Kahlos K, Lakari E, Paakko P, Kinnula V, Soini Y. Inducible nitric oxide synthase expression, apoptosis, and angiogenesis in in situ and invasive breast carcinomas. Clin Cancer Res 2000;6(6):2408-16.

84. Thomsen LL, Miles DW, Happerfield L, Bobrow LG, Knowles RG, Moncada S. Nitric oxide synthase activity in human breast cancer. Br J Cancer 1995;72(1):41-4.

85. Tschugguel W, Schneeberger C, Unfried G, et al. Expression of inducible nitric oxide synthase in human breast cancer depends on tumor grade. Breast Cancer Res Treat 1999;56(2):145-51.

86. Mendes RV, Martins AR, de Nucci G, Murad F, Soares FA. Expression of nitric oxide synthase isoforms and nitrotyrosine immunoreactivity by B-cell non-Hodgkin's lymphomas and multiple myeloma. Histopathology 2001;39(2):172-8.

87. Patel A, Fenton C, Terrell R, et al. Nitrotyrosine, inducible nitric oxide synthase (iNOS), and endothelial nitric oxide synthase (eNOS) are increased in thyroid tumors from children and adolescents. J Endocrinol Invest 2002;25(8):675-83.

88. Cobbs CS, Brenman JE, Aldape KD, Bredt DS, Israel MA. Expression of nitric oxide synthase in human central nervous system tumors. Cancer Res 1995;55(4):727-30. 
89. Hibbs JB, Jr., Vavrin Z, Taintor RR. L-arginine is required for expression of the activated macrophage effector mechanism causing selective metabolic inhibition in target cells. J Immunol 1987;138(2):550-65.

90. Lancaster JR, Jr., Hibbs JB, Jr. EPR demonstration of iron-nitrosyl complex formation by cytotoxic activated macrophages. Proc Natl Acad Sci U S A 1990;87(3):1223-7.

91. Stuehr DJ, Nathan CF. Nitric oxide. A macrophage product responsible for cytostasis and respiratory inhibition in tumor target cells. J Exp Med 1989;169(5):1543-55.

92. MCDonald KK, Zharikov S, Block ER, Kilberg MS. A caveolar complex between the cationic amino acid transporter 1 and endothelial nitric oxide synthase may explain the "arginine paradox". J Biol Chem 1997;272(50):31213-31216.

93. Deslauriers J, Ginsberg RJ, Dubois P, Beaulieu M, Goldberg M, Piraux M. Current operative morbidity associated with elective surgical resection for lung cancer. Can J Surg 1989;32(5):335-9.

94. Rey-Ferro M, Castano R, Orozco O, Serna A, Moreno A. Nutritional and immunologic evaluation of patients with gastric cancer before and after surgery. Nutrition 1997;13(10):878-81.

95. Daly JM, Reynolds J, Thom A, et al. Immune and metabolic effects of arginine in the surgical patient. Ann Surg 1988;208(4):512-23.

96. Albina JE, Mills CD, Henry WL, Jr., Caldwell MD. Temporal expression of different pathways of 1-arginine metabolism in healing wounds. J Immunol 1990;144(10):387780.

97. Frank S, Madlener M, Pfeilschifter J, Werner S. Induction of inducible nitric oxide synthase and its corresponding tetrahydrobiopterin-cofactor-synthesizing enzyme GTP-cyclohydrolase I during cutaneous wound repair. J Invest Dermatol 1998; 111 (6):1058-64.

98. Reichner JS, Meszaros AJ, Louis CA, et al. Molecular and metabolic evidence for the restricted expression of inducible nitric oxide synthase in healing wounds. Am J Pathol 1999;154(4):1097-104.

99. Schaffer MR, Efron PA, Thornton FJ, Klingel K, Gross SS, Barbul A. Nitric oxide, an autocrine regulator of wound fibroblast synthetic function. J Immunol 1997; 158(5):2375-81.

100. Paulsen SM, Wurster SH, Nanney LB. Expression of inducible nitric oxide synthase in human burn wounds. Wound Repair Regen 1998;6(2):142-8.

101. Schaffer M, Bongartz M, Hoffmann W, Viebahn R. Regulation of nitric oxide synthesis in wounds by IFN-gamma depends on TNF-alpha. J Invest Surg 2006;19(6):371-9.

102. Jalkanen M, Larjava H, Heino J, Vihersaari T, Peltonen J, Penttinen R. Arginine depletion in macrophage medium inhibits collagen synthesis by fibroblasts. Immunol Lett 1982;4(5):259-61.

103. Norris KA, Schrimpf JE, Flynn JL, Morris SM, Jr. Enhancement of macrophage microbicidal activity: supplemental arginine and citrulline augment nitric oxide production in murine peritoneal macrophages and promote intracellular killing of Trypanosoma cruzi. Infect Immun 1995;63(7):2793-6.

104. Nirgiotis JG, Hennessey PJ, Andrassy RJ. The effects of an arginine-free enteral diet on wound healing and immune function in the postsurgical rat. $J$ Pediatr Surg $1991 ; 26(8): 936-41$. 
105. Seifter E, Rettura G, Barbul A, Levenson SM. Arginine: an essential amino acid for injured rats. Surgery 1978;84(2):224-30.

106. Yamasaki K, Edington HD, McClosky C, et al. Reversal of impaired wound repair in iNOS-deficient mice by topical adenoviral-mediated iNOS gene transfer. J Clin Invest 1998;101(5):967-71.

107. Debats IB, Booi D, Deutz NE, Buurman WA, Boeckx WD, van der Hulst RR. Infected chronic wounds show different local and systemic arginine conversion compared with acute wounds. J Surg Res 2006;134(2):205-14.

108. Reynolds JV, Daly JM, Shou J, Sigal R, Ziegler MM, Naji A. Immunologic effects of arginine supplementation in tumor-bearing and non-tumor-bearing hosts. Ann Surg 1990;211(2):202-10.

109. Tachibana K, Mukai K, Hiraoka I, Moriguchi S, Takama S, Kishino Y. Evaluation of the effect of arginine-enriched amino acid solution on tumor growth. JPEN 1985;9(4):428-34.

110. Szende B, Tyihak E, Trezl L. Role of arginine and its methylated derivatives in cancer biology and treatment. Cancer Cell Int 2001;1(1):3.

111. Millis RM, Diya CA, Reynolds ME, Dehkordi O, Bond V, Jr. Growth inhibition of subcutaneously transplanted hepatomas without cachexia by alteration of the dietary arginine-methionine balance. Nutr Cancer 1998;31 (1):49-55.

112. Lubec B, Hoeger H, Kremser K, Amann G, Koller DY, Gialamas J. Decreased tumor incidence and increased survival by one year oral low dose arginine supplementation in the mouse. Life Sci 1996:58(25):2317-25.

113. Milner JA, Stepanovich LV. Inhibitory effect of dietary arginine on growth of Ehrlich ascites tumor cells in mice. J Nutr 1979;109(3):489-94.

114. Edwards PD, Topping D, Kontaridis MI, Moldawer LL, Copeland EM, 3rd, Lind DS. Arginine-enhanced enteral nutrition augments the growth of a nitric oxide-producing tumor. JPEN 1997;21 (4):215-9.

115. Takeda Y, Tominaga T, Tei N, Kitamura M, Taga S. Inhibitory effect of L-arginine on growth of rat mammary tumors induced by 7,12-dimethylbenz(a)anthracene. Cancer Res 1975;35(9):2390-3.

116. Yeatman TJ, Risley GL, Brunson ME. Depletion of dietary arginine inhibits growth of metastatic tumor. Arch Surg 1991;126(11):1376-81; discussion 1381-2.

117. Oka T, Ohwada K, Nagao M, Kitazato K, Kishino Y. Arginine-enriched solution induces a marked increase in muscle glutamine concentration and enhances muscle protein synthesis in tumor-bearing rats. JPEN 1994;18(6):491-6.

1 18. Oka T, Ohwada K, Nagao M, Kitazato K. Effect of arginine-enriched total parenteral nutrition on the host-tumor interaction in cancer-bearing rats. JPEN 1993;17(4):37583.

119. Park KG, Heys SD, Blessing K, et al. Stimulation of human breast cancers by dietary L-arginine. Clin Sci (Lond) 1992;82(4):413-7.

120. Caso G, Matar S, McNurlan MA, McMillan DN, Eremin O, Garlick PJ. Metabolic effects of arginine on malignant tissues. Clin Nutr 1996;15:89-90.

121. Rettura G, Padawer J, Barbul A, Levenson SM, Seifter E. Supplemental arginine increases thymic cellularity in normal and murine sarcoma virus-inoculated mice and increases the resistance to murine sarcoma virus tumor. JPEN 1979;3(6):409-16. 
122. Lieberman MD, Nishioka K, Redmond HP, Daly JM. Enhancement of interleukin2 immunotherapy with L-arginine. Ann Surg 1992;215(2):157-65.

123. Reynolds JV, Daly JM, Zhang S, et al. Immunomodulatory mechanisms of arginine. Surgery 1988;104(2):142-51.

124. Brittenden J, Park KG, Heys SD, et al. L-arginine stimulates host defenses in patients with breast cancer. Surgery 1994;115(2):205-12.

125. Heys SD, Segar A, Payne S, Bruce DM, Kernohan N, Eremin O. Dietary supplementation with L-arginine: modulation of tumour-infiltrating lymphocytes in patients with colorectal cancer. Br J Surg 1997;84(2):238-41.

126. Brittenden J, Heys SD, Ross J, Park KG, Eremin O. Natural cytotoxicity in breast cancer patients receiving neoadjuvant chemotherapy: effects of L-arginine supplementation. Eur J Surg Oncol 1994;20(4):467-72.

127. Canturk NZ, Vural B, Canturk Z, et al. The role of L-arginine and neutrophils on incisional wound healing. Eur J Emerg Med 2001;8(4):311-5.

128. Shi HP, Efron DT, Most D, Tantry US, Barbul A. Supplemental dietary arginine enhances wound healing in normal but not inducible nitric oxide synthase knockout mice. Surgery 2000;128(2):374-8.

129. Arbss MA, Ferrando JM, Vidal J, et al. Early effects of exogenous arginine after the implantation of prosthetic material into the rat abdominal wall. Life Sci 2000;67(20):2493-512.

130. Sukumar P, Loo A, Magur E, Nandi J, Oler A, Levine RA. Dietary supplementation of nucleotides and arginine promotes healing of small bowel ulcers in experimental ulcerative ileitis. Dig Dis Sci 1997;42(7):1530-6.

131. Shashidharan M, Lin KM, Ternent CA, et al. Influence of arginine dietary supplementation on healing colonic anastomosis in the rat. Dis Colon Rectum 1999;42(12):1613-7.

132. Wittmann F, Prix N, Mayr S, et al. L-arginine improves wound healing after traumahemorrhage by increasing collagen synthesis. J Trauma 2005;59(1):162-8.

133. Kirk SJ, Hurson M, Regan MC, Holt DR, Wasserkrug HL, Barbul A. Arginine stimulates wound healing and immune function in elderly human beings. Surgery 1993; 114(2):155-9; discussion 160.

134. Barbul A, Lazarou SA, Efron DT, Wasserkrug HL, Efron G. Arginine enhances wound healing and lymphocyte immune responses in humans. Surgery 1990;108(2):331-6; discussion 336-7.

135. Riso S, Aluffi P, Brugnani M, Farinetti F, Pia F, D'Andrea F. Postoperative enteral immunonutrition in head and neck cancer patients. Clin Nutr 2000;19(6):407-12.

136. Sigal RK, Shou J, Daly JM. Parenteral arginine infusion in humans: nutrient substrate or pharmacologic agent? JPEN 1992;16(5):423-8.

137. McCarter MD, Gentilini OD, Gomez ME, Daly JM. Preoperative oral supplement with immunonutrients in cancer patients. JPEN 1998;22(4):206-11. 
partone | chapterone 


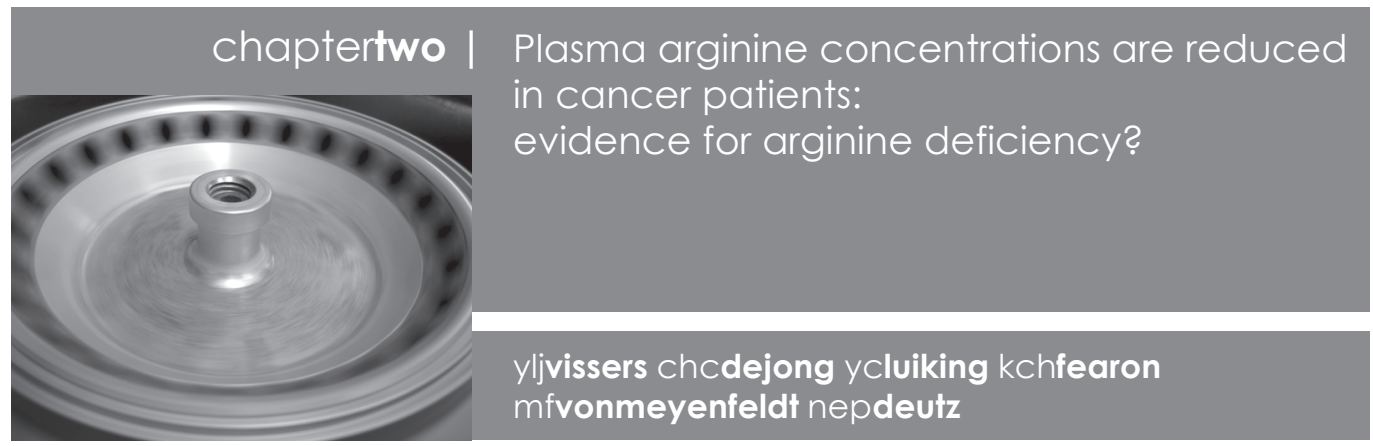

\section{introduction |}

Up to one third of cancer patients die from cachexia rather than from cancer itself, even after surgical removal of the tumour '. This suggests that cancer-related alterations in metabolism of the host are a very important factor in determining mortality. Unfortunately, attempts to reverse cachexia by supplying large amounts of protein or calories have been unsuccessful up to now. Therefore, more detailed insight in the disturbances in host metabolism of cancer patients is necessary.

Evidence is accumulating that the amino acid arginine is of importance in cancer. Both arginine and its product nitric oxide (NO) are important mediators in the defence against tumour cells, since both influence T-cell mediated immunity 2,3, cytokine induction ${ }^{4}$ and macrophage mediated tumour toxicity ${ }^{5}$. Besides, various malignant tumour tissues contain considerable amounts of the enzyme arginase 6-8, converting arginine to ornithine and urea. It was recently demonstrated that high arginase activity of tumours is a mechanism of tumour-induced immunosuppression via depletion of arginine levels in the microenvironment of the tumour ${ }^{9}$. However, it is not known whether this disturbs arginine metabolism of the host as well. Changes in systemic arginine concentrations of cancer patients could indicate whether the high arginase activity in the proximity of the tumour affects arginine metabolism on whole-body level as well.

Plasma arginine concentrations in cancer patients have been studied before, but interpretation of these data may not be valid because of incorrect collection of samples and the use of improper control groups. Thus, to determine whether there is evidence for a disturbed arginine metabolism in cancer, we measured arginine concentrations in venous blood samples from postabsorptive patients with various types of tumours and compared these with values obtained from age- and sexmatched controls collected previously in our laboratory. We aimed to collect blood samples in a way that prevented decomposition of samples and minimized variations in concentrations due to confounding variables. Three tumour types with a range of metabolic implications were studied: breast tumours (no weight loss), colonic tumours (sometimes weight loss) and pancreatic tumours (often weight loss). 


\section{methods}

patients |

Patients with breast cancer $(n=22)$ and colonic cancer $(n=9)$ were recruited from the Department of Surgery of the University Hospital Maastricht from 2003 to 2004. Patients with pancreatic cancer $(n=21)$ and contemporary age- and sex-matched controls ( $n=17)$ were recruited from the Department of Surgery of the Royal Infirmary of Edinburgh from 1999 to 2000. Exclusion criteria were previous therapy (surgery, chemotherapy or radiotherapy), metastatic disease and known metabolic or endocrine disease. The Medical Ethical Committee of the University Hospital Maastricht and the Royal Infirmary of Edinburgh approved the study. Written informed consent was obtained from all patients. Diagnosis of malignancy was confirmed by histological examination of tumour tissue after surgical removal. Tumour stages were classified according to the guidelines of the American Joint Committee on Cancer. Patient characteristics are summarized in table one. Amino acid concentrations of all patient groups were compared with a data set of age and sex matched control subjects from a group of individuals collected previously by our laboratory ${ }^{10}$ and are referred to as historical controls.

tableone | patient characteristics

\begin{tabular}{|c|c|c|c|c|c|}
\hline & & $\begin{array}{c}\text { breast } \\
\text { cancer } \\
n=22\end{array}$ & $\begin{array}{c}\text { colonic } \\
\text { cancer } \\
n=9\end{array}$ & $\begin{array}{c}\text { pancreatic } \\
\text { cancer } \\
n=21\end{array}$ & $\begin{array}{c}\text { controls } \\
\text { (pancreas) } \\
n=17\end{array}$ \\
\hline age (years) & & $59 \pm 10(43-74)$ & $72 \pm 10(55-84)$ & $67 \pm 8(55-82)$ & $68 \pm 10(45-86)$ \\
\hline sex & $\begin{array}{l}F \\
M\end{array}$ & $100 \%$ & $\begin{array}{l}18 \% \\
82 \%\end{array}$ & $\begin{array}{l}33 \% \\
67 \%\end{array}$ & $\begin{array}{l}35 \% \\
65 \%\end{array}$ \\
\hline tumour stage & & $\begin{array}{l}\text { T1: } 27 \% \\
\text { T2: } 32 \% \\
\text { T3: } 36 \% \\
\text { T4: } 0 \%\end{array}$ & $\begin{array}{l}\text { T1: } 22 \% \\
\text { T2: } 67 \% \\
\text { T3: } 11 \% \\
\text { T4: } 0 \%\end{array}$ & $\begin{array}{l}\text { 1: } 0 \% \\
\text { 2: } 10 \% \\
\text { 3: } 14 \% \\
4: 76 \%\end{array}$ & \\
\hline $\begin{array}{l}\text { body mass } \\
\text { index }\end{array}$ & & $28 \pm 4(21-36)$ & $25 \pm 3(21-28)$ & $22 \pm 4(16-28)^{\#}$ & $27 \pm 5(19-35)$ \\
\hline $\begin{array}{l}\text { weight } \\
\text { loss (kg) }\end{array}$ & & $1 \pm 2(0-5)$ & $3 \pm 4(0-12)$ & $13 \pm 10(0-38)^{\#}$ & $0(0)$ \\
\hline
\end{tabular}

Values are means \pm SD (range). F: female, M: male. Statistics with Mann-Whitney U test, $\# p<0.05$ vs. age and sex matched controls without tumour.

handling of samples |

All blood samples were collected in the morning after an overnight fast. Blood was collected from a peripheral vein into precooled heparinized tubes and immediately put on ice. Body weight and length were determined and patients were asked for weight loss in the previous six months. Within half an hour after 
sampling, samples were centrifuged for 10 min at $4000 \mathrm{~g}, 4^{\circ} \mathrm{C}$, and plasma was deproteinized using sulfosalicylic acid ( $8 \mathrm{mg}$ per $100 \mu \mathrm{l}$ plasma). Samples were subsequently put into liquid nitrogen and stored at $-80^{\circ} \mathrm{C}$ until analysis.

Amino acid concentrations were determined in plasma using HPLC as described by Van Eijk " with variation coefficients of less than $3 \%$.

statistical analysis |

Mann-Whitney $U$ test was used to test for differences between groups with malignant tumours and their age and sex matched controls, hypothesizing that cancer decreased amino acid concentrations. Correlations between amino acid concentrations and tumour stage were tested using Kendall's tau; correlations between amino acid concentrations and weight loss or BMI were tested using Spearman's rho. Significance was defined as $p<0.05$.

\section{results}

patient characteristics (table one) I

Of the patients with breast cancer, four out of 22 had experienced weight loss in the past six months. Four of the nine patients with colonic cancer had lost weight in the past six months. None of the patients in these two groups had lost more than $10 \%$ of their body weight and all subjects had BMl's higher than 21 . Of the patients with pancreatic cancer, all but one had lost weight in the past six months. Twelve out of 21 had lost more than 10\% of their initial body weight and five patients had BMl's less than 19. All age and sex matched controls groups were weight stable with an average BMI of $25 \pm 1$ in each group.

amino acid concentrations |

Most plasma amino acid concentrations of contemporary and historical controls of pancreatic cancer patients were not different (table two).

In all patients with malignant disease, plasma arginine concentrations were lower than in age and sex matched controls (figure one). Branched chain amino acid concentrations were also lower in all cancer patients. Total amino acid concentrations were only lower in patients with pancreatic cancer (table two).

correlations |

There was no significant correlation between arginine or total amino acid concentrations and tumour stage, weight loss or BMl in either patient group.

\section{discussion |}

This study shows that plasma arginine concentrations are reduced in patients with cancer, even without weight loss being present and irrespective of tumour type, tumour stage or BMI. Plasma arginine concentrations in various types of cancer have been investigated before. 


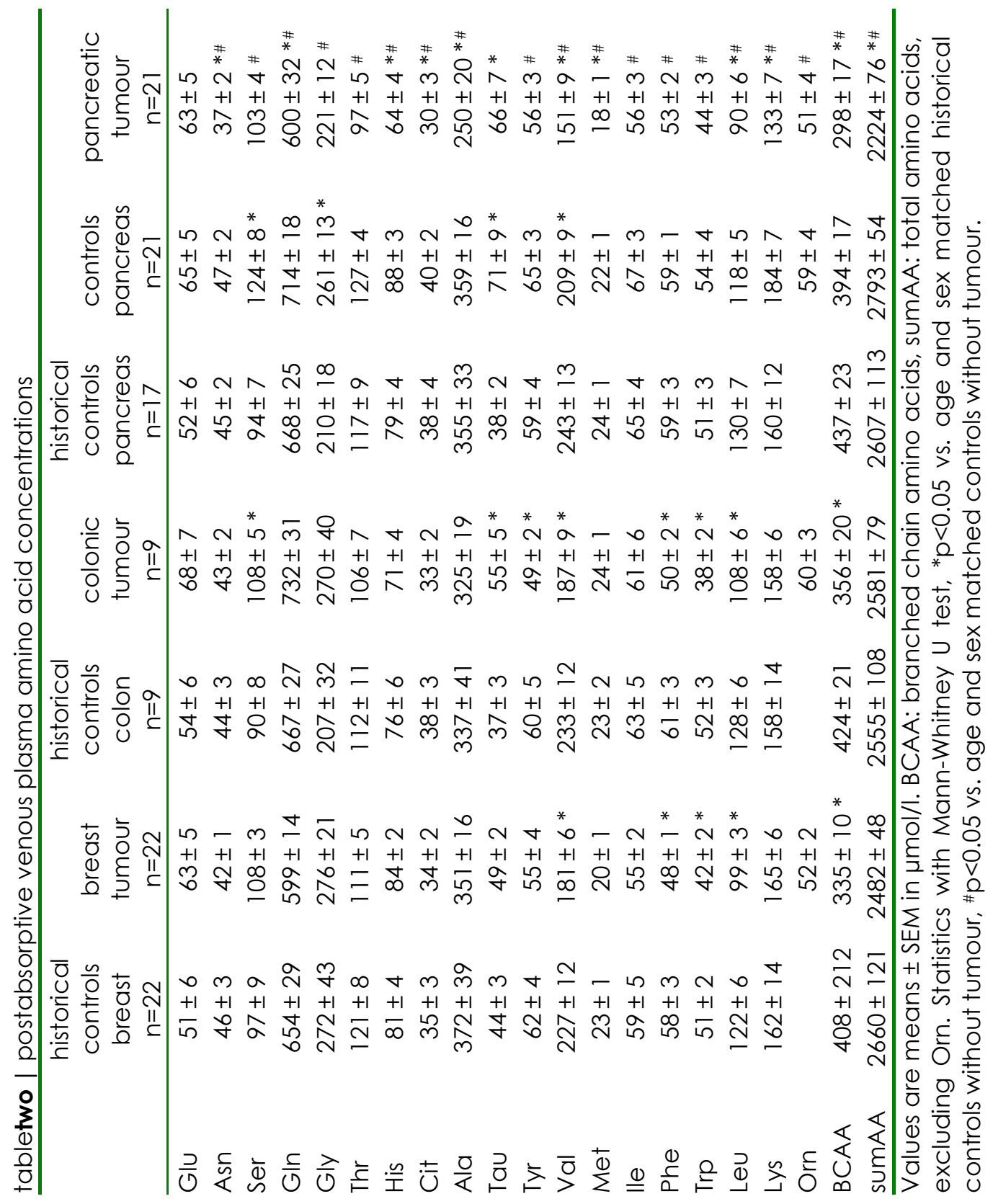


figureone | arginine concentrations

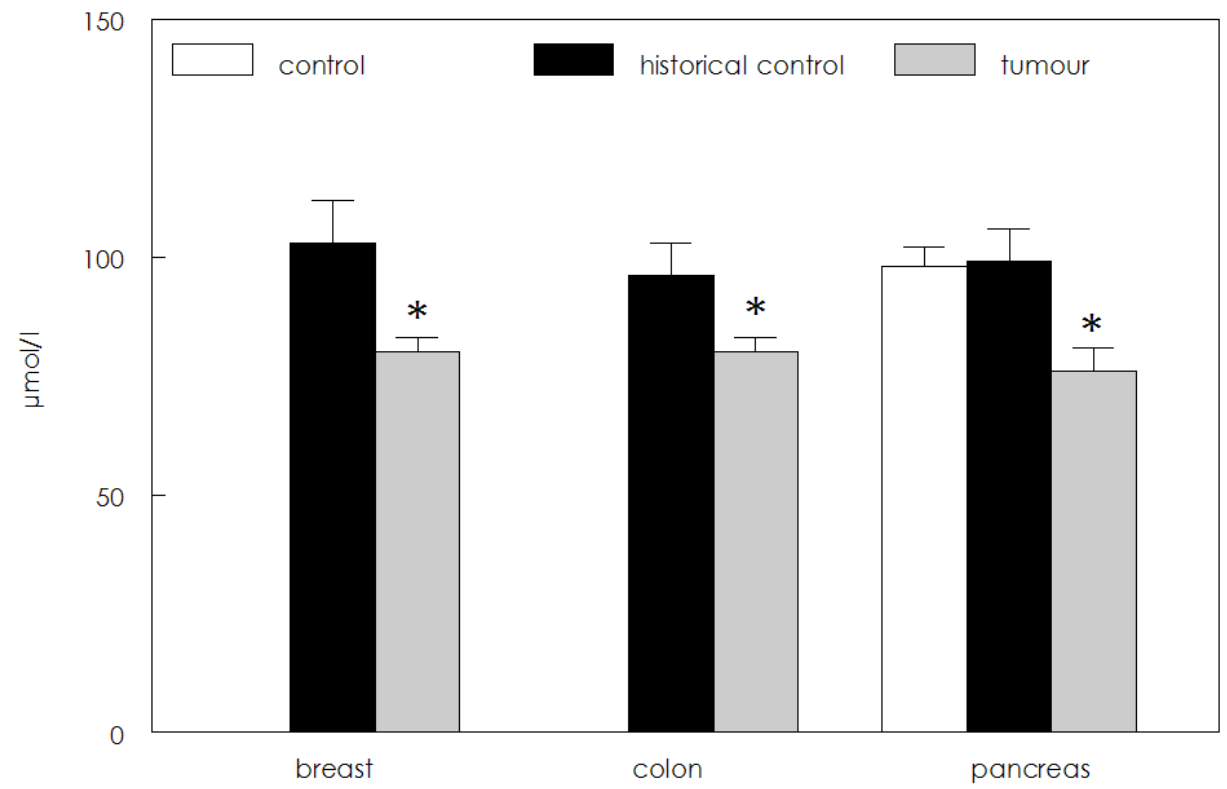

Values are means \pm SEM in $\mu \mathrm{mol} / \mathrm{l}$. Postabsorptive venous plasma arginine concentrations from patients with various types of malignant tumours and groups of age and sex matched historical controls. Breast cancer and historic controls $n=22$ per group, colonic cancer and historic controls $n=9$ per group, pancreatic cancer and historic controls $n=21$ per group. For pancreatic cancer, a contemporary group of age and sex matched controls was included as well $(n=17)$. Comparisons between malignant and control groups with Mann-Whitney U test, ${ }^{*} p<0.05$ compared with age and sex matched controls without malignant disease.

These have been reported to be decreased in lung cancer ${ }^{13}$, higher in breast cancer 7,14 , unchanged ${ }^{14}$ or higher ${ }^{12}$ in gastrointestinal cancer, unchanged in head and neck cancer ${ }^{14}$ and unchanged in oesophageal cancer ${ }^{13}$ (overview in table three). However, none of these studies report that plasma samples were deproteinized before storage, which leaves enzymatic activity of arginase (converts arginine to ornithine) intact. As we have shown before, ongoing arginase activity in plasma can decrease arginine concentrations up to $94 \%{ }^{10}$. This could explain why plasma arginine concentrations were already relatively low in control groups reported in the literature (table three). Thus, interpretation of these data may be invalid. To prevent decomposition by enzymatic activity, samples must be deproteinized immediately and stored at $-80^{\circ} \mathrm{C}$ until analysis. Moreover, the sampling site must be equal in all subjects, since we observed that the arterial and venous pool give different results for some amino acids, including arginine, varying from 8 to 38\% (unpublished observation, YC Luiking, 2003). Furthermore, all subjects studied must be postabsorptive to overcome acute effects of amino acid intake by food. Finally, to enable interpretation of differences in amino acid 
concentrations between subjects, control groups should be at least age- and sexmatched since we have shown that amino acid concentrations vary with the sex of the individual and increase with age ${ }^{10}$. Only Naini's study used age-matched controls and observed that plasma arginine concentrations were decreased in patients with lung cancer and unchanged in patients with oesophageal cancer ${ }^{13}$.

tablethree | literature data

\begin{tabular}{|c|c|c|c|c|c|c|}
\hline authors & tumour & $\begin{array}{l}\text { weight } \\
\text { loss }\end{array}$ & $\begin{array}{c}\text { plasma } \\
\text { [Arg] } \\
\text { cancer }\end{array}$ & $\begin{array}{c}\text { plasma } \\
\text { [Arg] } \\
\text { controls }\end{array}$ & $\begin{array}{l}\text { storage } \\
-80^{\circ} \mathrm{C}\end{array}$ & $\begin{array}{l}\text { one } \\
\text { pool }\end{array}$ \\
\hline Glass 12 & gastrointestinal & yes & $70 \pm 4$ & $48 \pm 4$ & no & yes \\
\hline Naini 13 & $\begin{array}{c}\text { oesophageal } \\
\text { lung }\end{array}$ & $\begin{array}{l}? \\
?\end{array}$ & $\begin{array}{l}79 \pm 7 \\
61 \pm 5\end{array}$ & $84 \pm 3$ & no & $?$ \\
\hline Park 7 & $\begin{array}{l}\text { breast } \\
\text { colon }\end{array}$ & $\begin{array}{l}? \\
?\end{array}$ & $\begin{array}{l}167 \pm 17 \\
126 \pm 10\end{array}$ & $\begin{array}{l}111 \pm 10 \\
115 \pm 11\end{array}$ & yes & yes \\
\hline Kubota ${ }^{14}$ & $\begin{array}{c}\text { head/neck } \\
\text { breast } \\
\text { gastrointestinal }\end{array}$ & $\begin{array}{l}\text { yes } \\
\text { no } \\
\text { yes }\end{array}$ & $\begin{array}{cc}77 \pm 9 & (\mathrm{~F}) \\
72 \pm 10 & (\mathrm{M}) \\
109 \pm 7 & \\
91 \pm 13 & (\mathrm{~F}) \\
77 \pm 7 & (\mathrm{M})\end{array}$ & $\begin{array}{c}83 \pm 6(F) \\
83 \pm 8(M)\end{array}$ & no & yes \\
\hline
\end{tabular}

Values are means \pm SEM in $\mu \mathrm{mol} / \mathrm{l}$. None of the samples were deproteinized. None of the control groups were age and sex matched. None of the authors report whether samples were collected at one time point. F: female, M: male, question mark: not mentioned.

However, in a clinical situation, it can be difficult to obtain samples from healthy control groups with age- and sex-matched subjects. Therefore, using historical controls of various age groups is an acceptable alternative. Most amino acid concentrations in contemporary controls of the pancreatic cancer patients were not different from the concentrations in historical controls (table two). This indicates that there are no major differences in amino acid patterns between the two control groups and that the historical controls can be used for comparison with current patient data. Thus, our study is the first to report plasma arginine concentrations in cancer patients using strict methods for collection and storage of samples, and where proper control groups were used.

Evidence for abnormal arginine metabolism in cancer has accumulated. As such, various malignant tissues such as lung ${ }^{6}$, skin ${ }^{15}$, prostate ${ }^{16}$ colon and breast tumours 7.8 contain high amounts of arginase. It was shown recently that arginase activity in tumours induces arginine deficiency in the microenvironment of the tumour, enabling tumours to escape the immune response ?. However, it is not known whether this has systemic effects on arginine metabolism. The low arginine 
concentrations in cancer patients suggest that the presence of a tumour indeed affects arginine metabolism on whole-body level. Whether this is due to increased arginine uptake by the tumour or secretion of arginase into the circulation remains to be determined. Apart from arginase, arginine can be converted by NO synthase (NOS) to produce citrulline and NO. NO is a highly reactive molecule to which many of the functions of arginine are ascribed. For example, NO is the effector molecule of the tumour cytotoxic mechanism of macrophages ${ }^{5}$. Therefore, arginine deficiency could decrease NO production and have adverse effects in cancer patients. On basis of the $K_{m}$ for NOS $(2-20 \mu m o l / l)$, the observed decrease in arginine concentrations in cancer patients should not limit NO production. However, the existence of caveolar complexes between NOS and membrane transporters of arginine ${ }^{17}$ suggest that arginine transporters may be more important than the $K_{m}$ of NOS for regulation of NO production. Since these arginine transporters have $K_{m}$ values in the range of physiological arginine concentrations 18, decreases in arginine concentrations such as observed in the present study may indeed limit NO production.

Disturbances in arginine/NO metabolism in the presence of cancer can be unfavourable, especially when cancer patients undergo treatment such as surgical removal of the fumour or radio- or chemotherapy, representing situations in which tissue damage occurs. Since arginine has been demonstrated to stimulate the immune system ${ }^{19}$ and anabolism ${ }^{3,20}$, abnormal arginine metabolism can disturb repair responses such as the acute phase protein response. We recently observed that low arginine concentrations in tumour-bearing mice prohibit the postoperative increase in arginine and NO production, concomitant with a suppressed acute phase response ${ }^{21}$, indicating that metabolic disturbances become even more pronounced when metabolism is challenged to respond to stress.

There was no relation between arginine or total amino acid concentrations and tumour stage or previous weight loss. Strikingly, plasma arginine concentrations were decreased in all tumour types studied, including breast and colonic cancer, which have always been assumed to cause little metabolic derangements. Moreover, the decreased arginine concentrations were specific, since total amino acid concentrations were maintained. Furthermore, previous studies from our group investigating amino acid metabolism in patients with chronic obstructive pulmonary disease did not show changes in plasma arginine concentrations compared with healthy age- and sex-matched controls ${ }^{22,23}$. Moreover, there was no relation between plasma arginine concentrations and $\mathrm{BMI}$, weight loss or fat free mass ${ }^{22}$, indicating that the observed arginine depletion in the presence of tumour is probably specific for cancer. In the pancreatic cancer patients, where weight loss was present, all amino acid concentrations were decreased. This suggests that arginine concentrations change early in the course of tumour development and could indicate that this contributes to the initiation of the cascade of metabolic disturbances leading to cachexia. Other factors playing a role may well be BCAA or essential amino acid metabolism. Obviously, further studies are necessary to elucidate whether derangements in arginine metabolism are causally related to the phenotypical characteristics of cachexia. 
Over the last decade, it has become clear that the host's metabolism in cancer is different from that in simple starvation or fasting, and that mere supplementation of calories cannot reverse cachexia. This resulted in studies investigating the metabolic changes accompanying weight loss in cancer. Still, the mechanism of cancer cachexia remains to be unravelled, which might be due to the complexity of the metabolic abnormalities that are present in the stage where symptoms such as weight loss or anorexia have already become obvious. Therefore, studying early changes in cancer may provide insight in the onset of events ultimately leading to cachexia. In this respect, it is clear from the present data of patients with breast cancer and colonic cancer that metabolic changes were indeed already apparent without weight loss being present. Our observation supports the idea of cancer inducing disturbances before anorexia and loss of muscle and fat become obvious. In fact, data from non-cachectic patients may give better clues for factors involved in initiating cachexia than than data from metabolic disturbancies accompanying cachexia. In this respect, disturbances in arginine metabolism may play a role.

In conclusion, both in cancer patients with and without weight loss, plasma arginine concentrations are decreased specifically, indicating that arginine metabolism is disturbed in the presence of a malignant tumour. Therefore, further study of actual in vivo production rates of arginine and NO in cancer patients is indicated.

\section{references |}

1. Talamonti MS, Kim SP, Yao KA, et al. Surgical outcomes of patients with gastric carcinoma: the importance of primary tumor location and microvessel invasion. Surgery 2003;134(4):720-7; discussion 727-9.

2. Bronte V, Serafini P, Mazzoni A, Segal DM, Zanovello P. L-arginine metabolisme in myeloid cells controls T-lymphocyte functions. Trends in Immunol 2003;24(6):3015.

3. Daly JM, Reynolds J, Thom A, et al. Immune and metabolic effects of arginine in the surgical patient. Ann Surg 1988;208(4):512-23.

4. Reynolds JV, Daly JM, Shou J, Sigal R, Ziegler MM, Naji A. Immunologic effects of arginine supplementation in tumor-bearing and non-tumor-bearing hosts. Ann Surg 1990;211(2):202-10.

5. Hibbs JB, Jr., Vavrin Z, Taintor RR. L-arginine is required for expression of the activated macrophage effector mechanism causing selective metabolic inhibition in target cells. J Immunol 1987;138(2):550-65.

6. Suer Gokmen S, Yoruk Y, Cakir E, Yorulmaz F, Gulen S. Arginase and ornithine, as markers in human non-small cell lung carcinoma. Cancer Biochem Biophys 1999;17(1-2):125-31.

7. Park KG, Heys SD, Harris $\mathrm{Cl}$, et al. Arginine metabolism in benign and malignant disease of breast and colon: evidence for possible inhibition of tumor-infiltrating macrophages. Nutrition 1991;7(3):185-8. 
8. Porembska Z, Luboinski G, Chrzanowska A, Mielczarek M, Magnuska J, BaranczykKuzma A. Arginase in patients with breast cancer. Clin Chim Acta 2003;328(12):105-11.

9. Rodriguez PC, Quiceno DG, Zabaleta J, et al. Arginase I production in the tumor microenvironment by mature myeloid cells inhibits T-cell receptor expression and antigen-specific T-cell responses. Cancer Res 2004;64(16):5839-49.

10. Van Eijk HMH, Dejong CHC, Deutz NEP, Soeters PB. Influence of storage conditions on normal plasma amino-acid concentrations. Clin Nutr 1994;13:374380.

11. van Eijk HMH, Rooyakkers DR, Deutz NEP. Rapid routine determination of amino acids in plasma by high-performance liquid chromatography with a 2-3 $\mu \mathrm{M}$ Spherisorb ODS II column. J Chromatogr 1993;620:143-148.

12. Glass RE, Goode AW, Houghton BJ, Rowell LW. Plasma arginine in cancer of the gastrointestinal tract: effect of surgical treatment. Gut 1986;27(7):844-8.

13. Naini AB, Dickerson JW, Brown MM. Preoperative and postoperative levels of plasma protein and amino acid in esophageal and lung cancer patients. Cancer 1988;62(2):355-60.

14. Kubota A, Meguid MM, Hitch DC. Amino acid profiles correlate diagnostically with organ site in three kinds of malignant tumors. Cancer 1992;69(9):2343-8.

15. Gokmen SS, Aygit AC, Ayhan MS, Yorulmaz F, Gulen S. Significance of arginase and ornithine in malignant tumors of the human skin. J Lab Clin Med $2001 ; 137(5): 340-4$.

16. Keskinege A, Elgun S, Yilmaz E. Possible implications of arginase and diamine oxidase in prostatic carcinoma. Cancer Detect Prev 2001;25(1):76-9.

17. McDonald KK, Zharikov S, Block ER, Kilberg MS. A caveolar complex between the cationic amino acid transporter 1 and endothelial nitric oxide synthase may explain the "arginine paradox". J Biol Chem 1997;272(50):31213-31216.

18. Wu G, Morris SM. Arginine metabolism: nitric oxide and beyond. Biochem J 1998;336:1-17.

19. Reynolds JV, Daly JM, Zhang S, et al. Immunomodulatory mechanisms of arginine. Surgery 1988;104(2):142-51.

20. Bruins MJ, Soeters PB, Lamers WH, Deutz NE. L-arginine supplementation in pigs decreases liver protein turnover and increases hindquarter protein turnover both during and after endotoxemia. Am J Clin Nutr 2002;75(6):1031-44.

21. Vissers $Y L$, von Meyenfeldt MF, Luiking YC, Dejong $\mathrm{CH}$, Buurman WA, Deutz NE. Presence of tumour inhibits the normal post-operative response in arginine and NO production in non-cachectic mice. Clin Sci (Lond) 2007;1 12(10):527-32.

22. Engelen MP, Wouters EF, Deutz NE, Menheere PP, Schols AM. Factors contributing to alterations in skeletal muscle and plasma amino acid profiles in patients with chronic obstructive pulmonary disease. Am J Clin Nutr 2000;72(6):1480-7.

23. Engelen MP, Wouters EF, Deutz NE, Does JD, Schols AM. Effects of exercise on amino acid metabolism in patients with chronic obstructive pulmonary disease. Am J Respir Crit Care Med 2001;163(4):859-64. 


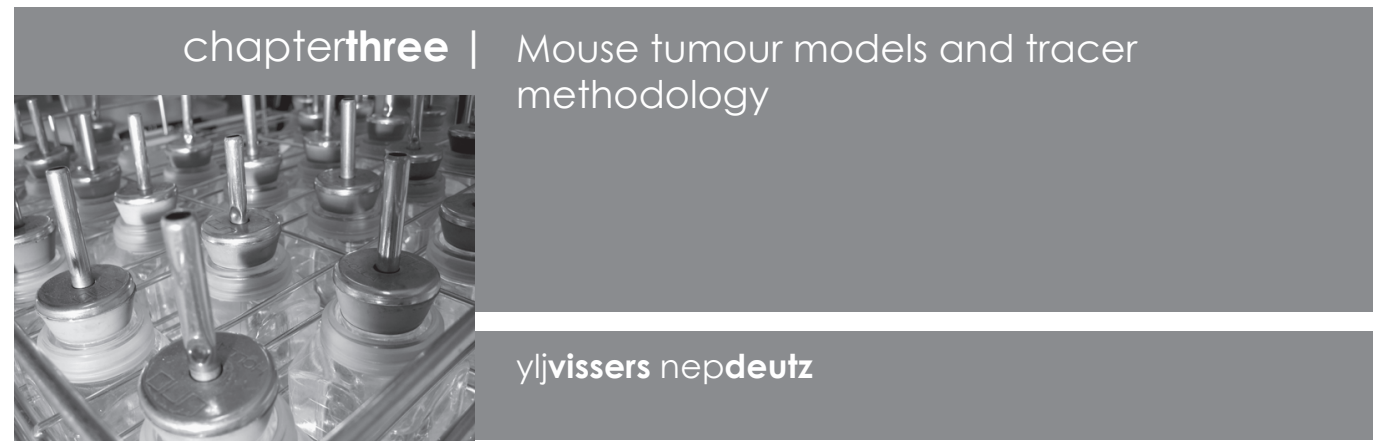

\section{tumour models to study cancer cachexia |}

Besides human studies, animal models are indispensable to achieve insight in the pathophysiology of cancer. Animal models allow measurements that are difficult to perform in humans for ethical reasons, such as interorgan measurements across intestine, liver and kidney. Animal models also enable the use of specific blockers or supplemental interventions to elucidate the contribution of specific factors and pathways.

Animal tumour models only exist in rats and mice. In contrast to rats, the use of mice enables studies in transgeneticly modified strains and knock-out models, creating opportunities to investigate the contribution of single components. Rats have the advantage of larger size, which facilitates measurements where a relatively large sample size is necessary. However, in the last decade, increased sensitivity of laboratory techniques has enabled the use of very small specimens, thus overcoming this problem in mice.

All animal models for cancer have the disadvantage that they do not display the exact characteristics of human tumours. Firstly, for practical reasons of time, researchers usually select those tumour models that develop within several weeks, whereas human tumours usually grow over the course of many decades. Secondly, most human tumours have a relative size of less than $0.5 \%$ of body weight, whereas most animal tumour models are studied at tumour sizes of $5-15 \%$ of body weight. Thirdly, experimental tumours are often highly immunogenic and elicit an immune response by their presence per se, while most human cancers are not.

Moreover, human cancers also display huge variations of characteristics, with a range of metabolic effects. For example, breast tumours seldom induce weight loss, whereas pulmonary tumours often do. Moreover, some tumours affect host metabolism by mechanic obstruction by their volume, an example of which are oesophageal tumours reducing food intake. This makes experiments with a specific tumour type hard to extrapolate to others, and therefore comparison of studies is difficult.

Because of the known variation between tumour models, we chose to use two different mouse models for cancer. In part one, a methylcholantrene (MCA)-induced sarcoma is used. The fumour that we induced in our laboratory (Maastricht MCA, MMCA) was 
induced subcutaneously. Although methylcholantrene was injected into various mouse strains, tumour growth only occurred in FVB mice (table one). Thereupon, tumour fragments have been serially transplanted subcutaneously into the flanks of FVB mice. MCA-tumours have been used both in rats ${ }^{1-3}$ and mice ${ }^{4,5}$ to study host metabolism in cancer. Most studies report that these tumours induce anorexia from week two after implantation (table two), but in our study, food intake in tumour-bearing mice did not decline (figure one). This could explain why we did not observe body weight loss in this model (figure two), while others did. This enabled us to study host metabolism in cancer without anorexia as confounding factor.

figureone | food intake in MMCA mice

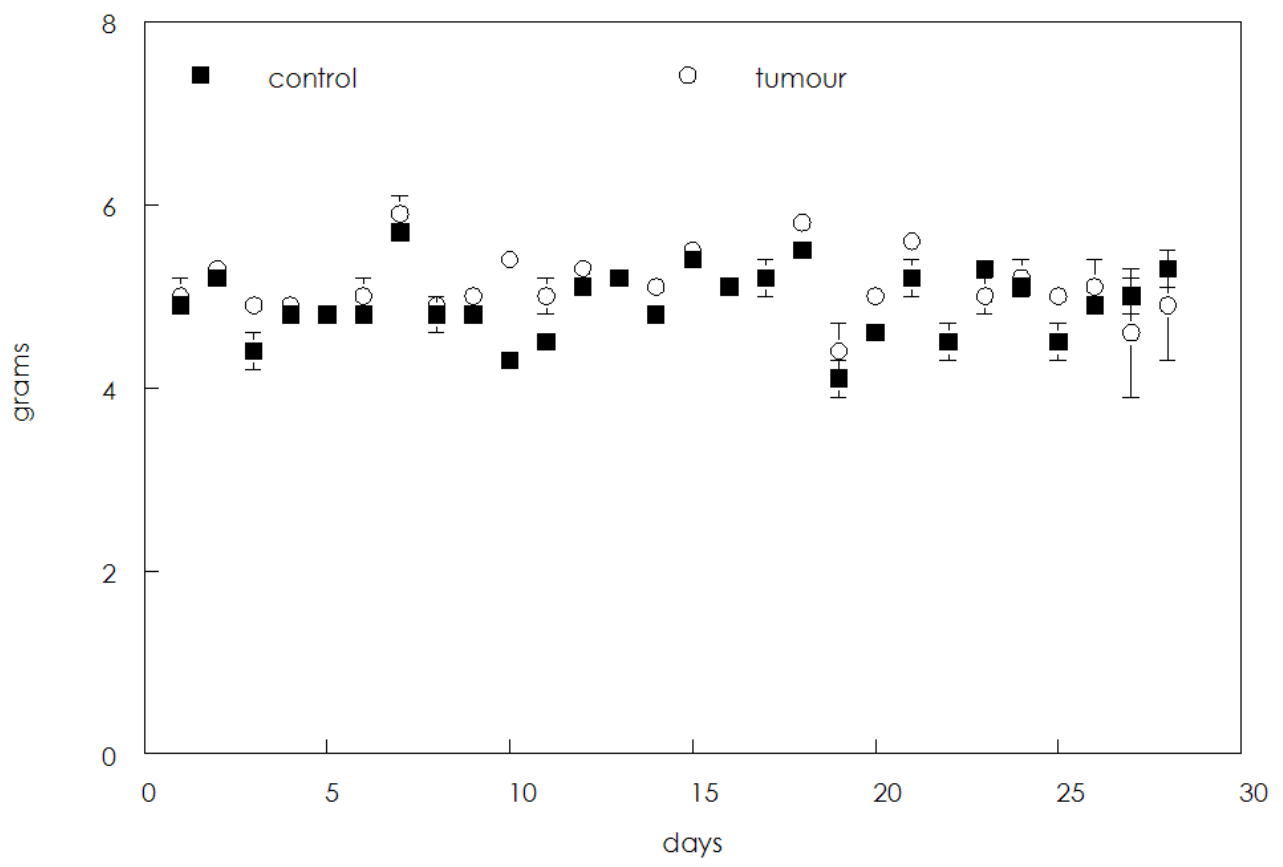

Values are means \pm SEM in grams. Food intake was measured by daily weighing of chow. 
figuretwo | body weight in MMCA mice

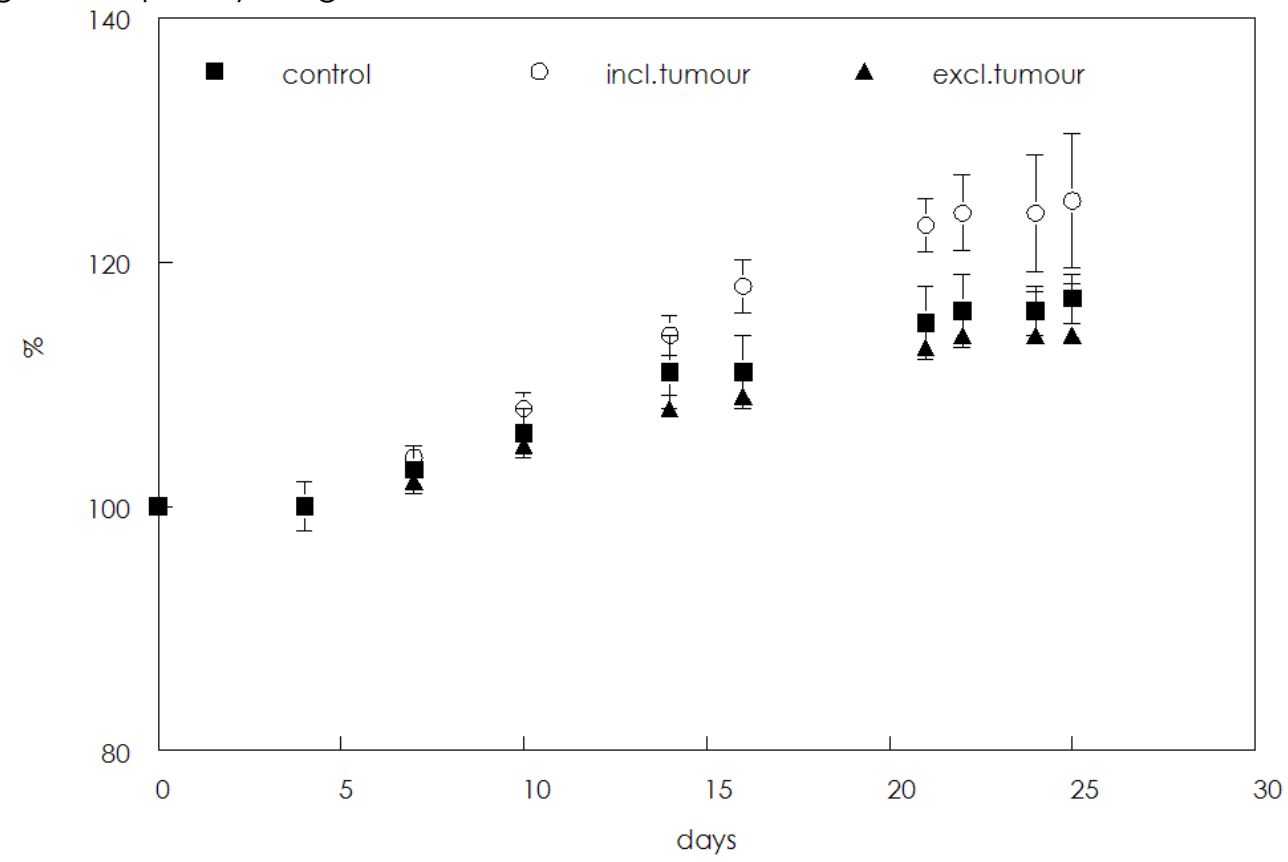

Values are means \pm SEM in percentages. Changes in body weight after implantation of subcutaneous tumour fragments (day zero) of control mice (sham implanted) and tumour-bearing mice. Body-weight excluding tumour was calculated by subtracting tumour weight from body weight including tumour.

tableone | induction MMCA tumours and subsequent growth

\begin{tabular}{lc}
\hline mouse strain & tumour \\
\hline FVB & $3(7)$ \\
Swiss & $0(7)$ \\
C57Bl6 & $0(9)$ \\
\hline
\end{tabular}

In part two of the thesis, a murine adenocarcinoma (MAC) tumour model is used. Induction of MAC was originally performed by repeated subcutaneous injections of 1,2-dimethylhydrazine, resulting in various colonic tumours ${ }^{6}$. From these tumours, MAC series 16 were serially transplanted subcutaneously and have been used as an experimental model for cancer ${ }^{7}$. The MAC 16 tumour model is thought to be highly relevant for human cancer for several reasons. Firstly, the tumour induces weight loss at tumour burdens of less than $1 \%$ of the host weight ${ }^{8}$ (see figure three for pattern of weight loss in MACl6 in Maastricht). Secondly, from these tumour-bearing mice proteolysis inducing factor (PIF) has been isolated that induces catabolism when injected into healthy mice? Moreover, a similar molecule was also present in urine of cachectic cancer patients, but was absent from normal subjects, patients with weight 
loss due to trauma, and cancer patients with little or no weight loss ${ }^{10}$. This suggests that cachexia in MAC 16 mice and in humans may be produced by this same molecule. Although food intake of MAC 16 tumour-bearing mice is similar to that of controls at the start of weight loss, anorexia does occur when weight loss reaches $10 \%$. Therefore, in our studies, control mice were pair-fed.

In contrast to MCA tumours, MAC 16 tumours have been reported not to elicit a cytokine response as measured by plasma levels of interleukine- 6 and tumour-necrosis factor alpha $^{11}$.

figurethree | body weight in MAC16 mice in Maastricht

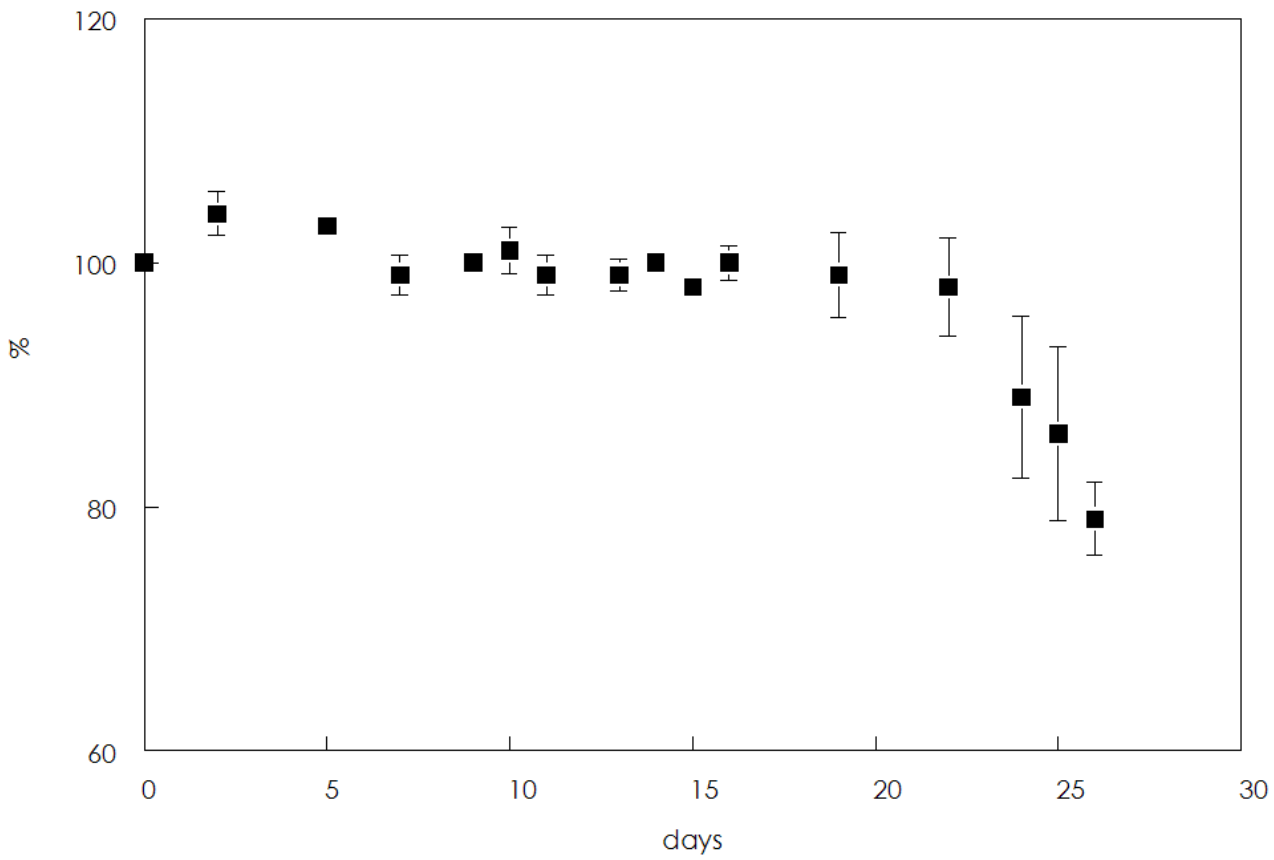

Values are means \pm SEM in percentages. Changes in body weight after implantation of subcutaneous tumour fragments on day zero.

It is known from previous studies in our laboratory that differences exist in arginine metabolism between various mouse strains (table three). Therefore, it was necessary to use strain-matched control groups for the two tumour models. In addition, we have shown that arginine metabolism in mice is determined by sex. Plasma arginine concentrations were higher in female than in male mice (table three). Furthermore, the response to metabolic stress was different in proportion, since male Swiss mice increased NO production by 1.8 times upon LPS-injection, compared to 2.5 times in females 36,37 . Thus, to prevent confounding, we used only male mice in the studies presented in this thesis. 
tabletwo | literature data MAC16 and MCA mouse tumour models

\begin{tabular}{lcc}
\hline & MCA & MACl6 \\
\hline food intake & $\downarrow 4,12,13$ & $=14-17$ \\
fat mass & $\downarrow 18,19$ & $\downarrow 720-22$ \\
dry body weight & $\downarrow 4$ & $\downarrow 7,20$ \\
energy expenditure & $\uparrow 19$ & \\
glucose turnover & $\uparrow 23$ & $\downarrow 8,24,25$ \\
arterial glucose & $\downarrow 4$ & $\downarrow 7$ \\
arterial insulin & & $\downarrow 7$ \\
arterial lactate & $\uparrow 23$ & $\uparrow 21$ \\
urea excretion & $\downarrow 4$ & $\downarrow 24,26$ \\
arterial urea & & $\downarrow 21$ \\
arterial triglycerides & & $\uparrow \downarrow 21$ \\
arterial amino acids & & $\downarrow 22,28$ \\
nitrogen excretion & & $\uparrow 28,22,29,30$ \\
protein synthesis muscle & & \\
protein breakdown muscle & & \\
protein synthesis liver & & \\
glycogen content liver & & \\
TNFa & $\uparrow 18,27,31$ & $\downarrow 11$ \\
IL6 & $\uparrow, 32$ & $\uparrow 34=11,35$ \\
\hline
\end{tabular}

tablethree | characteristics MMCA and MAC16 Maastricht

\begin{tabular}{lcc}
\hline & MMCA & MACl6 \\
\hline mouse strain & FVB & NMRI/Bradford \\
body weight loss & none & $10-15 \%$ \\
tissue invasion & no & no \\
anorexia & no & yes \\
metastasis & no & no \\
tumour size & $5-15 \%$ & $<1 \%$ \\
tumour site & subcutaneous & subcutaneous \\
\hline
\end{tabular}

tablefour | sex and strain related differences in arginine metabolism ${ }^{36,37}$

\begin{tabular}{lcccccc}
\hline & $\begin{array}{c}\text { FVB } \\
\text { male }\end{array}$ & $\begin{array}{c}\text { FVB } \\
\text { female }\end{array}$ & $\begin{array}{c}\text { Swiss } \\
\text { male }\end{array}$ & $\begin{array}{c}\text { Swiss } \\
\text { female }\end{array}$ & $\begin{array}{c}\text { C57BI6 } \\
\text { male }\end{array}$ & $\begin{array}{c}\text { C57BI6 } \\
\text { female }\end{array}$ \\
\hline arterial [Arg] & $149 \pm 13$ & $174 \pm 22$ & $105 \pm 7$ & $138 \pm 10$ & $120 \pm 4$ & $151 \pm 5$ \\
Arg production & $39 \pm 4$ & $43 \pm 3$ & $58 \pm 5$ & $77 \pm 3$ & $46 \pm 5$ & $49 \pm 2$ \\
Cit production & $25 \pm 2$ & $28 \pm 2$ & $23 \pm 3$ & $25 \pm 2$ & $21 \pm 2$ & $24 \pm 2$ \\
NO production & $3.0 \pm 1.4$ & $3.9 \pm 1.2$ & $3.5 \pm 1.1$ & $2.0 \pm 0.5$ & $1.3 \pm 0.2$ & $2.2 \pm 0.4$ \\
de novo Arg & $12 \pm 2$ & $13 \pm 1$ & $5 \pm 1$ & $14 \pm 1$ & $5 \pm 1$ & $7 \pm 1$ \\
\hline
\end{tabular}

Values are means \pm SEM in $\mathrm{nmol} / 10 \mathrm{~g} / \mathrm{min}$ (except arterial [Arg] in $\mu \mathrm{mol} / \mathrm{l}$ ). 


\section{tracer methods}

In the following studies, kinetic in vivo measurements are conducted in mice. To be able to measure true substrate fluxes and collect information on actual production and consumption rates, isotopes are used.

Substrate fluxes on whole-body level are assessed in a one-compartment model using infusion of an isotope of the substrate of interest. This model assumes that the rate of appearance (Ra) of substrate (tracee) and the infusion of labelled substrate (tracer) occur in a single homogenous pool. Thus, the ratio between the infused tracer and naturally occurring tracee (TTR) in the pool is a measure for the rate of appearance of substrate, which is calculated as follows ${ }^{38}$ :

$\mathrm{Ra}=\mathrm{I} / \mathrm{TTR}$,

where $\mathrm{I}$ is the rate of infusion of tracer and TTR is the tracer-tracee ratio of the infused labelled substrate and the naturally occurring substrate.

Both stable and radioactive tracers exist. The most obvious advantage of stable isotopes is that they are not radioactive and thus are not harmful. Another advantage is that there are stable isotopes of all elements, whereas availability of radioactive isotopes is limited. Moreover, when using stable isotopes, various tracers with similar labels can be used simultaneously. A disadvantage is that measurements of TTR require mass spectrometry methods that have high analytical sensitivity.

In essence, rate of appearance of any essential amino acid that is exported out of the cell without further modification, can be used as a measure for protein breakdown rate on whole-body level, for example glycine, lysine, valine or phenylalanine. Using a phenylalanine tracer has the advantage that apart from measuring protein breakdown, protein synthesis can be calculated by measuring both conversion of phenylalanine to tyrosine and rate of appearance of phenylalanine. In this thesis, L[ring- ${ }^{2} \mathrm{H}_{5}$ ] phenylalanine that is subsequently hydroxylated to $\mathrm{L}$-[ring- ${ }^{2} \mathrm{H}_{4}$ ] tyrosine is used. Because the TTR of $\mathrm{L}-\left[\mathrm{ring}_{-}{ }^{2} \mathrm{H}_{4}\right]$ tyrosine is diluted with tyrosine produced from sources other than phenylalanine, correction for the total amount of tyrosine that is produced is calculated using L-[ring- $\left.{ }^{2} \mathrm{H}_{2}\right]$ tyrosine. Protein synthesis on whole-body level is then calculated as follows:

$$
P S=Q_{\text {Phe }}-Q_{\text {Phe-Tyr }}=Q_{\text {phe }}-\operatorname{TTR}_{\text {Tyr (2H2) }} \times \operatorname{TTR}_{\text {Tyr (2H4) }} / \operatorname{TTR}_{\text {phe }(2 \mathrm{H} 5)^{\prime}} \text {. }
$$

where $Q_{\text {phe }}$ is the plasma phenylalanine flux estimated from infusion of L-[ring${ }^{2} \mathrm{H}_{5}$ ] phenylalanine.

A method commonly used to determine myofibrillar protein breakdown is based on the presence of the methylated histidine $N^{\hat{o}}$-methylhistidine in actin and myosin heavy chain protein ${ }^{39}$. These proteins can be found mainly in muscle and to a lesser degree in other tissues such as intestine and skin. When actin-myosin proteins are broken down, 3-methylhistdidine is released. Because 3-methylhistidine has no specific tRNA, it cannot be re-used for protein synthesis, and is therefore excreted in urine. Therefore, the amount of 3-methylhistidine found in urine can be used to determine the amount of actin-myosin proteins broken down in the body ${ }^{40}$. However, the urine excretion method is invalid in mice, which led us to develop a method determining the whole-body production rate of 3-methylhistidine (chapter four). 
Nitric oxide (NO) is a highly reactant molecule that is rapidly converted to nitrite and nitrate in vivo. Other products of $\mathrm{NO}$ are peroxynitrite and nitrosothiols. Nitrate concentrations in blood or urine are often used as a measure of NO production ${ }^{41,42}$, even though these methods have several disadvantages. Firstly, they cannot discern between nitrate coming from $\mathrm{NO}$ or nitrate derived from other sources such as food intake and production by bacteria in the gastrointestinal tract ${ }^{43}$. Secondly, since plasma nitrate levels depend on the rate of elimination by the kidney, diminished renal function is a confounding factor in disease states ${ }^{44}$. Thirdly, measurements of nitrate concentrations cannot monitor acute changes because nitrate has a half-life of circa eight hours. We found discrepancies between the degree of plasma nitrate/ nitrite increases and actual NO production in animal models ${ }^{45}$. For example, in septic pigs, NO production increased while plasma nitrate/nitrite did not change ${ }^{46}$.

To overcome these disadvantages, a stable isotope technique can be used using labelled arginine and citrulline. This method was first applied in humans ${ }^{47}$ and allows in vivo measurements of true production rates of NO. The technique is based on the fact that stochiometric amounts of citrulline are formed when $\mathrm{NO}$ is produced from arginine. In this way, by measuring citrulline production from arginine, NO production rate is quantitated.

In the studies presented in this thesis, conversion of L-[guanidino- ${ }^{15} \mathrm{~N}_{2}, 5,5-{ }^{2} \mathrm{H}_{2}$ ] arginine to $\mathrm{L}$-[guanidino- ${ }^{15} \mathrm{~N}, 5,5-{ }^{2} \mathrm{H}_{2}$ ] citrulline is used. Because the TTR of $\mathrm{L}$-[guanidino- ${ }^{15} \mathrm{~N}, 5,5-$ ${ }^{2} \mathrm{H}_{2}$ ] citrulline is diluted with citrulline produced from other sources, it is necessary to correct for total citrulline production. In order to do so, we use a L-[guanidino${ }^{15} \mathrm{~N}$ ] citrulline tracer in addition. NO production on whole-body level is then calculated as follows:

$\mathrm{NO}$ production $=Q_{\text {Arg-Cit }}=Q_{\text {Cit }} \times \operatorname{TTR}_{\mathrm{Cit}(15 \mathrm{~N}-2 \mathrm{H} 2)} / \operatorname{TTR}_{\mathrm{Arg}(15 \mathrm{~N} 2-2 \mathrm{H} 2)^{\prime}}$ where $Q_{\text {Cit }}$ is the plasma citrulline flux estimated from infusion of L-[guanidino${ }^{15 N}$ ] citrulline.

Substrate fluxes across organs can be assessed in a two-compartment model using infusion of an isotope of the substrate of interest. In contrast to a single-pool model, this model assumes that the administration of the tracer and the production of the tracee occur in two different compartments, the first being the plasma pool and the latter being the interstitial fluid. In addition, it assumes that the substrate that is released into the interstitial compartment subsequently exchanges with the plasma pool. Measurement of blood flow across the organ of interest is crucial to enable flux measurements across organs. The technique of flow measurements that is used throughout this thesis is based on Fick's dilution principle: the concentration of indicator (in our case ${ }^{14} \mathrm{C}$-para-amino hippuric acid, ${ }^{14} \mathrm{C}-\mathrm{PAH}$ ) downstream from where it is entered depends on the flow rate. In steady state conditions, the amount of indicator entering the stream is equal to the amount of indicator that is excreted. Therefore, when the indicator is infused with a known constant rate at a site lying before the organ of interest, flow rate can be calculated as follows:

flow $==1 /\left(\left[{ }^{14} \mathrm{C}-\mathrm{PAH}\right]_{\mathrm{V}}-\left[{ }^{14} \mathrm{C}-\mathrm{PAH}\right]_{\mathrm{A}}\right)$, 
where I is the rate of infusion of ${ }^{14} \mathrm{C}$-para-amino hippuric acid, $\left[{ }^{14} \mathrm{C}-\mathrm{PAH}\right]_{v}$ is the venous concentration of ${ }^{14} \mathrm{C}$-para-amino hippuric acid and $\left[{ }^{14} \mathrm{C}-\mathrm{PAH}\right]_{\mathrm{A}}$ is the arterial concentration of ${ }^{14} \mathrm{C}$-para-amino hippuric acid.

Net uptake or release of substrate is calculated as arterial-venous difference across the organ involved. By simultaneous measurements of blood flow across the organ of interest, substrate net balances (NB) across organs can be calculated as follows:

$N B=$ flow $x\left(\left[\right.\right.$ tracee $_{V}-\left[\right.$ tracee $\left._{A}\right)$,

where [tracee $]_{V}$ is the concentration of substrate in a vein coming from the organ of interest and [tracee] ${ }_{A}$ is the arterial concentration of substrate. A positive flux represents net release and a negative flux net uptake.

However, these organ balances do not give information on the dynamic processes of disposal and production. The latter requires the use of stable isotopes. For example, when net release of substrate is $8 \mathrm{~mol} / \mathrm{h}$, this can be accomplished by disposal of 20 $\mathrm{mol} / \mathrm{h}$ and production of $28 \mathrm{~mol} / \mathrm{h}$, but also by disposal of $250 \mathrm{~mol} / \mathrm{h}$ and production of $258 \mathrm{~mol} / \mathrm{h}$. Thus, using tracers, additional information on substrate turnover rates is provided and organ fluxes (nb) can be calculated using the venous and arterial tracer concentration as follows:

$\mathrm{nb}=$ flow $\times\left(\right.$ [tracer $_{\mathrm{A}}-\left[\right.$ tracer $\left._{\mathrm{V}}\right)$,

where $\left[\right.$ tracer] ${ }_{A}{ }_{i}$ is the arterial concentration of tracer and [tracer] ${ }_{V}$ is the concentration of tracer in a vein coming from the organ of interest; TTR ${ }_{A}$ is the arterial tracer-tracee ratio of substrate and TTR $R_{v}$ is the tracer-tracee ratio of substrate in a vein coming from the organ of interest.

Next, disposal (D) can be calculated as follows:

$\mathrm{D}=\mathrm{nb} / \mathrm{TTR} \mathrm{V}_{\mathrm{V}}$

assuming that the venous tracer-tracee ratio best approaches the tracer-tracee ratio of the intracellular precursor pool of substrate.

Because NB of substrate across an organ is the net difference between actual disposal and production rate, substrate production $(\mathrm{P})$ can be calculated as follows:

$P=D-N B$.

Measurements of organ fluxes are only possible when both arterial and venous sampling sites are accessible. Our group developed methods to measure metabolic fluxes across hindquarter and kidney simultaneously, or portal drained viscera and liver simultaneously in anesthetized mice ${ }^{48}$. In the current thesis, these two models were combined to study hindquarter, kidney, portal drained viscera and liver in one mouse (figure four). 
figurefour | mouse model for metabolic studies across organs

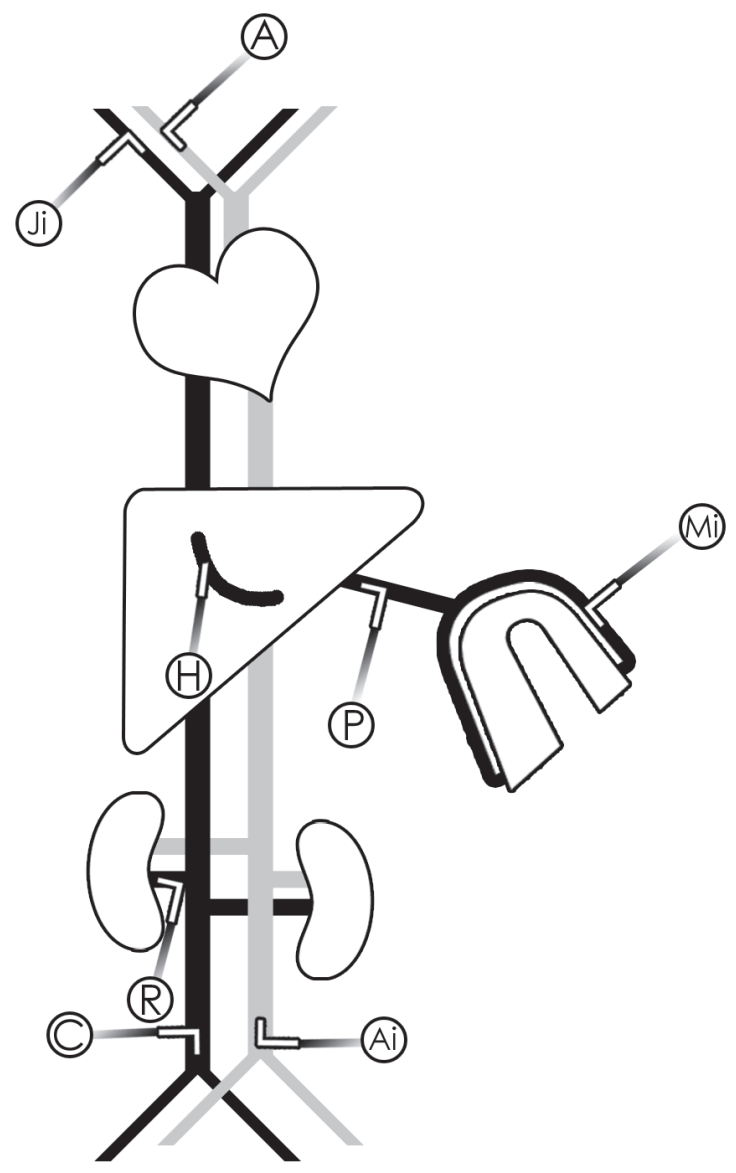

For AV-fluxes across organs, catheters were inserted in the right carotid artery (A) for arterial blood sampling, in the portal vein (P) for blood sampling from portal-drained viscera, in a hepatic vein $(\mathrm{H})$ for blood sampling from the liver, in the right renal vein (R) for blood sampling from the kidney and in the inferior caval vein for blood sampling from the hindquarter. Infusion of saline and tracers was into the right jugular vein (Ji). Infusion of ${ }^{14} \mathrm{C}$-para-amino hippuric acid was into the inferior abdominal aorta (Ai) and a mesenteric vein (Mi). 
We used ketamine-medetomidine anaesthesia, because it allows abdominal surgery without the need for ventilation. Moreover, it has fewer metabolic side effects than barbiturates ${ }^{49}$. To keep animals in a stable condition during surgery, several precautions were taken. Firstly, body temperature was kept at $37^{\circ} \mathrm{C}$ using heat pads and rectal temperature control. Secondly, to counteract the fluid loss due to evaporation and lack of physical activity, saline was continuously infused intravenously via the right jugular vein.

For stable isotope infusion, a second catheter was placed in the right jugular vein. Two other infusion catheters were placed: one in a colonic vein and one in the abdominal aorta. The latter two were used to infuse radioactive para aminohippuric acid for blood flow measurements ${ }^{4}$.

Fluxes across hindquarter were used to study skeletal muscle. Although this method cannot separate muscle from other tissues in the hindquarter, such as skin and bone, we assume that the contribution of muscle far exceeds that of other tissues. A catheter for venous blood sampling was placed in the inferior caval vein. To study the intestines, fluxes across the viscera drained by the portal vein are used, including stomach, spleen and gut. However, since the gut is the most metabolically active, blood from a catheter in the portal vein mainly represents the gut. For measurements across the liver, catheters were placed in a hepatic vein and the portal vein, since the latter is mainly responsible for supply of nutrients to the liver. For renal fluxes, a catheter was placed in the renal vein of the right kidney. For arterial sampling, blood was taken from the carotid artery.

\section{references |}

1. de Blaauw I, Deutz NEP, van der Hulst RRWJ, von Meyenfeldt MF. Glutamine depletion and increased gut permeability in nonanorectic, non- weight-losing tumor-bearing rats. Gastroenterology 1997;112(1):118-26.

2. Kurzer M, Janiszewski J, Meguid MM. Amino acid profiles in tumor-bearing and pairfed nontumor-bearing malnourished rats. Cancer 1988;62(8):1492-6.

3. Chen MK, Espat NJ, Bland KI, Copeland EM, 3rd, Souba WW. Influence of progressive tumor growth on glutamine metabolism in skeletal muscle and kidney. Ann Surg 1993;217(6):655-66; discussion 666-7.

4. Lundholm K, Edstrom S, Karlberg I, Ekman L, Schersten T. Relationship of food intake, body composition, and tumor growth to host metabolism in nongrowing mice with sarcoma. Cancer Res 1980;40(7):2516-22.

5. Fraker DL, Sheppard BC, Norton JA. Impact of tolerance on antitumor efficacy of tumor necrosis factor in mice. Cancer Res 1990;50(8):2261-7.

6. Haase P, Cowen DM, Knowles JC, Cooper EH. Evaluation of dimethylhydrazine induced tumours in mice as a model system for colorectal cancer. $\mathrm{Br} J$ Cancer 1973;28(6):530-43.

7. Bibby MC, Double JA, Ali SA, Fearon KC, Brennan RA, Tisdale MJ. Characterization of a transplantable adenocarcinoma of the mouse colon producing cachexia in recipient animals. J Natl Cancer Inst 1987;78(3):539-46.

8. Tisdale MJ, Brennan RA. Metabolic substrate utilization by a tumour cell line which induces cachexia in vivo. Br J Cancer 1986;54(4):601-6. 
9. Todorov PT, McDevitt TM, Cariuk P, Coles B, Deacon M, Tisdale MJ. Induction of muscle protein degradation and weight loss by a tumor product. Cancer Res 1996:56(6):1256-61.

10. Todorov P, Cariuk P, McDevitt T, Coles B, Fearon K, Tisdale M. Characterization of a cancer cachectic factor. Nature 996;379(6567):739-42.

11. Mahony SM, Beck SA, Tisdale MJ. Comparison of weight loss induced by recombinant tumour necrosis factor with that produced by a cachexia-inducing tumour. Br J Cancer 1988;57(4):385-9.

12. Llovera M, Garcia-Martinez C, Agell N, Lopez-Soriano FJ, Argiles JM. Muscle wasting associated with cancer cachexia is linked to an important activation of the ATPdependent ubiquitin-mediated proteolysis. Int J Cancer 1995;61 (1):138-41.

13. Ternell M, Lonnroth $C$, Lundholm K. Nuclear RNA polymerase activity in tumor-host livers. Am J Physiol 1985;249(5 Pt 1):E461-9.

14. Tisdale MJ, Brennan RA, Fearon KC. Reduction of weight loss and tumour size in a cachexia model by a high fat diet. Br J Cancer 1987;56(1):39-43.

15. McDevitt TM, Tisdale MJ. Tumour-associated hypoglycaemia in a murine cachexia model. Br J Cancer 1992;66(5):815-20.

16. Mulligan HD, Tisdale MJ. Lipogenesis in tumour and host tissues in mice bearing colonic adenocarcinomas. Br J Cancer 1991;63(5):719-22.

17. Beck SA, Tisdale MJ. Lipid mobilising factors specifically associated with cancer cachexia. Br J Cancer 1991;63(6):846-50.

18. Lundholm K, Karlberg I, Ekman L, Edstrom S, Schersten T. Evaluation of anorexia as the cause of altered protein synthesis in skeletal muscles from nongrowing mice with sarcoma. Cancer Res 1981;41 (5):1989-96.

19. Lindmark L, Edstrom S, Ekman L, Karlberg I, Lundholm K. Energy metabolism in nongrowing mice with sarcoma. Cancer Res 1983;43(8):3649-54.

20. Tisdale MJ, Dhesi JK. Inhibition of weight loss by omega-3 fatty acids in an experimental cachexia model. Cancer Res 1990;50(16):5022-6.

21. Beck SA, Tisdale MJ. Nitrogen excretion in cancer cachexia and its modification by a high fat diet in mice. Cancer Res 1989;49(14):3800-4.

22. Smith KL, Tisdale MJ. Increased protein degradation and decreased protein synthesis in skeletal muscle during cancer cachexia. Br J Cancer 1993;67(4):680-5.

23. Edstrom S, Reinholdtsen L, Lundholm K. Glucose turnover in adult non-growing tumour-bearing mice. Int J Biochem 1985;17(5):649-52.

24. Mulligan HD, Tisdale MJ. Metabolic substrate utilization by tumour and host tissues in cancer cachexia. Biochem J 1991;277(P+ 2):321-6.

25. Mahony SM, Tisdale MJ. Metabolic effects of tumour necrosis factor alpha in NMRI mice. Br J Cancer 1990;61 (4):514-9.

26. Briddon S, Beck SA, Tisdale MJ. Changes in activity of lipoprotein lipase, plasma free fatty acids and triglycerides with weight loss in a cachexia model. Cancer Lett $1991 ; 57(1): 49-53$.

27. Lundholm K, Edstrom S, Ekman L, Karlberg I, Bylund AC, Schersten T. A comparative study of the influence of malignant tumor on host metabolism in mice and man: evaluation of an experimental model. Cancer 1978;42(2):453-61. 
28. Beck SA, Smith KL, Tisdale MJ. Anticachectic and antitumor effect of eicosapentaenoic acid and its effect on protein turnover. Cancer Res 1991;51 (22):6089-93.

29. Tisdale MJ, Brennan RA. A comparison of long-chain triglycerides and mediumchain triglycerides on weight loss and tumour size in a cachexia model. $\mathrm{Br} J$ Cancer 1988;58(5):580-3.

30. Whitehouse AS, Smith HJ, Drake JL, Tisdale MJ. Mechanism of attenuation of skeletal muscle protein catabolism in cancer cachexia by eicosapentaenoic acid. Cancer Res 2001;61 (9):3604-9.

31. Lundholm K, Ekman L, Edstrom S, Karlberg I, Jagenburg R, Schersten T. Protein synthesis in liver tissue under the influence of a methylcholanthrene-induced sarcoma in mice. Cancer Res 1979:39(11):4657-61.

32. Edstrom S, Lindmark L, Ekman L, et al. Evaluation of oxidative metabolism in tumourhost livers as a possible cause of energy loss in cachectic sarcoma-bearing mice. Eur J Cancer Clin Oncol 1983;19(5):671-80.

33. Lonnroth C, Moldawer LL, Gelin J, Kindblom L, Sherry B, Lundholm K. Tumor necrosis factor-alpha and interleukin-1 alpha production in cachectic, tumor-bearing mice. Int J Cancer 1990:46(5):889-96.

34. Mori K, Fujimoto-Ouchi K, Ishikawa T, Sekiguchi F, Ishitsuka H, Tanaka Y. Murine interleukin-12 prevents the development of cancer cachexia in a murine model. Int J Cancer 1996;67(6):849-55.

35. Mulligan HD, Mahony SM, Ross JA, Tisdale MJ. Weight loss in a murine cachexia model is not associated with the cytokines tumour necrosis factor-alpha or interleukin6. Cancer Lett 1992;65(3):239-43.

36. Hallemeesch MM, Soeters PB, Deutz NEP. Renal arginine and protein synthesis are increased during early endotoxemia in mice. Am J Physiol Renal Physiol 2002;282(2):F316-23.

37. Luiking YC, Hallemeesch MM, Vissers YLJ, Lamers WH, Deutz NEP. In vivo whole body and organ arginine metabolism during endotoxemia (sepsis) is dependent on mouse strain and gender. J Nutr 2004;134(10):2768S-74S.

38. Wolfe RR. Radioactive and stable isotope tracers in biomedicine. Principles and practice of kinetic analysis. 1992; Wiley-Liss, Inc.(New York).

39. Young VR, Alexis SD, Baliga BS, Munro HN, Muecke W. Metabolism of administered 3-methylhistidine. Lack of muscle transfer ribonucleic acid charging and quantitative excretion as 3-methylhistidine and its $\mathrm{N}$-acetyl derivative. J Biol Chem 1972;247(11):3592-600.

40. Young VR, Munro HN. Ntau-methylhistidine (3-methylhistidine) and muscle protein turnover: an overview. Fed Proc 1978;37(9):2291-300.

41. Oudenhoven IMJ, Klaasen HLBM, Lapre JA, Weerkamp AH, van der Meer R. Nitric oxide-derived urinary nitrate as a marker of intestinal bacterial translocation in rats. Gastroenterology 1994;107:47-53.

42. Guarner C, Soriano G, Tomas A, et al. Increased serum nitrite and nitrate levels in patients with cirrhosis: relationship to endotoxemia. Hepatology 1993;18:1 139-1 143.

43. Rhodes PM, Leone AM, Francis PL, Struthers AD, Moncada S. The L-arginine:nitric oxide pathway is the major source of plasma nitrite in fasted humans. Biochem.Biophys Res Comm 1995;209(2):590-596. 
44. Kirkeboen KA, Strand OA. The role of nitric oxide in sepsis - an overview. Acta Anaesthesiologica 1999;43:275-288.

45. Hallemeesch MM, Soeters PB, Deutz NEP. Renal arginine and protein synthesis are increased during early endotoxemia in mice. Am J Physiol Renal Physiol 2002;282(2):F316-23.

46. Bruins MJ, Lamers WH, Soeters PB, Deutz NEP. In vivo measurements of organ nitric oxide production during hyperdynamic endotoxemia in pigs determined from stable isotope conversion. Br J Pharmacol 2002;137(8):1225-36.

47. Castillo L, Beaumier L, Ajami AM, Young VR. Whole body nitric oxide synthesis in healthy men determined from [15N] arginine-to-[15N]citrulline labeling. Proc Natl Acad SciU S A 1996:93(21):11460-5.

48. Hallemeesch MM, ten Have GAM, Deutz NEP. Metabolic flux measurements across portal drained viscera, liver, kidney and hindquarter in mice. Lab Animals 2001;35:101110.

49. Hall LW, Clarke KW. Veterinary anaesthesia. London: Baillière Tindall, 1991. 


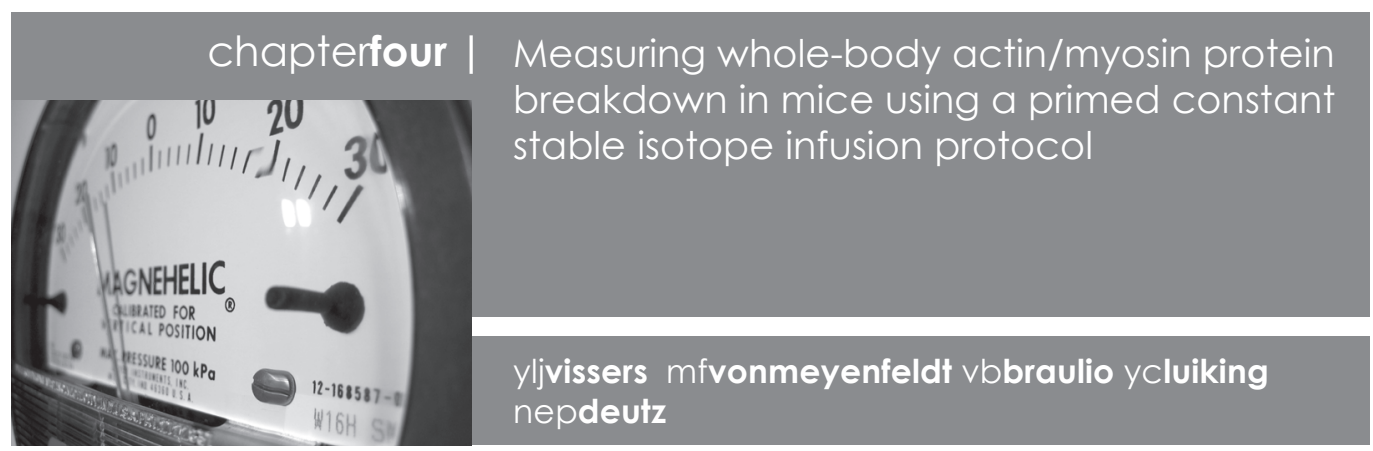

\section{introduction |}

A method commonly used to determine myofibrillar protein breakdown is based on the presence of the methylated histidine $\mathrm{N}^{\text {tau}}$-methylhistidine in actin and myosin heavy chain protein '. These proteins can be found mainly in muscle and to a lesser degree in other tissues like intestine and skin. When actin-myosin proteins are broken down, 3-methylhistidine is released. Because 3-methylhistidine has no specific tRNA, it cannot be re-used for protein synthesis, and its only fate is excretion in urine. Therefore, the amount of 3-methylhistidine found in urine can be used to determine the amount of actin-myosin proteins broken down in the body ${ }^{2}$. This method requires quantitative collection of urine, which is usually done for $24 \mathrm{~h}$, and is based on the assumption that all released 3-methylhistidine ends up directly in urine, without being metabolised or pooled before excretion ${ }^{3}$.

The development of transgenic and knockout mice has created possibilities to obtain new information on metabolic processes. The ability to measure wholebody myofibrillar protein breakdown in these genetically modified mice would produce new insights on protein metabolism. However, the urine excretion method is invalid in mice because, like in pigs ${ }^{4}$, sheep ${ }^{5}$ and rats ${ }^{1}$, a large part of 3methylhistidine is not directly excreted into urine ${ }^{5}$. As a result, excretion in urine underestimates the true production rate of 3-methylhistidine. 3-methylhistidine is retained and temporarily stored in a sink of 3-methylhistidine, possibly in muscle, rather than excreted into urine ${ }^{6.7}$. Moreover, 3-methylhistidine is extensively metabolised via various pathways: a part enters a histamine pathway to end up as $N^{\text {tau}}$-methylimidazolacetic acid ${ }^{6}$, a part is acetylated to $N^{\text {tau}}$-acetylmethylhistidine ${ }^{6,7}$, and another part is metabolised via unknown pathways ${ }^{6}$. Both Murray ${ }^{6}$ and Harris ${ }^{7}$ studied urinary recovery of radioactively labelled 3methylhistidine in mice. They found that in male mice, only $70 \%$ of the radioactive label was excreted into urine after $24 \mathrm{~h}$. From this $70 \%$, only $70 \%$ was actually excreted as 3-methylhistidine without being metabolized. Thus, merely $50 \%$ of the released 3-methylhistidine is recovered in the urine of male mice. In female mice, $90 \%$ of the radioactive label was excreted after $24 \mathrm{~h}$. From this $90 \%$, only $30 \%$ was excreted as 3-methylhistidine without being metabolized. Thus, merely $30 \%$ of the released 3-methylhistidine is recovered in the urine of female mice. In conclusion, 3- 
methylhistidine excretion in urine is underestimated both in male and female mice and as a consequence cannot be used to determine myofibrillar protein breakdown.

We wanted to develop a method determining the whole-body production rate of 3methylhistidine that avoids the problems posed by metabolism and delayed excretion of 3-methylhistidine in the urine of mice. This method will not give an answer to the origin of 3-methylhistidine in the body, but a primed constant tracer infusion protocol 8 would enable whole-body measurements of 3-methylhistidine production in mice. Besides, such a method has several additional advantages. It enables measuring acute changes in actin-myosin protein breakdown, in contrast to the $24 \mathrm{~h}$ urine excretion method. Furthermore, by simultaneous infusion of other stable isotope tracers, it is possible to measure different aspects of protein and amino acid metabolism from a single blood sample.

To test a primed constant infusion protocol with the stable isotope L-3-[methyl${ }^{2} \mathrm{H}_{3}$ ] methylhistidine in mice, we conducted a study using starvation and administration of endotoxin as models for total protein breakdown and muscle protein breakdown respectively. We hypothesized that the contribution of myofibrillar protein breakdown to total protein breakdown would increase when starvation was accompanied by endotoxin administration compared to starvation alone. Apart from L-3-[methyl${ }^{2} \mathrm{H}_{3}$ ] methylhistidine, we infused $\mathrm{L}$-[ring- ${ }^{2} \mathrm{H}_{5}$ ] phenylalanine and $\mathrm{L}$-[ring- $\left.{ }^{2} \mathrm{H}_{2}\right]$ tyrosine to be able to compare myofibrillar protein breakdown to total protein breakdown, net protein breakdown ${ }^{9}$ and protein synthesis ${ }^{10}$. Since there is at present no other method to measure actin-myosin protein breakdown in mice, it is not possible to validate this method by comparing it to a known method. It is neither possible to extend the data achieved with our stable isotope study to a $24 \mathrm{~h}$ period and correct them for the expected underestimation with the data of Murray ${ }^{6}$ and Harris ${ }^{7}$, since our measurements will yield information on the production of 3-methylhistidine at the specific moment of blood sampling. As myofibrillar protein breakdown is expected to fluctuate during a $24 \mathrm{~h}$ time course, one measurement at a certain time point cannot be converted to the 3-methylhistidine production rate of the whole period. To study an extended time course, it is necessary to obtain multiple blood samples in time, which is a problem because of the limited blood volume of mice.

\section{methods}

animals |

Male Swiss mice (20-30 g) were obtained from the breeding facilities at the Centralized Animals Facility at the Maastricht University. The mice were fed standard lab chow (Hope Pharms, Woerden, NL) and were subject to standard 12 hour light-dark cycle periods (7:30 a.m. to 7:30 p.m.). Room temperature was maintained at $25^{\circ} \mathrm{C}$. Water was provided ad libitum throughout the experiment. Experiments were performed in accordance with the recommendations of the Guide for the Care and Use of Laboratory animals ", and approved by the Ethical Committee of Animal Research of the Maastricht University. 
experimental protocol |

All experiments started between 06:00 and 08:00 a.m. At $t=-2 h$, animals were weighed and food was withheld but drinking water was provided ad libitum. Intake of nutrients is therefore equal in all groups. At $t=0$, mice received lipopolysaccharide (LPS, $250 \mu \mathrm{g}$ in $0.5 \mathrm{ml}$ of saline; Escherichia coli O55:B5, Sigma, St. Louis, MO, USA) via intraperitoneal injection ${ }^{12}$. Control animals received a corresponding volume of saline.

The tracer infusion protocol was conducted in three experimental groups: (1) mice receiving saline (CON, $n=9)$, (2) mice receiving saline and starved for $9 \mathrm{~h}$ (STA, $n=10$ ) and (3) mice receiving LPS and starved for $9 \mathrm{~h}$ (STA+LPS, $\mathrm{n}=10$ ).

tracer infusion protocol |

At $t=0$ (control group) or $t=9 \mathrm{~h}$ (STA group and STA+LPS group), the animals were weighed again to determine weight loss compared to $t=-2 \mathrm{~h}$ and anaesthesia was induced by an intraperitoneal injection of a mixture of ketamine $162.5 \mathrm{mg} / \mathrm{kg} \mathrm{bw}$, Nimatek, AUV, Cuyk, NL) and medetomidine $(400 \mu \mathrm{g} / \mathrm{kg}$ bw, Domitor, Farmos, Espoo, FI) ${ }^{12}$. Anaesthesia was maintained with a continuous subcutaneous infusion of a mixture of ketamine (17.5 $\left.\mathrm{mg} \cdot \mathrm{kg} \mathrm{bw}^{-1} \cdot \mathrm{h}^{-1}\right)$ and medetomidine $\left(112 \mu \mathrm{gg} \mathrm{kw}^{-1} \cdot \mathrm{h}^{-1}\right)^{12}$. During the surgical procedures, the mice were kept at $37^{\circ} \mathrm{C}$ using a temperature controller (Technical Service, Maastricht University, NL) and heat pads. The jugular vein and carotid artery were catheterised using a 30-gauge needle fixed in a silastic tube (Silastic Medical Grade tubing 0.40 mm ID, 0.84 mm OD, Dow Corning Corporation, Medical Products, Midland, MO, USA), and fixed with cyano-acrylate (Cyanolit 201, Het Rubberhuis, Maastricht, NL) ${ }^{12}$.

A primed-constant infusion of the stable isotopes L-3-methyl [(tau)- ${ }^{2} \mathrm{H}_{3^{\prime}} 99$ AP ${ }^{2} \mathrm{H}_{1}$ ] histidine, L-phenylalanine [phenyl- ${ }^{2} \mathrm{H}_{5}, 99 \mathrm{AP}^{2} \mathrm{H}_{1}$ ] and L-tyrosine [phenyl-3,5- ${ }^{2} \mathrm{H}_{2}, 98$ $A P^{2} \mathrm{H}_{1}$ ] (Mass Trace, Woburn, MA, USA) was given in the jugular vein (see table one for concentrations and infusion rates). In a pilot experiment, the time to reach tracer steady state in mice was determined $(n=6)$. Steady state was present from 20 to 60 minutes (figure one, $\mathrm{p}>0.05$ with ANOVA for repeated measures). In the current experiment we therefore sampled blood at 30 minutes after the start of the primed continuous infusion of stable isotopes.

tableone | tracer prime and infusion rates

\begin{tabular}{lccc}
\hline tracer & abbreviation & $\begin{array}{c}\text { prime } \\
\text { (nmol/mouse) }\end{array}$ & $\begin{array}{c}\text { continuous infusion } \\
\text { (nmol/hour) }\end{array}$ \\
\hline L-3-[methyl-2 $\mathrm{H}_{3}$ ]histidine & {$\left[{ }^{2} \mathrm{H}_{3}\right] 3 \mathrm{mHH}$} & 29 & 7 \\
L-[phenyl-2 ${ }_{5}$ ] & {$\left[{ }^{2} \mathrm{H}_{5}\right] \mathrm{Phe}$} & 292 & 1500 \\
L-[phenylalanine & {$\left[{ }^{2} \mathrm{H}_{2}\right] \mathrm{Tyr}$} & 292 & 1350 \\
\hline
\end{tabular}




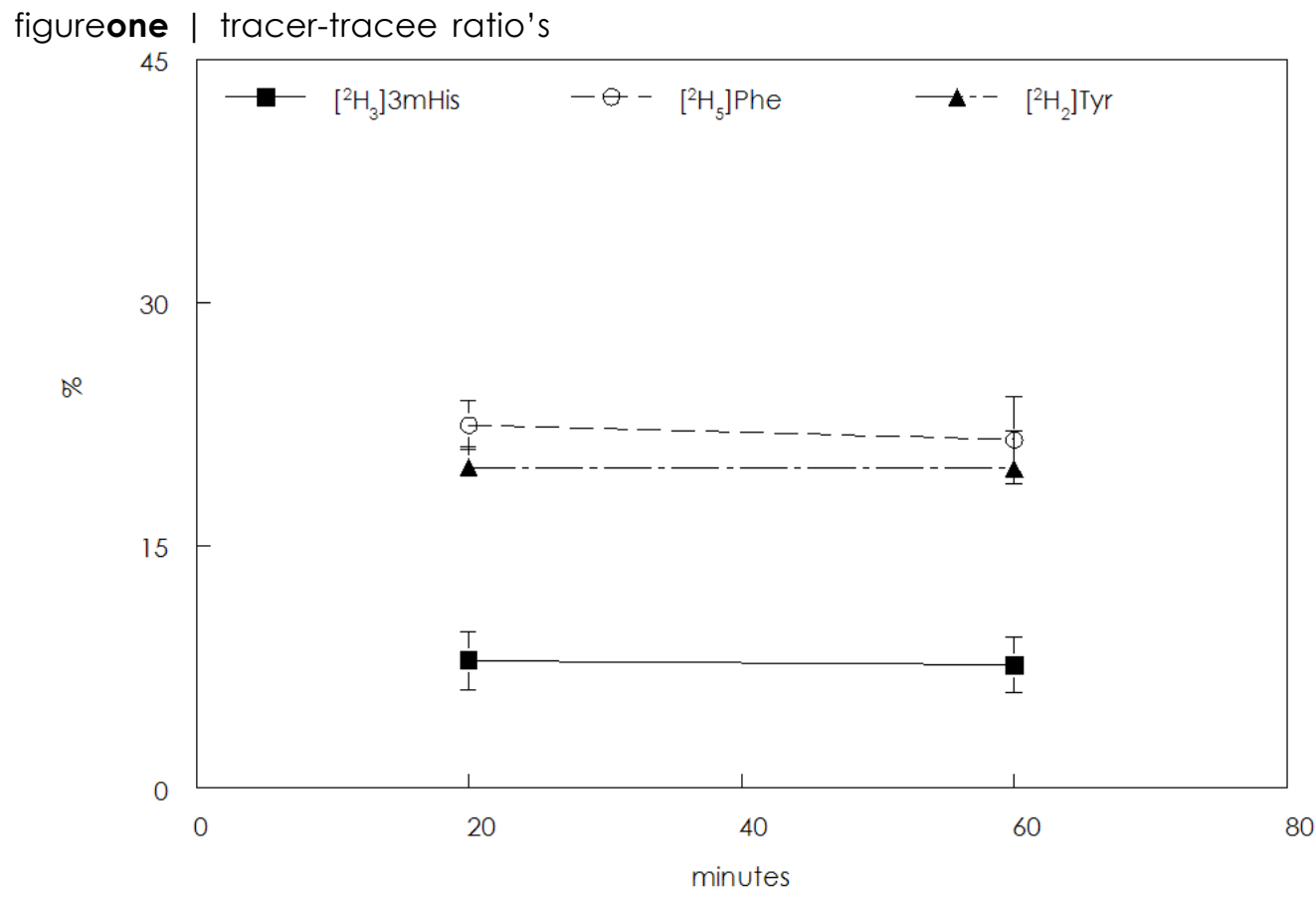

Values are means \pm SEM. Results from a pilot experiment. Steady state for $\left[{ }^{2} \mathrm{H}_{3}\right] 3 \mathrm{mH}$ is, $\left[{ }^{2} \mathrm{H}_{5}\right]$ Phe and $\left[{ }^{2} \mathrm{H}_{2}\right] \mathrm{Tyr}$ was present from 20 to 60 minutes. Statistics with ANOVA for repeated measures, $\mathrm{p}>0.05$ for all tracers.

blood sampling and processing |

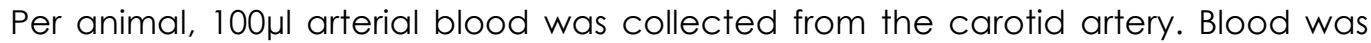
collected in heparinized cups (Sarstedt, Nümbrecht, DE) on ice, and centrifuged (4 $\min , 4^{\circ} \mathrm{C}, 8500 \mathrm{~g}$ ) to obtain plasma.

For determination of amino acid concentrations and tracer-tracee ratios (TTR), $65 \mu \mathrm{l}$ plasma was added to $4 \mathrm{mg}$ solid 5'-sulfosalicylic acid, vortexed, frozen in liquid nitrogen and stored at $-80^{\circ} \mathrm{C}$.

analysis in samples |

Plasma amino acid concentrations and enrichments, calculated as TTR, were measured using a fully automated LC-MS system, using pre-column derivatization with o-phthaldialdehyde ${ }^{13,14}$. Detailed information on the accuracy and precision of this method was given before ${ }^{14}$. Non-enriched blood samples from mice were used to subtract background enrichment from the experiment samples.

calculations |

TTR is an equivalent of specific activity. Therefore, formulae were derived from metabolic studies using radioactive tracers. Correction for the contribution of lower isotopomers in $\left[{ }^{2} \mathrm{H}_{4}\right]$ Tyr was performed as described by Wolfe ${ }^{8}$. Plasma 
3-methylhistidine, phenylalanine and tyrosine whole-body rate of appearance (Wb Ra) were calculated from the arterial isotope TTR values of respectively $\left[{ }^{2} \mathrm{H}_{3}\right] 3 \mathrm{mHis}$, $\left[{ }^{2} \mathrm{H}_{5}\right]$ Phe and $\left[{ }^{2} \mathrm{H}_{2}\right] \mathrm{Ty}$, using steady state isotope dilution equation ${ }^{8}$ :

$\mathrm{Wb} \mathrm{Ra}=\mathrm{I} / \mathrm{TTR}$,

Where TTR is the arterial tracer-tracee ratio, and $I$ is the rate of infusion of the tracer. Whole-body myofibrillar protein breakdown (Wb MPB) is measured as Wb Ra of 3methylhistidine. Whole-body total protein breakdown (Wb TPB) is measured as Wb Ra of phenylalanine.

Whole-body net protein breakdown (Wb NPB) is measured by calculation of the plasma phenylalanine to tyrosine flux (phenylalanine hydroxylation) as follows 9 :

$\mathrm{Wb}_{\text {Phe } \rightarrow \mathrm{Tyr}}=\mathrm{Q}_{\mathrm{Tyr}} \times \operatorname{TTR}_{\mathrm{Tyr}(\mathrm{M}+4)} / \mathrm{TTR}_{\mathrm{Phe}(\mathrm{M}+5)^{\prime}}$

where $Q_{\text {Tyr }}$ is the plasma tyrosine flux (nmol/10 $\mathrm{g} / \mathrm{min}$ ), estimated from the primed constant infusions of the $\left[{ }^{2} \mathrm{H}_{2}\right] T y r$ tracer and $\operatorname{TTR}_{\mathrm{Tyr}(\mathrm{M}+4)}$ and $\operatorname{TTR}_{\mathrm{Phe}(\mathrm{M}+5)}$ are the respective (arterial) TTRs of $\left[{ }^{2} \mathrm{H}_{4}\right]$ Tyr and $\left[{ }^{2} \mathrm{H}_{5}\right]$ Phe.

Contribution of myofibrillar protein breakdown to total protein breakdown is determined as percentage of myofibrillar to total protein breakdown and is calculated as follows:

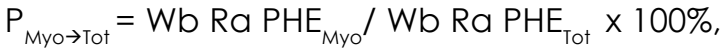

where $\mathrm{Wb}$ Ra $\mathrm{PHE}_{\text {Myo }}$ is whole-body rate of appearance of phenylalanine coming from myofibrillar protein breakdown and $\mathrm{Wb} R a \mathrm{PHE}_{\text {Tot }}$ is whole-body rate of appearance of phenylalanine coming from total protein breakdown.

Whole-body rate of appearance of phenylalanine coming from myofibrillar protein breakdown is calculated considering the following: For every mol actin broken down 1 mol 3-methylhistidine and $28 \mathrm{~mol}$ phenylalanine are produced, and for every mol myosin heavy chain broken down 1 mol 3-methylhistidine and $56 \mathrm{~mol}$ phenylalanine are produced (SWISS-PROT/TrEMBL, protein knowledgebase. Swiss Institute of Bioformatics and The European Bioinformatics Institute. http://www.expasy.ch/sprot). Given the fact that the molar ratio of actin and myosin heavy chain in muscle is 5:2 ${ }^{15}$, for every mol myofibrillar protein broken down $1 \mathrm{~mol} 3$-methylhistidine and an average of $36 \mathrm{~mol}$ phenylalanine are released. Whole-body rate of appearance of phenylalanine coming from myofibrillar protein breakdown is thus calculated as follows:

$\mathrm{Wb}$ Ra PHE $\mathrm{Pyo}_{\text {Mo }}=\mathrm{Wb}$ Ra $3 \mathrm{mH}$ is $\times 36$.

Whole-body protein synthesis is calculated by subtracting phenylalanine hydroxylation from the whole-body rate of appearace of phenylalanine ${ }^{10}$.

statistics |

Results are presented as means \pm SEM per $10 \mathrm{~g}$ body weight. Differences between treatment groups were tested using one-way ANOVA with LSD as post-hoc test ${ }^{16}$. Significance was defined as $\mathrm{p}<0.05$. 


\section{results |}

Starvation decreased body weight (figure two) with $1.4 \pm 0.3 \mathrm{~g}$ versus $0.7 \pm 0.1 \mathrm{~g}$ in controls ( $p<0.05)$, whereas starvation+LPS did not result in a further decrease.

Arterial plasma concentrations (table two) of phenylalanine and tyrosine remained unchanged after starvation+LPS. Starvation alone increased arterial plasma concentration of 3-methylhistidine, with an additional increase after LPS.

figuretwo | weight loss

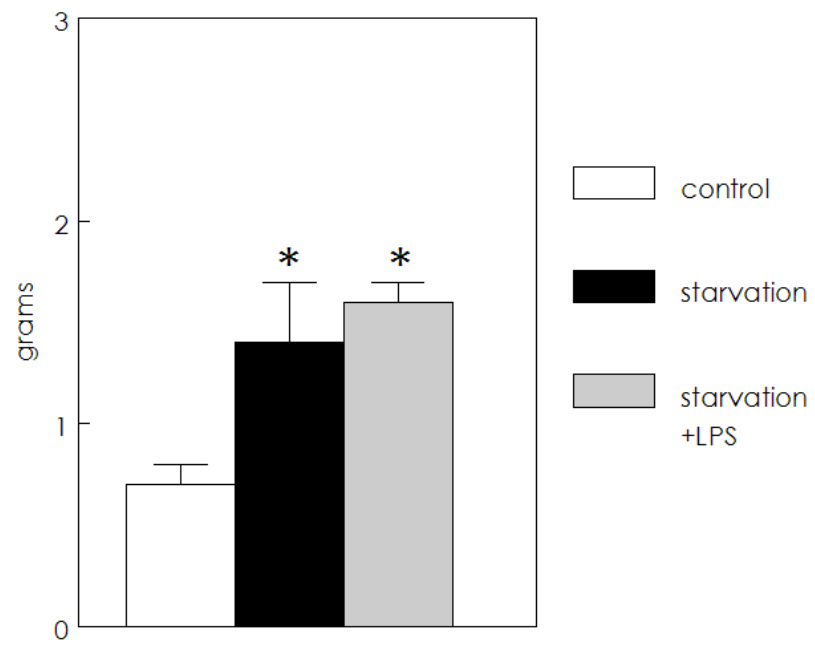

Values are means \pm SEM in grams. Mice were weighed at $t=0$ and $t=2 h$ (control) or $t=1 \mathrm{lh}$ (starvation and starvation+LPS) after food deprivation. Statistics with ANOVA, ${ }^{*} \mathrm{p}<0.05$ vs. control.

tabletwo | arterial amino acid concentrations

\begin{tabular}{lrlrllrl}
\hline & phenylalanine & \multicolumn{2}{c}{ tyrosine } & 3-methylhistidine \\
\hline control & 101 & \pm 17 & 96 & \pm 10 & 5.4 & \pm 0.4 \\
starvation & 97 & \pm 7 & 111 & \pm 18 & 7.1 & $\pm 0.5^{*}$ \\
starvation+LPS & 101 & \pm 9 & 101 & \pm 16 & $10.9 \pm 1.0^{\dagger}$ \\
\hline
\end{tabular}

Values are means \pm SEM in $\mu \mathrm{mol} / \mathrm{l}$. Statistics with ANOVA, ${ }^{*} p<0.05$ vs. control and ${ }^{\dagger} p<0.01$ vs. control and starvation.

Whole-body myofibrillar protein breakdown (table three), measured from whole-body rate of appearance of 3-methylhistidine, was unchanged after starvation $(p=0.11)$. A trend $(p=0.06)$ towards an increase in whole-body myofibrillar protein breakdown from $0.48 \pm 0.07 \mathrm{nmol} / 10 \mathrm{~g} / \mathrm{min}$ in starvation to $0.82 \pm 0.14 \mathrm{nmol} / 10 \mathrm{~g} / \mathrm{min}$ in starvation+LPS was observed. 
Whole-body total protein breakdown (table three), measured from whole-body rate of appearance of phenylalanine, was not significantly different between the groups.

Contribution of myofibrillar to total protein breakdown (figure three) was significantly lower after starvation than in controls ( $54 \pm 14 \%$ versus $30 \pm 4 \%, p<0.05)$, and was significantly higher after starvation+LPS than after starvation alone $(52 \pm 7 \%$ versus 30 $\pm 4 \%, \mathrm{p}<0.05)$.

Whole-body protein synthesis and net protein breakdown were not significantly different between the groups (table three).

tablethree | whole-body protein turnover

\begin{tabular}{lcccccccccc}
\hline & \multicolumn{2}{c}{ Wb MPB } & \multicolumn{2}{c}{ Wb TPB } & \multicolumn{2}{c}{ Wb NPB } & \multicolumn{2}{c}{ Wb PS } \\
\hline control & 0.73 & \pm 0.2 & 54 & \pm 2 & 6.4 & \pm 0.6 & 53 & \pm 2 \\
starvation & 0.48 & \pm 0.1 & 58 & \pm 3 & 7.4 & \pm & 0.5 & 55 & \pm 2 \\
starvation+LPS & 0.82 & \pm 0.1 & 56 & \pm 5 & 6.5 & \pm 0.6 & 49 & \pm 3 \\
\hline
\end{tabular}

Values are means \pm SEM in $\mathrm{nmol} / 10 \mathrm{~g} / \mathrm{min}$. Wb MPB= whole-body myopfibrillar protein breakdown, Wb TPB = whole-body total protein breakdown, Wb NPB= whole-body net protein breakdown, Wb PS= whole-body protein synthesis. Statistics with ANOVA, no significant differences.

\section{discussion |}

aim |

This study was undertaken to test a primed constant tracer infusion protocol with a deuterated stable isotope of Nô-methylhistidine to measure actin-myosin protein breakdown in mice. We were able to assess whole-body production rates of 3methylhistidine in mice, which, up to now, was impossible because of the invalid interpretation of 3-methylhistidine urinary excretion in mice. Urinary excretion of 3methylhistidine is known to underestimate myofibrillar protein breakdown for roughly $50 \%$ in male and $70 \%$ in female mice respectively and as a consequence cannot be used to determine myofibrillar protein breakdown. This problem was overcome using a stable isotope protocol. Even if 3-methylhistidine would be metabolized in the tissue where it is produced, the measured 3-methylhistidine production with a tracer technique will produce a true value, assuming the tracer enrichment of the plasma pool to be representative for the enrichment of the tissue pool. Also, such a protocol enables measurements of acute changes, without the need of a bolus protocol with multiple blood samples ${ }^{17}$. Because of the limited blood volume in mice, this is an important advantage of the presented method. 
figurethree | percentage myofibrillar protein breakdown

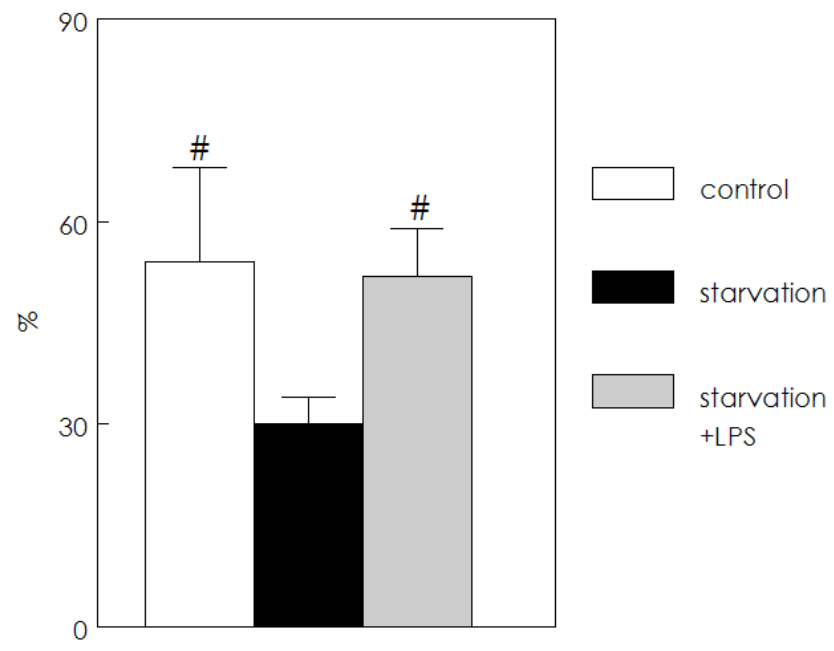

Values are means \pm SEM in percentages. Percentage myofibrillar protein breakdown of total protein breakdown was calculated as $\mathrm{P}_{\text {Myo } \rightarrow \text { Tot }}=\mathrm{Wb} \mathrm{RaPHE}_{\text {MYO }} / \mathrm{Wb} \mathrm{RaPHE}_{\text {Tot }} \mathrm{x}$ $100 \%$, where $\mathrm{Wb} \mathrm{RaPHE}_{\text {Myo }}$ is whole-body rate of appearance of phenylalanine coming from myofibrillar protein breakdown and $\mathrm{Wb}$ Ra $\mathrm{PHE}_{\text {Tot }}$ is whole-body rate of appearance of phenylalanine coming from total protein breakdown. Statistics with ANOVA, $" \mathrm{p}<0.05$ vs. starvation.

arterial concentrations |

There was no correlation between arterial plasma concentrations of 3-methylhistidine and whole-body myofibrillar protein breakdown measured with L-3-[methyl${ }^{2} \mathrm{H}_{3}$ ] histidine. This illustrates that arterial plasma concentrations of 3-methylhistidine are not representative for whole-body actin-myosin protein breakdown.

design |

When comparing the priming dose and infusion rate of the different stable isotope tracers used, it is remarkable that the infusion rate of $\mathrm{L}-3-\left[\right.$ methyl- ${ }^{2} \mathrm{H}_{3}$ ] histidine is relatively small compared to the amount of prime that is used. We calculated the infusion rate from pilot experiments by fitting curves of rates of appearance of 3-methylhistidine obtained with this tracer in mice. The priming dose was calculated from a measured concentration of $8 \mu \mathrm{M}$ 3-methylhistidine in plasma of mice in the pilot. Assuming that the tracer is distributed across the water pool, which has a volume of $70 \%$ of body weight, the priming dose was estimated to be $29 \mathrm{nmol} / \mathrm{mouse}$. Because steady state was reached after 20 min (figure one), apparently no other large pools of 3methylhistidine exist in mice that contribute to 3-methylhistidine turnover. This is in contrast to primed constant stable isotope infusion experiments with L-3-[methyl${ }^{2} \mathrm{H}_{3}$ ] methylhistidine in lambs ${ }^{17}$, were no steady state could be reached after $12 \mathrm{~h}$. 
myofibrillar versus total protein breakdown |

Compared with controls, there were no significant effects of starvation on total protein breakdown, myofibrillar protein breakdown, protein synthesis and net protein breakdown. However, the contribution of myofibrillar to total protein breakdown was decreased. Evidently, myofibrillar proteins are initially spared during starvation. This fits with the observation that loss of muscle protein is initially prevented and only more prominent after longer food deprivation, whereas the liver and other viscera lose considerable protein during the first phase of starvation 18,19 . It is probably related to different phases of protein breakdown after various levels of metabolic stress.

We hypothesized that the contribution of myofibrillar protein breakdown to total protein breakdown would increase when starvation was accompanied by endotoxin administration compared to starvation alone. Indeed, with adding LPS as an extra stressor to starvation, the contribution of myofibrillar to total protein breakdown increased. Besides, the data on myofibrillar and total protein breakdown illustrate that measuring both provides different information on protein breakdown and is thus valuable. Starvation studies in rats have also reported different results on myofibrillar and total protein breakdown ${ }^{20,21}$. Distinctive regulation pathways for myofibrillar and non- myofibrillar proteins might contribute to the different responses. In starvation for example, protein breakdown in non-muscle tissues has been contributed to a lysosomal activity process ${ }^{22-24}$, whereas the ATP-ubiquitin dependent proteolytic pathway has been held responsible for protein breakdown in skeletal muscle ${ }^{24-26}$ and myofibrillar proteins ${ }^{27}$. In endotoxemia, a similar pattern might be present, since the ATP-ubiquitin dependent proteolytic pathway was responsible for protein breakdown of skeletal muscle in sepsis as well ${ }^{28-31}$.

These in vivo data show no changes in whole-body total protein breakdown after LPS or starvation. We showed this before in LPS-treated mice ${ }^{32}$. Others have measured in vitro or ex vivo after starvation in rats and reported an increase 27,33,34, a decrease 20,34 or no changes ${ }^{21,35}$ in total protein breakdown in muscle perfusions or incubations. Results appeared to be influenced by the age of the animals and the duration of starvation ${ }^{27,34}$. More in vivo studies will be necessary to confirm information obtained from these in vitro and ex vivo results.

whole-body versus organ level |

The present in vivo data give information on 3-methylhistidine production on wholebody level. In this experiment, we have not assessed 3-methylhistidine production rates of different organs, since this requires measurements across organs. Using the current primed-constant stable isotope infusion protocol in combination with measurements across organs can identify different sources of 3-methylhistidine in the body. Such data could answer the question to what extent different organs contribute to total 3methylhistidine production. Next to skeletal muscle, intestine, skin, lungs and the vascular system contain actin-myosin proteins as well. Besides the amount of myofibrillar proteins, the turnover rate determines the amount of 3-methylhistidine that is produced. 
Since especially intestine is thought to have a high turnover rate, it might contribute significantly to whole-body 3 -methylhistidine production ${ }^{36-41}$.

clinical application |

The current stable isotope protocol to measure 3-methylhistidine production rates can easily be transferred to a human model. This would create the possibility to assess acute changes in myofibrillar protein breakdown in humans, in contrast to $24 \mathrm{~h}$ urine collection, which measures changes over time. It would also enable simultaneous infusion of other stable isotope tracer to assess different aspects of protein and amino acid metabolism at the same time. The presented protocol will also exclude the necessity of quantitative urine collection. The latter is an important advantage, especially in the non-clinical setting, where continuous sampling of urine can be a problem. Neither is it necessary to adjust the subjects' diet before and during the study period in order to prevent contamination of urine with 1-methylhistidine, which is present in meat.

\section{conclusion |}

In conclusion, we showed that myofibrillar protein breakdown in mice is measurable with this tracer method. Up to now, this was not possible because urinary excretion of 3-methylhistidine in mice is not representative for myofibrillar protein breakdown. Therefore, studies with this primed constant stable isotope infusion protocol of L-3-[methyl-2 $\mathrm{H}_{3}$ ] histidine can provide valuable information on protein metabolism in mice. The proposed protocol can easily be applied in human studies and will thereby provide measurements of acute changes in myofibrillar protein breakdown and exclude the need of collecting quantitative urine samples in order to determine 3methylhistidine excretion in urine.

\section{references |}

1. Young VR, Alexis SD, Baliga BS, Munro HN, Muecke W. Metabolism of administered 3-methylhistidine. Lack of muscle transfer ribonucleic acid charging and quantitative excretion as 3- methylhistidine and its $\mathrm{N}$-acetyl derivative. J Biol Chem 1972;247(1 1):3592-600.

2. Young VR, Munro HN. Ntau-methylhistidine (3-methylhistidine) and muscle protein turnover: an overview. Fed Proc 1978;37(9):2291-300.

3. Nissen S. Measurement of muscle proteolysis and the impact on muscle wasting. Proc Nutr Soc 1997:56(2):793-9.

4. Milne $\mathrm{G}$, Harris $\mathrm{Cl}$. The inadequacy of urinary 3-methylhistidine excretion as an index of muscle protein degradations in the pig. Proc Nutr Soc 1978;37(1):18A.

5. Ballard FJ, Tomas FM. 3-Methylhistidine as a measure of skeletal muscle protein breakdown in human subjects: the case for its continued use. Clin Sci 1983;65(3):20915.

6. Murray AJ, Nield MK, Jones LM, Galbraith N, Tomas FM. Metabolism of N taumethylhistidine by mice. Biochem J 1985;232(2):409-13. 
7. Harris Cl, Rucklidge GJ, McDiarmid RM, Milne G. Sex- and phenotype-dependent metabolism of $\mathrm{N}$ tau-methylhistidine by mice. Biochem J 1986;239(1):229-32.

8. Wolfe RR. Radioactive and stable isotope tracers in biomedicine. Principles and practice of kinetic analysis. 1992; Wiley-Liss, Inc.(New York).

9. Moldawer LL, Kawamura I, Bistrian BR, Blackburn GL. The contribution of phenylalanine to tyrosine metabolism in vivo. Studies in the post-absorptive and phenylalanine-loaded rat. Biochem J 1983;210(3):811-7.

10. Thompson GN, Pacy PJ, Merritt H, et al. Rapid measurement of whole body and forearm protein turnover using a [2H5]phenylalanine model. Am J Physiol 1989;256(5 Pt 1):E631-9.

11. Waldegrave W. Guide for the care and use of laboratory animals. EEC 1986:publication 86/609.

12. Hallemeesch MM, ten Have GAM, Deutz NEP. Metabolic flux measurements across portal drained viscera, liver, kidney and hindquarter in mice. Lab Animals 2001;35:101110.

13. van Eijk HMH, Rooyakkers DR, Deutz NEP. Rapid routine determination of amino acids in plasma by high-performance liquid chromatography with a 2-3 $\mu$ M Spherisorb ODS II column. J Chromatogr 1993;620:143-148.

14. van Eijk HM, Rooyakkers DR, Soeters PB, Deutz NEP. Determination of amino acid isotope enrichment using liquid chromatography-mass spectrometry. Anal Biochem $1999 ; 271(1): 8-17$.

15. Bates PC, Grimble GK, Sparrow MP, Millward DJ. Myofibrillar protein turnover. Synthesis of protein-bound 3- methylhistidine, actin, myosin heavy chain and aldolase in rat skeletal muscle in the fed and starved states. Biochem J 1983;214(2):593-605.

16. SPSS I. SPSS for Windows Version 11.0.1. 1 ed. Chicago: SPSS Inc. 2001.

17. Rathmacher JA, Nissen SL. Development and application of a compartmental model of 3- methylhistidine metabolism in humans and domestic animals. Adv Exp Med Biol 1998;445:303-24.

18. Goodman MN, Ruderman NB. Starvation in the rat. I. Effect of age and obesity on organ weights, RNA, DNA, and protein. Am J Physiol 1980;239(4):E269-E276.

19. Mosoni L, Malmezat T, Valluy MC, Houlier ML, Attaix D, Mirand PP. Lower recovery of muscle protein lost during starvation in old rats despite a stimulation of protein synthesis. Am J Physiol 1999;277(4 Pt 1):E608-16.

20. Lowell BB, Ruderman NB, Goodman MN. Regulation of myofibrillar protein degradation in rat skeletal muscle during brief and prolonged starvation. Metabolism 1986;35(12):1121-7.

21. Kadowaki M, Harada N, Takahashi S, Noguchi T, Naito H. Differential regulation of the degradation of myofibrillar and total proteins in skeletal muscle of rats: effects of streptozotocin-induced diabetes, dietary protein and starvation. J Nutr 1989; 119(3):471-7.

22. Dice JF. Molecular determinants of protein half-lives in eukaryotic cells. Faseb J $1987 ; 1(5): 349-57$.

23. Mortimore GE, Poso AR, Lardeux BR. Mechanism and regulation of protein degradation in liver. Diabetes Metab Rev 1989;5(1):49-70. 
24. Medina R, Wing SS, Goldberg AL. Increase in levels of polyubiquitin and proteasome mRNA in skeletal muscle during starvation and denervation atrophy. Biochem J 1995;307(Pt 3):631-7.

25. Medina R, Wing SS, Haas A, Goldberg AL. Activation of the ubiquitin-ATPdependent proteolytic system in skeletal muscle during fasting and denervation atrophy. Biomed Biochim Acta 1991;50(4-6):347-56.

26. Wing SS, Haas AL, Goldberg AL. Increase in ubiquitin-protein conjugates concomitant with the increase in proteolysis in rat skeletal muscle during starvation and atrophy denervation. Biochem J 1995;307(Pt 3):639-45.

27. Lowell BB, Ruderman NB, Goodman MN. Evidence that lysosomes are not involved in the degradation of myofibrillar proteins in rat skeletal muscle. Biochem J 1986;234(1):237-40.

28. Tiao G, Hobler S, Wang JJ, et al. Sepsis is associated with increased mRNAs of the ubiquitin-proteasome proteolytic pathway in human skeletal muscle. J Clin Invest 1997;99(2):163-8.

29. Tiao G, Fagan JM, Samuels $N$, et al. Sepsis stimulates nonlysosomal, energydependent proteolysis and increases ubiquitin mRNA levels in rat skeletal muscle. J Clin Invest 1994;94(6):2255-64.

30. Solomon V, Baracos V, Sarraf P, Goldberg AL. Rates of ubiquitin conjugation increase when muscles atrophy, largely through activation of the $\mathrm{N}$-end rule pathway. Proc Natl Acad Sci U S A 1998;95(21):12602-7.

31. Hobler SC, Williams A, Fischer D, et al. Activity and expression of the 205 proteasome are increased in skeletal muscle during sepsis. Am J Physiol 1999;277(2 P† 2):R434-40.

32. Hallemeesch MM. Role of arginine in endotoxemia. Studies in mice with reduced arginine availability. Thesis, Maastricht University, The Netherlands 2001.

33. Tracey KJ, Legaspi A, Albert JD, et al. Protein and substrate metabolism during starvation and parenteral refeeding. Clin Sci 1988;74(2):123-32.

34. Goodman MN, McElaney MA, Ruderman NB. Adaptation to prolonged starvation in the rat: curtailment of skeletal muscle proteolysis. Am J Physiol 1981;241 (4):E321-7.

35. Sjolin J, Stjernstrom H, Arturson G, Andersson E, Friman G, Larsson J. Exchange of 3methylhistidine in the splanchnic region in human infection. Am J Clin Nutr 1989:50(6):1407-14.

36. Rennie MJ, Millward DJ. 3-Methylhistidine excretion and the urinary 3methylhistidine/creatinine ratio are poor indicators of skeletal muscle protein breakdown. Clin Sci 1983;65(3):217-25.

37. Afting EG, Bernhardt W, Janzen RW, Rothig HJ. Quantitative importance of nonskeletal-muscle $\mathrm{N}$ tau-methylhistidine and creatine in human urine. Biochem $\mathrm{J}$ 1981;200(2):449-52.

38. Lundholm K, Bennegard K, Eden E, Svaninger G, Emery PW, Rennie MJ. Efflux of 3methylhistidine from the leg in cancer patients who experience weight loss. Cancer Res 1982;42(11):4807-11.

39. Brenner $U$, Herbertz $L$, Thul $P$, et al. The contribution of small gut to the 3methylhistidine metabolism in the adult rat. Metabolism 1987;36(5):416-8.

40. Wassner SJ, Li JB. N tau-methylhistidine release: contributions of rat skeletal muscle, Gl tract, and skin. Am J Physiol 1982;243(4):E293-7. 
41. Millward DJ, Bates PC. 3-Methylhistidine turnover in the whole body, and the contribution of skeletal muscle and intestine to urinary 3-methylhistidine excretion in the adult rat. Biochem J 1983;214(2):607-15. 



\section{non-cachecticmodel}

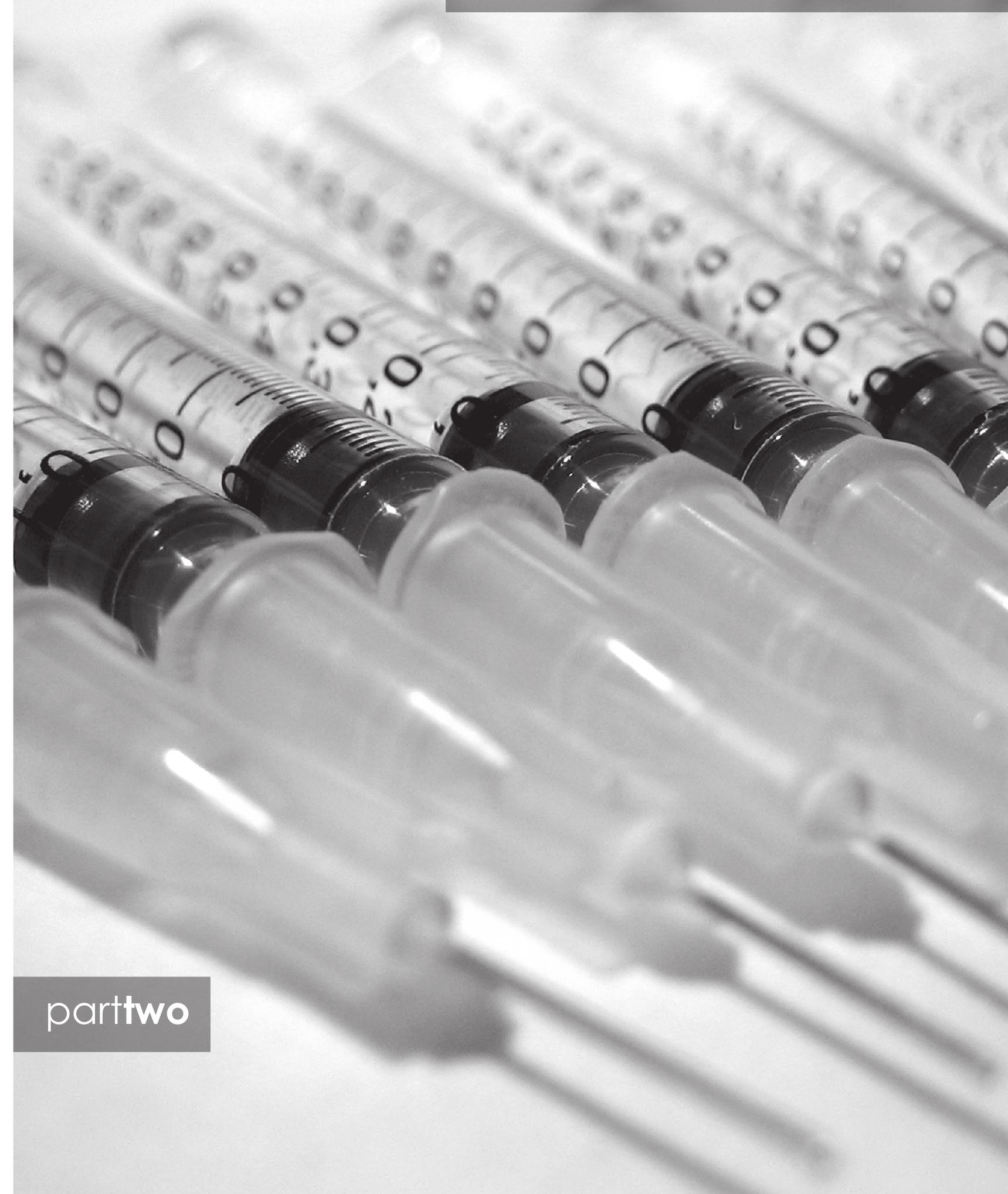




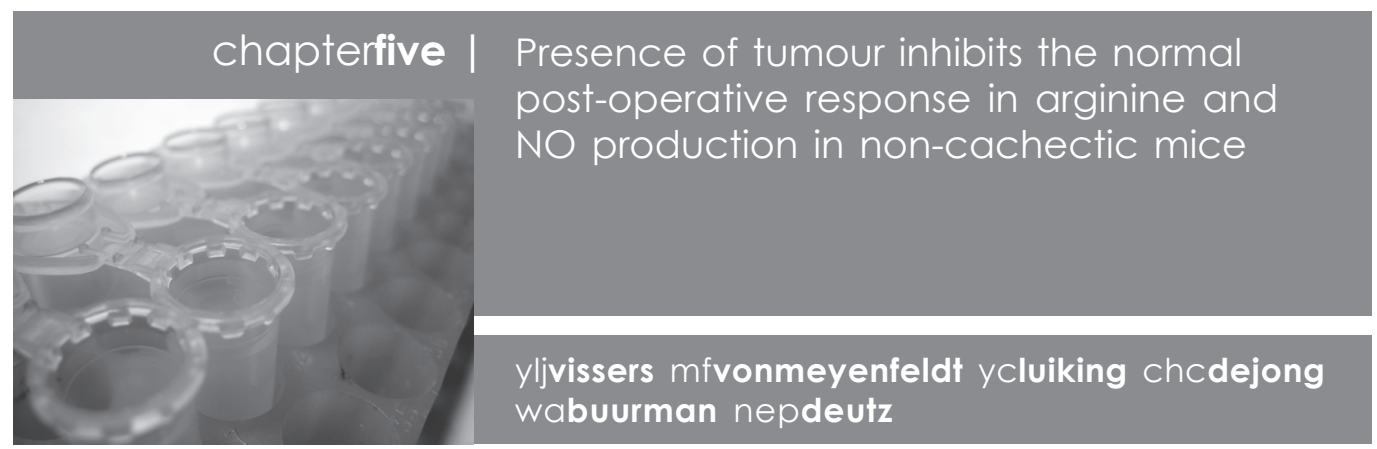

\section{introduction |}

We recently described that patients with malignant tumours inducing various degrees of metabolic derangements have decreased plasma arginine concentrations, even without weight loss being present ', suggesting that decreased arginine availability may be a specific feature of host metabolism in the presence of cancer. Moreover, up to one third of cancer patients die from cachexia rather than from cancer itself ${ }^{2}$, even after surgical removal of the tumour 3 , indicating that cancer-related alterations in the metabolism of the host are a very important factor in determining mortality. In addition, cancer patients undergoing surgical treatment have more postoperative complications ${ }^{4}$ and higher mortality ${ }^{5}$ than patients undergoing surgery for non-malignant disease. Apparently, the host's response to surgery in cancer patients is different from the response of healthy subjects undergoing surgery. Since arginine plays a central role in the host response to surgical trauma, both via nitric oxide (NO) (produced from arginine in the nitric oxide synthase pathway) and ornithine (produced from arginine in the arginase pathway), arginine deficiency could compromise postoperative recovery of cancer patients.

In the last two decades, many studies investigating the perioperative metabolic changes in cachectic cancer patients have been conducted. Still, the mechanism of cancer-related postoperative disturbances remains to be unravelled, which may be due to the complexity of the metabolic abnormalities that are present in the advanced stage where symptoms such as weight loss or anorexia have already become obvious. Therefore, we chose to investigate early derangements in the postoperative host response in a non-cachectic tumour mouse model.

The primary aim of the study was to investigate whether the postoperative response in arginine and NO production was different in the presence of a malignant tumour. The secondary aim was to investigate whether tumour-bearing mice undergoing surgery had an impaired postoperative acute phase response. Thus, we studied basal and postoperative response in arginine/NO production in MCA sarcomabearing mice and healthy controls. To monitor the magnitude of the immune response after surgery, the acute phase response was measured as plasma concentration of the acute phase reactant serum amyloid $P$ component (SAP) ${ }^{6}$, the mouse homologue of C-reactive protein (CRP) in humans. 


\section{methods |}

animals |

Male FVB mice were bred at the Central Animal Facilities of Maastricht University. Mice were fed standard lab chow (Hope Pharms, Woerden, NL) and subjected to a standard 12 hour light-dark cycle. Room temperature was maintained at $22^{\circ} \mathrm{C}$. Water was provided ad libitum throughout the experiment. Male mice of 20-23 grams were randomized into six groups: 1) control; 2) control undergoing laparotomy; 3) small tumour of $5-15 \%$ of carcass weight; 4) small tumour undergoing laparotomy; 5) large tumour of more than 15\% of carcass weight; 6) large tumour undergoing laparotomy. Based on a power calculation using wholebody arginine production as primary outcome parameter, we calculated the group size to be $n=8$. To compensate for mortality during the course of the experiment (related to bleeding during catheter placement and cardiac arrest due to anaesthesia), 12 animals were initially included per group. Food intake was measured daily by weighing the amount of chow in the cage and comparing it with the chow weight of the day before. Experiments were approved by the Ethical Committee of Animal Research of Maastricht University.

\section{tumour model |}

MCA tumours were initially induced by subcutaneous injection of $1 \mathrm{mg}$ methylcholantrene (Sigma-Aldrich Chemie, Zwijndrecht, NL) in mice in our laboratory. These tumours were maintained in vivo by serially transplanting tumour tissue through a $15 \mathrm{G}$ needle. The MCA tumour has been widely used as a model for cancer in metabolic studies in mice and rats and has the histological characteristics of malignant sarcoma, with locally aggressive growth ${ }^{7,8}$. In our hands, the tumour does not induce anorexia or weight loss. Control mice were sham implanted.

\section{surgical trauma |}

When the tumour reached $5-15 \%$ of carcass weight (small tumour groups) or more than 15\% (large tumour groups) ${ }^{9}$, a midline laparotomy was performed as a model for surgical trauma. In short, ketamine/medetomidine anaesthesia, fluid and temperature control were performed as described previously ${ }^{10}$. Under aseptic conditions, a midline incision from the level of the superior iliac spines until the xyphoid process was made. Intestines were put aside and wrapped in wet gauze. Five minutes later, intestines were put back and the abdomen was closed with wound clips (Autoclip, Clay Adams, Becton Dickinson and Company, Parsippany, NJ, USA). After surgical trauma, food was taken away from all mice to prevent differences in food intake between groups. Water was provided ad libitum.

\section{metabolic measurements |}

Twenty-four hours after laparotomy, ketamine/medetomidine anaesthesia and fluid and temperature maintenance were performed as described by Hallemeesch et al. ${ }^{10}$. A primed-constant infusion of the stable isotopes L-arginine [guanidino${ }^{15} \mathrm{~N}_{2}-{ }^{2} \mathrm{H}_{2}, 99 \%$ atom percent excess] ([ ${ }^{15} \mathrm{~N}_{2}{ }^{2} \mathrm{H}_{2}$ ]Arg) and L-citrulline [ureido- ${ }^{15} \mathrm{~N}, 99 \%$ atom percent excess] ([ $\left.\left.{ }^{15} \mathrm{~N}\right] \mathrm{Cit}\right)$ (Mass Trace, Woburn, MA, USA) was given in the 
jugular vein (prime: $146 \mathrm{nmol} / 10 \mathrm{~g}\left[{ }^{15} \mathrm{~N}_{2}{ }_{2} \mathrm{H}_{2}\right] \mathrm{Arg}$ and $44 \mathrm{nmol} / 10 \mathrm{~g}\left[{ }^{15} \mathrm{~N}\right]$ Cit; infusion: $960 \mathrm{nmol} / 10 \mathrm{~g} / \mathrm{h}\left[{ }^{15} \mathrm{~N}_{2}{ }^{2} \mathrm{H}_{2}\right] \mathrm{Arg}$ and $\left.90 \mathrm{nmol} / 10 \mathrm{~g} / \mathrm{h}\left[{ }^{15} \mathrm{~N}\right] \mathrm{Cit}\right)$. This stable isotope protocol yields tracer-tracee steady state in plasma within 30 minutes. Blood was collected from the carotid artery and processed as described before ${ }^{10}$. Amino acid concentrations and tracer/tracee ratios (TTR) were determined in plasma using HPLC and LC-MS as described by Van Eijk ${ }^{11,12}$.

serum amyloid $P$ component $\mid$

Serum amyloid $\mathrm{P}$ component (SAP) concentrations in plasma were measured using a sandwich ELISA as described before ${ }^{13}$.

\section{calculations |}

Plasma arginine and citrulline production rates were calculated from the arterial isotope TTR values of respectively $\left[{ }^{15} \mathrm{~N}_{2}{ }^{2} \mathrm{H}_{2}\right] \mathrm{Arg}$ and $\left[{ }^{15} \mathrm{~N}\right] \mathrm{Cit}$ as described recently ${ }^{14}$. Whole-body NO production was calculated as plasma arginine to citrulline flux ${ }^{14}$, based on the fact that conversion of arginine to NO yields stochiometric amounts of citrulline. Data are expressed per $10 \mathrm{~g}$ carcass weight, which was calculated by subtracting tumour weight from body weight including tumour.

statistics |

Results are presented as means \pm SEM. Data were analyzed with SPSS ${ }^{15}$. To reduce the chance of false-positive significances, we only tested the effect of i) laparotomy in control mice, ii) the presence of tumour per se, iii) laparotomy in mice bearing small tumours, iv) laparotomy in mice bearing large tumours. Since data were not normally distributed, non-parametric Mann-Whitney $U$ test was used. Significance was defined as $p<0.05$.

\section{results |}

drop out I

As a consequence of drop out due to intra-operative mortality, the final group sizes were: 1) control $(n=12)$; 2) control undergoing laparotomy $(n=12)$; 3) small tumour of $5-15 \%$ of carcass weight $(n=9) ; 4)$ small tumour undergoing laparotomy $(n=9)$; 5) large tumour of more than $15 \%$ of carcass weight $(n=7) ; 6)$ large tumour undergoing laparotomy $(n=7)$.

normal postoperative response |

In healthy mice, arginine and NO production increased postoperatively by respectively 29 and $27 \%$ (figure one), concomitant with a 30 -fold increase in SAP concentrations (table one). Laparotomy did not affect total amino acid concentrations, including arginine (table one). 


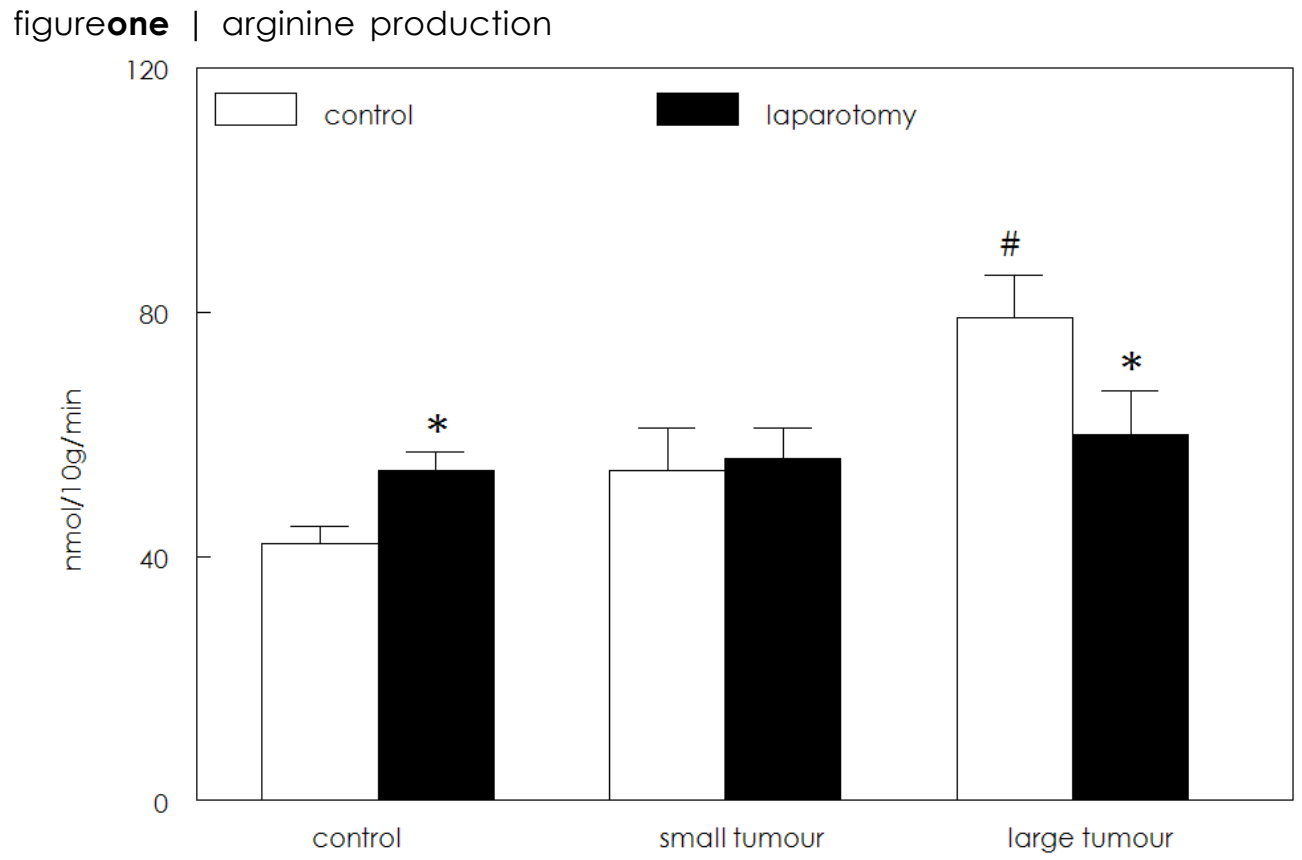

Values are means \pm SEM in $\mathrm{nmol} / 10 \mathrm{~g} / \mathrm{min}$. Statistics with Mann-Whitney $U$ test, ${ }^{*} \mathrm{p}<0.05$ tumour effect, ${ }^{*} \mathrm{p}<0.05$ laparotomy effect.

effects of tumour I

There were no significant differences between tumour-bearing and control mice in carcass weight (control 25.4 \pm 0.4 ; small tumour 25.5 \pm 0.7 ; large tumour 23.9 $\pm 0.8 \mathrm{~g}$ ) or food intake (control 4.2 \pm 0.1 ; small tumour $4.1 \pm 0.2$; large tumour $4.3 \pm 0.2 \mathrm{~g} / \mathrm{day}$ ). Compared with controls, plasma arginine concentrations were specifically decreased in mice with small tumours without changes in total amino acid concentrations including glutamine and citrulline (table one). Concomitantly, plasma ornithine concentrations were increased (table one). In mice with small tumours, whole-body arginine and NO production were unaffected (figures one and two). However, in mice bearing large tumours, whole-body arginine and NO production were $88 \%$ and $54 \%$ higher than in controls $(p<0.05$, figures one and two), without changes in plasma arginine concentration (table one). The presence of a small tumour increased SAP concentrations by 80 -fold, while in the presence of a large tumour SAP concentrations rose even 280 -fold higher than in controls (table one).

attenuated postoperative response in tumour-bearing mice |

In contrast to controls, laparotomy did not increase whole-body arginine and NO production in the presence of a small or a large tumour (figures one and two). In mice with large tumours, whole-body NO production decreased by $24 \%$ after laparotomy (figure two). In contrast to healthy mice undergoing surgery, the 
postoperative SAP concentration did not increase in the presence of a small tumour or a large tumour (table one). Similar to controls, laparotomy did not affect total amino acid concentrations including arginine in the presence of small tumour. Unlike in healthy animals, laparotomy decreased total amino acid concentrations by $25 \%$ in mice with large tumours (table one).

figuretwo | NO production

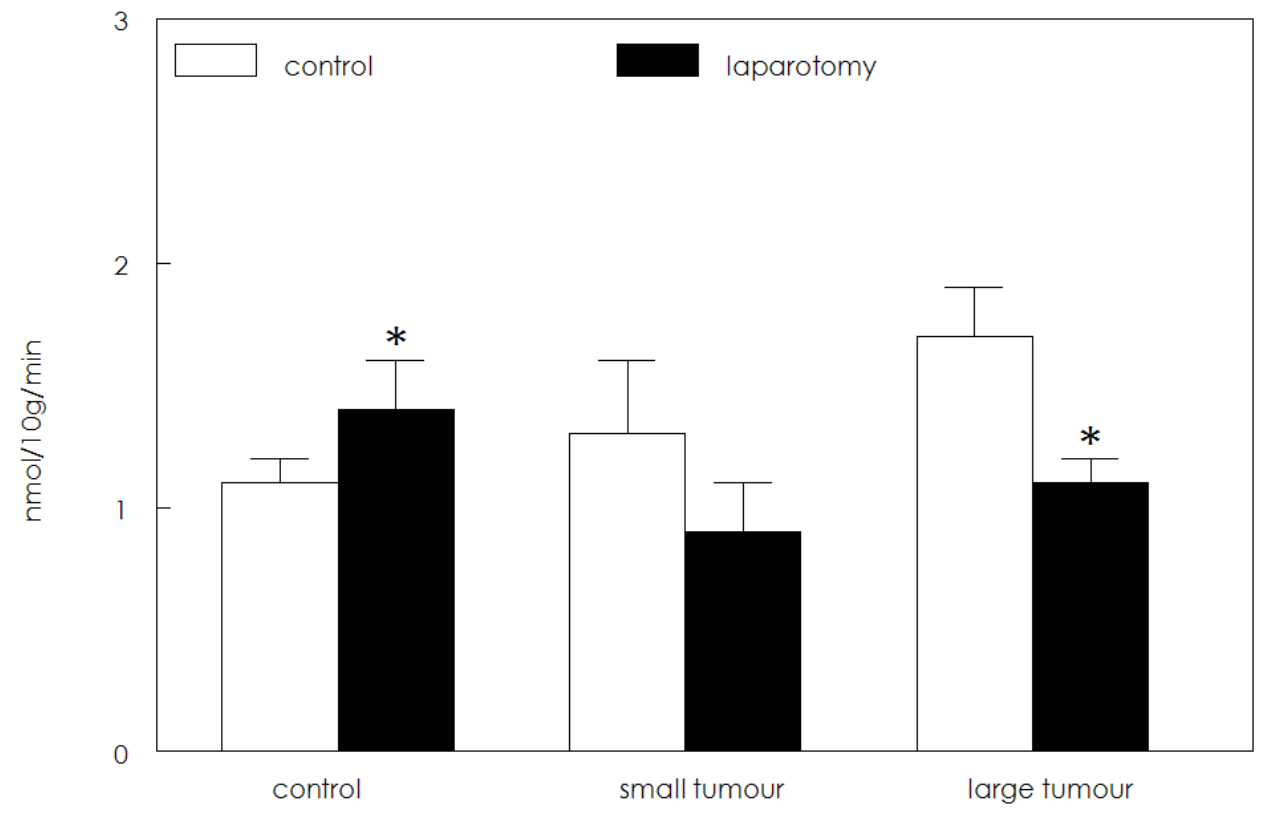

Values are means \pm SEM in $\mathrm{nmol} / 10 \mathrm{~g} / \mathrm{min}$. Statistics with Mann-Whitney $U$ test, $* p<0.05$ laparotomy effect.

\section{discussion |}

This study shows that the postoperative increase in arginine and NO production and the acute phase response that were observed in healthy control mice, were absent in MCA tumour-bearing mice. This indicates that the presence of tumour compromised postoperative arginine metabolism and attenuated the host inflammatory response to surgical trauma.

Arginine is a non-essential amino acid that can be metabolized by NO synthase (NOS) or arginase. Conversion by NOS produces NO and citrulline, whereas conversion by arginase yields ornithine. Various malignant human tumours including lung, colon, prostate and breast carcinoma contain large quantities of arginase 16-18. Recently, arginase activity in cancer was shown to be a mechanism for tumourinduced immune-suppression via depletion of arginine in the microenvironment of murine lung tumours ${ }^{19}$, allowing the tumour to escape the immune response 


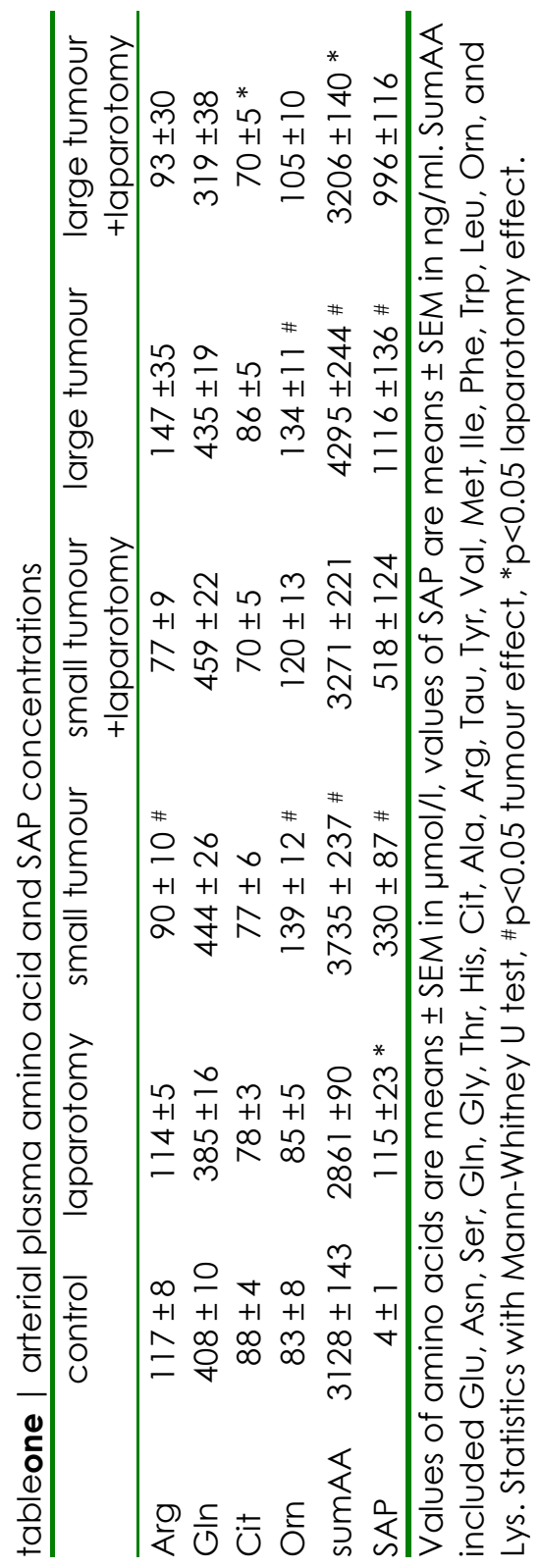


of the host. Subsequently, this mechanism was confirmed in patients with renal cell carcinoma's ${ }^{20}$. This may imply that maintenance amounts of arginine in the tumour environment could play a role in host defence against the tumour. The present study demonstrates that the presence of tumour also induces changes in arginine metabolism at whole body level, which appeared different in mice bearing small and large tumours. In the first group, plasma arginine concentrations were decreased without significantly affecting whole-body arginine production. In mice bearing large tumours, whole-body arginine production was increased with slightly (but not significantly) raised plasma arginine concentrations. It can be calculated that arginine clearance (the amount of plasma that is completely cleared from arginine each minute ${ }^{21}$ ) was increased both in the presence of small and large tumours.

It is important at this stage to address the relevance of these observations for human cancers. MCA rodent tumour models have the histological appearance of sarcoma's and induce several metabolic characteristics of human malignancies, with wasting of fat tissue ${ }^{8}$ and altered protein turnover ${ }^{22}$. In analogy to common human malignancies such as colonic carcinoma and breast carcinoma, MCA tumours do not induce weight loss. MCA tumour-bearing mice may therefore represent cancer patients in whom no weight loss is present. If so, this may imply that cancer at a phase where no cachexia is present already induces disturbances in host amino acid metabolism. Because human tumours are usually small compared to the patient's body weight, the experimental model with the small tumour might be the most clinically relevant of the two.

A common treatment for cancer is surgical removal of the tumour. In the postoperative period, several immune processes rely on arginine as substrate. NO is required for the cytotoxic effect of macrophages, both in animals ${ }^{23}$ and humans ${ }^{24}$. Furthermore, arginine is necessary for a functional T cell response after trauma in mice ${ }^{25}$ and humans ${ }^{26}$. Besides, both arginine and its products $\mathrm{NO}$ and ornithine are indispensable for wound healing in mice ${ }^{27}$. Recently, NO was shown to enhance collagen synthesis in human tendon cells ${ }^{28}$. Therefore, the disturbances in arginine metabolism induced by a tumour could have consequences for the host repair response of cancer patients to surgical trauma. We thus investigated the postoperative response in arginine and NO metabolism in relation to the acute phase response in tumour-bearing mice.

In the current study we demonstrate that the presence of MCA tumour prohibited a postoperative increase in arginine and NO production. If we assume the response of control mice to be normal, this indicates that tumour-bearing mice had a defective postoperative metabolic response. Thus, cancer appears to induce disturbances in arginine metabolism that affect host arginine metabolism, which become even more pronounced when metabolism is challenged during metabolic stress. Concomitantly, SAP concentrations did not increase further. In a previous study, an attenuated CRP response was also reported in undernourished cancer patients that underwent surgery ${ }^{29}$. However, at that time, no metabolic information was present to explain this phenomenon. Some years later, we reported an impaired metabolic response to surgery in tumour-bearing rats in muscle ${ }^{9}$ and intestine ${ }^{30}$. This suggested that the attenuated response to surgery 
as observed in cancer was not related to malnutrition, but rather due to the presence of tumour per se. The current study characterizes the metabolic inability in cancer further, describing an impaired capacity to mobilize arginine and NO after surgical stress with concomitant suppression of the acute phase response. Unfortunately, in the MCA tumour model, tumour removal is not possible without mortality, at least not in our hands, probably due to the relatively large size (ca. $10 \times 20 \mathrm{~mm}$ ) of the tumour. Strictly, the currently used model thus compares with patients in whom radical resection of tumour was not possible.

Strikingly, there was a "chronic" acute phase response ongoing in the presence of tumour. This is probably different from the "acute" acute phase response that usually occurs after surgical trauma. We speculate that the ongoing acute phase response as observed in tumour-bearing mice attenuates the initiation of the inflammatory response upon acute metabolic stress, such as surgical trauma. Hypothetically, this may be due to exhaustion of endogenous sources (possibly amino acids from muscle protein) for substrate for the acute phase response (possibly acute phase protein). Because absolute SAP concentrations in tumourbearing mice were higher than postoperative values in healthy animals, point for discussion remains whether absolute values or relative increases are important for postoperative recovery. Further studies are needed to solve this issue.

In conclusion, our data suggest that the acute phase response normally observed after surgery does not occur in the presence of cancer. This non-responsiveness was concomitant to absence of the increase in whole-body arginine and NO production after surgery, indicating a role for altered arginine metabolism in cancer. Hypothetically, such changes may contribute to postoperative morbidity and mortality, and if similar changes would occur in humans with cancer undergoing surgery this could have consequences for clinical practice.

\section{references}

1. Vissers YLJ, Dejong CHC, Luiking YC, Fearon $\mathrm{KCH}$, von Meyenfeldt MF, Deutz NEP. Plasma arginine concentrations are decreased in cancer: evidence for arginine deficiency? Am J Clin Nutr 2005;81(5):1142-6.

2. Norton JA, Peacock JL, Morrison SD. Cancer cachexia. Crit Rev Oncol Hematol 1987;7(4):289-327.

3. Talamonti MS, Kim SP, Yao KA, et al. Surgical outcomes of patients with gastric carcinoma: the importance of primary tumor location and microvessel invasion. Surgery 2003;134(4):720-7; discussion 727-9.

4. Deslauriers J, Ginsberg RJ, Dubois P, Beaulieu M, Goldberg M, Piraux M. Current operative morbidity associated with elective surgical resection for lung cancer. Can J Surg 1989:32(5):335-9.

5. Rey-Ferro M, Castano R, Orozco O, Serna A, Moreno A. Nutritional and immunologic evaluation of patients with gastric cancer before and after surgery. Nutrition 1997;13(10):878-81.

6. Baltz ML, Dyck RF, Pepys MB. Studies of the in vivo synthesis and catabolism of serum amyloid P component (SAP) in the mouse. Clin Exp Immunol 1985;59(1):23542. 
7. Boyland $E$, Warren F. The induction of tumours by methylcholantrene in two strains of mice. J Path Bact 1937;45:171-177.

8. Lundholm K, Edstrom S, Ekman L, Karlberg I, Bylund AC, Schersten T. A comparative study of the influence of malignant fumor on host metabolism in mice and man: evaluation of an experimental model. Cancer 1978;42(2):45361.

9. de Blaauw I, Deutz NEP, von Meyenfeldt MF. Cancer reduces the metabolic response of muscle to surgical stress in the rat. J Surg Res 1998;80(1):94-101.

10. Hallemeesch MM, ten Have GAM, Deutz NEP. Metabolic flux measurements across portal drained viscera, liver, kidney and hindquarter in mice. Lab Animals 2001;35:101-110.

11. van Eijk HMH, Rooyakkers DR, Deutz NEP. Rapid routine determination of amino acids in plasma by high-performance liquid chromatography with a 2-3 $\mu \mathrm{M}$ Spherisorb ODS II column. J Chromatogr 1993;620:143-148.

12. van Eijk HM, Rooyakkers DR, Soeters PB, Deutz NEP. Determination of amino acid isotope enrichment using liquid chromatography-mass spectrometry. Anal Biochem 1999;271(1):8-17.

13. Daemen MA, Heemskerk VH, van't Veer $\mathrm{C}$, et al. Functional protection by acute phase proteins alpha(1)-acid glycoprotein and alpha(1)-antitrypsin against ischemia/reperfusion injury by preventing apoptosis and inflammation. Circulation 2000;102(12):1420-6.

14. Hallemeesch MM, Soeters PB, Deutz NEP. Renal arginine and protein synthesis are increased during early endotoxemia in mice. Am J Physiol Renal Physiol 2002;282(2):F316-23.

15. SPSS I. SPSS for Windows Version 11.0.1. 1 ed. Chicago: SPSS Inc. 2001.

16. Park KG, Heys SD, Harris $\mathrm{Cl}$, et al. Arginine metabolism in benign and malignant disease of breast and colon: evidence for possible inhibition of tumor-infiltrating macrophages. Nutrition 1991;7(3):185-8.

17. Keskinege A, Elgun S, Yilmaz E. Possible implications of arginase and diamine oxidase in prostatic carcinoma. Cancer Detect Prev 2001;25(1):76-9.

18. Suer Gokmen S, Yoruk Y, Cakir E, Yorulmaz F, Gulen S. Arginase and ornithine, as markers in human non-small cell lung carcinoma. Cancer Biochem Biophys 1999;17(1-2):125-31.

19. Rodriguez PC, Quiceno DG, Zabaleta J, et al. Arginase I production in the tumor microenvironment by mature myeloid cells inhibits T-cell receptor expression and antigen-specific T-cell responses. Cancer Res 2004;64(16):5839-49.

20. Zea AH, Rodriguez PC, Atkins MB, et al. Arginase-producing myeloid suppressor cells in renal cell carcinoma patients: a mechanism of tumor evasion. Cancer Res 2005;65(8):3044-8.

21. Luiking $Y C$, Hallemeesch MM, Vissers $Y L$, Lamers $W H$, Deutz NE. In vivo whole body and organ arginine metabolism during endotoxemia (sepsis) is dependent on mouse strain and gender. J Nutr 2004;134(10):2768S-74S.

22. Lindmark L, Edstrom S, Ekman L, Karlberg I, Lundholm K. Energy metabolism in nongrowing mice with sarcoma. Cancer Res 1983;43(8):3649-54. 
23. Hibbs JB, Jr., Vavrin Z, Taintor RR. L-arginine is required for expression of the activated macrophage effector mechanism causing selective metabolic inhibition in target cells. J Immunol 1987;138(2):550-65.

24. Bose M, Farnia P. Proinflammatory cytokines can significantly induce human mononuclear phagocytes to produce nitric oxide by a cell maturationdependent process. Immunol Lett 1995;48(1):59-64.

25. Rodriguez PC, Zea AH, DeSalvo J, et al. L-Arginine Consumption by Macrophages Modulates the Expression of CD3zeta Chain in T Lymphocytes. J Immunol 2003;171 (3):1232-9.

26. Zea AH, Rodriguez PC, Culotta KS, et al. L-Arginine modulates CD3zeta expression and T cell function in activated human T lymphocytes. Cell Immunol 2004;232(1-2):21-31.

27. Shi HP, Efron DT, Most D, Tantry US, Barbul A. Supplemental dietary arginine enhances wound healing in normal but not inducible nitric oxide synthase knockout mice. Surgery 2000;128(2):374-8.

28. Xia W, Szomor Z, Wang Y, Murrell GA. Nitric oxide enhances collagen synthesis in cultured human tendon cells. J Orthop Res 2006;24(2):159-72.

29. Cruickshank AM, Hansell DT, Burns HJ, Shenkin A. Effect of nutritional status on acute phase protein response to elective surgery. Br J Surg 1989;76(2):165-8.

30. de Blaauw I, Deutz NEP, von Meyenfeldt MF. Cancer attenuates postoperative intestinal proteolysis. Clin Nutr 1996;15:8-O29. 
parttwo | chapterfive 


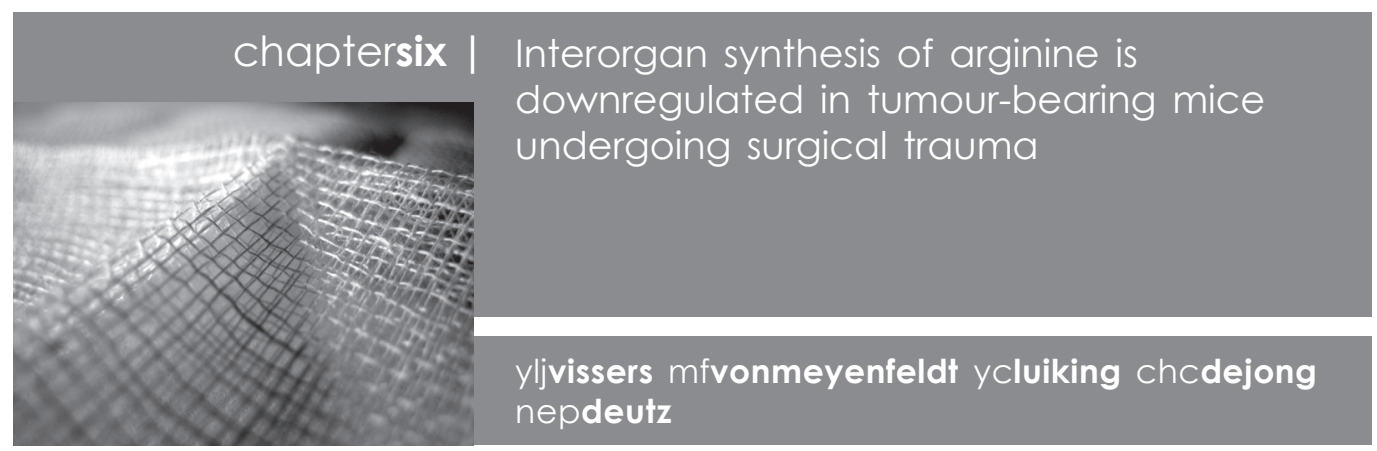

\section{introduction |}

In vivo, in the postabsorptive state arginine production results from protein breakdown and endogenous synthesis via renal de novo arginine production '. An important step in de novo arginine production takes place in the gut, where glutamine (mainly derived from muscle) is converted to citrulline, which is subsequently converted to arginine in the kidney ${ }^{2,3}$. Although contributing for only $10-20 \%$ to total arginine production in healthy circumstances 4,5 , de novo renal arginine production has been shown to regulate arginine production in sepsis ${ }^{6}$. We therefore hypothesize that it may also regulate arginine production in other diseases, for example in cancer, where we recently found indications for disturbances in arginine metabolism (low plasma arginine concentrations) ${ }^{7}$.

A common treatment for cancer is surgical removal of the tumour. In the postoperative period several immune processes rely on arginine as substrate. Arginine is necessary for a functional $\mathrm{T}$ cell response after trauma ${ }^{8}$ and is indispensable for wound healing ${ }^{9}$. Therefore, the de novo arginine production pathway may also be involved in amino acid metabolism after surgical trauma. The aim of the current study was to investigate whether the pathway for de novo arginine production is disturbed in tumour-bearing mice undergoing surgical trauma. Since simultaneous measurements across several organs in humans are difficult in may situations for ethical reasons, we used a mouse model to study the in vivo relation between the amino acid fluxes across the organs that are part of the de novo arginine production pathway: muscle, intestine, liver and kidney. In this way we could visualize the complete inter-organ axis involved in endogenous arginine synthesis. In addition, arginine production from protein breakdown was measured.

\section{methods |}

animals |

Male FVB mice were bred at the Centralized Animal Facilities of Maastricht University. The mice were fed standard lab chow (Hope Pharms, Woerden, NL) and subjected to standard 12 hour light-dark cycle periods. Room temperature was maintained at $22^{\circ} \mathrm{C}$. Water was provided ad libitum throughout the experiment. Experiments 
were approved by the Ethical Committee of Animal Research of Maastricht University. Mice were randomly divided into four groups: controls $(n=12)$; controls undergoing laparotomy ( $n=12)$; tumour-bearing mice $(n=9)$; tumour-bearing mice undergoing laparotomy $(n=9)$.

\section{tumour model |}

Tumours were initially induced by subcutaneous injection of $1 \mathrm{mg}$ methylcholantrene (MCA, Sigma-Aldrich Chemie, Zwijndrecht, NL) in mice in our laboratory. These tumours were maintained in vivo by serially transplanting tumour tissue through a $15 \mathrm{G}$ needle. The MCA tumour has been widely used as a model for cancer in metabolic studies in mice and rats and has the histological characteristics of malignant sarcoma, with locally aggressive growth but without the tendency to metastasize ${ }^{10-12}$. In our hands, the tumour does not induce anorexia or weight loss. Control mice were sham implanted.

\section{surgical trauma |}

When the tumour reached $5-15 \%$ of carcass weight, a midline laparotomy was performed as a model for surgical trauma. In short, anaesthesia was performed by a single intraperitoneal injection of a mixture of ketamine and medetomidine 13. Mice were kept at $37^{\circ} \mathrm{C}$ using a rectal temperature controller and heat pads. A midline incision from the level of the superior iliac spines to the xyphoid process was made. Intestines were put aside and wrapped in wet gauze. Five minutes later, intestines were put back and the abdomen was closed with wound clips (Autoclip, Clay Adams, Becton Dickinson and Company, Parsippany, NJ, USA). In total, the procedure of surgical trauma took about 15 minutes. Afterwards, food was taken away from all groups of mice to prevent differences due to variations in food intake. Water was provided ad libitum.

metabolic measurements |

Twenty-four hours after laparotomy, measurements were performed essentially as described by Hallemeesch et al. ${ }^{13}$ with some adaptations. In short, anaesthesia was induced by an intraperitoneal injection of a mixture of ketamine and medetomidine. Subsequently, anaesthesia was maintained with a continuous subcutaneous infusion of a mixture of ketamine and medetomidine. Mice were kept at $37^{\circ} \mathrm{C}$ using a rectal temperature controller and heat pads. Catheterization of blood vessels for infusion of fluids or sampling of blood was performed using a 30 gauge needle fixed in a silastic tube. All catheters were filled with heparinized saline until blood sampling. To counteract the loss of body fluids by evaporation, saline was continuously infused via the jugular vein. For blood sampling, the carotid artery, portal vein, hepatic vein, right renal vein and inferior caval vein (the latter just above the bifurcation) were catheterized. Plasma flows across organs were measured using an indicator-dilution technique with [glycyl-1-14 C]-p-aminohippuric acid $\left({ }^{14} \mathrm{C}-\mathrm{PAH}, \mathrm{NEN}\right.$ Life Science Products, Boston, MA, USA) as described in detail before ${ }^{13}$. In short, ${ }^{14} \mathrm{C}$-PAH was administered both via a colonic vein for blood flow measurements across portal-drained viscera and liver, and via the inferior 
abdominal aorta for blood flow across hindquarter. Plasma flow across the kidney was based on renal extraction of ${ }^{14} \mathrm{C}-\mathrm{PAH}$.

In contrast with the original paper by Hallemeesch et al., all organ measurements were performed simultaneously in one animal. In total, the procedure for catheterization of blood vessels took about 30 minutes. Then, $120 \mu$ blood was collected from the renal vein, carotid artery, hepatic vein, portal vein and inferior caval vein respectively, in that order. To reduce the dead volume, blood was pulled until the catheter was filled and all heparinized saline disappeared from the catheter, after which a clean needle and syringe were inserted in the catheter and blood was sampled. Blood sampling took about two minutes in total. After blood sampling, mice were killed by cervical dislocation when still under anaesthesia.

analysis |

${ }^{14} \mathrm{C}-\mathrm{PAH}$ concentrations were determined in trichloroacetic acid deproteinized whole blood using a Winspectral 1414 counter ${ }^{13}$. Amino acid concentrations were determined in sulfosalisylic acid deproteinized plasma by HPLC as described by Van Eijk et al. ${ }^{14}$.

\section{calculations |}

Blood flow across hindquarter, liver and portal-drained viscera was calculated from the arterial-venous concentration difference of ${ }^{14} \mathrm{C}-\mathrm{PAH}$ across the organ of interest ${ }^{13}$, based on the dilution principle as posed by Fick: the concentration of ${ }^{14} \mathrm{C}-\mathrm{PAH}$ downstream from the place where it is infused depends on the flow rate through the organ of interest. At steady state, the amount of indicator entering the blood stream equals the amount of indicator excreted. If the infusion rate and the concentration of the indicator upstream and downstream are known, the flow rate can be calculated. Renal blood flow was calculated as renal extraction of ${ }^{14} \mathrm{C}-\mathrm{PAH}$.

Hindquarter amino acid fluxes were calculated by multiplying the inferior caval venous-arterial concentrations differences with the mean hindquarter plasma flow. Assuming the hindquarter to be responsible for half of the total muscular compartment 15, values were multiplied by two to represent whole-body muscular fluxes. Portal drained viscera amino acid fluxes were calculated by multiplying the portal venous-arterial concentration differences with the mean portal drained viscera plasma flow. Portal drained viscera amino acid fluxes were assumed to represent mainly intestinal metabolism. Splanchnic flux was calculated by multiplying the mean hepatic plasma flow with hepatic venous-arterial concentration differences. Hepatic amino acid fluxes were calculated by subtracting portal drained visceral flux from the splanchnic flux. Renal amino acid fluxes were calculated by multiplying the renal venous-arterial concentrations differences with the mean renal plasma flow. A positive flux indicates net release and a negative flux reflects net uptake.

Net protein breakdown in muscle and intestine was estimated from the respective phenylalanine fluxes. Net protein breakdown in liver and kidney was estimated from the respective valine fluxes. 
Data are expressed per $10 \mathrm{~g}$ carcass weight, which was calculated by subtracting tumour weight from body weight including tumour.

statistics |

Results are presented as means \pm SEM. Data were analyzed with SPSS ${ }^{16}$.To reduce the chance of false-positive significances, we only tested the effect of i) laparotomy in control mice, ii) the presence of tumour per se, iii) laparotomy in tumour-bearing mice. ANOVA was used to test differences. Significance was defined as $p<0.05$.

\section{results |}

normal postoperative response |

In healthy mice, muscular glutamine release and intestinal glutamine uptake and citrulline production were maintained after laparotomy (table one and figure one A-C). The contribution of muscular glutamine release to intestinal glutamine uptake increased from $77 \pm 9 \%$ to $99 \pm 16 \%$. In the liver, there was no net citrulline uptake both under control circumstances and after laparotomy (figure one D). In the kidneys of control mice, citrulline uptake as well as arginine production were maintained after laparotomy (figure one E, F). Both before and after surgery, renal citrulline uptake exceeded intestinal citrulline production (figure one $C, E$ ). Net protein breakdown in muscle, intestine, liver and kidney was not affected by laparotomy (table one).

figureone | de novo arginine pathway
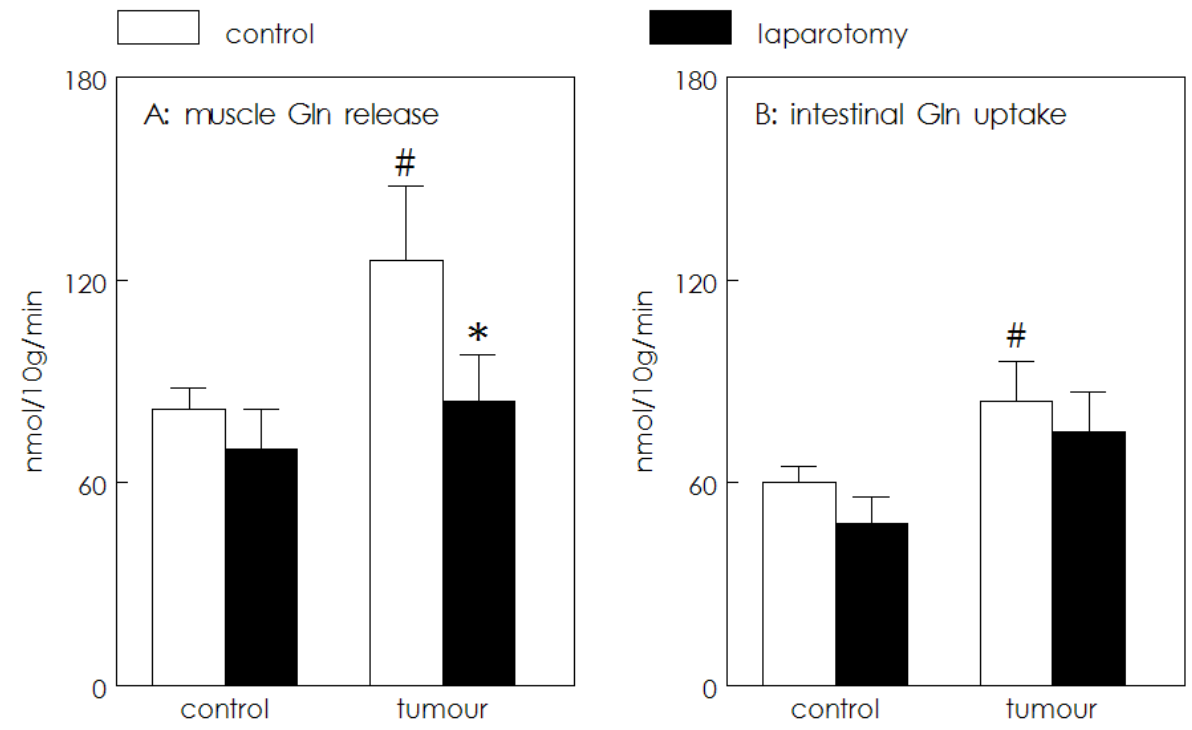
parttwo | chaptersix
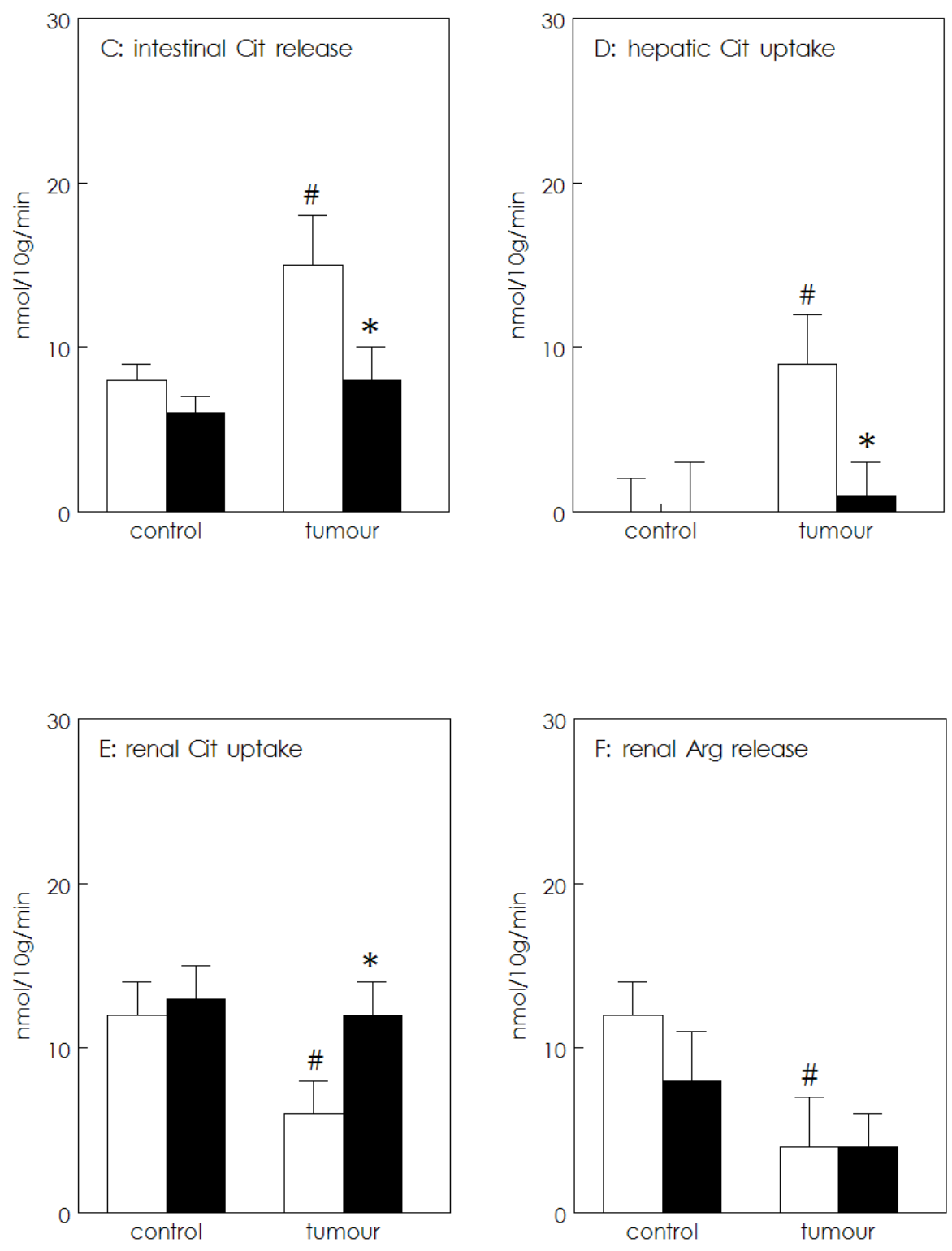

Values are means \pm SEM in $\mathrm{nmol} / 10 \mathrm{~g} / \mathrm{min}$. Statistics with ANOVA: ${ }^{p} \mathrm{p}<0.05$ tumour effect, " $p<0.05$ laparotomy effect. 
tableone | amino acid fluxes across organs

\begin{tabular}{|c|c|c|c|c|}
\hline & control & laparotomy & tumour & $\begin{array}{c}\text { tumour } \\
\text { +laparotomy }\end{array}$ \\
\hline \multicolumn{5}{|l|}{ muscle } \\
\hline blood flow & $0.33 \pm 0.04$ & $0.38 \pm 0.06$ & $0.33 \pm 0.07$ & $0.45 \pm 0.08$ \\
\hline Glu & $-6 \pm 3$ & $-2 \pm 3$ & $-18 \pm 4 \#$ & $-19 \pm 7$ \\
\hline Cit & $-6 \pm 2$ & $-7 \pm 1$ & $-5 \pm 3$ & $-5 \pm 1$ \\
\hline $\mathrm{BCAA}$ & $-15 \pm 16$ & $-26 \pm 25$ & $-11 \pm 15$ & $-8 \pm 15$ \\
\hline Phe (PB) & $8 \pm 1$ & $10 \pm 3$ & $9 \pm 4$ & $13 \pm 4$ \\
\hline \multicolumn{5}{|l|}{ intestine } \\
\hline blood flow & $0.36 \pm 0.08$ & $0.37 \pm 0.08$ & $0.61 \pm 0.20$ & $0.51 \pm 0.19$ \\
\hline Glu & $10 \pm 2$ & $9 \pm 1$ & $15 \pm 4$ & $6 \pm 3^{*}$ \\
\hline Ala & $81 \pm 14$ & $45 \pm 14^{*}$ & $148 \pm 22 \#$ & $96 \pm 22^{*}$ \\
\hline Phe (PB) & $3 \pm 1$ & $3 \pm 1$ & $6 \pm 2$ & $5 \pm 2$ \\
\hline \multicolumn{5}{|l|}{ liver } \\
\hline blood flow & $0.73 \pm 0.12$ & $0.77 \pm 0.14$ & $0.83 \pm 0.19$ & $0.86 \pm 0.21$ \\
\hline Arg & $-25 \pm 5$ & $-18 \pm 4$ & $-29 \pm 8$ & $-15 \pm 4^{*}$ \\
\hline Val (PB) & $10 \pm 3$ & $6 \pm 6$ & $-2 \pm 2^{\#}$ & $-2 \pm 5$ \\
\hline \multicolumn{5}{|l|}{ kidney } \\
\hline blood flow & $0.79 \pm 0.10$ & $0.86 \pm 0.13$ & $0.96 \pm 0.12$ & $0.77 \pm 0.09$ \\
\hline Gln & $-32 \pm 11$ & $-28 \pm 14$ & $0 \pm 8^{\#}$ & $-26 \pm 8^{*}$ \\
\hline Val (PB) & $3 \pm 3$ & $-6 \pm 5$ & $3 \pm 2$ & $-3 \pm 3$ \\
\hline
\end{tabular}

Values are means \pm SEM in $\mathrm{nmol} / 10 \mathrm{~g} / \mathrm{min}$, except for blood flow in $\mathrm{ml} / 10 \mathrm{~g} / \mathrm{min}$. A positive flux indicates net release and a negative flux reflects net uptake. BCAA: branched chain amino acids. Statistics with ANOVA: $" p<0.05$ tumour effect, " $p<0.05$ laparotomy effect.

effects of tumour I

The presence of tumour significantly increased muscular glutamine release and intestinal glutamine uptake and citrulline production (figure one A-C and table one). The percentage of muscular glutamine release that was taken up by intestine was $76 \pm 15 \%$, similar to controls. In tumour-bearing mice, the liver took up citrulline from the circulation (figure one D). In relation, less citrulline was taken up by the kidneys and renal arginine production was lower (figure one E, F). Net hepatic protein breakdown (table one) was reduced in tumour-bearing mice.

postoperative response in presence of tumour 1

In contrast with healthy mice, postoperative glutamine release from muscle was not maintained but decreased in the presence of tumour (figure one A). Glutamine uptake by the gut was maintained postoperatively (figure one B). The percentage of muscular glutamine release that contributed to intestinal glutamine uptake increased from $76 \pm 16 \%$ to $93 \pm 16 \%$ in the postoperative period. However, intestinal citrulline and glutamate production decreased and hepatic citrulline uptake 
returned to zero (figure one $\mathrm{C}, \mathrm{D}$ and table one). In the kidneys of tumour-bearing mice, postoperative citrulline uptake increased but arginine production remained unchanged (figure one E, F). Again, renal citrulline uptake exceeded intestinal citrulline production (figure one $\mathrm{C}, \mathrm{E}$ ). Postoperative net protein breakdown in muscle, intestine, liver and kidney was not affected compared with healthy mice undergoing surgery (table one).

\section{discussion |}

The present study was performed to improve our understanding of the role of endogenous arginine synthesis in cancer and after surgical trauma. We observed that tumour-bearing mice upregulated muscle glutamine release, intestinal glutamine uptake and citrulline production but decreased renal citrulline uptake and arginine production. This coincided with the presence of hepatic citrulline uptake. When tumour-bearing mice underwent surgery, upregulation of these pathways in muscle and intestine could not be maintained and intestinal citrulline production decreased. Although citrulline was no longer taken up by the liver after surgery and renal citrulline uptake increased, this did not result in elevated renal arginine production. Thus, the de novo arginine production pathway was compromised in the presence of tumour, irrespective of the metabolic stress of surgery.

\section{tumour effects |}

The presence of tumour increased muscular glutamine production with concomitant increased glutamate uptake, suggesting that more glutamate was converted to glutamine. Since this was not accompanied by increased phenylalanine efflux, increased protein breakdown was probably not a source for the enhanced glutamine production. Besides, glutamine production increased more than could be explained by the increased uptake of its precursors branched chain amino acids and glutamate alone. Therefore, release from the intracellular glutamine pool was probably also increased in tumour-bearing mice. In a previous study in tumour-bearing rats we observed a similar increase in glutamine production by muscle that was accompanied by decreased intracellular glutamine concentrations ${ }^{17}$, suggesting that membrane transport rates were increased. Thus, the presence of tumour probably upregulated muscular amino acid metabolism. At the same time, the gut took up and converted more glutamine, reflected by increased intestinal citrulline, glutamate (not significant) and alanine production. We calculated that intestinal glutamine uptake accounted for $76 \%$ of the glutamine released from muscle. Since glutamine is the most important fuel for intestinal cells, it indicates that intestinal metabolism was increased in the presence of a tumour.

Remarkably, we observed net hepatic citrulline uptake in tumour-bearing mice, extracting more than half of the citrulline produced by the gut from the circulation. From previous flux studies, it was known that in healthy conditions there is only a small net uptake of citrulline by the liver in rats ${ }^{18,19}$ and dogs ${ }^{20}$. Recently, our 
group described hepatic citrulline uptake in patients during gastrointestinal surgery 21,22. The physiological significance of these observations remains to be elucidated. In contrast to upregulated intestinal conversion of glutamine to citrulline, renal uptake of citrulline and arginine production were decreased in tumour-bearing mice. Similarly to our results in endotoxemic mice ${ }^{6}$, renal protein metabolism assessed by the flux of branched chain amino acids across the kidney was unaffected, suggesting that decreased renal protein metabolism was not the source of decreased arginine release. Thus, the presence of tumour led to upregulation of intestinal citrulline production, whereas renal citrulline uptake was downregulated. Concomitantly, the liver took up citrulline in tumour-bearing mice.

\section{effect of tumour on postoperative metabolism I}

In tumour-bearing mice, laparotomy led to a reduction in glutamine production in muscle to levels similar to pre-operative controls. This is in line with previous experiments in tumour-bearing rats undergoing surgery ${ }^{23}$. It was not related to reduced uptake of its precursors glutamate and branched chain amino acids or net protein breakdown in muscle, suggesting that release from the intracellular glutamine pool was decreased in muscle.

Despite the postoperative decrease in muscular glutamine production, tumourbearing mice maintained intestinal glutamine uptake after surgery. In fact, the contribution of muscular glutamine release to intestinal glutamine uptake increased from 76 to $93 \%$. Therefore, it appears that the intestine of tumour-bearing mice was more dependent on muscular glutamine production after surgery. However, intestinal citrulline release was not maintained. Other products of intestinal glutamine metabolism such as glutamate and alanine were also released in smaller quantities. Apparently, enterocytes used more glutamine as fuel in the postoperative condition, leaving less to be converted to citrulline, alanine and glutamate. Additional studies with specific tracers for these amino acids are necessary to confirm this assumption.

Strikingly, although intestinal citrulline production decreased, renal citrulline uptake increased in tumour-bearing mice undergoing laparotomy, illustrating that there was no direct relation between intestinal citrulline production and renal citrulline uptake in this situation. This is in keeping with another mice study, showing no relation between intestinal citrulline production and renal citrulline uptake ${ }^{24}$. From the present data it can be calculated that about half of renal citrulline uptake originated from extra-intestinal sources. Besides intestine, both muscle and liver ${ }^{18}$ have shown the capacity to synthesize citrulline. However, in our study neither muscle nor liver released net quantities of citrulline, suggesting the presence of other sources of citrulline, presumably in cells of the immune system ${ }^{25}$. Despite the postoperative increase in renal citrulline uptake, renal arginine release into the circulation did not increase after surgery in tumour-bearing mice, which is in contrast with a study in rats with short bowel resections where a relation was present between renal citrulline uptake and renal arginine production ${ }^{5}$. Speculating on this discrepancy between renal citrulline uptake and arginine production, urinary excretion of arginine is unlikely, since the fractional excretion of arginine in rats has been reported to be as small as $0.0003{ }^{26}$. Urinary excretion of arginine can 
thus be calculated to be about $0.007 \mathrm{nmol} / 10 \mathrm{~g} / \mathrm{min}$ and is too small to explain the $5 \mathrm{nmol} / 10 \mathrm{~g} / \mathrm{min}$ difference between renal citrulline uptake and arginine production. In addition, nitric oxide production is also probably too small to account for the difference. In a previous study from our group, renal nitric oxide production in control mice was only $1.9 \mathrm{nmol} / 10 \mathrm{~g} / \mathrm{min}$. Therefore, arginine probably has disappeared intracellularly into other pathways or was converted (e.g. to urea, creatine, proline or agmatine) and subsequently released either back to plasma or into urine. However, there was no compensatory efflux of amino acids other than arginine from the kidney.

In summary, in tumour-bearing mice, intestinal conversion of glutamine to citrulline increased, while renal citrulline uptake decreased in relation with increased hepatic citrulline uptake. Concomitantly, renal arginine production was reduced to values approaching zero. When undergoing surgery, renal arginine production in tumourbearing mice remained close to zero. At the same time, intestinal citrulline production decreased, despite increased renal citrulline uptake. Thus, our data demonstrate that the de novo arginine production pathway can be regulated at various organ sites depending on the pathophysiological situation. In all tumourbearing groups de novo arginine production by the kidney was reduced. In the pre-operative situation this occurred together with hepatic citrulline uptake; in the postoperative period this coincided with decreased citrulline production by the gut.

It seems that renal arginine production was quite independent of gut citrulline production, independent of liver citrulline uptake and independent of renal citrulline uptake. We recently published arterial plasma amino acid concentrations of these mice, showing that citrulline concentrations were not different between the groups ${ }^{27}$, thus suggesting that renal arginine production is also independent of circulating citrulline. This is in contrast with a study in rats where supplementation of glutamine increased arterial concentrations of citrulline and arginine together with increased renal citrulline uptake and renal arginine production ${ }^{28}$. On the other hand, in keeping with the present findings, a recent mice study showed no relation between intestinal citrulline production and renal citrulline uptake or renal arginine production ${ }^{24}$. Apparently, the interorgan relation between citrulline and arginine is more complicated than a mere substrate-driven one. In conclusion, in all tumour-bearing mice de novo arginine production was decreased compared with control mice, suggesting a role for altered arginine metabolism in the tumourbearing host.

\section{references |}

1. Dhanakoti SN, Brosnan JT, Herzberg GR, Brosnan ME. Renal arginine synthesis: studies in vitro and in vivo. Am J Physiol 1990;259(3 Pt 1):E437-42.

2. Tizianello A, de Ferrari G, Caribotto G, Gurreri G. Renal metabolism of amino acids and ammonia in subjects with normal renal function and in patients with chronic renal insufficiency. J Clin Invest 1980;65:1162-1173. 
3. van de Poll MC, Soeters PB, Deutz NE, Fearon KC, Dejong CH. Renal metabolism of amino acids: its role in interorgan amino acid exchange. Am J Clin Nutr 2004;79(2):185-97.

4. Wu G, Morris SM. Arginine metabolism: nitric oxide and beyond. Biochem J 1998:336:1-17.

5. Dejong CHC, Welters CFM, Deutz NEP, Heineman E, Soeters PB. Renal arginine metabolism in fasted rats with subacute short bowel syndrome. Clin Sci 1998:95:409-418.

6. Hallemeesch MM, Soeters PB, Deutz NEP. Renal arginine and protein synthesis are increased during early endotoxemia in mice. Am J Physiol Renal Physiol 2002;282(2):F316-23.

7. Vissers YLJ, Dejong CHC, Luiking YC, Fearon $\mathrm{KCH}$, von Meyenfeldt MF, Deutz NEP. Plasma arginine concentrations are decreased in cancer: evidence for arginine deficiency? Am J Clin Nutr 2005;81(5):1142-6.

8. Rodriguez PC, Zea AH, DeSalvo J, et al. L-Arginine Consumption by Macrophages Modulates the Expression of CD3zeta Chain in T Lymphocytes. J Immunol 2003;171(3):1232-9.

9. Shi HP, Efron DT, Most D, Tantry US, Barbul A. Supplemental dietary arginine enhances wound healing in normal but not inducible nitric oxide synthase knockout mice. Surgery 2000;128(2):374-8.

10. Boyland $E$, Warren $F$. The induction of tumours by methylcholantrene in two strains of mice. J Path Bact 1937;45:171-177.

11. Lundholm K, Edstrom S, Ekman L, Karlberg I, Bylund AC, Schersten T. A comparative study of the influence of malignant tumor on host metabolism in mice and man: evaluation of an experimental model. Cancer 1978;42(2):45361.

12. Colmenero P, Liljestrom $P$, Jondal M. Induction of P815 tumor immunity by recombinant Semliki Forest virus expressing the PlA gene. Gene Ther 1999;6(10):1728-33.

13. Hallemeesch MM, ten Have GAM, Deutz NEP. Metabolic flux measurements across portal drained viscera, liver, kidney and hindquarter in mice. Lab Animals 2001;35:101-110.

14. van Eijk HMH, Rooyakkers DR, Deutz NEP. Rapid routine determination of amino acids in plasma by high-performance liquid chromatography with a 2-3 $\mu \mathrm{M}$ Spherisorb ODS II column. J Chromatogr 1993;620:143-148.

15. Ruderman NB, Houghton CRS, Hems R. Evaluation of the isolated perfused rat hindquarter for the study of muscle metabolism. Biochem J 1971;124:639-651.

16. SPSS I. SPSS for Windows Version 11.0.1. 1 ed. Chicago: SPSS Inc. 2001.

17. de Blaauw I, Heeneman S, Deutz NEP, von Meyenfeldt MF. Increased wholebody protein and glutamine turnover in advanced cancer is not matched by an increased muscle protein and glutamine turnover. J Surg Res 1997;68(1):4455.

18. Windmueller HG, Spaeth AE. Source and fate of circulating citrulline. Am J Physiol 1981;241(6):E473-80. 
19. Hartman WJ, Prior RL. Dietary arginine deficiency alters flux of glutamine and urea cycle intermediates across the portal-drained viscera and liver of rats. $J$ Nutr 1992;122(7):1472-82.

20. YU YM, Burke JF, Tompkins RG, Martin R, Young VR. Quantitative effects of interorgan relationships among arginine and citrulline metabolism. Am J Physiol 1996:271:E1098-E1109.

21. van de Poll MC, Ligthart-Melis GC, Boelens PG, Deutz NE, van Leeuwen PA, Dejong $\mathrm{CH}$. Intestinal and hepatic metabolism of glutamine and citrulline in humans. J Physiol 2007.

22. van de Poll MC, Siroen MP, van Leeuwen PA, et al. Interorgan amino acid exchange in humans: consequences for arginine and citrulline metabolism. Am J Clin Nutr 2007:85(1):167-72.

23. de Blaauw I, Deutz NEP, von Meyenfeldt MF. Cancer reduces the metabolic response of muscle to surgical stress in the rat. J Surg Res 1998;80(1):94-101.

24. Boelens PG, van Leeuwen PA, Dejong CH, Deutz NE. Intestinal renal metabolism of L-citrulline and L-arginine following enteral or parenteral infusion of L-alanyl-L$[2,15 \mathrm{~N}]$ glutamine or L-[2,15N]glutamine in mice. Am J Physiol Gastrointest Liver Physiol 2005;289(4):G679-85.

25. Benninghoff B, Lehmann V, Eck HP, Droge W. Production of citrulline and ornithine by interferon-gamma treated macrophages. Int Immunol 1991;3(5):4137.

26. Silbernagl S, Volker K, Dantzler WH. Cationic amino acid fluxes beyond the proximal convoluted tubule of rat kidney. Pflugers Arch 1994;429(2):210-5.

27. Vissers YL, von Meyenfeldt MF, Luiking YC, Dejong CH, Buurman WA, Deutz NE. Presence of tumour inhibits the normal postoperative response in arginine and NO production in non-cachectic mice. Clin Sci (Lond) 2007.

28. Houdijk APJ, van Leeuwen PAM, Teerlink T, et al. Glutamine-enriched enteral diet increases renal arginine production. JPEN 1994;18:422-426. 


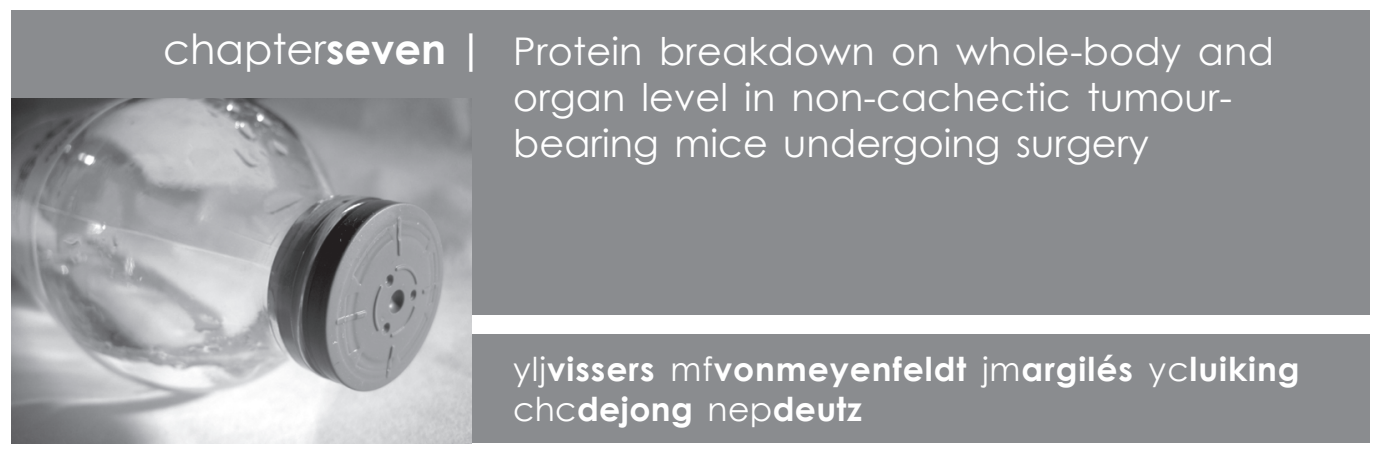

\section{introduction |}

The metabolic response to surgery is characterized by protein breakdown in muscle ${ }^{1}$ and intestine ${ }^{2}$ with subsequent production and release of amino acids from these organs. It is generally accepted that these tissues are broken down to mobilize amino acids for gluconeogenesis and acute-phase protein synthesis in the liver, and for protein synthesis at the wound site.

In contrast to the acute changes in protein turnover after surgical trauma, cancer is accompanied by chronic disturbances in protein metabolism, characterized by increased protein turnover ${ }^{3,4}$. It is assumed that these disturbances in protein metabolism are mainly present in skeletal muscle, eventually leading to the syndrome of cancer cachexia with decreased muscle mass.

A common treatment for cancer is surgical removal of the tumour. Because cancer affects protein turnover, the disturbances in protein metabolism may influence protein turnover after surgery and therefore may have clinical consequences for the postoperative response of cancer patients. Thus, we hypothesized that the presence of tumour impairs postoperative protein breakdown in muscle and intestine.

Since whole-body protein turnover reflects the sum of many tissues, whole-body protein turnover measurements do not effectively inform on protein metabolism of specific organs. A specific feature of tumour-bearing conditions is the loss of muscle mass. Thus, it is crucial to get information that is specific for muscular protein metabolism and many methods have been used to shed light on the role of this major metabolic organ. Here, we used a mouse model to study how cancer affects protein breakdown in muscle, intestine, liver and kidney. Next, we used this model to study whether cancer influences postoperative protein turnover in these organs. Organ protein turnover was measured using various techniques. Stable isotope tracer methods were used to assess whole-body and organ protein breakdown and body composition. In addition, a recently developed stable isotope technique to measure myofibrillar protein breakdown rates was used to specifically measure myofibrillar protein breakdown ${ }^{5}$. Ex vivo proteasomal activity was measured to determine activity of the ATP-dependent ubiquitin proteasomal pathway in gastrocnemius muscle. 


\section{methods |}

animals |

Male FVB mice were bred at the Centralized Animal Facilities of Maastricht University. The mice were fed standard lab chow (Hope Pharms, Woerden, NL) and subjected to standard 12 hour light-dark cycle periods. Room temperature was maintained at $22^{\circ} \mathrm{C}$. Water was provided ad libitum throughout the experiment. Experiments were approved by the Ethical Committee of Animal Research of Maastricht University. For metabolic measurements and measurement of proteasomal activity, mice were divided into four groups: 1) control $(n=8) ; 2)$ control undergoing laparotomy $(n=8)$; 3) tumour-bearing $(n=8)$; tumour-bearing undergoing laparotomy $(n=8)$. Because the method to measure body composition interfered with the radioactive blood flow method of the metabolic experiment, body composition and carcass and gastrocnemius weights were assessed in four extra groups of mice ( $n=8$ per group) with the same characteristics as group one to four.

\section{tumour model |}

Tumours were initially induced by subcutaneous injection of $1 \mathrm{mg}$ methylcholantrene (MCA, Sigma-Aldrich Chemie, Zwijndrecht, NL) in mice in our laboratory. These tumours were maintained in vivo by serially transplanting tumour tissue through a $15 \mathrm{G}$ needle. The MCA tumour has been widely used as a model for cancer in metabolic studies in mice and rats and has the histological characteristics of malignant sarcoma, with locally aggressive growth ${ }^{6,7}$. In our hands, the tumour does not induce anorexia or weight loss (table one). Control mice were sham implanted.

\section{surgical trauma}

About two weeks after implantation of tumour fragments, when the tumour reached $5-15 \%$ of carcass weight (calculated by subtracting tumour weight from body weight including tumour), laparotomy was performed as a model for surgical trauma. In short, ketamine/medetomidine anaesthesia, fluid and temperature control were performed as described previously ${ }^{8}$. A midline incision from the level of the superior iliac spines until the xyphoid process was made. The intestines were put aside and wrapped in wet gauze. Five minutes later, the intestines were put back and the abdomen was closed with wound clips (Autoclip, Clay Adams, Becton Dickinson and Company, Parsippany, NJ, USA). After laparotomy, food was taken away from all mice to prevent differences in food intake between groups. Drinking water was provided ad libitum.

metabolic measurements |

Twenty-four hours after laparotomy, ketamine/medetomidine anaesthesia and fluid and temperature maintenance were performed again as described before 8. A primed-constant infusion of the stable isotopes L-phenylalanine [phenyl- ${ }^{2} \mathrm{H}_{5^{\prime}}, 99$ atoms percent excess $\left.{ }^{2} \mathrm{H}_{1}\right]\left(\left[{ }^{2} \mathrm{H}_{5}\right]\right.$ Phe) and L-3-methyl [tau- ${ }^{2} \mathrm{H}_{3}, 99$ atoms percent excess $\left.{ }^{2} \mathrm{H}_{1}\right]$ histidine $\left(\left[{ }^{2} \mathrm{H}_{3}\right] \mathrm{mHis}\right)$ (Mass Trace, Woburn, MA, USA) was given in the jugular vein (prime: $117 \mathrm{nmol}\left[{ }^{2} \mathrm{H}_{5}\right] \mathrm{Phe} / 10 \mathrm{~g}$ and $12 \mathrm{nmol}\left[{ }^{2} \mathrm{H}_{3}\right] \mathrm{mHis} / 10 \mathrm{~g}$; infusion: 
$600 \mathrm{nmol}\left[{ }^{2} \mathrm{H}_{5}\right] \mathrm{Phe} / 10 \mathrm{~g} / \mathrm{h}$ and $\left.10 \mathrm{nmol}\left[{ }^{2} \mathrm{H}_{3}\right] \mathrm{mHis} / 10 \mathrm{~g} / \mathrm{h}\right)$. Plasma flows were measured using an indicator-dilution technique with [glycyl-1-14 $\mathrm{C}$ ]-p-aminohippuric acid ( ${ }^{14} \mathrm{C}-\mathrm{PAH}, \mathrm{NEN}$ Life Science Products, Boston, MA, USA) as described in detail before ${ }^{8}$. Briefly, renal plasma flow was calculated as extraction of ${ }^{14} \mathrm{C}-\mathrm{p}$ aminohippuric acid ${ }^{8}$. Hindquarter, liver and gut plasma flows were calculated as arterial-venous dilutions of ${ }^{14} \mathrm{C}$-p-aminohippuric acid. The method is based on the principle that, in steady state conditions, the amount of indicator entering the blood stream is equal to the amount of indicator that is excreted by the organ of interest. Flow rate can be calculated as:

flow $=1 /\left(\left[{ }^{14} \mathrm{C}-\mathrm{PAH}\right]_{\vee}-\left[{ }^{14} \mathrm{C}-\mathrm{PAH}\right]_{\mathrm{A}}\right)$, where $\mathrm{I}$ is the rate of infusion ${ }^{1{ }^{14} \mathrm{C}-}$ para-amino hippuric acid, $\left[{ }^{14} \mathrm{C}-\mathrm{PAH}\right]_{\vee}$ is the venous concentration of ${ }^{14} \mathrm{C}$-paraamino hippuric acid downstream of the organ of interest and $\left[{ }^{14} \mathrm{C}-\mathrm{PAH}\right]_{\mathrm{A}}$ is the arterial concentration of ${ }^{14} \mathrm{C}$-para-amino hippuric acid.

Since this protocol yields steady state within 30 minutes ${ }^{5}$, blood was collected 30 minutes after the start of the tracer infusion from the carotid artery, inferior caval vein, portal vein, hepatic vein and right renal vein as described before ${ }^{8}$. Gastrocnemius muscles were dissected and immediately frozen in liquid nitrogen. Amino acid concentrations and tracer/tracee ratio's (TTR) were determined in plasma as described by Van Eijk ${ }^{9,10}$.

Protein breakdown on whole-body level was assessed in a one-compartment model using infusion of stable isotopes. This model assumes that the rate of appearance ( $\mathrm{Ra}$ ) of substrate (tracee) and the infusion of labelled substrate (tracer) occur in a single homogenous pool. Thus, the ratio between the infused tracer and naturally occurring tracee (TTR) in the pool is a measure for the rate of appearance of substrate, which is calculated as "1:

$R a=I / T T R$, where I is the rate of infusion of tracer and TTR is the tracertracee ratio of the infused labelled substrate and the naturally occurring substrate. Whole-body protein breakdown was assessed as plasma phenylalanine flux, calculated from the arterial isotope TTR values of the $\left[{ }^{2} \mathrm{H}_{5}\right]$ Phe isotope as detailed previously ${ }^{12}$. Myofibrillar protein breakdown was assessed as whole-body plasma 3-methylhistidine flux, calculated from the arterial isotope TTR values of the $\left[{ }^{2} \mathrm{H}_{3}\right] \mathrm{mH}$ is isotope as described recently ${ }^{5}$.

Organ protein breakdown was assessed in a two-compartment model as phenylalanine production rate ${ }^{13}$. Briefly, phenylalanine net balances (NB Phe) across organs are calculated:

NB Phe $=$ flow $\times\left([\mathrm{Phe}]_{V}-[\mathrm{Phe}]_{\mathrm{A}}\right)$, where $[\mathrm{Phe}]_{V}$ is the concentration of phenylalanine in a vein coming from the organ of interest (inferior caval vein for hindquarter, portal vein for intestine, hepatic vein for liver, right renal vein for kidneys) and $[\mathrm{Phe}]_{\mathrm{A}}$ is the arterial concentration of phenylalanine. Assuming the hindquarter to be responsible for half of the total muscular compartment ${ }^{14}$, values were multiplied by two to represent whole-body muscular fluxes. Next, tracer net balances of phenylalanine ( $\mathrm{nb}\left[{ }^{2} \mathrm{H}_{5}\right]$ Phe) are- calculated:

$\mathrm{nb}\left[{ }^{2} \mathrm{H}_{5}\right]$ Phe $=$ flow $\times\left(\left[{ }^{2} \mathrm{H}_{5}\right]\right.$ Phe ${ }_{\mathrm{A}}-\left[{ }^{2} \mathrm{H}_{5}\right]$ Phe $\left.{ }_{\mathrm{V}}\right)$, where $\left[{ }^{2} \mathrm{H}_{5}\right]$ Phe ${ }_{\mathrm{A}}$ is the arterial concentration of $\left[{ }^{2} \mathrm{H}_{5}\right]$ Phe and $\left[{ }^{2} \mathrm{H}_{5}\right] \mathrm{Phe}{ }_{v}$ is the concentration of $\left[{ }^{2} \mathrm{H}_{5}\right]$ Phe in a vein 
coming from the organ of interest. Disposal of penylalanine (D Phe) can than be calculated as:

D Phe $=n b\left[{ }^{2} \mathrm{H}_{5}\right]$ Phe $/$ TTR ${ }_{v^{\prime}}$ assuming that the venous tracer-tracee ratio best approaches the tracer-tracee ratio of the intracellular precursor pool of phenylalanine. Phenylalanine production across an organ ( $P$ Phe) can thus be calculated as follows:

$P$ Phe $=$ D Phe - NB Phe.

proteasomal activity |

Chymotrypsin-like activity of the proteasome was determined fluorometrically according to the method of Orino ${ }^{15}$ with minor modifications as described by Whitehouse ${ }^{16}$. Briefly, muscles were pulverized in liquid nitrogen and homogenized in buffer $(20 \mathrm{mM}$ Tris $\mathrm{HCl} \mathrm{pH} \mathrm{7.5,} 2 \mathrm{mM}$ ATP, $5 \mathrm{mM} \mathrm{MgCl}, 1 \mathrm{mM}$ dithiothreitol; $\mathrm{W}: \mathrm{V}=$ 1:50). Cells were dissociated by sonication with three pulses of $15 \mathrm{~s}$ with $10 \mathrm{~s}$ intervals at $4^{\circ} \mathrm{C}$. The sonicate was centrifuged for $10 \mathrm{~min}$ at $15000 \mathrm{rpm}$ at $4^{\circ} \mathrm{C}$. In the presence or absence of $10 \mu \mathrm{l}$ of the proteasome inhibitor lactacystin (final concentration 25 $\mu \mathrm{M}$, Biotrend Chemikalien, Köln, GE), $100 \mu$ l supernatant (final sample dilution 1:500) was used to determine chymotrypsin-like activity using $100 \mu$ fluorogenic substrate succinyl-leucine-leucine-valine-tyrosine-7-amido-4-methylcoumarin (Biotrend Chemikalien, Köln, GE) in $100 \mathrm{mM}$ Tris $\mathrm{HCl}, \mathrm{pH} 8.0$ (final concentration $0.1 \mathrm{mM}$ ). Fluorescence was determined at $22^{\circ} \mathrm{C}$ at $\mathrm{t}=30 \mathrm{~min}$ and $\mathrm{t}=60 \mathrm{~min}$ with excitation wavelength of $360 \mathrm{~nm}$ and emission wavelength of $460 \mathrm{~nm}$. A calibration curve with various dilutions of supernatant was made to confirm linearity of the reaction. Activity was assessed in duplo and adjusted for protein concentration of the sample using Bradford assay ${ }^{17}$. Slopes of activity with and without lactacystin were calculated.

Proteasomal activity was calculated by subtracting chymotryptic activity in the presence of the specific proteasomal inhibitor lactacystin from total chymotryptic activity. Calcium-dependent chymotryptic activity was calculated as the slope of chymotryptic activity in the presence of lactacystin.

\section{body composition |}

Dry fat free mass and fat mass were determined using ${ }^{3} \mathrm{H}_{2} \mathrm{O}$ in a dilution protocol 18. Briefly, 60 min. after intraperitoneal administration of a bolus of ${ }^{3} \mathrm{H}_{2} \mathrm{O}(980 \mathrm{nCi} /$ $200 \mu \mathrm{ll}$, blood was sampled and centrifuged to obtain plasma. Radioactivity was counted on a Wallac 1414 Winspectral counter (Perkin Elmer, Brussels, B). After blood sampling, wet weights of paired gastrocnemius muscles and carcass (total body weight minus visceral organs, skin and tumour) were determined. Assuming the ratio of fat-free dry mass to total body water is $0.38{ }^{19}$ and ${ }^{2} \mathrm{H}_{2} \mathrm{O}$ dilution measurements to overestimate total body water in mice by $12 \% 18$, total body water was calculated as ${ }^{3} \mathrm{H}_{2} \mathrm{O}$ dilution space $\times(1-0.12)$; fat-free dry mass = total body water $\times$ 0.38; fat mass = carcass weight - (total body water + fat free dry mass) ${ }^{18}$. In tumour-bearing mice, fat free dry mass was corrected for tumour volume by subtracting tumour weight from fat free dry mass. Data are expressed per $10 \mathrm{~g}$ carcass weight, which was calculated by subtracting tumour weight from body weight including tumour. 
statistics |

Results are presented as means \pm SEM. Data were analyzed with SPSS ${ }^{20}$. To reduce the chance of false-positive significances, we only tested the effect of i) laparotomy in control mice, ii) the presence of tumour per se, iii) laparotomy in tumour-bearing mice, using ANOVA. Significance was defined as $p<0.05$.

\section{results |}

body composition |

There were no significant differences between tumour-bearing and control mice in carcass weight (table one) or food intake (control $4.2 \pm 0.1$; tumour $4.1 \pm 0.2 \mathrm{~g}$ / day).

Control mice had a fat mass of $5.4 \pm 0.6 \mathrm{~g}$ and dry fat free mass of $6.0 \pm 0.2 \mathrm{~g}$ (figure one A, B). Body composition of tumour-bearing mice was not significantly different with a fat mass of $4.0 \pm 1.3 \mathrm{~g}$ and fat free mass of $6.5 \pm 0.5 \mathrm{~g}$ and (figure one A, B). Surgery did not affect fat mass or dry fat free mass significantly in either group (figure one A, B). Carcass wet weights of tumour-bearing mice decreased significantly after laparotomy but not in controls (table one).

whole-body protein breakdown I

The presence of tumour increased whole-body total protein breakdown from $47 \pm$ 6 to $58 \pm 4 \mathrm{nmol} / 10 \mathrm{~g} / \mathrm{min}$ ( $\mathrm{p}<0.05$, figure two A) and myofibrillar protein breakdown from $0.70 \pm 0.04$ to $1.22 \pm 0.14 \mathrm{nmol} / 10 \mathrm{~g} / \mathrm{min}(p<0.05$, figure two $B)$. Laparotomy increased whole-body myofibrillar protein breakdown to a similar extent both in healthy mice (from $0.70 \pm 0.04$ to $0.98 \pm 0.12 \mathrm{nmol} / 10 \mathrm{~g} / \mathrm{min}, \mathrm{p}<0.05$ ) and in tumourbearing mice (from $1.22 \pm 0.14$ to $1.54 \pm 0.22 \mathrm{nmol} / 10 \mathrm{~g} / \mathrm{min}, \mathrm{p}=0.15$, figure two $B$ ) although the increase in the tumour-bearing group did not reach significance. Both in healthy and tumour-bearing mice, laparotomy did not affect whole-body total protein breakdown (figure two A).

organ protein breakdown |

Phenylalanine net balances across muscle, intestine, liver and kidney were not significantly different between groups (table two). Total organ protein breakdown in muscle, intestine, liver and kidney were not significantly affected by the presence of tumour or laparotomy (figure three A-D).

ubiquitin proteasome pathway |

In gastrocnemius muscle, slopes of calcium-dependent and proteasomal chymotryptic activity were not affected by the presence of tumour or laparotomy (figure four $A, B$ ). 

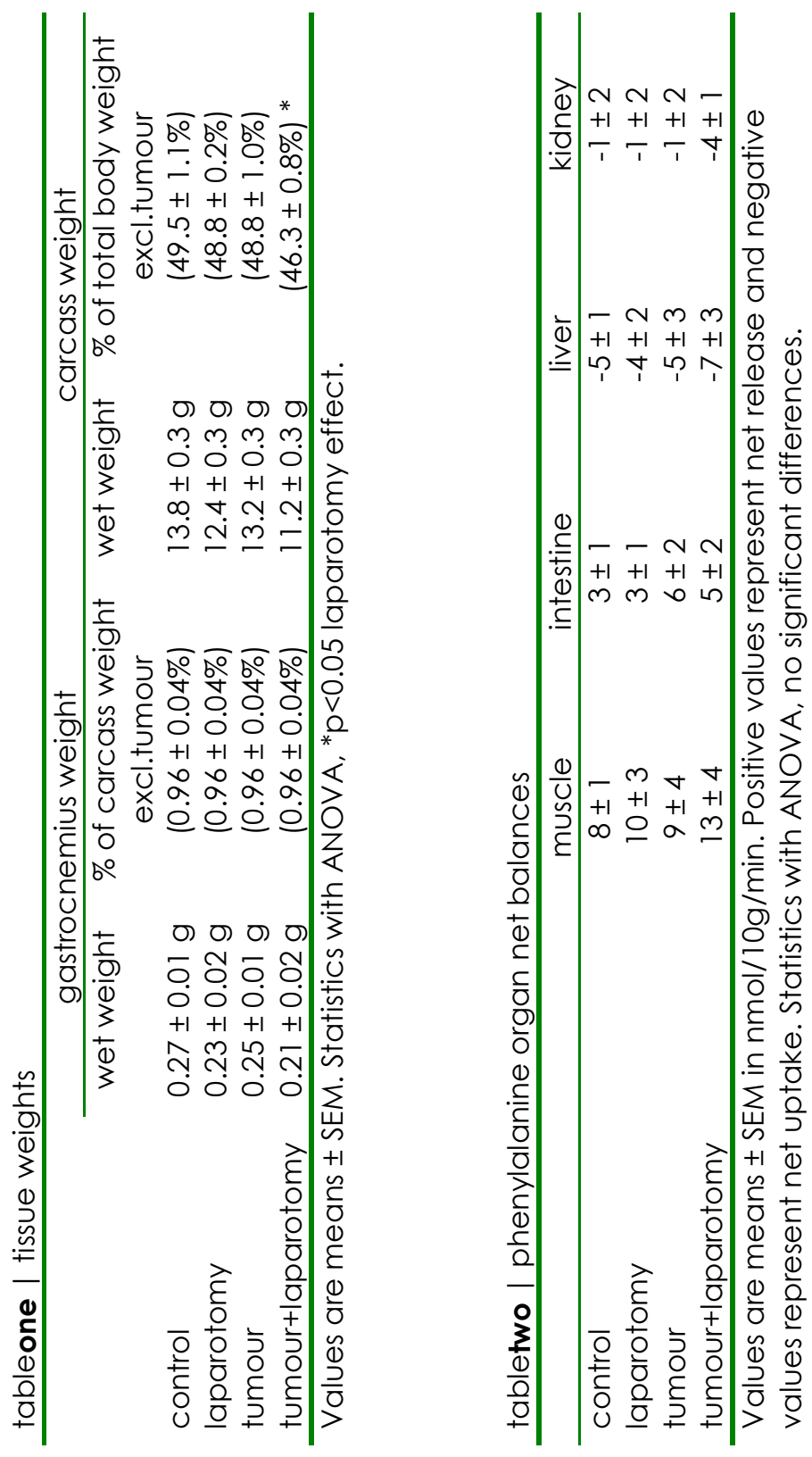
figureone | body composition
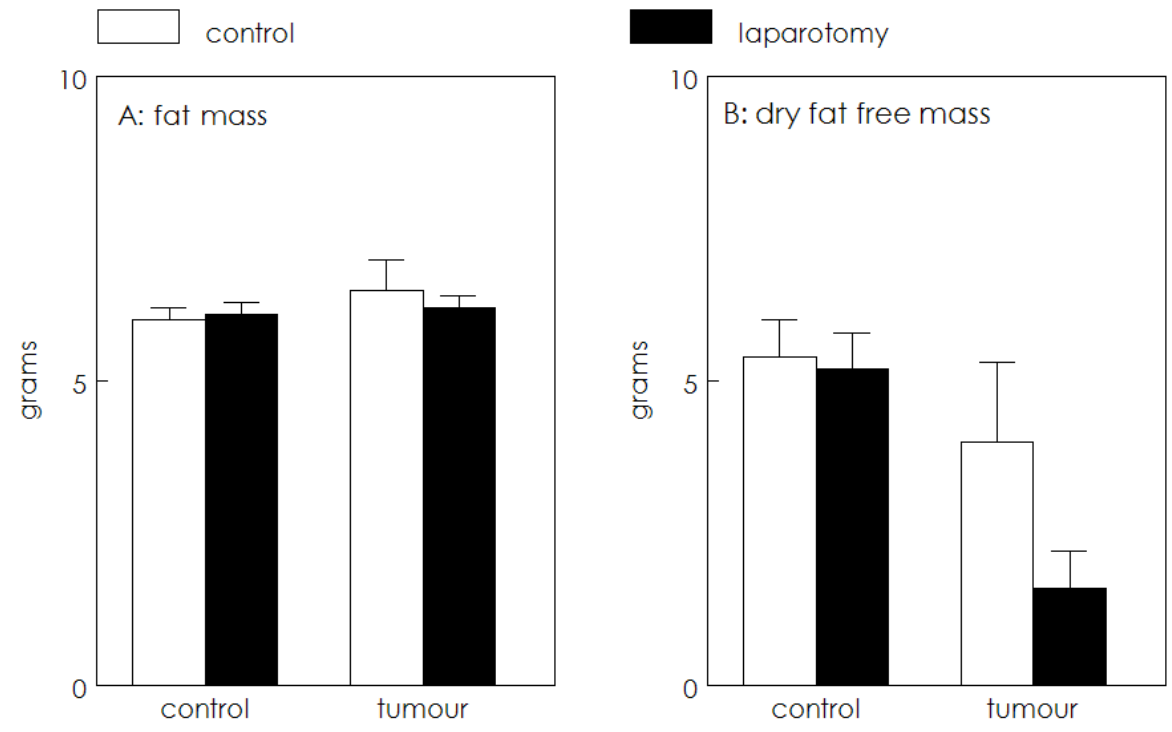

Values are means \pm SEM in grams. Statistics with ANOVA, no significant differences.

figuretwo | whole-body protein breakdown
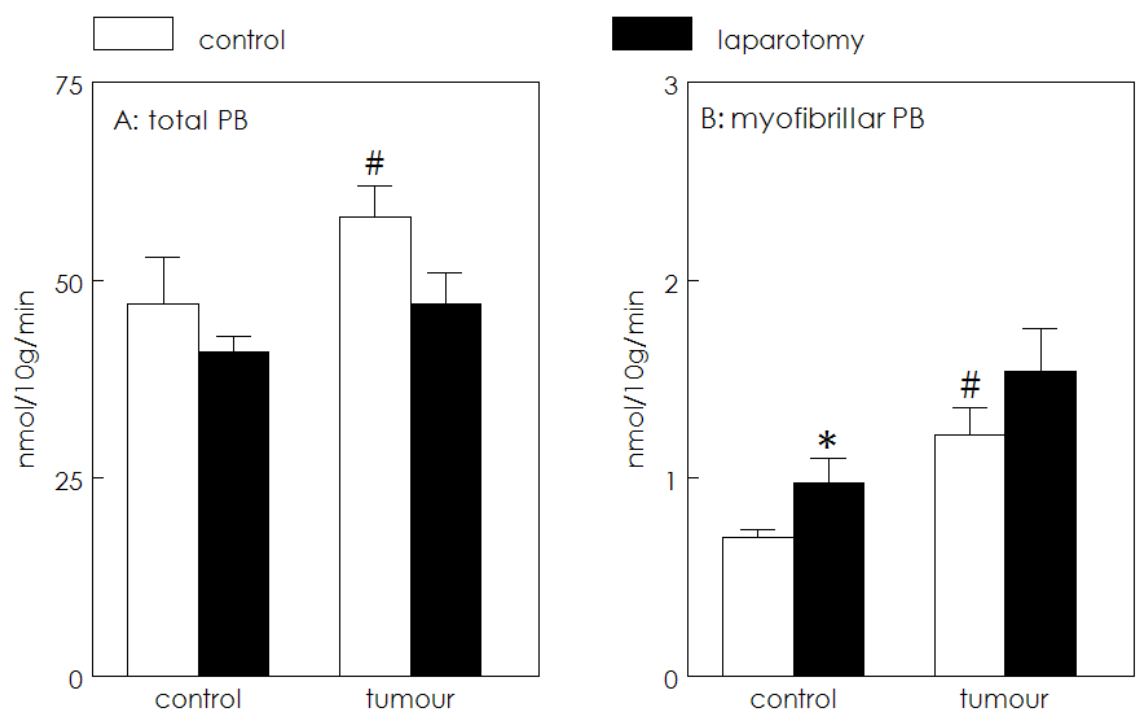

Values are means $\pm \mathrm{SEM}$ in $\mathrm{nmol} / 10 \mathrm{~g} / \mathrm{min}$. Statistics with ANOVA, $\# p<0.05$ tumour effect, " $p<0.05$ laparotomy effect. 
figurethree | organ total protein breakdown
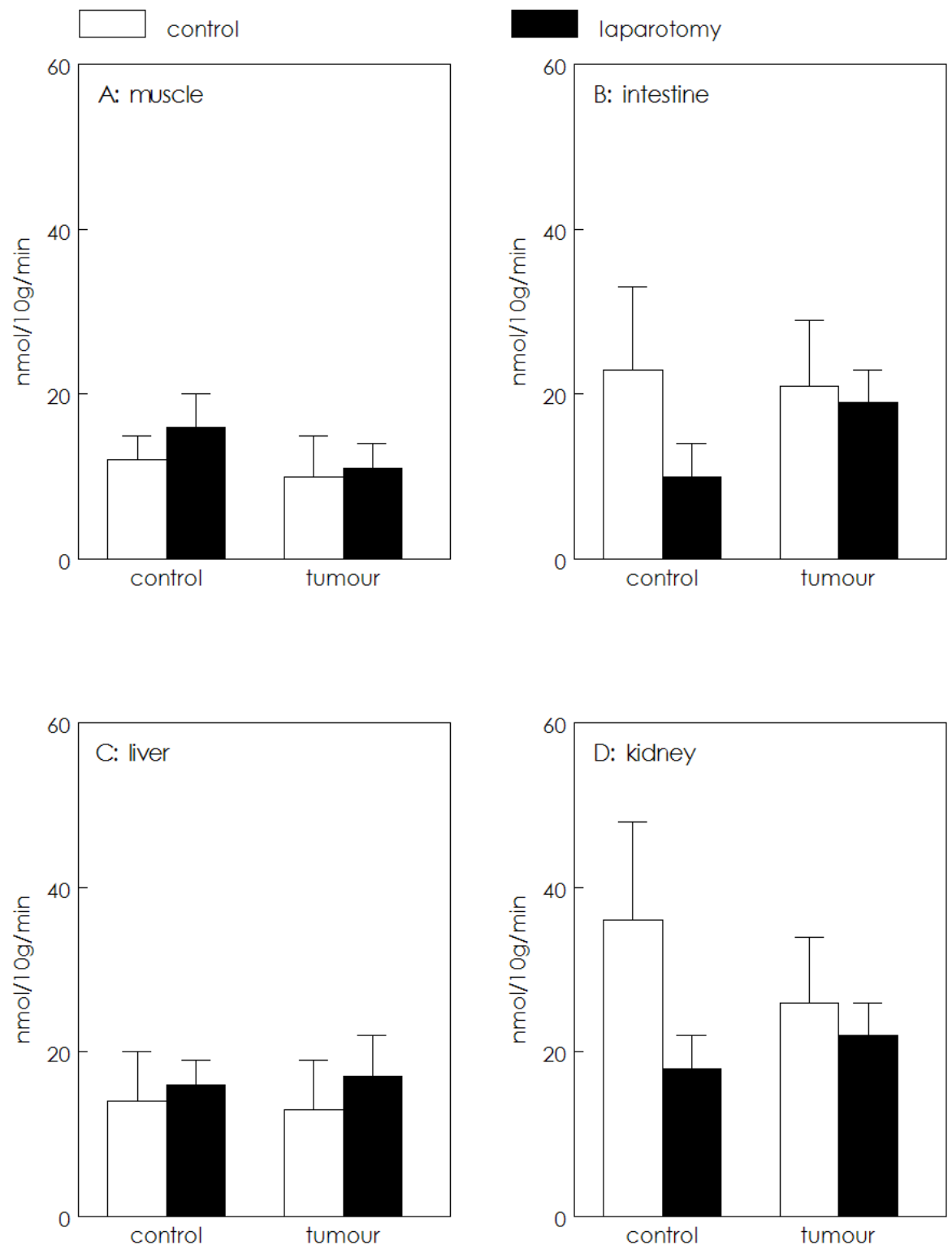

Values are means \pm SEM in $\mathrm{nmol} / 10 \mathrm{~g} / \mathrm{min}$. Statistics with ANOVA, no significant differences. 
figurefour | proteasomal activity
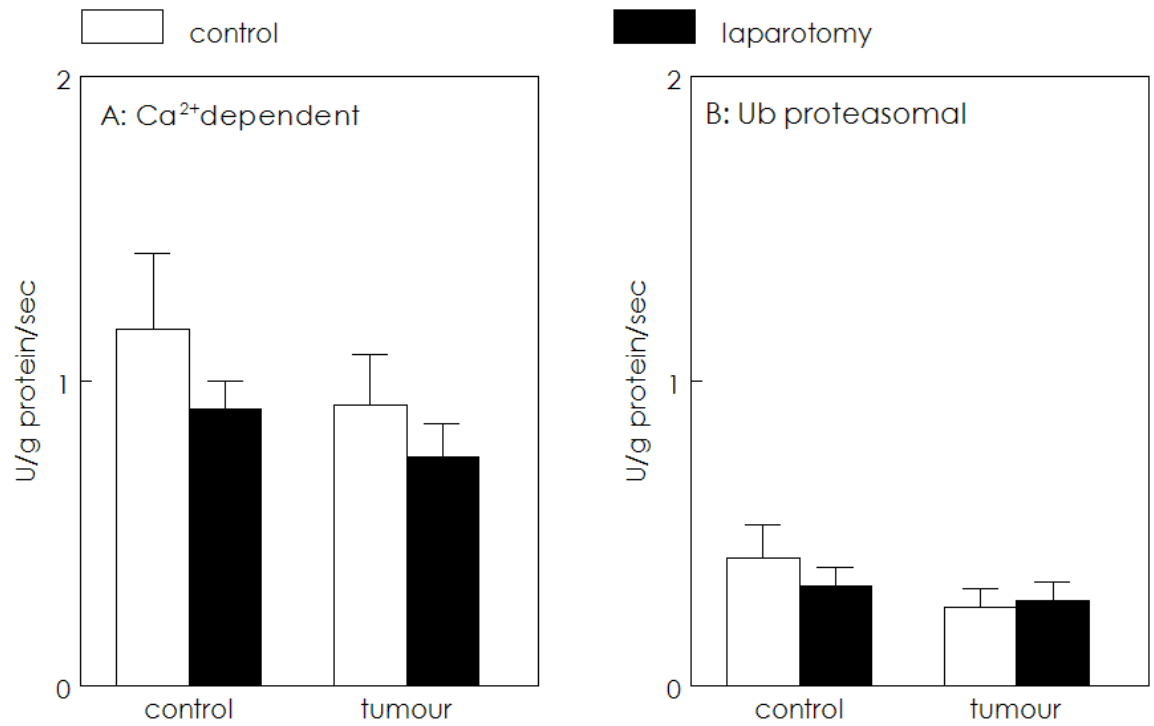

Values are means \pm SEM in units fluorescence/g protein/s. Statistics with ANOVA, no significant differences.

\section{discussion |}

In the present study we addressed the question how cancer related protein catabolism interferes with the changes in protein breakdown following surgical trauma. To do so we used a mouse model with extensive blood and tissue sampling, enabling us to get a global view on protein turnover. We demonstrated that tumour-bearing mice have increased rates of total and myofibrillar protein breakdown on whole-body level even before weight loss is obvious. These changes in protein metabolism in the presence of tumour did not change the postoperative response in protein breakdown as measured by total protein breakdown on wholebody and organ level, whole-body myofibrillar protein breakdown or proteasomal activity in gastrocnemius muscle.

A commonly used method to measure myofibrillar protein breakdown is quantitative collection of 3-methylhistidine in urine. However, this method is invalid in mice because it underestimates myofibrillar protein breakdown by about $50 \%$ in male and $70 \%$ in female mice due to metabolism and delayed excretion of 3methylhistidine ${ }^{21,22}$. This problem was overcome using a stable isotope protocol with $\mathrm{L}-3-\left[\right.$ methyl-$^{2} \mathrm{H}_{3}$ ] methylhistidine ${ }^{5}$, which allows for the measurement of wholebody myofibrillar protein breakdown. Myofibrillar proteins are present in skeletal muscle, intestine, skin, lungs and the vascular system. Using the tracer approach it is not possible to determine the origin of 3-methylhistidine. Unfortunately, we were not able to produce valid data for the 3-methylhistidine method on organ level 
to produce information on the contribution of various organs to total myofibrillar protein breakdown. This was probably due to the very low arteriovenous concentration differences of 3-methylhistidine ${ }^{23}$. Moreover, since turnover of muscle protein is relatively slow compared with protein from other organs such as liver and intestine, acute changes in actin-myosin protein breakdown may not be large enough to be picked up.

\section{effects of tumour I}

Myofibrillar protein breakdown mainly derives from skeletal muscle (high amounts of myofibrillar proteins) and from intestine (low amounts but high turnover of myofibrillar proteins) and to minor extent from skin ${ }^{24}$. In the current experiment the presence of tumour increased total and myofibrillar protein breakdown on wholebody level, without changes in total protein breakdown in muscle or intestine. This may indicate that other tissues have contributed significantly to whole-body protein breakdown, such as skin. Tumour tissue could also partly account for the increase in protein breakdown including myofibrillar protein breakdown, since MCA-induced tumours share characteristics of sarcoma, known to contain actin ${ }^{25}$. Therefore, measuring across the tumour would yield interesting data on protein metabolism in tumour-bearing hosts. In contrast to our data, a study in noncachectic cancer patients reported whole-body protein breakdown to be decreased compared with healthy individuals ${ }^{26}$. Apart from differences in species and tumours, we speculate that variations of protein turnover in time could also contribute to different results. However, both studies underline that metabolic changes in protein metabolism are present even without the phenotypic characteristics of cachexia. This warrants more studies examining pre-cachectic cancer, thus possibly providing insight in early disturbances in cancer that can give clues to underlying mechanisms of cachexia. The discrepancy between the two studies also illustrates the difficulties of animal studies when trying to compare the findings with those of human data. All animal models for cancer have the disadvantage that they do not display the exact characteristics of human tumours. First, for practical reasons, researchers usually select those tumour models that develop within a time period of several weeks, whereas human tumours usually develop over the course of many years. Second, most human tumours have a relative size of less than $0.5 \%$ of body weight, whereas most animal tumour models are studied at tumour sizes of $5-15 \%$ of body weight. However, animal models are still indispensable to achieve insight in the pathophysiology of cancer, since they allow measurements that are difficult to perform in humans for ethical reasons, such as measurements in muscle as performed in the current experiment. Moreover, animal models enable the use of specific blockers or supplemental interventions in follow up experiments to elucidate the contribution of specific factors and pathways.

Although both surgery and tumour induce changes in protein breakdown, the acute changes in protein turnover after surgical trauma are probably different from the chronic disturbances in protein metabolism in the presence of tumour. This may be related to involvement of specific proteolytic pathways in cancer. Three major proteolytic pathways are known to be involved in muscle catabolism: 
(i) the lysosomal system, which operates through cathepsins B, H, L and D; (ii) a calcium dependent system in the cytosol, in which calpains $\mu$ and $\mathrm{m}$ are involved; (iii) the ATP-dependent ubiquitin proteasome pathway. In the last years, the role of the ubiquitin proteasome pathway in cancer has received considerable attention. In animal models, up-regulation of ubiquitination ${ }^{27}$ and mRNA of various subunits of the proteasome ${ }^{28}$ and ubiquitin ${ }^{29}$ have been demonstrated. In cancer patients, proteasomal subunits were either upregulated ${ }^{30}$ or normal ${ }^{31}$. No increased proteasomal activity was observed in gastrocnemius muscles of our tumour-bearing mice, suggesting that the ubiquitin proteasomal pathway was not upregulated at the time of this experiment. This is compatible with two recent studies in mice and patients with cancer showing that activity of the ubiquitin proteasomal pathway probably follows a parabolic pattern with an initial rise and then a decline in proteasomal proteolysis with advanced weight loss ${ }^{32.33}$. Since ex vivo calcium dependent protein breakdown was not upregulated in our study, the observed increased myofibrillar protein breakdown may have resulted from increased activity of the lysosomal system. Cathepsins of the lysosomal system were indeed suggested to be involved in cancer-related proteolysis in patients with lung cancer ${ }^{31}$. Because cathepsins are probably not able to break down myofibrillar protein ${ }^{34}$, the lysosomal system may be important in early cancer for initiation of proteolysis, after which the ATP- dependent ubiquitin proteolytic pathway degrades structural proteins. The involvement of the lysosomal system may thus not be unlikely in the non-cachectic tumour model that we used in our study.

In addition, body composition was not affected by presence of tumour, although there was a non-significant decrease in fat mass in tumour-bearing animals. Gastrocnemius weights showed a similar pattern. Apparently, these parameters are only clearly affected in later stages of cachexia. However, because body composition and gastrocnemius weight were determined in separate groups of mice, the relation between these results and the results on protein breakdown must be interpreted with caution. Thus, in this mouse model of cancer without the cachectic syndrome, only myofibrillar protein breakdown and whole-body total protein breakdown were affected.

\section{effects of tumour on postoperative metabolism I}

Both control and tumour-bearing mice had increased myofibrillar protein breakdown rates after surgery. Although statistical analysis showed that this increase was significant in control mice whereas it was not in tumour-bearing mice, it is clear from figure two that postoperative increases were comparable in controls and in tumour-bearing mice. Furthermore, tumour-bearing mice had similar postoperative patterns in total protein breakdown, proteasomal activity and body composition as control mice undergoing surgery, indicating that there was no interaction between the presence of tumour and these aspects of the postoperative response either. This is in contrast with previous data from our group where in tumour-bearing rats an attenuated postoperative response in muscle and intestine was observed two days after hysterectomy 1,2. Still, surgery decreased carcass weight in tumour-bearing mice but not control mice, indicating that net 
protein breakdown was differently affected in these two groups. Since protein turnover is the result of breakdown and synthesis, this suggests that postoperative protein synthesis was relatively more decreased in tumour-bearing mice. This would fit with early observations of Lee et al. in hysterectomized rats that postoperative protein synthesis is affected to a greater extent than protein breakdown ${ }^{35}$.

The catabolic response to surgery has been suggested to have two phases: an early phase with mobilisation of protein from pools with a rapid turnover, such as gut and liver (visceral protein breakdown); and a later phase in which protein from pools with a slower turnover is mobilised, such as muscle (structural protein breakdown). The finding that myofibrillar protein breakdown was increased postoperatively suggests that the current experiments were performed during the late phase. Previous studies on postoperative protein breakdown in patients have reported contradicting results with decreased ${ }^{36}$, increased ${ }^{37}$ or unchanged ${ }^{38}$ rates after surgery, probably caused by variations in the extent of trauma and depending on the chosen time point (early or late postoperative phase) and method to quantify protein breakdown. These data warrant studies in time comparing postoperative protein metabolism of cancer patients with that of patients undergoing surgery for benign disease.

From the present experiment, it is not possible to deduct the specific effect of starvation, because all animals were fasted for the same time period to overcome confounding due to differences in food intake. Theoretically, $24 \mathrm{~h}$ starvation could interact with another metabolic stressor, such as surgery or the presence of tumour, in various ways. First, starvation could increase protein breakdown to supply the body with endogenous amino acid sources in the absence of protein from food. This would probably mainly have affected protein breakdown from visceral protein. If so, this may have influenced the current results by increasing total protein breakdown. Second, a possibility is that $24 \mathrm{~h}$ starvation could have depleted the body from its endogenous amino acid sources and thereby results in an attenuated response in protein breakdown after surgery.

In conclusion, tumour-bearing mice had increased rates of total and myofibrillar protein breakdown on whole-body level even before weight loss was obvious. These changes in protein metabolism in the presence of tumour did not change the postoperative response in protein breakdown.

\section{references |}

1. de Blaauw I, Deutz NEP, von Meyenfeldt MF. Cancer reduces the metabolic response of muscle to surgical stress in the rat. J Surg Res 1998;80(1):94-101.

2. de Blaauw I, Deutz NEP, Hulsewé KWE, von Meyenfeldt MF. Attenuated metabolic response to surgery in tumor-bearing rats. J Surg Res 2003;110(2):371-7.

3. Jeevanandam M, Horowitz GD, Lowry SF, Brennan MF. Cancer cachexia and protein metabolism. Lancet 1984;1(8392):1423-6.

4. Norton JA, Stein TP, Brennan MF. Whole body protein synthesis and turnover in normal man and malnourished patients with and without known cancer. Ann Surg $1981 ; 194(2): 123-8$. 
5. Vissers YLJ, von Meyenfeldt MF, Braulio VB, Luiking YC, Deutz NEP. Measuring actin-myosin protein breakdown in mice using a primed constant stable isotope infusion protocol. Clinical Science 2003;104(6):585-590.

6. Boyland $E$, Warren $F$. The induction of tumours by methylcholantrene in two strains of mice. J Path Bact 1937;45:171-177.

7. Lundholm K, Edstrom S, Ekman L, Karlberg I, Bylund AC, Schersten T. A comparative study of the influence of malignant tumor on host metabolism in mice and man: evaluation of an experimental model. Cancer 1978;42(2):45361.

8. Hallemeesch MM, ten Have GAM, Deutz NEP. Metabolic flux measurements across portal drained viscera, liver, kidney and hindquarter in mice. Lab Animals $2001 ; 35: 101-110$.

9. van Eijk HMH, Rooyakkers DR, Deutz NEP. Rapid routine determination of amino acids in plasma by high-performance liquid chromatography with a 2-3 $\mathrm{MM}$ Spherisorb ODS II column. J Chromatogr 1993;620:143-148.

10. van Eijk HM, Rooyakkers DR, Soeters PB, Deutz NEP. Determination of amino acid isotope enrichment using liquid chromatography-mass spectrometry. Anal Biochem 1999;271(1):8-17.

11. Wolfe RR. Radioactive and stable isotope tracers in biomedicine. Principles and practice of kinetic analysis. 1992; Wiley-Liss, Inc.(New York).

12. Hallemeesch MM, Soeters PB, Deutz NEP. Renal arginine and protein synthesis are increased during early endotoxemia in mice. Am J Physiol Renal Physiol 2002;282(2):F316-23.

13. Bruins MJ, Soeters PB, Deutz NEP. Endotoxemia affects organ protein metabolism differently during prolonged feeding in pigs. J Nutr 2000;130(12):3003-13.

14. Ruderman NB, Houghton CRS, Hems R. Evaluation of the isolated perfused rat hindquarter for the study of muscle metabolism. Biochem J 1971;124:639-651.

15. Orino E, Tanaka K, Tamura T, Sone S, Ogura T, Ichihara A. ATP-dependent reversible association of proteasomes with multiple protein components to form $26 \mathrm{~S}$ complexes that degrade ubiquitinated proteins in human HL-60 cells. FEBS Lett 1991;284(2):206-10.

16. Whitehouse AS, Smith HJ, Drake JL, Tisdale MJ. Mechanism of attenuation of skeletal muscle protein catabolism in cancer cachexia by eicosapentaenoic acid. Cancer Res 2001;61 (9):3604-9.

17. Bradford MM. A rapid and sensitive method for the quantitation of microgram quantities of protein utilizing the principle of protein-dye binding. Anal Biochem 1976;72:248-54.

18. McCabe BJ, Previs SF. Using isotope tracers to study metabolism: application in mouse models. Metabolic Engeneering 2004;6:25-35.

19. Dawson NJ, Stephenson SK, Fredline DK. Body composition of mice subjected to genetic selection for different body proportions. Comp Biochem Physiol $B$ 1972;42(4):679-91.

20. SPSS I. SPSS for Windows Version 11.0.1. 1 ed. Chicago: SPSS Inc. 2001.

21. Murray AJ, Nield MK, Jones LM, Galbraith N, Tomas FM. Metabolism of N taumethylhistidine by mice. Biochem J 1985;232(2):409-13. 
22. Harris Cl, Rucklidge GJ, McDiarmid RM, Milne G. Sex- and phenotype-dependent metabolism of $N$ tau-methylhistidine by mice. Biochem J 1986;239(1):229-32.

23. Lundholm K, Bennegard K, Eden E, Svaninger G, Emery PW, Rennie MJ. Efflux of 3-methylhistidine from the leg in cancer patients who experience weight loss. Cancer Res 1982;42(11):4807-11.

24. Rennie MJ, Millward DJ. 3-Methylhistidine excretion and the urinary 3methylhistidine/creatinine ratio are poor indicators of skeletal muscle protein breakdown. Clin Sci 1983;65(3):217-25.

25. Eyden B. The myofibroblast: a study of normal, reactive and neoplastic tissues, with an emphasis on ultrastructure. part 2 - tumours and tumour-like lesions. J Submicrosc Cytol Pathol 2005;37(3-4):231-96.

26. Melville S, McNurlan MA, Calder AG, Garlick PJ. Increased protein turnover despite normal energy metabolism and responses to feeding in patients with lung cancer. Cancer Res 1990;50(4):1125-31.

27. Lazarus DD, Destree AT, Mazzola LM, et al. A new model of cancer cachexia: contribution of the ubiquitin- proteasome pathway [In Process Citation]. Am J Physiol 1999;277(2 Pt 1):E332-41.

28. Temparis S, Asensi M, Taillandier D, et al. Increased ATP-ubiquitin-dependent proteolysis in skeletal muscles of tumor-bearing rats. Cancer Res 1994;54(21):556873.

29. Costelli P, Garcia-Martinez C, Llovera M, et al. Muscle protein waste in tumorbearing rats is effectively antagonized by a beta 2-adrenergic agonist (clenbuterol). Role of the ATP-ubiquitin- dependent proteolytic pathway. J Clin Invest 1995;95(5):2367-72.

30. Williams A, Sun X, Fischer JE, Hasselgren PO. The expression of genes in the ubiquitin-proteasome proteolytic pathway is increased in skeletal muscle from patients with cancer. Surgery 1999;126(4):744-9; discussion 749-50.

31. Jagoe RT, Redfern CP, Roberts RG, Gibson GJ, Goodship TH. Skeletal muscle mRNA levels for cathepsin B, but not components of the ubiquitin-proteasome pathway, are increased in patients with lung cancer referred for thoracotomy. Clin Sci (Lond) 2002;102(3):353-61.

32. Khal J, Hine AV, Fearon KC, Dejong $\mathrm{CH}$, Tisdale MJ. Increased expression of proteasome subunits in skeletal muscle of cancer patients with weight loss. Int $J$ Biochem Cell Biol 2005;37(10):2196-206.

33. Khal J, Wyke SM, Russell ST, Hine AV, Tisdale MJ. Expression of the ubiquitinproteasome pathway and muscle loss in experimental cancer cachexia. $\mathrm{Br} J$ Cancer 2005:93(7):774-80.

34. Lowell BB, Ruderman NB, Goodman MN. Evidence that lysosomes are not involved in the degradation of myofibrillar proteins in rat skeletal muscle. Biochem J 1986;234(1):237-40.

35. Lee VM, Hansen RJ, Wolfe BM, Clifford AJ. Muscle protein metabolism of rats in surgical trauma. JPEN 1988;12(5):445-51.

36. Carli F, Ramachandra V, Gandy J, et al. Effect of general anaesthesia on whole body protein turnover in patients undergoing elective surgery. $\mathrm{Br} \mathrm{J}$ Anaesth 1990;65(3):373-9. 
37. Clague MB, Keir MJ, Wright PD, Johnston ID. The effects of nutrition and trauma on whole-body protein metabolism in man. Clin Sci (Lond) 1983;65(2):165-75.

38. Waterlow JC, Golden J, Picou D. The measurements of rates of protein turnover, synthesis, and breakdown in man and the effects of nutritional status and surgical injury. Am J Clin Nutr 1977;30(8):1333-9. 



\section{cachecticmodel}

\section{partthree}




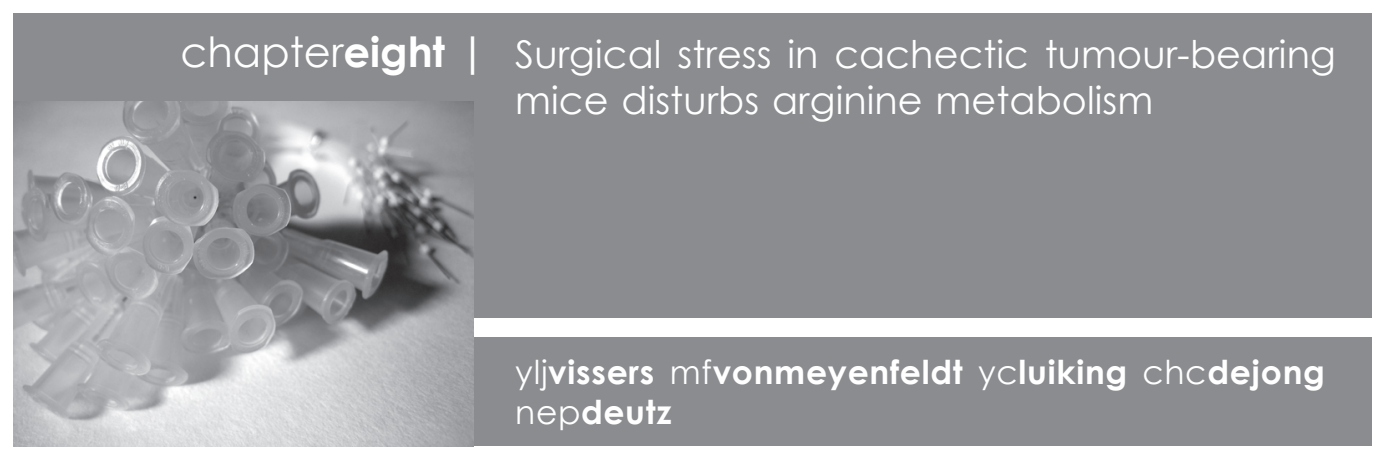

\section{introduction |}

We ${ }^{1}$ and others ${ }^{2}$ recently described that the presence of malignant tumours in patients is associated with decreased plasma arginine concentrations, suggesting that decreased arginine availability may be a specific feature of host metabolism in the presence of cancer. Furthermore, decreased arginine availability induced by arginase producing cells was previously shown to cause immune dysfunction in the microenvironment of tumours ${ }^{3}$, suggesting that maintenance of arginine levels is important for anti-tumour activity in vivo.

Since arginine also plays a role in several metabolic pathways in the postoperative period, pre-existent derangements in arginine metabolism may be related to poor postoperative recovery. First, since arginine is necessary for postoperative cytokine induction ${ }^{4}$ via activation of T-cells ${ }^{5}$, decreased availability of arginine could suppress the immune response after surgery. Second, because arginine is necessary for wound collagen deposition ${ }^{6}$ via conversion to proline, decreased availability of arginine could impair wound healing. Third, nitric oxide (NO), another product of arginine metabolism, is a cytotoxic molecule for bacterial pathogens ${ }^{7}$. Thus, insufficient quantities of $\mathrm{NO}$ could be related to infectious complications.

We hypothesized that subjects with cancer have a defective arginine metabolism in response to surgical trauma. Aim of the present study was therefore to investigate the postoperative response in arginine metabolism, both in normal and in tumourbearing mice. Apart from oral intake and protein breakdown, in vivo arginine production can derive from endogenous de novo production, involving intestinal conversion of glutamine (mainly derived from muscle) to citrulline, which is subsequently converted to arginine in the kidney ${ }^{8}$. Therefore, besides whole-body arginine production, the interorgan axis of de novo arginine production was studied. To monitor the magnitude of the immune response after surgery, the acute phase response was measured as plasma concentration of the acute phase reactant serum amyloid $\mathrm{P}$ component $(\mathrm{SAP})^{9}$, the mouse homologue of C-reactive protein (CRP) in humans.

For these studies, we used the MAC16 tumour model, which is thought to be a relevant model for human cancer as it induces weight loss at tumour burdens of less than $1 \%$ of the host weight ${ }^{10}$. Moreover, from these tumour-bearing mice a proteolysis inducing factor (PIF) has been isolated that induces catabolism when 
injected into healthy mice ". A similar molecule was also present in the urine of cachectic cancer patients, suggesting that the process of human cachexia can be validly studied using MAC16 mice.

\section{methods |}

animals |

NMRI/Bradford mice were bred at the Central Animal Facilities of Maastricht University. Mice were housed in standard cages and fed standard lab chow (Hope Pharms, Woerden, NL) and subjected to a standard 12 hour light-dark cycle. Room temperature was maintained at $22^{\circ} \mathrm{C}$. Water was provided ad libitum throughout the experiment. To control for possible effects of MAC 16 tumours on food intake, control mice were pair-fed.

Four groups of male mice of 20-23 grams were used ( $n=14$ per group): 1) controls; 2) controls undergoing laparotomy; 3) tumour-bearing mice; 4) tumour-bearing mice undergoing laparotomy. Experiments were approved by the Ethical Committee of Animal Research of Maastricht University.

tumour model |

Induction of murine adenocarcinomas (MAC) was originally performed by Haase et al. by repeated subcutaneous injections of 1,2-dimethylhydrazine, resulting in various colonic tumours ${ }^{12}$. In our laboratory, tumours were initially induced by subcutaneous injection of $10^{6}$ MAC 16 cells (a kind gift of professor MJ Tisdale, Aston University, Birmingham, UK) in mice in our laboratory. These tumours were maintained in vivo by serially transplanting tumour fragments of $1 \times 2 \mathrm{~mm}$ subcutaneously through a $15 \mathrm{G}$ needle. Control mice were sham implanted and pair-fed to tumour-bearing mice.

surgical trauma |

When tumour-bearing mice had lost $10 \%$ of body weight (about two weeks after tumour induction), laparotomy was performed as a model for surgical trauma. In short, ketamine/medetomidine anaesthesia, fluid and temperature control were performed as described previously ${ }^{13}$. A midline incision from the level of the superior iliac spines to the xyphoid process was made. Intestines were put aside and wrapped in wet gauze. Five minutes later, intestines were put back and the abdomen was closed with wound clips (Autoclip, Clay Adams, Becton Dickinson and Company, Parsippany, NJ, USA). After laparotomy, food was taken away from all groups to prevent differences due to variations in food intake. Drinking water was provided ad libitum.

metabolic measurements |

Twenty-four hours after laparotomy, ketamine/medetomidine anaesthesia and fluid and temperature maintenance were performed again, as described by Hallemeesch et al. ${ }^{13}$. A primed-constant infusion of the stable isotopes L-arginine [guanidino- $\left.{ }^{15} \mathrm{~N}_{2}-{ }^{2} \mathrm{H}_{2}\right]\left(\left[{ }^{5} \mathrm{~N}_{2}{ }^{2} \mathrm{H}_{2}\right] \mathrm{Arg}\right), \mathrm{L}$-citrulline [ureido-15 $\left.\mathrm{N}\right]\left(\left[{ }^{5} \mathrm{~N}\right] \mathrm{Cit}\right)$ and L-glutamine $\left[{ }^{15} \mathrm{~N}\right]\left(\left[{ }^{15} \mathrm{~N}\right] \mathrm{GIn}\right)$ (Mass Trace, Woburn, MA, USA) was given in the jugular vein (prime: 
$146 \mathrm{nmol} / 10 \mathrm{~g}\left[{ }^{15} \mathrm{~N}_{2}{ }^{2} \mathrm{H}_{2}\right] \mathrm{Arg}, 44 \mathrm{nmol} / 10 \mathrm{~g}\left[{ }^{15} \mathrm{~N}\right] \mathrm{Cit}, 584 \mathrm{nmol} / 10 \mathrm{~g}\left[{ }^{15} \mathrm{n}\right] \mathrm{Gln}$; infusion: $\left.960 \mathrm{nmol} / 10 \mathrm{~g} / \mathrm{h}\left[{ }^{15} \mathrm{~N}_{2}{ }^{2} \mathrm{H}_{2}\right] \mathrm{Arg}, 90 \mathrm{nmol} / 10 \mathrm{~g} / \mathrm{h}\left[{ }^{15} \mathrm{~N}\right] \mathrm{Cit}, 7574 \mathrm{nmol} / 10 \mathrm{~g} / \mathrm{h}\left[{ }^{15} \mathrm{n}\right] \mathrm{Gln}\right)$. Plasma flows across hindquarter, kidneys and portal drained viscera were measured using an indicator-dilution technique with [glycyl-1-14 $\mathrm{C}$ ]-p-aminohippuric acid $\left({ }^{14} \mathrm{C}-\mathrm{PAH}, \mathrm{NEN}\right.$ Life Science Products, Boston, MA, USA) as described in detail before ${ }^{13}$. Blood was collected from the carotid artery, inferior caval vein, portal vein and right renal vein, and deproteinized with sulfosalisylic acid and processed as described before ${ }^{13}$. At the end of the measurements, animals were killed by cervical dislocation while still anesthetized. Amino acid concentrations and tracer/ tracee ratios (TTR) were determined in plasma using HPLC and LC-MS as described by Van Eijk et al ${ }^{14,15}$.

serum amyloid $P$ |

Serum amyloid $P$ (SAP) concentrations in plasma were measured using a sandwich ELISA as described before ${ }^{16}$.

calculations |

Whole-body plasma amino acid fluxes (Q) were calculated from arterial isotope TTR values. TTR is an equivalent of specific activity. Therefore, equations were derived from metabolic studies using radioactive tracers, using steady state isotope dilution equation ${ }^{17}$ :

$$
Q=I / T T R
$$

where $\mathrm{I}$ is the rate of infusion of the stable isotope tracer. Correction for the contribution of lower isotopomers was performed as described by Wolfe ${ }^{17}$. Plasma arginine and citrulline fluxes were calculated from the arterial isotope TTR values of respectively $\left[{ }^{15} \mathrm{~N}_{2}{ }^{2} \mathrm{H}_{2}\right] \mathrm{Arg}$ and $\left[{ }^{15} \mathrm{~N}\right] \mathrm{Cit}$ as described recently ${ }^{18,19}$. Whole-body NO production was calculated as plasma arginine to citrulline flux ${ }^{18}$, based upon the fact that conversion of $\left[{ }^{15} \mathrm{~N}_{2}{ }^{2} \mathrm{H}_{2}\right] \mathrm{Arg}$ to $\left[{ }^{15} \mathrm{~N}\right] \mathrm{NO}$ yields stochiometric amounts of $\left[{ }^{15} \mathrm{~N}^{2} \mathrm{H}_{2}\right]$ Cit.

Hindquarter and gut plasma flows were calculated as arterial-venous dilutions of ${ }^{14} \mathrm{C}$-p-aminohippuric acid ${ }^{13}$. Renal plasma flow was calculated as extraction of ${ }^{14} \mathrm{C}$-p-aminohippuric acid ${ }^{13}$. Organ amino acid turnover was calculated in a twocompartment model ${ }^{17}$. Disposal (D) of an amino acid across the organ was calculated as:

$D=\left\{\right.$ plasma flow $\times\left(\left(\right.\right.$ conc $\left._{a} \times \operatorname{TTR}_{\mathrm{a}}\right)-\left(\right.$ conc $\left.\left.\left._{\mathrm{v}} \times \operatorname{TTR}_{\mathrm{v}}\right)\right)\right\} / \mathrm{TTR}_{\mathrm{v}}$

where conc $c_{a}$ and conc $c_{v}$ are the concentrations of a particular amino acid in arterial and venous plasma respectively; TTR $R_{a}$ and TTR are the TTR of the amino acid in the arterial plasma and venous plasma respectively.

Production $(\mathrm{P})$ of an amino acid across each organ was calculated as

$P=D-\left\{\right.$ plasma flow $\times\left(\right.$ conc $_{a}-$ conc $\left.\left._{v}\right)\right\}$.

Data are expressed per $10 \mathrm{~g}$ body weight.

statistics |

Results are presented as means \pm SEM. Data were analyzed with SPSS ${ }^{20}$. To reduce the chance of false-positive significances, we only tested the effect of i) laparotomy in control mice, ii) the presence of tumour per se, iii) laparotomy in tumour-bearing 
mice. Since data were not normally distributed, non-parametric Mann-Whitney U test was used. Significance was defined as $p<0.05$.

\section{results |}

whole-body |

Body weight of MAC16 mice decreased by $12 \pm 1 \%$ from $25.6 \pm 0.5$ to $22.5 \pm 0.5 \mathrm{~g}$ after tumour implantation $(\mathrm{p}<0.05)$, whereas body weight of mice without tumours did not change (from $25.1 \pm 0.6$ to $25.4 \pm 0.6 \mathrm{~g}$ ).

In the presence of tumour, concentrations of plasma citrulline, the direct precursor for de novo arginine synthesis, were decreased (table one). Both in controls and in tumour-bearing mice, citrulline concentrations were lower after laparotomy (table one). In tumour-bearing mice undergoing surgery, plasma arginine concentrations were lower than in all other groups (table one). Whole-body citrulline production in control mice undergoing surgery was slightly lower than in the other groups (table two). Despite the above mentioned changes in plasma concentrations, whole-body arginine and NO production were similar in all groups (table two).

SAP concentrations in control mice undergoing laparotomy were higher than in controls (table one). Furthermore, SAP concentrations in the presence of MACl6 were also higher than in controls. In MAC 16 mice undergoing laparotomy, SAP concentrations were not significantly different from MACl6 mice without surgical trauma (table one).

tableone | arterial plasma concentrations

\begin{tabular}{lcccc}
\hline & control & laparotomy & tumour & $\begin{array}{c}\text { tumour } \\
\text { tlaparotomy }\end{array}$ \\
\hline Arg & $105 \pm 6$ & $110 \pm 5$ & $98 \pm 4$ & $87 \pm 3^{*}$ \\
Cit & $86 \pm 4$ & $67 \pm 3^{*}$ & $76 \pm 4^{\#}$ & $63 \pm 4^{*}$ \\
Gin & $683 \pm 25$ & $617 \pm 17^{*}$ & $635 \pm 19$ & $624 \pm 34$ \\
SAP & $4 \pm 2$ & $167 \pm 41^{*}$ & $84 \pm 24^{\#}$ & $149 \pm 30$ \\
\hline
\end{tabular}

Valves are means \pm SEM; amino acids in $\mu \mathrm{mol} / \mathrm{l}$, SAP in $\mathrm{ng} / \mathrm{ml}$. Statistics with MannWhitney $U$ test, ${ }^{p}<<0.05$ tumour effect, $* p<0.05$ laparotomy effect.

\section{organs |}

Blood flow across hindquarter, intestine and kidneys was not significantly different between groups (table three). Hindquarter glutamine production, intestinal glutamine uptake and citrulline production were not different between control mice and control mice undergoing laparotomy (figure one A-C). Furthermore, the presence of MACl6 tumour did not change glutamine, citrulline or arginine fluxes across hindquarter or gut (figure one A-C, table three). Both in controls and in tumour-bearing mice, renal citrulline uptake and arginine production decreased after undergoing laparotomy (table two). 
tabletwo | stable isotope data

\begin{tabular}{|c|c|c|c|c|}
\hline & control & laparotomy & tumour & $\begin{array}{c}\text { tumour } \\
\text { +laparotomy }\end{array}$ \\
\hline \multicolumn{5}{|l|}{ whole-body } \\
\hline Arg production & $57 \pm 3$ & $55 \pm 2$ & $58 \pm 4$ & $53 \pm 2$ \\
\hline Cit production & $11 \pm 1$ & $9 \pm 1 *$ & $11 \pm 1$ & $10 \pm 1$ \\
\hline $\begin{array}{l}\text { NO production } \\
\text { kidney }\end{array}$ & $0.8 \pm 0.1$ & $0.8 \pm 0.1$ & $0.9 \pm 0.1$ & $0.9 \pm 0.1$ \\
\hline Cit disposal & $24 \pm 3$ & $13 \pm 2 *$ & $24 \pm 5$ & $13 \pm 3^{*}$ \\
\hline Arg production & $44 \pm 4$ & $28 \pm 1^{*}$ & $40 \pm 3$ & $30 \pm 3^{*}$ \\
\hline
\end{tabular}

Values are means \pm SEM in $\mathrm{nmol} / 10 \mathrm{~g} / \mathrm{min}$. Statistics with Mann-Whitney U test, ${ }^{*} \mathrm{p}<0.05$ laparotomy effect.

In MACl6 mice undergoing surgery, glutamine production from hindquarter (figure one A) and intestinal glutamine uptake was decreased (figure one B). Equally, intestinal citrulline production was lower than in all other groups (figure one C).

tablethree | organ plasma flows

\begin{tabular}{lcccc}
\hline control & laparotomy & tumour & $\begin{array}{c}\text { tumour } \\
\text { +laparotomy }\end{array}$ \\
\hline hindquarter & $0.75 \pm 0.18$ & $1.01 \pm 0.22$ & $0.63 \pm 0.11$ & $0.72 \pm 0.16$ \\
gut & $0.62 \pm 0.13$ & $0.61 \pm 0.12$ & $0.56 \pm 0.11$ & $0.43 \pm 0.10$ \\
kidney & $1.16 \pm 0.21$ & $0.83 \pm 0.07$ & $1.05 \pm 0.18$ & $0.91 \pm 0.12$ \\
\hline
\end{tabular}

Values are means \pm SEM in $\mathrm{ml} / 10 \mathrm{~g} / \mathrm{min}$. Statistics with Mann-Whitney $U$ test, no significant differences.

\section{discussion ।}

This study shows that cachectic MACl6 tumour-bearing mice undergoing surgery had decreased plasma arginine concentrations. Moreover, in contrast to healthy mice undergoing surgery, MAC 16 tumour-bearing mice had decreased muscular glutamine production and intestinal glutamine disposal and citrulline production postoperatively. Thus, cancer cachexia induced postoperative disturbances in intestinal metabolism that were related to the de novo arginine production pathway. At the same time, the postoperative increase in concentrations of the acute phase protein SAP was attenuated. The presence of MACl6 tumour by itself had remarkably little effect on arginine metabolism, despite evidence of an ongoing acute phase response and pronounced weight loss.

Surgical removal of the tumour is a common treatment for cancer. In contrast to healthy mice undergoing surgery, tumour-bearing mice had decreased plasma arginine concentrations postoperatively. Disturbances in arginine metabolism became apparent when surgical trauma and cancer concurred, which may be due to concurrence of two situations of increased conversion of arginine: 1) high 
figureone | organ citrulline and glutamine fluxes
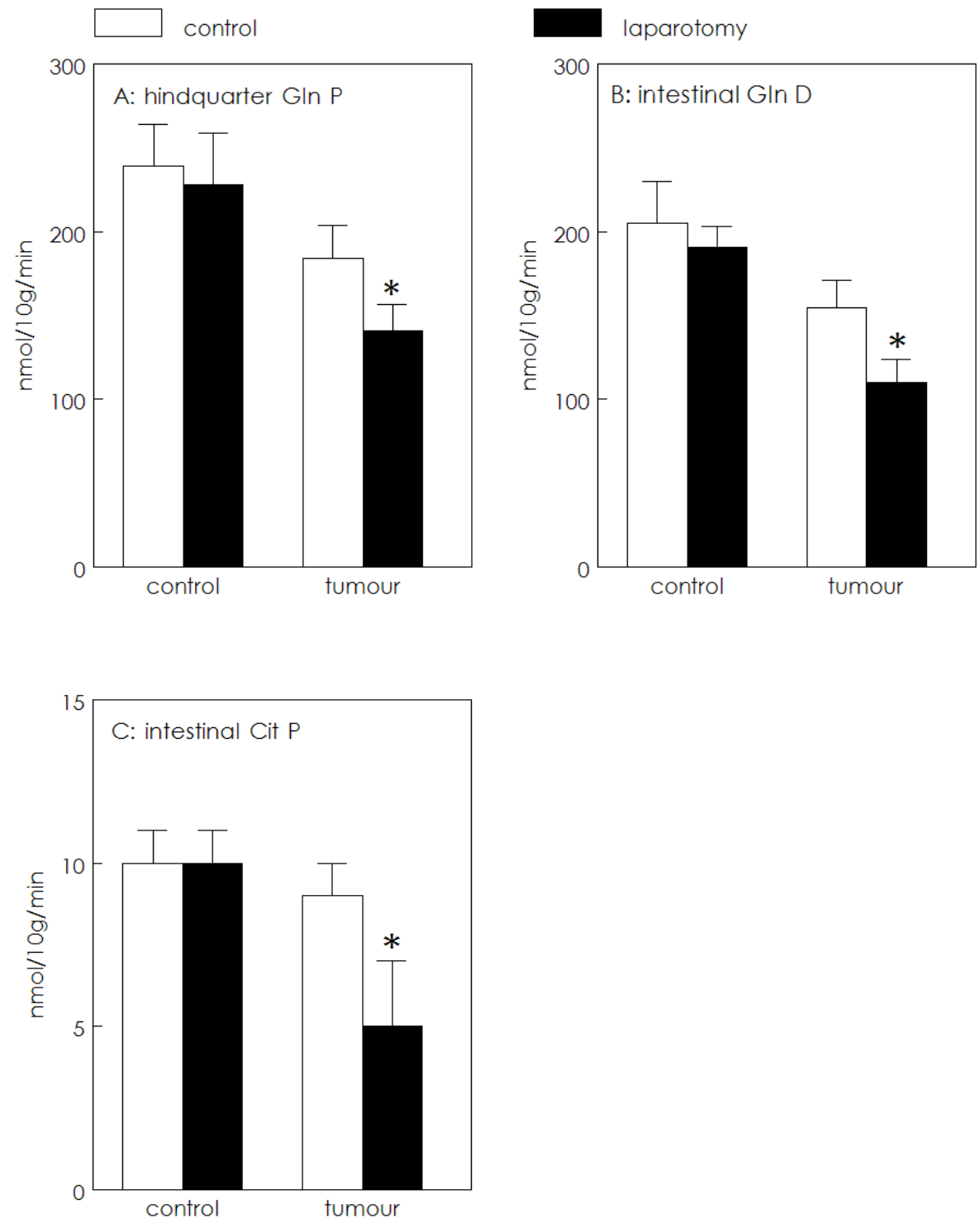

Values are means \pm SEM in $\mathrm{nmol} / 10 \mathrm{~g} / \mathrm{min}$. Statistics with Mann-Whitney U test, ${ }^{*} \mathrm{p}<0.05$ laparotomy effect. 
arginase activity after trauma ${ }^{21}$ and 2) high arginase activity in the microenvironment of tumours ${ }^{2}$. Hypothetically, this leaves less substrate for several pathways that rely on arginine as substrate in the postoperative period. NO is required for the cytotoxic effect of macrophages ${ }^{22}$ and arginine is necessary for a functional $\mathrm{T}$ cell response after trauma ${ }^{23}$. Besides, both arginine and its products $\mathrm{NO}$ and ornithine are indispensable for wound healing ${ }^{24}$. Therefore, disturbances in arginine metabolism could have consequences for the host response of cancer patients to surgical trauma.

Moreover, tumour-bearing mice did not develop a postoperative acute phase response of the same magnitude as healthy mice. In fact, whereas SAP concentrations rose by $163 \mathrm{ng} / \mathrm{ml}$ in normal mice, the increase in the presence of tumour was only $45 \mathrm{ng} / \mathrm{ml}$ (not significant) and may be indicative for an impaired response after surgery. Since an intact immune response is necessary for reparative processes after surgery, this may be unfavourable. An attenuated acute phase response was also reported in undernourished cancer patients undergoing surgery 25, suggesting that this phenomenon is also present in patients.

In a postabsorptive situation, arginine production is regulated by protein breakdown and endogenous de novo production. The latter comprises only a minor part of total arginine production ${ }^{26}$, but appears to play a role in regulation of arginine metabolism in disease ${ }^{18}$. Indeed, in the present study, de novo arginine production was disturbed in tumour-bearing mice undergoing surgery, whereas whole-body arginine production remained unaffected. This is in contrast with studies by Castillo where healthy volunteers did not show differences in de novo arginine production in response to arginine deficient diets ${ }^{27}$, but in line with a study where septic patients had decreased de novo arginine synthesis [Luiking YC, Steens L, Poeze $M$, et al: Low plasma arginine concentration in septic patients is related to diminished de novo arginine production from citrulline. Clin Nutr 2003; 22 (Suppl 1):S26]. De novo arginine production results from interplay between gut and kidneys, where citrulline, which is produced by the gut from glutamine, is taken up by the kidneys and converted to arginine. Since glutamine production is mainly derived from muscle, muscle may also take part in regulation of de novo arginine production. In cachectic tumour-bearing mice undergoing surgery, the muscle-gut axis appeared to play a central role in the postoperative metabolic aberrations in arginine metabolism.

In conclusion, the present study demonstrates that the cachexia inducing MAC 16 tumour induces disturbances in arginine metabolism after surgical trauma, with decreased plasma arginine concentrations and the inability to maintain muscular glutamine production and intestinal citrulline production. Hypothetically, these changes may compromise pathways in the postoperative period with arginine as substrate, for example wound collagen deposition and clearing of bacterial pathogens. If similar changes would occur in humans with cancer undergoing surgery this could have consequences for clinical practice. 


\section{references}

1. Vissers YLJ, Dejong CHC, Luiking YC, Fearon KCH, von Meyenfeldt MF, Deutz NEP. Plasma arginine concentrations are decreased in cancer: evidence for arginine deficiency? Am J Clin Nutr 2005;81(5):1142-6.

2. Zea $A H$, Rodriguez PC, Atkins MB, et al. Arginase-producing myeloid suppressor cells in renal cell carcinoma patients: a mechanism of tumour evasion. Cancer Res 2005;65(8):3044-8.

3. Rodriguez PC, Quiceno DG, Zabaleta J, et al. Arginase I production in the tumour microenvironment by mature myeloid cells inhibits T-cell receptor expression and antigen-specific T-cell responses. Cancer Res 2004;64(16):5839-49.

4. Reynolds JV, Daly JM, Shou J, Sigal R, Ziegler MM, Naji A. Immunologic effects of arginine supplementation in tumour-bearing and non-tumour-bearing hosts. Ann Surg 1990;211(2):202-10.

5. Daly JM, Reynolds J, Thom A, et al. Immune and metabolic effects of arginine in the surgical patient. Ann Surg 1988;208(4):512-23.

6. Seifter E, Rettura G, Barbul A, Levenson SM. Arginine: an essential amino acid for injured rats. Surgery 1978;84(2):224-30.

7. Hibbs JB, Jr., Taintor RR, Vavrin Z. Macrophage cytotoxicity: role for L-arginine deiminase and imino nitrogen oxidation to nitrite. Science 1987;235(4787):473-6.

8. Tizianello A, de Ferrari G, Caribotto G, Gurreri G. Renal metabolism of amino acids and ammonia in subjects with normal renal function and in patients with chronic renal insufficiency. J Clin Invest 1980;65:1162-1173.

9. Baltz ML, Dyck RF, Pepys MB. Studies of the in vivo synthesis and catabolism of serum amyloid P component (SAP) in the mouse. Clin Exp Immunol 1985;59(1):23542.

10. Tisdale MJ, Brennan RA. Metabolic substrate utilization by a tumour cell line which induces cachexia in vivo. Br J Cancer 1986;54(4):601-6.

11. Todorov PT, McDevitt TM, Cariuk P, Coles B, Deacon M, Tisdale MJ. Induction of muscle protein degradation and weight loss by a tumour product. Cancer Res 1996:56(6):1256-61.

12. Haase P, Cowen DM, Knowles JC, Cooper EH. Evaluation of dimethylhydrazine induced tumours in mice as a model system for colorectal cancer. $\mathrm{Br} \mathrm{J}$ Cancer $1973 ; 28(6): 530-43$.

13. Hallemeesch MM, ten Have GAM, Deutz NEP. Metabolic flux measurements across portal drained viscera, liver, kidney and hindquarter in mice. Lab Animals 2001;35:101-110.

14. van Eijk HMH, Rooyakkers DR, Deutz NEP. Rapid routine determination of amino acids in plasma by high-performance liquid chromatography with a 2-3 $\mathrm{MM}$ Spherisorb ODS II column. J Chromatogr 1993;620:143-148.

15. van Eijk HM, Rooyakkers DR, Soeters PB, Deutz NEP. Determination of amino acid isotope enrichment using liquid chromatography-mass spectrometry. Anal Biochem 1999;271(1):8-17.

16. Daemen MA, Heemskerk VH, van't Veer C, et al. Functional protection by acute phase proteins alpha(1)-acid glycoprotein and alpha(1)-antitrypsin against ischemia/reperfusion injury by preventing apoptosis and inflammation. Circulation 2000;102(12):1420-6. 
17. Wolfe RR. Radioactive and stable isotope tracers in biomedicine. Principles and practice of kinetic analysis. 1992; Wiley-Liss, Inc.(New York).

18. Hallemeesch MM, Soeters PB, Deutz NEP. Renal arginine and protein synthesis are increased during early endotoxemia in mice. Am J Physiol Renal Physiol 2002;282(2):F316-23.

19. Braulio VB, Ten Have GA, Vissers YL, Deutz NE. Time course of nitric oxide production after endotoxin challenge in mice. Am J Physiol Endocrinol Metab 2004;287(5):E912-8.

20. SPSS I. SPSS for Windows Version 11.0.1. 1 ed. Chicago: SPSS Inc. 2001.

21. Ochoa JB, Bernard AC, O'Brien WE, et al. Arginase I expression and activity in human mononuclear cells after injury. Ann Surg 2001;233(3):393-9.

22. Hibbs JB, Jr., Vavrin Z, Taintor RR. L-arginine is required for expression of the activated macrophage effector mechanism causing selective metabolic inhibition in target cells. J Immunol 1987;138(2):550-65.

23. Rodriguez PC, Zea AH, DeSalvo J, et al. L-Arginine Consumption by Macrophages Modulates the Expression of CD3zeta Chain in T Lymphocytes. J Immunol 2003;171 (3):1232-9.

24. Shi HP, Efron DT, Most D, Tantry US, Barbul A. Supplemental dietary arginine enhances wound healing in normal but not inducible nitric oxide synthase knockout mice. Surgery 2000;128(2):374-8.

25. Cruickshank AM, Hansell DT, Burns HJ, Shenkin A. Effect of nutritional status on acute phase protein response to elective surgery. Br J Surg 1989;76(2):165-8.

26. van de Poll MC, Soeters PB, Deutz NEP, Fearon KC, Dejong CHC. Renal metabolism of amino acids: its role in interorgan amino acid exchange. Am J Clin Nutr 2004;79(2):185-97.

27. Castillo L, Chapman TE, Sanchez M, et al. Plasma arginine and citrulline kinetics in adults given adequate and arginine-free diets. Proc Natl Acad Sci USA 1993:90:7749-7753. 


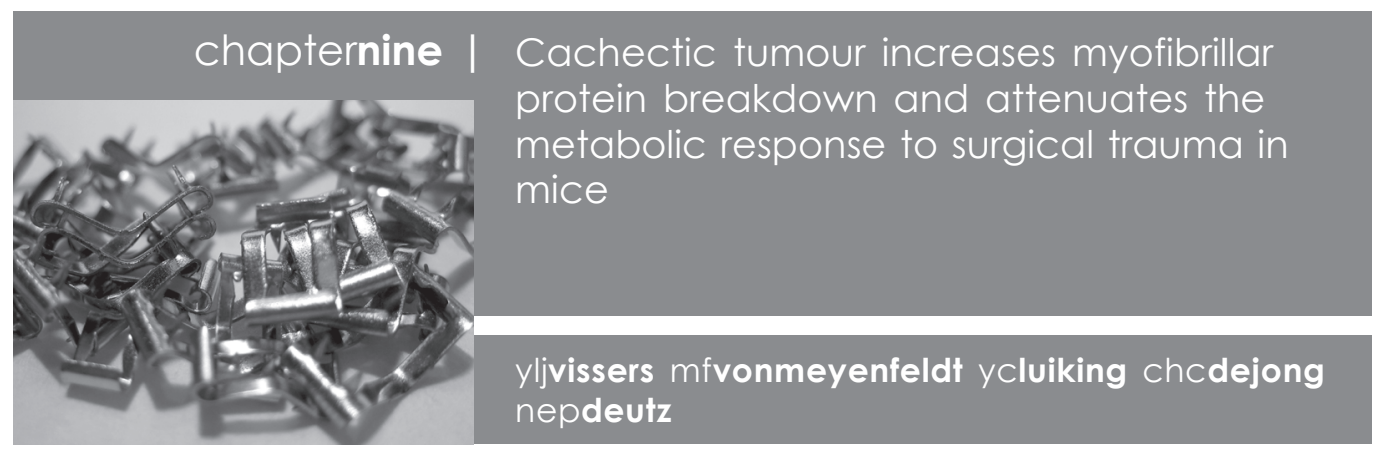

\section{introduction |}

Cancer is accompanied by changes in host metabolism often leading to cachexia, a syndrome characterized by loss of body fat and chronic protein wasting with loss of muscle mass. A common treatment for various types of cancer is surgical removal of the tumour. In contrast with the chronic protein wasting in cachexia, surgery induces an acute increase in protein synthesis and breakdown '. Postoperative breakdown of protein stores, mainly in muscle ${ }^{2}$ and intestine ${ }^{3}$, results in amino acid mobilization and is thereby thought to serve hepatic gluconeogenesis and acute phase protein synthesis, as well as protein synthesis at the wound site. Thus, enhanced postoperative protein breakdown appears to be necessary for normal recovery after surgery.

Cachectic cancer patients frequently have a poor postoperative recovery compared with non-cancer patients undergoing surgery, reflected in more postoperative complications ${ }^{4,5}$ and higher mortality ${ }^{6,7}$. Apparently, the host's response to surgery in cachectic patients is different from the response of healthy subjects undergoing surgery. This may well be related to an inability to mobilize amino acids in the postoperative period due to a chronic exhaustion of muscle as present in cachexia.

Therefore, the aims of the present study were to investigate 1) whether the presence of cancer cachexia leads to an impaired postoperative mobilization of protein and 2) which organs are responsible for this impaired response. Since whole-body protein turnover reflects the sum of many tissues, whole-body protein turnover measurements do not effectively provide information on protein metabolism of specific organs. Therefore, we used a mouse model to study how cancer cachexia affects protein breakdown on the whole-body level and in muscle. In addition, this model allowed the assessment of the contribution of other organs to wholebody protein breakdown, such as intestine, liver and kidneys. A recently developed stable isotope technique to measure myofibrillar protein breakdown rates in plasma was used ${ }^{8}$ to discern structural myofibrillar protein breakdown from total protein breakdown. 


\section{methods |}

animals |

NMRI/Bradford mice were bred at the Central Animal Facilities of Maastricht University. Mice were fed standard lab chow (Hope Pharms, Woerden, NL) and subjected to a standard 12 hour light-dark cycle. Room temperature was maintained at $22^{\circ} \mathrm{C}$. Water was provided ad libitum throughout the experiment. Male mice of 20-23 grams were randomized into four groups: 1) control; 2) control undergoing laparotomy; 3) tumour-bearing; 4) tumour-bearing undergoing laparotomy ( $n=14$ per group). Experiments were approved by the Ethical Committee of Animal Research of Maastricht University.

tumour model |

Induction of murine adenocarcinomas (MAC) was originally performed by Haase et al. by repeated subcutaneous injections of 1,2-dimethylhydrazine, resulting in various colonic tumours ${ }^{9}$. From these tumours, MAC 16 was serially transplanted subcutaneously and has been used as an experimental model for cancer because it shares several characteristics with human tumours ${ }^{10,11}$. In our laboratory, tumours were initially induced in mice by subcutaneous injection of $10^{6} \mathrm{MAC} 16$ cells (a kind gift of professor MJ Tisdale, Aston University, Birmingham, UK). These tumours were maintained in vivo by serially transplanting tumour fragments of $1 \times 2 \mathrm{~mm}$ through a $15 \mathrm{G}$ needle. Control mice were sham implanted and pair-fed to tumour-bearing mice.

\section{surgical trauma |}

When tumour-bearing mice had lost about $10 \%$ of body weight, laparotomy was performed as a model for surgical trauma. In short, ketamine/medetomidine anaesthesia, fluid and temperature control were performed as described previously ${ }^{12}$. A midline incision from the level of the superior iliac spines until the xyphoid process was made. Intestines were put aside and wrapped in wet gauze. Five minutes later, intestines were put back and the abdomen was closed with wound clips (Autoclip, Clay Adams, Becton Dickinson and Company, Parsippany, NJ, USA). After laparotomy, food was taken away from all groups to prevent differences due to variations in food intake. Drinking water was provided ad libitum.

metabolic measurements |

Twenty-four hours after laparotomy, under controlled anaesthetic conditions ${ }^{12}$, a primed-constant infusion of the stable isotopes L-3-methyl [(tau)- $\left.{ }^{2} \mathrm{H}_{3}\right]$ histidine $\left(\left[{ }^{2} \mathrm{H}_{3}\right] 3 \mathrm{mH}\right.$ is) and L-phenylalanine [phenyl-2 $\left.\mathrm{H}_{5}\right]\left(\left[{ }^{2} \mathrm{H}_{5}\right] \mathrm{Phe}\right)$ (Mass Trace, Woburn, MA, USA) was given in the jugular vein (prime: $12 \mathrm{nmol} / 10 \mathrm{~g}\left[{ }^{2} \mathrm{H}_{3}\right] 3 \mathrm{mHis}, 117 \mathrm{nmol} / 10 \mathrm{~g}$ $\left[{ }^{2} \mathrm{H}_{5}\right]$ Phe; infusion: $10 \mathrm{nmol} / 10 \mathrm{~g} / \mathrm{h}\left[{ }^{2} \mathrm{H}_{3}\right] 3 \mathrm{mHis}, 600 \mathrm{nmol} / 10 \mathrm{~g} / \mathrm{h}\left[{ }^{2} \mathrm{H}_{5}\right]$ Phe). This stable isotope protocol yields tracer-tracee steady state in plasma within 30 minutes (not shown). Plasma flows across hindquarter, kidney, portal drained viscera and liver were measured using an indicator-dilution technique with [glycyl-1-14C]-paminohippuric acid ( ${ }^{14} \mathrm{C}-\mathrm{PAH}, \mathrm{NEN}$ Life Science Products, Boston, MA, USA) as described in detail before ${ }^{12}$. Blood was collected from the carotid artery, inferior 
caval vein, portal vein, hepatic vein and right renal vein, and deproteinized and further processed as described before ${ }^{12}$. Amino acid concentrations and tracer/ tracee ratios (TTR) were determined in sulfosalisylic acid deproteinized plasma using HPLC and LC-MS as described by Van Eijk et al ${ }^{13,14}$.

\section{calculations |}

Whole-body plasma amino acid fluxes (Q) were calculated from arterial isotope tracer-tracee (TTR) values. TTR is an equivalent of specific activity. Therefore, equations were derived from metabolic studies using radioactive tracers, using steady state isotope dilution equation ${ }^{15}$ :

$$
Q=\mathrm{I} / \mathrm{TTR} \text {, }
$$

where $\mathrm{I}$ is the rate of infusion of the stable isotope tracer. Correction for the contribution of lower isotopomers was performed as described by Wolfe ${ }^{15}$. Protein breakdown was assessed as plasma phenylalanine flux, calculated from the arterial isotope TTR values of the $\left[{ }^{2} \mathrm{H}_{5}\right]$ Phe isotope as detailed previously ${ }^{16}$. Myofibrillar protein breakdown was assessed as plasma 3-methylhistidine flux, calculated from the arterial isotope TTR values of the $\left[{ }^{2} \mathrm{H}_{3}\right] \mathrm{mH}$ is isotope as described recently ${ }^{8}$. Hindquarter, gut and liver plasma flows were calculated as arterial-venous dilutions of ${ }^{14} \mathrm{C}$-p-aminohippuric acid, renal plasma flow was calculated as extraction of ${ }^{14} \mathrm{C}$ - $\mathrm{p}$-aminohippuric acid ${ }^{12}$. Organ protein breakdown was calculated in a twocompartment model ${ }^{15}$ as phenylalanine production, calculated from the respective arterial and venous (inferior caval vein for hindquarter, portal vein for intestine, hepatic vein for liver, renal vein for kidney) TTR values of the $\left[{ }^{2} \mathrm{H}_{5}\right]$ Phe isotope ${ }^{17}$. Phenylalanine production (P) across the organ (a measure of protein breakdown) was calculated as

$$
P=D-\left\{\text { plasma flow } \times\left(\text { conc }_{a}-\text { conc }_{v}\right)\right\},
$$

where conc $c_{a}$ and conc are the concentrations of phenylalanine in arterial and venous plasma respectively and where disposal (D) of phenylalanine across the organ was calculated as:

$$
\mathrm{D}=\left\{\text { plasma flow } \times\left(\left(\text { conc }_{\mathrm{a}} \times \mathrm{TTR}_{\mathrm{a}}\right)-\left(\text { conc }_{v} \times \operatorname{TTR}_{\mathrm{v}}\right)\right)\right\} / \mathrm{TTR}_{\mathrm{v}}
$$

and where TTR ${ }_{a}$ and TTR are the TTR of phenylalanine in the arterial plasma and venous plasma respectively.

Data are expressed per $10 \mathrm{~g}$ body weight.

\section{statistics |}

Results are presented as means \pm SEM. Data were analyzed with SPSS ${ }^{18}$. To reduce the chance of false-positive significances, we only tested the effect of i) laparotomy in control mice, ii) the presence of tumour per se, iii) laparotomy in tumour-bearing mice. Since data were not normally distributed, non-parametric Mann-Whitney $U$ test was used. Significance was defined as $p<0.05$.

\section{results |}

effect of tumour I

MAC 16 mice had lost $11 \pm 1 \%$ of their initial body weight after tumour implantation, whereas control mice without tumour had gained $1 \pm 2 \%$ body weight $(p<0.05)$. 
On whole-body level, myofibrillar protein breakdown was higher in tumour-bearing mice than in controls (figure one A), without changes in whole-body total protein breakdown (table one).

figureone | myofibrillar and muscle protein breakdown
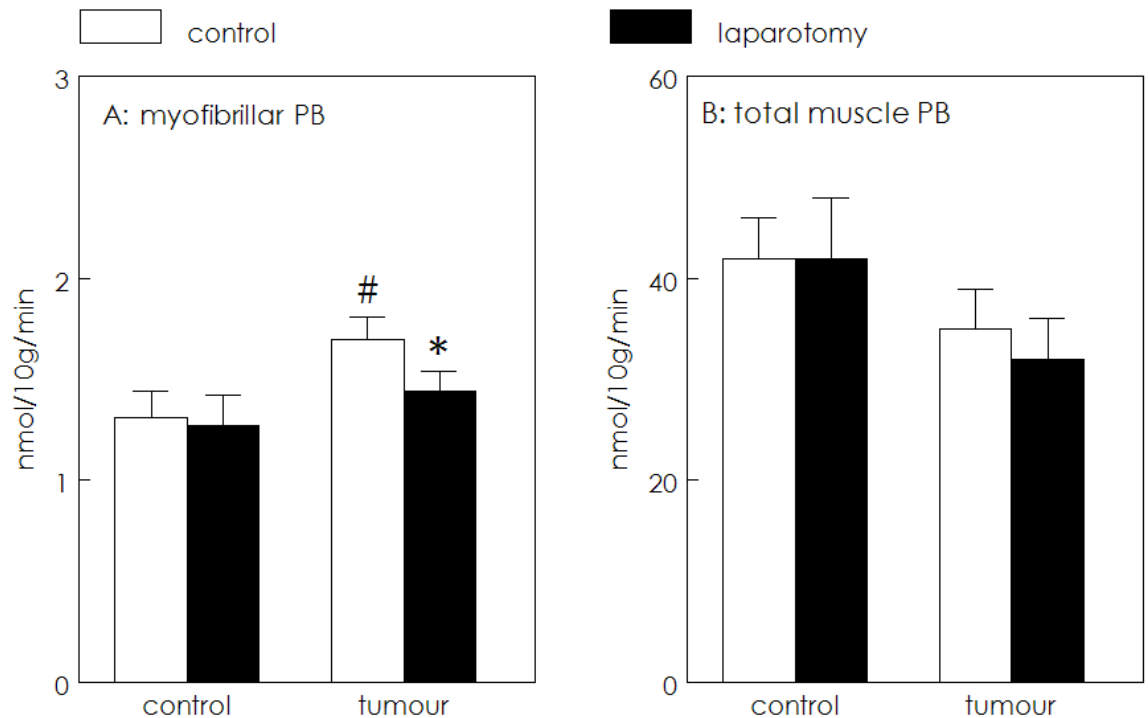

Values are means \pm SEM in $\mathrm{nmol} / 10 \mathrm{~g} / \mathrm{min}$. Statistics with Mann-Whitney $U$ test, \# $p<0.05$ tumour effect, $* p<0.05$ laparotomy effect.

On organ level, protein breakdown in muscle was not affected by the presence of tumour (figure one B). Besides, protein breakdown in intestine and kidney was not changed by the presence of tumour (table one). Only hepatic protein breakdown was significantly lower in tumour-bearing mice than in controls (table one).

tableone | total protein breakdown

\begin{tabular}{lcccc}
\hline & control & laparotomy & tumour & $\begin{array}{c}\text { tumour } \\
\text { +laparotomy }\end{array}$ \\
\hline whole-body & $48 \pm 2$ & $43 \pm 1^{*}$ & $50 \pm 2$ & $45 \pm 1^{*}$ \\
intestine & $20 \pm 3$ & $19 \pm 2$ & $17 \pm 3$ & $13 \pm 3$ \\
liver & $11 \pm 2$ & $6 \pm 2^{*}$ & $4 \pm 2 *$ & $12 \pm 2^{*}$ \\
kidneys & $21 \pm 2$ & $13 \pm 2^{*}$ & $20 \pm 3$ & $13 \pm 2^{*}$ \\
\hline
\end{tabular}

Values are means \pm SEM in $\mathrm{nmol} / 10 \mathrm{~g} / \mathrm{min}$. Statistics with Mann-Whitney $U$ test, \# $p<0.05$ tumour effect, $* p<0.05$ laparotomy effect. 


\section{effect of surgery |}

Both in control mice undergoing laparotomy and MAC 16 tumour mice undergoing laparotomy, whole-body total protein breakdown decreased (table one). In contrast, only in cachectic tumour-bearing mice undergoing surgery myofibrillar protein breakdown decreased (figure one).

On organ level, postoperative protein breakdown in muscle was not altered in control or tumour-bearing mice undergoing surgical trauma (figure one). Regarding other organs, changes in renal and intestinal protein breakdown after laparotomy were similar in tumour and non-tumour mice undergoing surgery (table one). In contrast to control mice, hepatic protein breakdown increased after surgery in tumour-bearing mice (table one).

\section{discussion |}

The present study was undertaken investigate the postoperative response in protein breakdown in cancer. Emphasis was put on the difference between myofibrillar protein breakdown and total protein breakdown, and the contribution of muscle and other organs. The data suggest that whole-body myofibrillar protein breakdown was increased in the presence of MACl6 tumour, whereas total protein breakdown was unaffected.

In control mice undergoing surgery, myofibrillar protein degradation remained unchanged but whole-body total protein breakdown rates decreased. This means that the relative contribution of myofibrillar protein breakdown to catabolism was increased postoperatively. In contrast, in tumour-bearing mice undergoing laparotomy, myofibrillar protein breakdown was decreased. We previously reported that fumour-bearing rats undergoing hysterectomy had suppressed postoperative protein breakdown in muscle ${ }^{2}$ and intestine ${ }^{3}$ compared with rats without tumour. Since gut and muscle are known to contribute to whole-body 3methylhistidine flux ${ }^{19}$, these data may represent a similar phenomenon as in the current study, namely attenuated catabolism of structural protein after surgical trauma in cancer. This attenuation of structural protein breakdown may appear beneficial in light of chronic wasting associated with cachexia, but could also have negative effects. Less myofibrillar protein breakdown in the postoperative period may imply less substrate for acute phase reactants due to less amino acid mobilization. Indeed, an attenuated response for the acute phase protein CRP was reported in undernourished cancer patients that underwent surgery ${ }^{20}$. Previous in vitro studies with the MACl6 model ${ }^{21-23}$, and in cancer patients ${ }^{24}$ showed that muscle protein breakdown depends on the amount of weight loss, suggesting that a phase-like pattern exists. This would support the idea that endogenous protein sources such as muscle become exhausted as cachexia proceeds ${ }^{25}$. Thus, MAC16 mice were possibly not able to respond normally to surgical trauma in relation with a decreased capacity to mobilize proteins.

In the present study we used the MACl6 tumour model, which is thought to be relevant for human cancer since the tumour induces weight loss at tumour burdens of less than $1 \%$ of the host's weight ${ }^{26}$. Moreover, from these tumour-bearing mice 
a proteolysis inducing factor (PIF) has been isolated that induces catabolism when injected into healthy mice ${ }^{27}$. A similar molecule was also found in the urine of cachectic cancer patients ", suggesting that the process of cachexia can be validly studied using the MAC 16 tumour model. In our study proteolysis in cachectic MAC 16 was mainly based upon loss of myofibrillar proteins. This is compatible with observations of us and others demonstrating involvement of the ubiquitindependent proteasomal system 24,28-30, which is thought to degrade structural muscle proteins preferentially. Previous studies using the MACl6 model reported higher protein degradation in muscle compared with controls but used in vitro techniques with isolated muscles ${ }^{28}{ }^{21}$ and may therefore inform on capacity rather than actual activity of proteolysis in vivo. To our knowledge this is the first in vivo study indicating that structural muscle proteins are degraded preferentially in cancer cachexia. Recently, cachexia due to COPD was also attributed to increased structural protein breakdown with unchanged total protein breakdown ${ }^{31}$.

In conclusion, increased protein breakdown in cachectic tumour bearing mice consisted of upregulated catabolism of structural myofibrillar proteins but without significant changes in total protein breakdown in muscle. Moreover, in the presence of cachexia there was an impaired response to surgery with respect to mobilization of myofibrillar protein. These in vivo results corroborate ex vivo studies from our department and others suggesting that structural myofibrillar proteins are degraded preferentially in the presence of cancer. Furthermore, 3methylhistidine data provide new evidence for an impaired response to surgery in cancer cachexia with respect to diminished mobilization of myofibrillar protein. This new model warrants patient studies investigating the relation between structural and total protein turnover specifically.

\section{references |}

1. Hill AG, Hill GL. Metabolic response to severe injury. Br J Surg 1998;85(7):884-90.

2. de Blaauw I, Deutz NEP, von Meyenfeldt MF. Cancer reduces the metabolic response of muscle to surgical stress in the rat. J Surg Res 1998;80(1):94-101.

3. de Blaauw I, Deutz NEP, Hulsewé KWE, von Meyenfeldt MF. Attenuated metabolic response to surgery in tumor-bearing rats. J Surg Res 2003;110(2):371-7.

4. Deslauriers J, Ginsberg RJ, Dubois P, Beaulieu M, Goldberg M, Piraux M. Current operative morbidity associated with elective surgical resection for lung cancer. Can J Surg 1989;32(5):335-9.

5. Busch E, Verazin G, Antkowiak JG, Driscoll D, Takita H. Pulmonary complications in patients undergoing thoracotomy for lung carcinoma. Chest 1994;105(3):7606.

6. Rey-Ferro M, Castano R, Orozco O, Serna A, Moreno A. Nutritional and immunologic evaluation of patients with gastric cancer before and after surgery. Nutrition 1997;13(10):878-81.

7. Grossmann EM, Longo WE, Virgo KS, et al. Morbidity and mortality of gastrectomy for cancer in Department of Veterans Affairs Medical Centers. Surgery 2002;131 (5):484-90. 
8. Vissers YLJ, von Meyenfeldt MF, Braulio VB, Luiking YC, Deutz NEP. Measuring actin-myosin protein breakdown in mice using a primed constant stable isotope infusion protocol. Clin Sci 2003;104(6):585-590.

9. Haase P, Cowen DM, Knowles JC, Cooper EH. Evaluation of dimethylhydrazine induced tumours in mice as a model system for colorectal cancer. $\mathrm{Br} \mathrm{J}$ Cancer $1973 ; 28(6): 530-43$.

10. Bibby MC, Double JA, Ali SA, Fearon KC, Brennan RA, Tisdale MJ. Characterization of a transplantable adenocarcinoma of the mouse colon producing cachexia in recipient animals. J Natl Cancer Inst 1987;78(3):539-46.

11. Todorov P, Cariuk P, McDevitt T, Coles B, Fearon K, Tisdale M. Characterization of a cancer cachectic factor. Nature 1996;379(6567):739-42.

12. Hallemeesch MM, ten Have GAM, Deutz NEP. Metabolic flux measurements across portal drained viscera, liver, kidney and hindquarter in mice. Lab Animals $2001 ; 35: 101-110$.

13. van Eijk HMH, Rooyakkers DR, Deutz NEP. Rapid routine determination of amino acids in plasma by high-performance liquid chromatography with a 2-3 $\mu \mathrm{M}$ Spherisorb ODS II column. J Chromatogr 1993;620:143-148.

14. van Eijk HM, Rooyakkers DR, Soeters PB, Deutz NEP. Determination of amino acid isotope enrichment using liquid chromatography-mass spectrometry. Anal Biochem 1999;271(1):8-17.

15. Wolfe RR. Radioactive and stable isotope tracers in biomedicine. Principles and practice of kinetic analysis. 1992; Wiley-Liss, Inc.(New York).

16. Hallemeesch MM, Soeters PB, Deutz NEP. Renal arginine and protein synthesis are increased during early endotoxemia in mice. Am J Physiol Renal Physiol 2002;282(2):F316-23.

17. Bruins MJ, Soeters PB, Deutz NEP. Endotoxemia affects organ protein metabolism differently during prolonged feeding in pigs. J Nutr 2000;130(12):3003-13.

18. SPSS I. SPSS for Windows Version 11.0.1. 1 ed. Chicago: SPSS Inc. 2001.

19. Millward DJ, Bates PC. 3-Methylhistidine turnover in the whole body, and the contribution of skeletal muscle and intestine to urinary 3-methylhistidine excretion in the adult rat. Biochem J 1983;214(2):607-15.

20. Cruickshank AM, Hansell DT, Burns HJ, Shenkin A. Effect of nutritional status on acute phase protein response to elective surgery. Br J Surg 1989;76(2):165-8.

21. Smith KL, Tisdale MJ. Increased protein degradation and decreased protein synthesis in skeletal muscle during cancer cachexia. Br J Cancer 1993;67(4):6805.

22. Beck SA, Tisdale MJ. Nitrogen excretion in cancer cachexia and its modification by a high fat diet in mice. Cancer Res 1989;49(14):3800-4.

23. Khal J, Wyke SM, Russell ST, Hine AV, Tisdale MJ. Expression of the ubiquitinproteasome pathway and muscle loss in experimental cancer cachexia. $\mathrm{Br} J$ Cancer 2005;93(7):774-80.

24. Khal J, Hine AV, Fearon KC, Dejong $\mathrm{CH}$, Tisdale MJ. Increased expression of proteasome subunits in skeletal muscle of cancer patients with weight loss. Int J Biochem Cell Biol 2005;37(10):2196-206. 
25. de Blaauw I, Heeneman S, Deutz NEP, von Meyenfeldt MF. Increased wholebody protein and glutamine turnover in advanced cancer is not matched by an increased muscle protein and glutamine turnover. J Surg Res 1997;68(1):4455.

26. Tisdale MJ, Brennan RA. Metabolic substrate utilization by a tumour cell line which induces cachexia in vivo. Br J Cancer 1986;54(4):601-6.

27. Todorov PT, MCDevitt TM, Cariuk P, Coles B, Deacon M, Tisdale MJ. Induction of muscle protein degradation and weight loss by a tumor product. Cancer Res 1996;56(6):1256-61.

28. Whitehouse AS, Smith HJ, Drake JL, Tisdale MJ. Mechanism of attenuation of skeletal muscle protein catabolism in cancer cachexia by eicosapentaenoic acid. Cancer Res 2001;61 (9):3604-9.

29. Whitehouse AS, Tisdale MJ. Increased expression of the ubiquitin-proteasome pathway in murine myotubes by proteolysis-inducing factor (PIF) is associated with activation of the transcription factor NF-kappaB. Br J Cancer 2003;89(6):111622.

30. De Jong $\mathrm{CH}$, Busquets $\mathrm{S}$, Moses $\mathrm{AG}$, et al. Systemic inflammation correlates with increased expression of skeletal muscle ubiquitin but not uncoupling proteins in cancer cachexia. Oncol Rep 2005;14(1):257-63.

31. Rutten EP, Franssen FM, Engelen MP, Wouters EF, Deutz NE, Schols AM. Greater whole-body myofibrillar protein breakdown in cachectic patients with chronic obstructive pulmonary disease. Am J Clin Nutr 2006;83(4):829-34. 
partthree | chapternine 



\section{summaryanddiscussion}

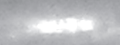

partfour 


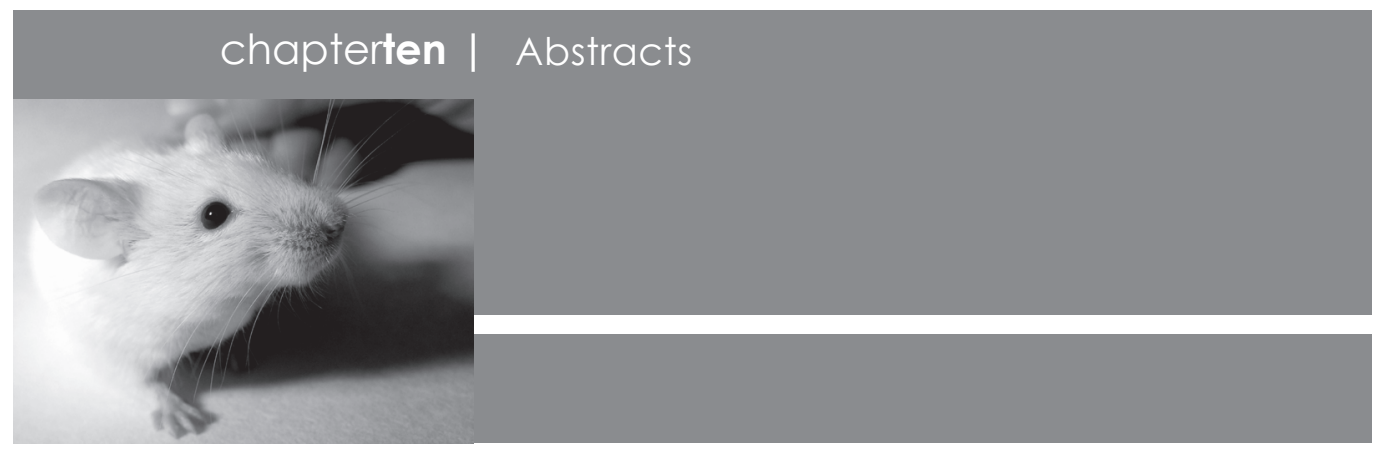

chapterone |

The amino acid arginine and one of its metabolites nitric oxide have gathered broad attention in the last decade. Although arginine is regarded as a conditionally essential amino acid in disease, L-arginine supplementation in has not found its way into clinical practice. This review will give an overview of knowledge of pathophysiological disturbances in arginine and $\mathrm{NO}$ metabolism in the presence of tumour. In addition, data from studies in healthy and diseased animals and patients with monotherapy of L-arginine with special emphasis on cancer and the postoperative period are discussed.

\section{chaptertwo |}

The disturbances leading to cancer cachexia still remain to be unravelled. There is preliminary evidence that arginine availability in cancer is decreased. However, no valid data are available on plasma arginine concentrations in cancer patients. To determine whether there is evidence for disturbed arginine metabolism in cancer, we measured plasma arginine concentrations in postabsorptive patients with various types of tumours, hypothesizing that arginine concentrations were decreased compared with age- and sex-matched controls.

Patients with localized tumours with a range of metabolic implications were studied: breast cancer (no weight loss), colonic cancer (sometimes weight loss) and pancreatic cancer (usually weight loss). Plasma amino acid concentrations were measured by HPLC.

Plasma arginine concentrations were specifically reduced in patients with cancer (breast cancer: $80 \pm 3$ vs.103 $19 \mu \mathrm{mol} / \mathrm{l}$; colonic cancer: $80 \pm 3$ vs. $96 \pm 7 \mu \mathrm{mol} / \mathrm{l}$; pancreatic cancer: $76 \pm 5$ vs. $99 \pm 7 \mu \mathrm{mol} / \mathrm{l} ; \mathrm{p}<0.05$ versus respective age- and sexmatched controls), irrespective of tumour type, weight loss, tumour stage or body mass index (correlations with $\mathrm{p}>0.05$ ).

In conclusion, malignant tumours associated with various degrees of metabolic derangements are all associated with decreased plasma arginine concentrations, even without weight loss being present. This suggests that decreased arginine availability is a specific feature of the presence of cancer. These disturbances in arginine metabolism could contribute to the cascade of metabolic events leading to cancer cachexia. 


\section{chapterthree |}

Animal models allow interorgan studies to gain insight in the metabolic changes in cancer when human studies are difficult to perform for ethical reasons. For the studies in this thesis, two mice models are used: i) methylcholantrene induced sarcoma, ii) murine adenocarcinoma series 16. For kinetic in vivo measurements, stable isotopes are applied in a multicatheter model in the mouse allowing calculation of organ fluxes across hindquarter, kidney, portal-drained viscera and liver simultaneously.

\section{chapterfour |}

To measure actin-myosin protein breakdown, the $24 \mathrm{~h}$ excretion of $\mathrm{N}^{\mathrm{o}}$-methylhistidine is used. However in mice, this method is invalid. Therefore, we developed a LC-MS technique to measure the tracer-tracee ratio and concentration of 3methylhistidine in plasma, enabling an in vivo primed-constant infusion protocol with a deuterated stable isotope of 3- methylhistidine.

We tested this model by giving a primed constant infusion of L-3methyl $\left[{ }^{2} \mathrm{H}_{3}\right.$ ] histidine, L-[phenyl- ${ }^{2} \mathrm{H}_{5}$ ] phenylalanine and $\mathrm{L}$-[phenyl- $\left.{ }^{2} \mathrm{H}_{2}\right]$ tyrosine to three anaesthetized experimental groups: 1) 2h postabsorptive mice (control), 2) $11 \mathrm{~h}$ starved mice (starvation) and 3) $11 \mathrm{~h}$ starved mice receiving lipopolysaccharide (LPS) intraperitoneally (starvation+LPS).

Contribution of myofibrillar to total protein breakdown was significantly lower after starvation than in controls (54 $\pm 0.14 \%$ vs. $0.30 \pm 0.04 \%$ resp., $p<0.05$ ), and was significantly higher starvation+LPS than after starvation only $10.52 \pm 0.07 \%$ vs. $0.30 \pm 0.04 \%$ resp., $p<0.05)$. Whole-body myofibrillar protein breakdown, wholebody total protein breakdown, whole-body protein synthesis and whole-body net protein breakdown were not different between the groups.

We conclude that this in vivo primed constant stable isotope infusion protocol can give valuable information about the role of actin-myosin protein breakdown in mice.

\section{chapterfive |}

We recently described that cancer patients have low plasma arginine concentrations, even without weight loss being present, suggesting that decreased arginine availability may be a specific feature of the presence of tumour. Since arginine is important in postoperative repair, we hypothesized that abnormalities in arginine metabolism in cancer lead to an aberrant postoperative response in arginine and nitric oxide (NO) metabolism. To investigate this, we studied postoperative alterations in arginine and $\mathrm{NO}$ production and the acute phase response in MCA sarcoma-bearing mice.

Controls, mice with small MCA tumours ( $<15 \%$ of carcass weight) and large MCA tumours (>15\% of carcass weight) were studied, either with or without undergoing laparotomy. The stable isotopes L-[guanidino- ${ }^{15} \mathrm{~N}_{2}-{ }^{2} \mathrm{H}_{2}$ ] arginine and L-[ureido${ }^{15} \mathrm{~N}$ ] citrulline were used to study whole-body arginine and $\mathrm{NO}$ production rates. Concentrations of serum amyloid P component (SAP) were measured to assess the acute-phase response. Significance was tested using Mann-Whitney U test. In healthy FVB mice, laparotomy significantly increased whole-body arginine 
production (from $42 \pm 3$ to $54 \pm 3 \mathrm{nmol} / 10 \mathrm{~g} / \mathrm{min}$ ), NO production (from $1.1 \pm 0.1$ to $1.4 \pm 0.2 \mathrm{nmol} / 10 \mathrm{~g} / \mathrm{min}$ ) and levels of serum amyloid $\mathrm{P}$ component (from $4 \pm 1$ to $115 \pm 23 \mathrm{ng} / \mathrm{ml}$ ), while in all MCA tumour-bearing mice baseline values of arginine metabolism and SAP concentrations were already elevated and the response to laparotomy was absent.

In conclusion, MCA tumour-bearing mice had a disturbed postoperative metabolic response as evidenced by attenuated postoperative arginine and NO production, concomittant with an attenuated acute phase response. This indicates that altered arginine metabolism may be a characteristic of the metabolic changes in cancer.

\section{chaptersix |}

Renal de novo arginine production has been suggested to be crucial for regulation of arginine production in disease. We investigated how the interorgan pathway for de novo arginine production is affected by the presence of malignant tumour and/or surgical trauma.

Controls and MCA sarcoma-bearing mice were studied, both with and without undergoing laparotomy. One day after laparotomy, amino acid fluxes across the hindquarter, intestine, liver and kidney were studied.

In contrast to healthy mice, the liver of tumour-bearing mice took up citrulline 19 \pm 3 vs. $1 \pm 2 \mathrm{nmol} / 10 \mathrm{~g} / \mathrm{min}, \mathrm{p}<0.05)$, simultaneous with attenuated renal arginine production ( $4 \pm 3$ vs. $12 \pm 2 \mathrm{nmol} / 10 \mathrm{~g} / \mathrm{min}, \mathrm{p}<0.05)$ despite increased intestinal conversion of glutamine to citrulline $(15 \pm 3$ vs. $8 \pm 1 \mathrm{nmol} / 10 \mathrm{~g} / \mathrm{min}, \mathrm{p}<0.05)$. In tumour-bearing mice undergoing surgery, intestinal citrulline production decreased (from $15 \pm 3$ to $8 \pm 2 \mathrm{nmol} / 10 \mathrm{~g} / \mathrm{min}, \mathrm{p}<0.05$ ) and renal arginine production remained close to zero despite increased renal citrulline uptake (from $6 \pm 2$ to $12 \pm 2 \mathrm{nmol}$ / $10 \mathrm{~g} / \mathrm{min}, \mathrm{p}<0.05$ ).

In conclusion, the interorgan pathway for de novo arginine production was differently regulated depending on the pathophysiological situation. In MCA sarcoma-bearing mice decreased de novo arginine production was accompanied by the presence of hepatic citrulline uptake, whereas tumour-bearing mice subjected to surgical trauma showed concomitant decreased intestinal citrulline production.

\section{chapterseven |}

Since both cancer and surgery are known to alter protein turnover, we investigated how the presence of tumour affects postoperative protein breakdown.

Controls and MCA sarcoma-bearing non-cachectic mice were studied, both with and without laparotomy. One day after laparotomy, stable isotopes of phenylalanine and 3-methylhistidine were used in a steady-state protocol to assess total protein breakdown on whole-body level and in muscle, intestines, liver and kidney, in addition to whole-body myofibrillar protein breakdown and body composition. Proteasomal chymotrypsin-like activity was measured to determine activity of the ATP-dependent ubiquitin pathway.

On whole-body level, the presence of tumour increased total protein breakdown from $47 \pm 6$ to $58 \pm 4 \mathrm{nmol} / 10 \mathrm{~g} / \mathrm{min}(\mathrm{p}<0.05)$ and myofibrillar protein breakdown from $0.70 \pm 0.04$ to $1.22 \pm 0.14 \mathrm{nmol} / 10 \mathrm{~g} / \mathrm{min}(\mathrm{p}<0.05)$ without affecting protein 
breakdown in organs, body composition or proteasomal activity. Laparotomy increased myofibrillar protein breakdown in controls (from $0.70 \pm 0.04$ to $0.98 \pm 0.12 \mathrm{nmol} / 10 \mathrm{~g} / \mathrm{min}, \mathrm{p}<0.05$ ) and MCA sarcoma-bearing mice (from $1.22 \pm$ 0.14 to $1.54 \pm 0.22 \mathrm{nmol} / 10 \mathrm{~g} / \mathrm{min}, \mathrm{p}=0.15)$ to a similar extent. Whole-body total protein breakdown, total protein breakdown across organs, body composition or proteasomal activity were not affected by laparotomy.

In conclusion, MCA sarcoma-bearing mice had increased total and myofibrillar protein breakdown on whole-body level even before weight loss was obvious. However, this did not affect the postoperative response in protein breakdown or body composition.

\section{chaptereight |}

We and others recently described that cancer patients have low plasma arginine concentrations. Apart from protein breakdown, arginine synthesis derives from de novo synthesis via glutamine-citrulline-arginine conversion in the gut-kidney axis. Since arginine is a substrate of several pathways that are active postoperatively, decreased arginine availability could lead to disturbances in arginine metabolism after surgery.

We studied cachectic MACl6 tumour-bearing mice and controls before and $24 \mathrm{~h}$ after laparotomy. Stable isotopes were used to measure whole-body arginine and nitric oxide (NO) synthesis, and arginine, citrulline and glutamine fluxes across hindquarter, gut and kidney. Plasma concentrations of serum amyloid protein (SAP) were measured to assess the acute-phase response.

MAC 16 mice had decreased plasma arginine levels after surgery $(-11 \pm 3 \%, p<0.05)$ with decreased gut glutamine disposal $(-29 \pm 8 \%, \mathrm{p}<0.05)$ and citrulline production postoperatively $(-66 \% \pm 19 \%, p<0.05)$. In contrast, control mice maintained plasma arginine levels ( $+5 \pm 5 \%)$, gut glutamine disposal $(-2 \pm 10 \%)$ and citrulline production after surgery $(0 \pm 25 \%)$. In MAC16 mice, postoperative SAP levels did not increase to a similar extent as in controls (laparotomy in controls $+4175 \pm 1556 \%$, laparotomy in tumour-bearing $+177 \pm 43 \%, \mathrm{p}<0.05)$. There was no effect of MACl6 on postoperative whole-body arginine and $\mathrm{NO}$ production.

Thus, despite unchanged whole-body arginine flux, arginine metabolism was disturbed in cachectic MACl6 tumour-bearing mice undergoing surgery as evidenced by changes in the interorgan pathway for de novo arginine synthesis and by decreased plasma arginine concentrations.

\section{chapternine |}

Cachectic cancer patients have a poor postoperative recovery compared with non-cancer patients undergoing surgery, which may be related to an inability to mobilize amino acids in the postoperative period due to chronic exhaustion of muscle. We aimed to investigate whether cancer cachexia leads to an impaired postoperative mobilization of protein, both on whole-body level and in muscle. Besides, myofibrillar protein breakdown rates were specifically studied.

We studied cachectic MACl6 tumour-bearing mice (10-15\% body weight loss) and controls before and $24 \mathrm{~h}$ after laparotomy. Stable isotopes were used to 
measure myofibrillar and total protein breakdown on whole-body level, and protein breakdown in hindquarter.

Cachectic MAC16 mice had increased whole-body myofibrillar protein breakdown compared with controls $(1.7 \pm 0.1$ vs $1.3 \pm 0.1 \mathrm{nmol} / 10 \mathrm{~g} / \mathrm{min}, \mathrm{p}<0.05)$ without changes in total protein breakdown on whole-body level (50 \pm 2 vs $48 \pm 2 \mathrm{nmol} /$ $10 \mathrm{~g} / \mathrm{min}$ ) or in muscle $(35 \pm 4$ vs $42 \pm 4 \mathrm{nmol} / 10 \mathrm{~g} / \mathrm{min})$. Following laparotomy, controls maintained myofibrillar protein breakdown $(1.3 \pm 0.2 \mathrm{vs} 1.3 \pm 0.1 \mathrm{nmol} /$ $10 \mathrm{~g} / \mathrm{min}$ ), whereas MAC16 mice did not ( $1.7 \pm 0.1$ vs $1.4 \pm 0.1 \mathrm{nmol} / 10 \mathrm{~g} / \mathrm{min}, \mathrm{p}<0.05)$. In conclusion, cachectic tumour-bearing mice displayed increased catabolism of structural myofibrillar muscle proteins without significant changes in total protein breakdown in muscle. Moreover, cachectic MAC16 mice had an impaired response to surgery with respect to mobilization of myofibrillar protein. 


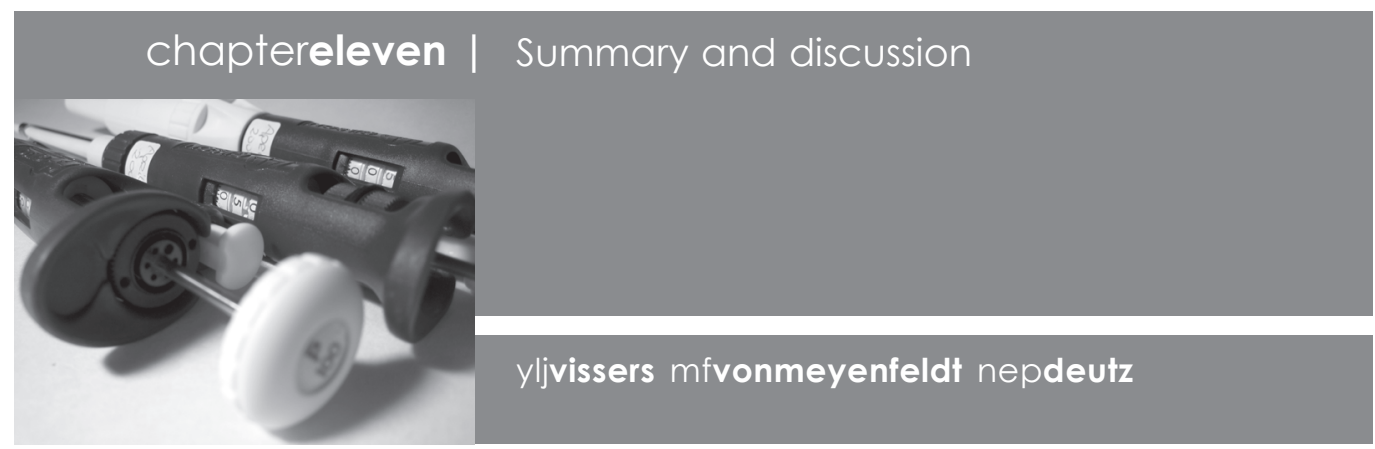

\section{summary}

Weight loss and malnutrition have been associated repeatedly with poor clinical outcome after surgery ${ }^{1-3}$, more specifically with the severity of complications once a complication had occurred ${ }^{4}$. This indicates that correction of nutritional depletion may positively affect postoperative recovery.

Cancer is often accompanied by cachexia, the syndrome of metabolic disturbances with weight loss, anorexia, wasting of muscle mass and adipose tissue as presenting features ${ }^{5}$. In contrast with patients with benign disease, supplementation of large amounts of protein and carbohydrates could not reverse catabolism in cancer patients ${ }^{6}$. This is probably related to the abnormal metabolic response that is present in cancer. Therefore, nutritional strategies in cancer have evolved from a quantitative approach of merely supplying protein and calories to a qualitative one where specific nutrients are used.

In this light, glutamine has been extensively studied, also by our group ${ }^{7,8}$. However, despite positive results on intestinal integrity ${ }^{9}$, infectious complications ${ }^{10}$ and length of stay ${ }^{10,11}$ in cancer patients, there is no consensus on the usefulness of glutamine supplementation in cancer patients. Conflicting results are partly due to variations in patient groups, diverse nutritional strategies and the lack of proper control groups.

Since arginine is a product of glutamine ${ }^{12}$ via conversion to citrulline ${ }^{13}$, weamong others-proposed that positive effects of glutamine supplementation on the postoperative response are mediated via normalisation of low arginine levels. Only limited information is available on in vivo arginine metabolism in cancer. Since both arginine and its product nitric oxide (NO) may affect various tissues in different ways, research into (inter)organ pathophysiology would be valuable. Because interorgan studies are only possible to a limited extent in patients for ethical reasons, animal models are a necessary source of information. Moreover, without knowledge on the pathophysiological changes in arginine metabolism, it is difficult to determine the optimal intervention strategy. Knowledge of interorgan arginine metabolism in the presence of cancer and of how arginine metabolism is affected by surgical trauma can provide a pathophysiological basis for the design of nutritional intervention studies. For example, studying the splanchnic area can give information on possible differences between enteral and parenteral supplementation. 
Therefore, the experiments in this thesis were designed to study interorgan perioperative arginine metabolism in cancer. In part one a rationale for studying perioperative arginine metabolism in cancer is provided and methods for the following experiments are described. In parts two and three the effects of cancer and surgery on arginine metabolism are investigated. Our specific aim was to study the interaction between the presence of tumour and surgical trauma. Both non-cachectic (part two) and cachectic (part three) mice tumour models were used. Since arginine can be produced both from protein breakdown and from endogenous de novo synthesis in the kidney, these two pathways were evaluated in both models.

part one |

Chapter one reviews current knowledge of arginine metabolism in cancer and results from studies with arginine supplementation in cancer. It was concluded that there is limited information on in vivo perioperative arginine metabolism in the presence of tumour. Furthermore, assumed effects of arginine supplementation are mainly based on studies using immune-enhancing diets containing arginine amongst other pharmaconutrients. It must be emphasized that studies using mixtures of pharmaconutrients do not yield valid conclusions on the separate effects of the contents.

Chapter two describes plasma amino acid concentrations in cancer patients in order to explore the concept of disturbances in arginine metabolism in the presence of tumour. We demonstrate that cancer is characterized by low arginine concentrations in plasma, irrespective of tumour type (breast, colonic or pancreatic cancer), cachexia, body mass index or tumour stage. Strikingly, plasma arginine concentrations were decreased in all tumour types studied, including breast cancer, which has always been assumed not to cause derangements in host metabolism, suggesting that decreased arginine concentrations are an early metabolic characteristic of cancer.

In chapter three, methods are described to study interorgan amino acid metabolism. Interorgan studies require blood sampling from vessels supplying and draining the organ of interest. In humans, this is only possible during laparotomy and therefore difficult to perform in the perioperative setting. Therefore, animal experiments are necessary. Advances in the sensitivity of measurement techniques allow the use of very small sample sizes ${ }^{14}$. With the perspective of using transgenetic and knock-out mice, the experiments in this thesis were conducted in mice.

Because whole-body protein turnover reflects both visceral and structural protein metabolism, it does not effectively inform on muscle protein catabolism per se. In chapter four, a new method was introduced to measure myofibrillar protein breakdown using a stable isotope of 3-methylhistidine, a product of actin and myosin heavy chain breakdown. Using this method, myofibrillar protein breakdown rates could be measured in mice for the first time. Although no differences in absolute values of total and myofibrillar protein breakdown were found between various catabolic states, the contribution of myofibrillar protein breakdown to 
total protein breakdown was different in starved animals and starved animals receiving LPS. This suggests that data on myofibrillar protein breakdown provide different information than data on total protein breakdown. It may therefore be of value to study myofibrillar protein breakdown in addition to total protein breakdown.

part two I

In part two, a non-cachectic mouse tumour model (MCA) in the FVB strain was used to study perioperative arginine and protein metabolism in cancer. Chapter five, six and seven demonstrate that non-cachectic tumour-bearing mice did not generate a normal postoperative metabolic response as described in detail below. In chapter five non-cachectic tumour-bearing mice had low plasma arginine concentrations, similar to the cancer patients described in chapter two, suggesting that this mouse tumour model shares features of human cancer. Whole-body arginine production was increased in the presence of tumour, reflecting a high turnover of arginine. Furthermore, serum amyloid P (SAP) concentrations were increased in tumour-bearing mice, indicative of the presence of an ongoing acute phase response in the presence of tumour. When undergoing surgery, MCA tumour mice had attenuated whole-body arginine and NO production rates at day one, and did not upregulate SAP concentrations in plasma postoperatively. ThUs, MCA tumour-bearing mice undergoing surgery had a metabolic arginine deficiency and did not increase acute phase protein synthesis upon surgery, whereas normal mice did.

In chapter six, perioperative interorgan arginine metabolism was studied in noncachectic MCA tumour-bearing mice with emphasis on the glutamine-citrullinearginine axis of de novo arginine production. The presence of tumour was accompanied by increased glutamine production from the hindquarter. Concomitantly, intestinal conversion of glutamine to citrulline was decreased. Furthermore, in contrast with controls, the liver took up citrulline in the presence of tumour, thereby decreasing availability of citrulline for the kidney and decreasing renal conversion of citrulline to arginine.

When undergoing surgery, control mice maintained the de novo arginine pathway while tumour-bearing mice did not maintain preoperative values. More specifically, glutamine production from hindquarter was downregulated in mice with MCA tumours, with less intestinal conversion of glutamine to citrulline. In line with this, renal production of arginine remained suppressed despite increased uptake of citrulline, indicating that renal citrulline was excreted or that arginine disappeared intracellularly in tumour-bearing mice undergoing surgery.

Chapter seven describes perioperative protein metabolism in non-cachectic MCA tumour-bearing mice. Tumour mice had increased rates of both total and myofibrillar protein breakdown on whole-body level, whereas proteasomal ubiquitin dependent protein breakdown was not affected. On organ level, no significant effects of tumour were observed in protein breakdown in the hindquarter, intestine, liver or kidneys. 
After surgical trauma, the increase in myofibrillar protein breakdown observed in control mice undergoing surgery was suppressed in tumour-bearing mice, although the higher variance in the tumour-bearing groups may indicate a type II error.

part three |

In part three, a cachectic mouse tumour model (MAC16) in the NMRI/Bradford strain was used to study perioperative arginine and protein metabolism in cancer. The MACl6 model shares some features of human cancer since it causes weight loss at very small tumour volumes and induces proteolysis inducing factor (PIF), a tumour product that has also been found in the urine of cachectic cancer patients. Chapter eight and nine demonstrate that cachectic tumour-bearing mice did not generate a normal postoperative metabolic response, as described in detail below.

Chapter eight describes that the presence of MACl6 produced few changes in arginine metabolism, including the interorgan de novo arginine pathway, despite ongoing weight loss. Only plasma citrulline concentrations were lower than in controls. Similar to non-cachectic MCA tumour-bearing mice, MACl6 increased SAP concentrations, indicative of an ongoing acute phase response.

The response of $\mathrm{MACl} 16$ tumour-bearing mice to surgical trauma was characterized by low plasma arginine concentrations. Besides, MACl6 caused disturbances in the interorgan de novo arginine pathway after surgery, with downregulated intestinal glutamine disposal and lower citrulline production by the gut. Because renal citrulline disposal remained unchanged, extra-intestinal citrulline production must have increased to compensate for the decreased intestinal citrulline production. In contrast with control mice undergoing surgery, postoperative SAP concentrations did not increase significantly in MACl6 tumour-bearing mice.

Chapter nine describes perioperative protein metabolism in cachectic MAC 16 tumour-bearing mice. MAC16 tumour per se increased whole-body myofibrillar protein breakdown specifically, without changing total protein breakdown or protein turnover in the hindquarter.

Contrary to control postoperative mice, surgery downregulated myofibrillar protein breakdown in MACl6 mice. While postoperative hepatic protein turnover decreased in controls, it increased in MACl6 mice undergoing surgery.

\section{discussion |}

For the studies in this thesis two mouse tumour models were used, the non-cachectic MCA model (FVB strain) and the cachectic MACl6 model (NMRI/Bradford strain). When comparing part two and three, it appears that the two models share several metabolic characteristics. In both tumour models inflammation appears to play a role as evidenced by increased SAP concentrations. MCA tumours induced higher SAP levels than MACl6 tumours. This could suggest that inflammation depended on tumour size. However, in a pilot experiment in MCA mice we found no relation between tumour size and the level of SAP (unpublished observation). Furthermore, because non-cachectic mice had higher SAP concentrations than cachectic 
tumour-bearing mice, it suggests that there was no relation between the level of inflammation and weight loss.

arginine metabolism |

Surgical trauma and cancer are two situations of increased conversion of arginine: 1) high arginase activity after trauma ${ }^{15}$ and 2) high arginase activity via myeloid suppressor cells in the microenvironment of tumours ${ }^{16}$. Hypothetically, this leaves less substrate for several pathways that rely on arginine as substrate in the postoperative period. NO is required for the cytotoxic effect of macrophages 17 and arginine is necessary for a functional T cell response after trauma ${ }^{18}$. Therefore, disturbances in arginine metabolism could have consequences for the host response of cancer patients to surgical trauma. The pathological presence of myeloid suppressor cells may thus lead to immunosuppression and poor outcome. We found low arginine levels in patients with various malignant tumours and in MCA tumour-bearing mice. In cachectic MAC16 tumour-bearing mice, arginine levels were not decreased. Thus, arginine depletion through myeloid suppressor cells may be tumour specific, but this needs further study. Alternatively, differences in mouse strains may account for the variations observed.

Both the non-cachectic MCA tumour and the cachectic MACl6 tumour induced disturbances in postoperative arginine metabolism, albeit with a different focus. In both tumour models the de novo arginine pathway was affected, with a role for diminished production of arginine's precursor citrulline by the gut. This may be related to the diminished supply of glutamine from muscle or be a result of a suppressed functional capacity of the gut per se. Cachectic MAC 16 tumour-bearing mice had low citrulline concentrations without changes in intestinal citrulline production. Therefore, decreased extra-intestinal sources of citrulline production, for example immune cells, or increased citrulline disposal may have contributed to low citrulline concentrations.

Both in FVB and NMRI/Bradford mice, low arginine concentrations were not related to decreased NO production. Thus, availability of extracellular arginine seems no limitation for NO production under the studied conditions. In previous studies in mice with reduced arginine availability, we found a linear relationship between circulating arginine and the rate of NO production. But when the NOS2 gene was disrupted, this relationship was lost ${ }^{19}$. In pigs recovering from endotoxemia, there was also a relation between arginine availability and NO production ${ }^{20}$. However, when arginine levels were reduced after injection of bovine arginase, NO production was not compromised ${ }^{21}$. In humans, arginine intake did not affect $\mathrm{NO}$ synthesis ${ }^{22,23}$. It thus seems that arginine availability may only be limiting for NO production in pathological situations with high NOS2 activity.

When arginine concentrations were decreased in MCA and MAC 16 tumour-bearing mice, this was not accompanied by a compensatory increase in de novo arginine production. Although it has been suggested that arginine synthesis is driven by reduced arginine levels in a rat study ${ }^{24}$, our results are in line with studies in healthy volunteers were de novo arginine synthesis was not upregulated when dietary intake of arginine was reduced ${ }^{25,26}$. Other data on regulation of arginine flux come 
from studies in neonatal piglets, where de novo arginine synthesis (mainly from proline) was upregulated when arginine deficient diets were fed ${ }^{27}$. However, because of the specific enzymatic intestinal machinery of newborns, these results are difficult to extrapolate to the situation of adult animals and humans.

\section{protein metabolism |}

The catabolic response to surgery has been suggested to have two phases: an early phase with mobilisation of protein from pools with a rapid turnover, such as gut and liver (visceral protein breakdown); and a later phase in which protein from pools with a slower turnover is mobilised, such as muscle (structural protein breakdown). It is generally accepted that these tissues are broken down to mobilize amino acids for gluconeogenesis and acute phase protein synthesis in the liver, and for protein synthesis at the wound site. Previous studies on postoperative protein breakdown in patients have reported contradicting results with decreased ${ }^{28}$, increased ${ }^{29}$ or unchanged ${ }^{30}$ rates after surgery, probably caused by variations in the extent of trauma and depending on the chosen time point (early or late postoperative phase) and method to quantify protein breakdown.

The finding that both in chapter seven and nine whole-body protein breakdown was decreased upon surgical trauma, suggests that the experiments were performed in the later phase of the catabolic response. The observation that myofibrillar protein breakdown in control FVB mice was increased postoperatively is also in line with characteristics of the late phase. However, myofibrillar protein breakdown in control NMRI/Bradford mice was not affected by surgery. Apparently, the postoperative response in protein turnover is mouse strain specific.

In contrast to the acute changes in protein turnover after surgical trauma, cancer is accompanied by chronic disturbances in protein metabolism, characterized by increased protein turnover ${ }^{31,32}$. It is assumed that these disturbances in protein metabolism are mainly present in skeletal muscle, eventually leading to the syndrome of cancer cachexia with decreased muscle mass. Proteins can be degraded via various pathways: the lysosomal system, which operates through cathepsins B, H, L and D; a calcium dependent system in the cytosol, in which calpains $\mu$ and $m$ are involved; the ATP-dependent ubiquitin proteasome pathway. The latter is an important route for protein breakdown in cancer and is activated in a parabolic fashion, with an initial rise and then a decline in proteasomal proteolysis with advanced weight loss ${ }^{33,34}$. The lysosomal system is also reported to be activated in cancer, for example in patients with lung cancer ${ }^{35}$. Because cathepsins are probably not able to break down myofibrillar protein ${ }^{36}$, the lysosomal system may be important in early cancer for initiation of proteolysis, after which the ATP- dependent ubiquitin proteolytic pathway degrades structural proteins.

Previous in vitro studies with the MACl6 model $34,37,38$, and in cancer patients 33 showed that muscle protein breakdown depends on the amount of weight loss, suggesting that a phase-like pattern exists. This would support the idea that endogenous protein sources such as muscle become exhausted as cachexia proceeds ${ }^{39}$. 


\section{partfour | chaptereleven}

acute phase response |

It is generally accepted that the amino acids that are released from protein breakdown after the acute injury of surgical trauma are reused by visceral organs, mainly the liver, to support the acute phase response. The role of the acute phase response in cancer is still subject of debate. In previous experiments various inflammatory mediators have been related to cancer. Cytokines such as TNF, IL6 and ILI have been shown to produce various aspects of cachexia in animal models 40. However, although antibodies against cytokines interfere with several pathways involved in proteolysis ${ }^{41}$, they did not reverse weight loss ${ }^{42}$. In cancer patients, plasma CRP levels correlated with production rates of IL6 and TNF 43 and have been used as an index of pro-inflammatory cytokine activity ${ }^{44}$. In line with our mice tumour models, various malignancies in humans are also associated with systemic inflammation and high CRP levels have been correlated with weight loss ${ }^{45}$, anorexia ${ }^{46}$, and poor prognosis ${ }^{47}$. It is long known that the onset of inflammation occurs in conjunction with elevated levels of circulating positive acute phase proteins and a redistribution of body protein, with loss of skeletal muscle proteins. The significance of this "chronic" acute phase response in the presence of tumour is yet to be determined, but is probably different from the "acute" acute phase response that usually occurs after surgical trauma. We speculate that the ongoing acute phase response as observed in tumour-bearing mice may attenuate the initiation of the inflammatory response upon acute metabolic stress, such as surgical trauma. Hypothetically, this may be due to exhaustion of endogenous sources (possibly amino acids from muscle protein) for substrates for acute phase proteins. In weight-losing cancer patients, it was demonstrated that a protein meal upregulated fibrinogen synthesis ${ }^{48}$, indicating that amino acid supplementation can stimulate the acute phase response in cancer. This suggests that the acute phase may be driven by amino acids as substrate. Therefore, the decreased mobilization of myofibrillar proteins in MAC16 tumour-bearing mice undergoing surgery as observed in chapter nine may be related to the observed attenuated immune response due to less substrate for acute phase reactants. This corroborates previous studies by our group in tumourbearing rats undergoing hysterectomy, where the postoperative response was characterized by attenuated protein breakdown in muscle ${ }^{49}$ and intestine ${ }^{50}$. Because absolute SAP concentrations in tumour-bearing mice were higher than (MCA) or as high as (MAC16) postoperative values in control animals, point for discussion remains whether absolute values or relative increases are important for initiation of the postoperative repair response. Further studies are needed to solve this issue.

model |

Some remarks can be made about the experimental mouse model that was used. It is not possible to study organ fluxes without invasive measurements. Strictly taken, the experimental setup may be seen as a double hit model: the first hit being laparotomy, the second hit being the experimental conditions of anaesthesia and placement of catheters for A-V fluxes. How this has affected the results remains speculative, but roughly two options are plausible: 1. The second hit has augmented 
the effects caused by the first hit due to greater metabolic stress. 2. The second hit has attenuated the effects of the first hit due to exhaustion of endogenous amino acid sources. This may explain why in both mouse strains, whole-body protein breakdown was decreased after laparotomy compared with controls, despite apparent weight loss due to starvation and the catabolic stimulus of surgical trauma.

In the present conditions, laparotomy without removal of tumour cannot uncouple the effects induced by the presence of tumour and those determined by laparotomy. In future experiments, it would be informative if a group tumourbearing mice is included in which the tumour is removed during laparotomy. This is also closer to clinical conditions where surgery aims at tumour eradication. The current experimental setup is probably best comparable to patients in whom radical resection of tumour was not possible.

To prevent confounding due to differences in food intake after surgery, all groups of mice were starved after the time of laparotomy. The latter has probably also affected protein and amino acid metabolism. Although 24h starvation did not alter whole-body protein breakdown and arginine or NO fluxes in previous mice studies ${ }^{51}$, it is difficult to reason how this has affected the results when starvation was combined with surgery and the presence of tumour.

precachexia |

From the low arginine concentrations in non-cachectic patients with breast cancer and colonic cancer, it must be concluded that metabolic changes in cancer were already apparent without weight loss being present. Similar findings were obtained from the non-cachectic MCA mouse tumour model, where low preoperative arginine concentrations were accompanied by attenuated postoperative arginine and NO production. It appears that metabolic pathways related to arginine were compromised in non-cachectic tumour-bearing mice. Besides, myofibrillar protein breakdown rates were already increased. The metabolic changes in non-weight losing patients and animals raise the question whether these disturbances are in fact an early phase of the metabolic cascade of that ultimately leads to cachexia. If so, interventions in early metabolic changes in cancer could prevent the onset of events ultimately leading to cachexia.

future |

The results of this thesis warrant further research exploring perioperative disturbances in arginine metabolism in cancer and ways to manipulate them. The focus of the current experiments was interorgan host metabolism. Tumour metabolism affects host metabolism by producing tumour-related factors such as proteolysis inducing factor but also by consuming nutrients at the expense of organs. Therefore, knowledge of amino acid fluxes across the tumour could give important information on the metabolic derangements in cancer. Ochoa and co-workers found that arginase activity in the tumour is a mechanism for tumour-induced immune suppression via depletion of arginine in the microenvironment of the tumour ${ }^{52}$. This would imply that the tumour is an arginine trap, extracting arginine from the circulation and thereby causing metabolic arginine deficiency in the 
host. To solve this issue, in vivo measurements across the tumour are necessary. This requires technical solutions for measuring blood flow across the tumour. The relation between metabolic arginine deficiency and the acute phase response also needs further study. Since the current experiments contained no intervention, no causal relationship between the attenuated acute phase response and postoperative arginine pathways could be studied. Because of arginine's role in T-cell mediated immunity ${ }^{53}$, cytokine induction ${ }^{54}$ and macrophage mediated bacterial toxicity ${ }^{17}$ it is not unlikely that decreased availability of arginine after surgery compromises the acute phase response. Using arginine supplementation could shed light on this issue.

Ultimate goal of the experimental studies in this thesis is to translate knowledge of derangements in arginine and protein metabolism in cancer into perioperative nutritional metabolic interventions in order to prevent or correct metabolic disturbances that impair postoperative recovery in cancer patients.

Firstly, our animal data need to be confirmed in cancer patients. For interorgan studies this is difficult in the perioperative setting, but whole-body measurements using stable isotopes are feasible. Next, effects of supplementation of arginine or one of its precursors on perioperative host metabolism should be investigated. Since the most important factor that determines postoperative recovery is probably surgical skill and decision-making, nutritional metabolic interventions do not have the potential to decrease mortality rates, but may affect the severity of complications once they have occurred. Therefore, the effect of nutritional interventions is probably too limited to be evaluated by crude clinical parameters as survival or number of complications. As a result, more sophisticates measures have to be applied, for example the ability to correct metabolic disturbances. The mechanism of cancer cachexia is probably too complex to be due to one single amino acid, so that modulating one single factor cannot be expected to correct all disturbances in host metabolism in the presence of tumour. However, nutritional supplements containing more than one component should not be evaluated without knowledge of the modulating potential of each of these components. Only interventions with one variable can result in conclusions regarding the effects of a single pharmaconutrient.

\section{references |}

1. Deslauriers J, Ginsberg RJ, Dubois P, Beaulieu M, Goldberg M, Piraux M. Current operative morbidity associated with elective surgical resection for lung cancer. Can J Surg 1989:32(5):335-9.

2. Martin-Ucar AE, Nicum R, Oey I, Edwards JG, Waller DA. En-bloc chest wall and lung resection for non-small cell lung cancer. Predictors of 60-day non-cancer related mortality. Eur J Cardiothorac Surg 2003;23(6):859-64.

3. van Bokhorst-de van der Schueren MA, van Leeuwen PA, Sauerwein HP, Kuik DJ, Snow GB, Quak JJ. Assessment of malnutrition parameters in head and neck cancer and their relation to postoperative complications. Head Neck 1997;19(5):419-25. 
4. Meijerink WHJ. Peri-operative nutrition in Gl cancer patients. Thesis 1992; University of Limburg, The Netherlands.

5. Kern KA, Norton JA. Cancer cachexia. JPEN J Parenter Enteral Nutr 1988;12(3):28698.

6. Brennan MF. Total parenteral nutrition in the cancer patient. $N$ Engl J Med $1981 ; 305(7): 375-82$.

7. van der Hulst RRWJ. Glutamine, an essential nutrient for the gut. Thesis 1996.

8. de Blaauw I. Interorgan protein and glutamine metabolism in the tumor bearing rat. Thesis, Maastricht University, The Netherlands 1996:1-240.

9. van der Hulst RRWJ, van Kreel BK, von Meyenfeldt MF, et al. Glutamine and the preservation of gut integrity. Lancet 1993;341 (8857):1363-5.

10. Ziegler TR, Young LS, Benfell K, et al. Clinical and metabolic efficacy of glutaminesupplemented parenteral nutrition after bone marrow transplantation. A randomized, double-blind, controlled study. Ann Intern Med 1992;116(10):821-8.

11. Schloerb PR, Amare M. Total parenteral nutrition with glutamine in bone marrow transplantation and other clinical applications (a randomized, doubleblind study). JPEN J Parenter Enteral Nutr 1993;17(5):407-13.

12. Houdijk AP, Visser JJ, Rijnsburger ER, Teerlink T, van Leeuwen PA. Dietary glutamine supplementation reduces plasma nitrate levels in rats. Clin Nutr 1998;17(1):11-4.

13. Windmueller HG, Spaeth AE. Intestinal metabolism of glutamine and glutamate from the lumen as compared to glutamine from the blood. Arch. Biochem. Biophys. 1975;171:662-672.

14. van Eijk HM, Rooyakkers DR, Soeters PB, Deutz NEP. Determination of amino acid isotope enrichment using liquid chromatography-mass spectrometry. Anal Biochem 1999;271(1):8-17.

15. Ochoa JB, Bernard AC, O'Brien WE, et al. Arginase I expression and activity in human mononuclear cells after injury. Ann Surg 2001;233(3):393-9.

16. Zea $\mathrm{AH}$, Rodriguez $\mathrm{PC}$, Atkins MB, et al. Arginase-producing myeloid suppressor cells in renal cell carcinoma patients: a mechanism of tumor evasion. Cancer Res 2005;65(8):3044-8.

17. Hibbs JB, Jr., Vavrin Z, Taintor RR. L-arginine is required for expression of the activated macrophage effector mechanism causing selective metabolic inhibition in target cells. J Immunol 1987;138(2):550-65.

18. Rodriguez PC, Zea AH, DeSalvo J, et al. L-Arginine Consumption by Macrophages Modulates the Expression of CD3zeta Chain in T Lymphocytes. J Immunol 2003; $171(3): 1232-9$.

19. Hallemeesch MM, Janssen BJ, de Jonge WJ, Soeters PB, Lamers WH, Deutz NE. NO production by CNOS and iNOS reflects blood pressure changes in LPSchallenged mice. Am J Physiol Endocrinol Metab 2003;285(4):E871-5.

20. Bruins MJ, Soeters PB, Lamers WH, Meijer AJ, Deutz NEP. L-arginine supplementation in hyperdynamic endotoxemic pigs: effect on $\mathrm{NO}$ synthesis by the different organs. Crit Care Med 2002;30(3):508-517.

21. Hallemeesch MM, Vissers YLJ, Soeters PB, Deutz NEP. Acute reduction of circulating arginine in mice does not compromise whole body $\mathrm{NO}$ production. Clin Nutr 2004;23(3):383-90. 
22. Castillo L, Sanchez M, Vogł J, et al. Plasma arginine, citrulline, and ornithine kinetics in adults, with observations on nitric oxide synthesis. Am J Physiol 1995;268:E360-E367.

23. Beaumier L, Castillo L, Ajami AM, Young VR. Urea cycle intermediate kinetics and nitrate excretion at normal and "therapeutic" intakes of arginine in humans. Am J Physiol 1995;269(5 Pt 1):E884-96.

24. Prins HA, Houdijk AP, Wiezer MJ, et al. Reduced arginine plasma levels are the drive for arginine production by the kidney in the rat. Shock 1999;11(3):199-204.

25. Castillo L, Chapman TE, Sanchez M, et al. Plasma arginine and citrulline kinetics in adults given adequate and arginine-free diets. Proc Natl Acad Sci USA 1993;90:7749-7753.

26. Dhanakoti SN, Brosnan JT, Brosnan ME, Herzberg GR. Net renal arginine flux in rats is not affected by dietary arginine or dietary protein intake. J Nutr 1992;122(5):1127-34.

27. Urschel KL, Rafii M, Pencharz PB, Ball RO. A multitracer stable isotope quantification of the effects of arginine intake on whole body arginine metabolism in neonatal piglets. Am J Physiol Endocrinol Metab 2007;293(3):E8118.

28. Carli F, Ramachandra V, Gandy J, et al. Effect of general anaesthesia on whole body protein turnover in patients undergoing elective surgery. $\mathrm{Br} J$ Anaesth 1990;65(3):373-9.

29. Clague MB, Keir MJ, Wright PD, Johnston ID. The effects of nutrition and trauma on whole-body protein metabolism in man. Clin Sci (Lond) 1983;65(2):165-75.

30. Waterlow JC, Golden J, Picou D. The measurements of rates of protein turnover, synthesis, and breakdown in man and the effects of nutritional status and surgical injury. Am J Clin Nutr 1977;30(8):1333-9.

31. Jeevanandam M, Horowitz GD, Lowry SF, Brennan MF. Cancer cachexia and protein metabolism. Lancet 1984;1 (8392):1423-6.

32. Norton JA, Stein TP, Brennan MF. Whole body protein synthesis and turnover in normal man and malnourished patients with and without known cancer. Ann Surg 1981;194(2):123-8.

33. Khal J, Hine AV, Fearon KC, Dejong CH, Tisdale MJ. Increased expression of proteasome subunits in skeletal muscle of cancer patients with weight loss. Int $\mathrm{J}$ Biochem Cell Biol 2005;37(10):2196-206.

34. Khal J, Wyke SM, Russell ST, Hine AV, Tisdale MJ. Expression of the ubiquitinproteasome pathway and muscle loss in experimental cancer cachexia. $\mathrm{Br} \mathrm{J}$ Cancer 2005:93(7):774-80.

35. Jagoe RT, Redfern CP, Roberts RG, Gibson GJ, Goodship TH. Skeletal muscle mRNA levels for cathepsin B, but not components of the ubiquitin-proteasome pathway, are increased in patients with lung cancer referred for thoracotomy. Clin Sci (Lond) 2002;102(3):353-61.

36. Lowell BB, Ruderman NB, Goodman MN. Evidence that lysosomes are not involved in the degradation of myofibrillar proteins in rat skeletal muscle. Biochem J 1986;234(1):237-40. 
37. Smith KL, Tisdale MJ. Increased protein degradation and decreased protein synthesis in skeletal muscle during cancer cachexia. Br J Cancer 1993;67(4):6805.

38. Beck SA, Tisdale MJ. Nitrogen excretion in cancer cachexia and its modification by a high fat diet in mice. Cancer Res 1989;49(14):3800-4.

39. de Blaauw I, Heeneman S, Deutz NEP, von Meyenfeldt MF. Increased wholebody protein and glutamine turnover in advanced cancer is not matched by an increased muscle protein and glutamine turnover. J Surg Res 1997;68(1):4455.

40. MCNamara MJ, Alexander HR, Norton JA. Cytokines and their role in the pathophysiology of cancer cachexia. JPEN J Parenter Enteral Nutr 1992;1616 Suppl):50S-55S.

41. Strassmann G, Fong M, Kenney JS, Jacob CO. Evidence for the involvement of interleukin 6 in experimental cancer cachexia. J Clin Invest 1992;89(5):1681-4.

42. Argiles JM, Busquets S, Lopez-Soriano FJ. Cytokines in the pathogenesis of cancer cachexia. Curr Opin Clin Nutr Metab Care 2003;6(4):401-6.

43. Falconer JS, Fearon KC, Plester CE, Ross JA, Carter DC. Cytokines, the acutephase response, and resting energy expenditure in cachectic patients with pancreatic cancer. Ann Surg 1994;219(4):325-31.

44. Fearon KC, Barber MD, Falconer JS, MCMillan DC, Ross JA, Preston T. Pancreatic cancer as a model: inflammatory mediators, acute-phase response, and cancer cachexia. World J Surg 1999;23(6):584-8.

45. Staal-van den Brekel AJ, Dentener MA, Schols AM, Buurman WA, Wouters EF. Increased resting energy expenditure and weight loss are related to a systemic inflammatory response in lung cancer patients. J Clin Oncol 1995;13(10):2600-5.

46. Wigmore SJ, Plester CE, RosS JA, Fearon KC. Contribution of anorexia and hypermetabolism to weight loss in anicteric patients with pancreatic cancer. $\mathrm{Br}$ J Surg 1997;84(2):196-7.

47. Falconer JS, Fearon KC, Ross JA, et al. Acute-phase protein response and survival duration of patients with pancreatic cancer. Cancer 1995;75(8):2077-82.

48. Barber MD, Fearon KC, MCMillan DC, Slater C, Ross JA, Preston T. Liver export protein synthetic rates are increased by oral meal feeding in weight-losing cancer patients. Am J Physiol Endocrinol Metab 2000;279(3):E707-14.

49. de Blaauw I, Deutz NEP, von Meyenfeldt MF. Cancer reduces the metabolic response of muscle to surgical stress in the rat. J Surg Res 1998;80(1):94-101.

50. de Blaauw I, Deutz NEP, Hulsewé KWE, von Meyenfeldt MF. Attenuated metabolic response to surgery in tumor-bearing rats. J Surg Res 2003;110(2):3717.

51. Braulio VB, Ten Have GA, Vissers YLJ, Deutz NEP. Time course of nitric oxide production after endotoxin challenge in mice. Am J Physiol Endocrinol Metab 2004;287(5):E912-8.

52. Rodriguez PC, Quiceno DG, Zabaleta J, et al. Arginase I production in the tumor microenvironment by mature myeloid cells inhibits T-cell receptor expression and antigen-specific T-cell responses. Cancer Res 2004;64(16):5839-49.

53. Daly JM, Reynolds J, Thom A, et al. Immune and metabolic effects of arginine in the surgical patient. Ann Surg 1988;208(4):512-23. 


\section{partfour | chaptereleven}

54. Reynolds JV, Daly JM, Shou J, Sigal R, Ziegler MM, Naji A. Immunologic effects of arginine supplementation in tumor-bearing and non-tumor-bearing hosts. Ann Surg 1990;211(2):202-10. 


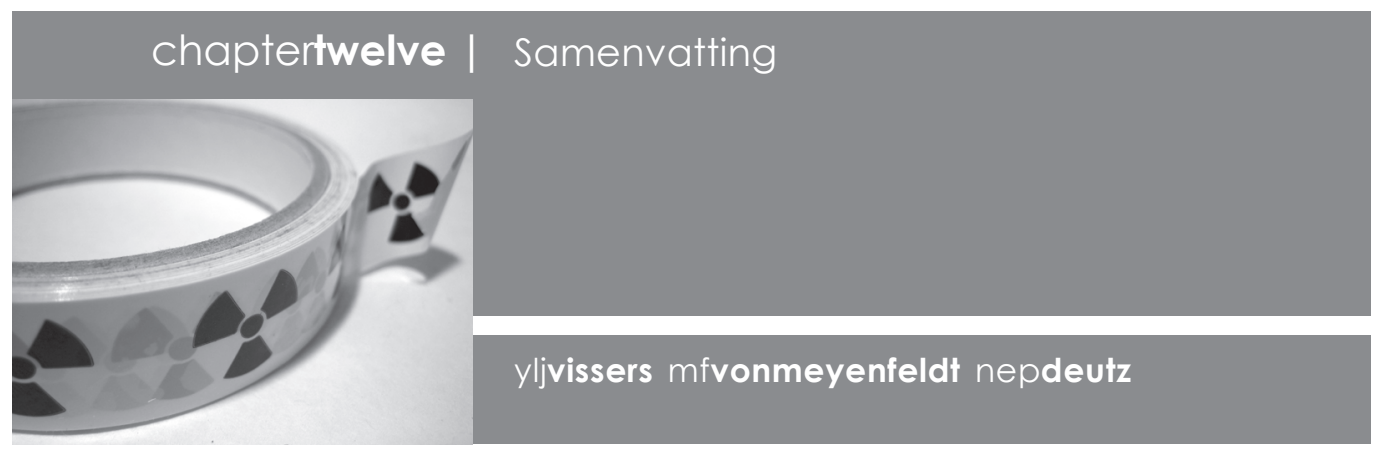

\section{samenvatting |}

De experimenten in dit proefschrift zijn gebaseerd op de observatie dat patiënten met kanker die geopereerd worden slechter herstellen van een operatie dan patiënten zonder tumor die geopereerd worden. Dit is waarschijnlijk gerelateerd aan cachexie, een syndroom van metabole verstoringen met anorexie en verlies van spiermassa en vetweefsel, dat vaak voorkomt bij kanker '. Ondanks vele studies in de afgelopen decennia is er tot nu toe geen interventie bekend die cachexie kan omkeren ${ }^{2}$. Voedingsinterventies zijn daarom geëvolveerd van een kwantitatieve aanpak waarin louter calorieën gesuppleerd worden naar een kwalitatieve, waarin de anticatabole potentie van specifieke voedingsstoffen wordt onderzocht. In dit kader is glutamine vitgebreid bestudeerd, ook door onze groep ${ }^{3,4}$. Ondanks positieve resultaten op darmintegriteit 5 , infectieuze complicaties 6 en opnameduur 6.7 van kankerpatiënten is glutaminesuppletie geen standaardtherapie geworden. Omdat glutamine via citrulline ${ }^{8}$ kan worden omgezet in arginine ${ }^{9}$, hebben wij en anderen gesuggereerd dat positieve effecten van glutaminesuppletie berusten op het corrigeren van lage argininespiegels. Mogelijk dat interventies direct gericht op arginine dus succesvoller zijn. Daarom richten de experimenten in dit proefschrift zich op de perioperatieve argininestofwisseling bij kanker.

Hoofdstuk één geeft een overzicht van de huidige kennis van de argininestofwisseling in kanker en van studies met argininesuppletie in kanker. $\mathrm{Er}$ is beperkte in vivo informatie over de perioperative argininestofwisseling in de aanwezigheid van tumor. Daarnaast zijn veel veronderstelde effecten van argininesuppletie afgeleid van studies met immuunbevorderende voeding die naast arginine andere farmaconutriënten bevat. Uit deze studies kunnen echter geen conclusies worden getrokken over de effecten van arginine alleen.

Hoofdstuk twee beschrijft plasma arginineconcentraties van patiënten met verschillende types tumoren. In onze patiëntengroep ging kanker samen met lage arginineconcentraties in plasma, onafhankelijk van het type tumor (borst-, darmof alvleesklierkanker), de aanwezigheid van cachexie, body mass index of tumorstadiëring. Dit suggereert dat verlaagde arginineconcentraties een specifiek 
kenmerk zijn van kanker. Het is opvallend dat plasma arginineconcentraties verlaagd waren in alle bestudeerde tumortypes, inclusief het mammacarcinoom, waarvan verondersteld werd dat het geen veranderingen in gastheerstofwisseling veroorzaakt. Mogelijk weerspiegelen de metabole veranderingen in mammacarcinoom een vroeg stadium van de cascade die viteindelijk tot cachexie leidt. In dat geval zou kennis van de aminozuur- en eiwitstofwisseling in niet-cachectische kankerpatiënten inzicht kunnen geven in de processen die viteindelijk leiden tot cachexie.

In hoofdstuk drie worden methodes beschreven om aminozuurstofwisseling in organen te bestuderen. Terwijl heel-lichaamsmetingen slechts informatie geven over het totaal van aminozuurfluxen in alle organen samen, geven metingen over organen meer gedetailleerde informatie over regulatiemechanismen. Voor interorgaanstudies is het nodig bloed te verzamelen van bloedvaten die naar het betreffende orgaan toe voeren en het draineren. In mensen is dit alleen mogelijk tijdens een operatie en daarom is dit moeilijk vitvoerbaar in een perioperatieve situatie. Hierom zijn dierproeven onontbeerlijk. Mede in verband met toekomstig onderzoek in transgenen en knock-outmuizen zijn de experimenten in dit proefschrift verricht in muizen.

Omdat heel-lichaamseiwitstofwisseling een optelsom is van orgaan- en myofibrillaire eiwitstofwisseling, is deze niet vanzelfsprekend een maat voor spiereiwitafbraak. In hoofdstuk vier wordt een nieuwe methode beschreven om myofibrillaire eiwitafbraak te meten met een stabiele isotoop van 3-methylhistidine, een product van actine- en myosine-zware-ketenafbraak. Met deze methode konden we myofibrillaire eiwitafbraaksnelheden meten in muizen. De methode maakt geen onderscheid tussen myofibrillaire eiwitafbraak afkomstig vit skeletspier en uit darm en huid. Omdat deze weefsels ook kleine hoeveelheden actine- en myosinevezels bevatten, dragen ze bij aan de totale 3-methylhistidineflux ${ }^{10}$.

Theoretisch geven metingen van 3-methylhistidinefluxen over de achterpoten in plaats van op heel-lichaamsniveau dus betere informatie over myofibrillaire eiwtafbraak vit spier, omdat de achterpoten relatief veel spierweefsel bevatten. In onze handen was de meting over de achterpoten echter niet mogelijk door de kleine arterieel-veneuze verschillen van 3-methylhistidine.

In deel twee en drie van dit proefschrift werden de effecten van kanker en chirurgie op de argininestofwisseling onderzocht. Het specifieke doel was de interactie tussen de aanwezigheid van tumor en chirurgisch trauma te bestuderen. Er werd gebruik gemaakt van zowel een niet-cachectisch (deel twee) als een cachectisch muismodel (deel drie). Omdat arginine zowel vit eiwitafbraak als de novo in de nier gevormd kan worden, werden beide routes bestudeerd.

In deel twee werd een niet-cachectische muistumor (MCA) in de FVB-stam gebruikt om de perioperatieve argininestofwisseling te bestuderen. De postoperatieve reactie in de aanwezigheid van deze niet-cachectische tumor werd gekarakteriseerd door een geremde respons op de operatie, welke wordt 
besproken in hoofdstuk vijf, zes en zeven. In hoofdstuk vijf beschrijven we dat niet-cachectische tumormuizen lage plasma arginineconcentraties hebben, vergelijkbaar met de patiënten met kanker zoals beschreven in hoofdstuk twee. Rodriguez toonde aan dat arginaseactiviteit in de tumor een mechanisme is voor tumorgeïnduceerde immunosuppressie via depletie van arginine in de directe omgeving van de tumor ". Mogelijk onttrekt de tumor op deze manier arginine vit de circulatie en veroorzaakt argininedeficiëntie. Om deze veronderstelling te bevestigen zijn metingen van tumormetabolisme nodig, maar hiervoor moet eerst het technische probleem om bloedstroomsnelheden door de tumor te meten opgelost worden. In vervolgstudies zou het tevens interessant zijn om arginaseactiviteit in weefsels en in plasma van individuen met tumoren te onderzoeken. Nadat MCA-tumormuizen geopereerd waren, bleken de productiesnelheden van arginine en NO op heel-lichaamsniveau verminderd in vergelijking met controlemuizen die geopereerd waren en was er geen stijging van serum amyloid $\mathrm{P}$ (SAP)-concentraties in plasma.

In hoofdstuk zes bleek dat de niet-cachectische tumormuizen tegelijkertijd een verlaagde endogene de novo arginineproductie hadden. Meer specifiek was de glutamineproductie uit de spier verminderd en werd er minder glutamine in citrulline omgezet in de darm. Daarbij was de arginineproductie door de nier verminderd, ondanks dat de nier meer citrulline opnam, wat wijst op vitscheiding van citrulline door de nier of op intracellulair verbruik van arginine in de nier.

Hoofdstuk zeven laat zien dat de aanwezigheid van een fumor in nietcachectische muizen op zich een verhoogde myofibrillaire eiwitafbraak veroorzaakt. Dit suggereert dat kanker verstoringen in de eiwitstofwisseling veroorzaakt reeds voordat er sprake is van gewichtverlies. De postoperatieve eiwitstofwisseling in niet-cachectische tumormuizen was echter niet anders dan die in muizen zonder tumor die geopereerd waren.

In deel drie werden cachectische muizen met tumoren (MAC 16) gebruikt om de perioperatieve argininestofwisseling in kanker te bestuderen. De postoperatieve respons van MACl6-tumormuizen werd gekenmerkt door lage arginineconcentraties in plasma (hoofdstuk acht). Na een operatie veroorzaakte de MACl6-tumor verstoringen in de endogene de novo arginineroute, met verminderde opname van glutamine door de darm en verminderde citrullineproductie door de darm. Dit resulteerde echter niet in verminderde arginineproductie door de nier. Ondanks voortdurend gewichtverlies had de MACl6-tumor opvallend weinig effect op de aminozuurstofwisseling van NMRI/ Bradford-muizen.

Hoofdstuk negen bespreekt dat het eiwitverbruik van MAC16 tumormuizen niet verschillend was van NMRI/Bradford controlemuizen ten tijde van de metingen. Waarschijnlijk zijn er al in een eerdere fase van gewichtverlies duidelijkere verstoringen in de eiwitstofwisseling geweest, waarna slechts kleine afwijkingen nodig zijn om in een katabole status te resulteren. Hiervan vitgaande zou bestuderen van de niet-cachectische fase van kanker wellicht inzicht kunnen geven in de processen die cachexie aansturen. 
De postoperatieve myofibrillaire eiwitafbraak in MAC16 muizen was onderdrukt in vergelijking met NMRI/Bradford controlemuizen. Hierdoor komen minder aminozuren vrij en is er mogelijk minder substraat voor de acute-fasereactie. Deze observatie is vergelijkbaar met eerder bestudeerde tumorratten bij wie de baarmoeder verwijderd werd; ook in deze dieren was de postoperatieve eiwitafbraak verminderd in spierweefsel ${ }^{12}$ en in de darm ${ }^{13}$. Samenvattend was er in de aanwezigheid van tumor een onderdrukte respons op chirurgie, wat postoperatieve herstelprocessen negatief zou kunnen beïnvloeden.

\section{referenties}

1. Kern KA, Norton JA. Cancer cachexia. JPEN 1988;12(3):286-98.

2. Brennan MF. Total parenteral nutrition in the cancer patient. $N$ Engl J Med 1981;305(7):375-82.

3. van der Hulst RRWJ. Glutamine, an essential nutrient for the gut. Thesis 1996.

4. de Blaauw I. Interorgan protein and glutamine metabolism in the tumor bearing rat. Thesis, Maastricht University, The Netherlands 1996:1-240.

5. van der Hulst RRWJ, van Kreel BK, von Meyenfeldt MF, et al. Glutamine and the preservation of gut integrity. Lancet 1993;341 (8857):1363-5.

6. Ziegler TR, Young LS, Benfell K, et al. Clinical and metabolic efficacy of glutaminesupplemented parenteral nutrition after bone marrow transplantation. A randomized, double-blind, controlled study. Ann Intern Med 1992;1 16(10):821-8.

7. Schloerb PR, Amare M. Total parenteral nutrition with glutamine in bone marrow transplantation and other clinical applications (a randomized, double-blind study). JPEN 1993;17(5):407-13.

8. Windmueller HG, Spaeth AE. Intestinal metabolism of glutamine and glutamate from the lumen as compared to glutamine from the blood. Arch Biochem Biophys 1975;171:662-672.

9. Houdijk AP, Visser JJ, Rijnsburger ER, Teerlink T, van Leeuwen PA. Dietary glutamine supplementation reduces plasma nitrate levels in rats. Clin Nutr 1998;17(1):11-4.

10. Rennie MJ, Millward DJ. 3-Methylhistidine excretion and the urinary 3methylhistidine/creatinine ratio are poor indicators of skeletal muscle protein breakdown. Clin Sci 1983;65(3):217-25.

11. Rodriguez PC, Quiceno DG, Zabaleta J, et al. Arginase I production in the tumor microenvironment by mature myeloid cells inhibits T-cell receptor expression and antigen-specific T-cell responses. Cancer Res 2004;64(16):583949.

12. de Blaauw I, Deutz NEP, von Meyenfeldt MF. Cancer reduces the metabolic response of muscle to surgical stress in the rat. J Surg Res 1998;80(1):94-101.

13. de Blaauw I, Deutz NEP, Hulsewé KWE, von Meyenfeldt MF. Attenuated metabolic response to surgery in tumor-bearing rats. J Surg Res 2003;1 10(2):3717. 
partfour | chaptertwelve 



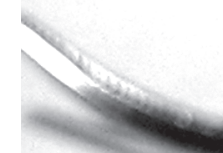

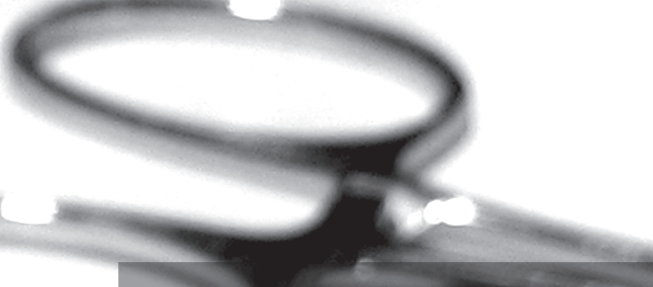

oppendices

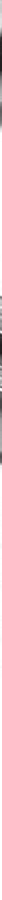

partfive 


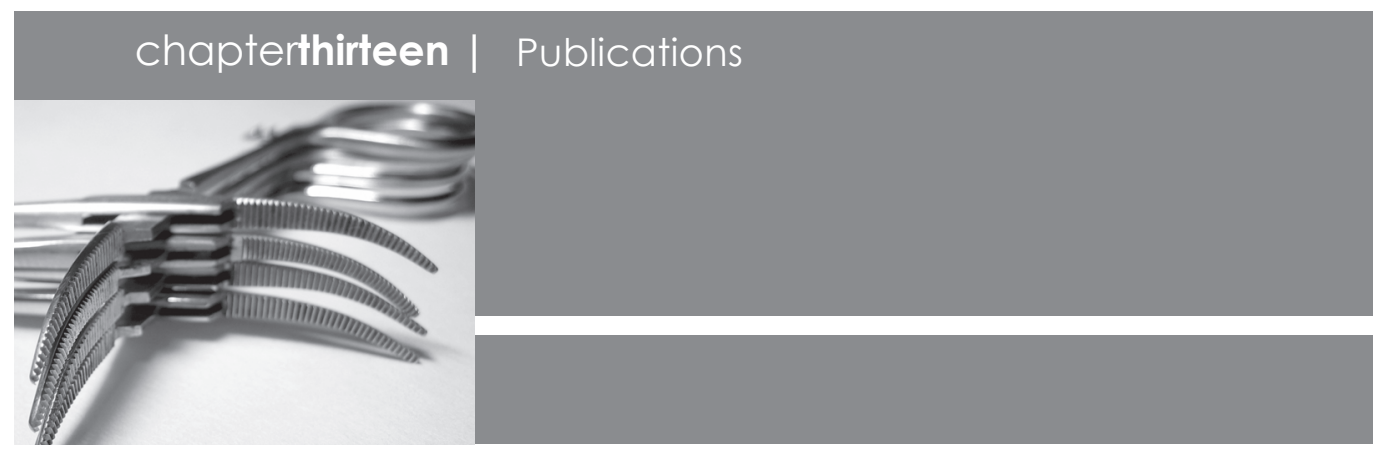

Interorgan synthesis of arginine is downregulated in tumour-bearing mice undergoing surgical trauma.

Vissers YLJ, von Meyenfeldt MF, Luiking YC, Dejong CHC, Deutz NEP. Metabolism, in press.

Presence of tumour inhibits the normal post-operative response in arginine and NO-production in non-cachectic mice.

Vissers YLJ, von Meyenfeldt MF, Luiking YC, Dejong CHC, Buurman WA, Deutz NEP. Clinical Science (London) 2007;1 12(10):527-32.

Protein breakdown on whole-body and organ level in non-cachectic tumourbearing mice undergoing surgery.

Vissers YLJ, von Meyenfeldt MF, Argilés JM, Luiking YC, Dejong CHC, Deutz NEP. Clinical Nutrition 2007;26(4):483-90.

Verstoring in het argininemetabolisme.

Vissers YLJ, von Meyenfeldt MF, Luiking YC, Dejong CHC, Deutz NEP. Tijdschrift Kanker 2007;februari(1):6-10.

Plasma arginine concentrations are reduced in cancer patients: evidence for arginine deficiency?

Vissers YLJ, Dejong CHC, Luiking YC, Fearon KC, von Meyenfeldt MF, Deutz NEP. American Journal of Clinical Nutrition 2005;81 (5):1 142-6.

Pro and con of L-arginine supplementation in disease.

Vissers YLJ, Debats IBJG, Luiking YC, R Jalan, RRWJ van der Hulst, CHC Dejong, NEP Deutz.

Nutrition Research Reviews 2004;17(2):193-210.

In vivo whole body and organ arginine metabolism during endotoxemia (sepsis) is dependent on mouse strain and gender.

Luiking YC, Hallemeesch MM, Vissers YLJ, Lamers WH, Deutz NEP.

Journal of Nutrition 2004;134(10 Suppl):2768S-2774S; discussion 2796S-2797S. 
Time course of nitric oxide production after endotoxin challenge in mice. Braulio VB, ten Have GAM, Vissers YLJ, Deutz NEP.

American Journal of Physiology - Endocrinology and Metabolism 2004;287(5):E9128.

Acute reduction of circulating arginine in mice does not compromise whole body NO production.

Hallemeesch MM, Vissers YLJ, Soeters PB, Deutz NEP.

Clinical Nutrition 2004;23(3):383-90.

Reliability and validity of a qualitative and quantitative motor test for 5- to 6year-old children.

Kroes M, Vissers YLJ, Sleijpen FA, Feron FJM, Kessels AGH, Bakker E, Kalff AC, Hendriksen JGM, Troost J, Jolles J, Vles JSH.

European Journal of Paediatric Neurology 2004;8(3):135-43.

NOS2 deficiency increases intestinal metabolism both in nonstimulated and endotoxemic mice.

Vissers YLJ, Hallemeesch MM, Soeters PB, Lamers WH, Deutz NEP.

American Journal of Physiology - Gastrointestinal and Liver Physiology 2004;286(5):G747-51.

Measuring whole-body actin/myosin protein breakdown in mice using a primed constant stable isotope infusion protocol.

Vissers YLJ, von Meyenfeldt MF, Braulio VB, Luiking YC, Deutz NEP.

Clinical Science (London) 2003;104(6):585-90.

Quality of movement as predictor of ADHD: results from a prospective population study in 5- and 6-year-old children.

Kroes $M$, Kessels AGH, Kalff AC, Feron FJM, Vissers YLJ, Jolles J, Vles JSH.

Developmental Medicine \& Child Neurology 2002;44(11):753-60. 
partfive | chapterthirteen 


\section{partfive | chapterfourteen}

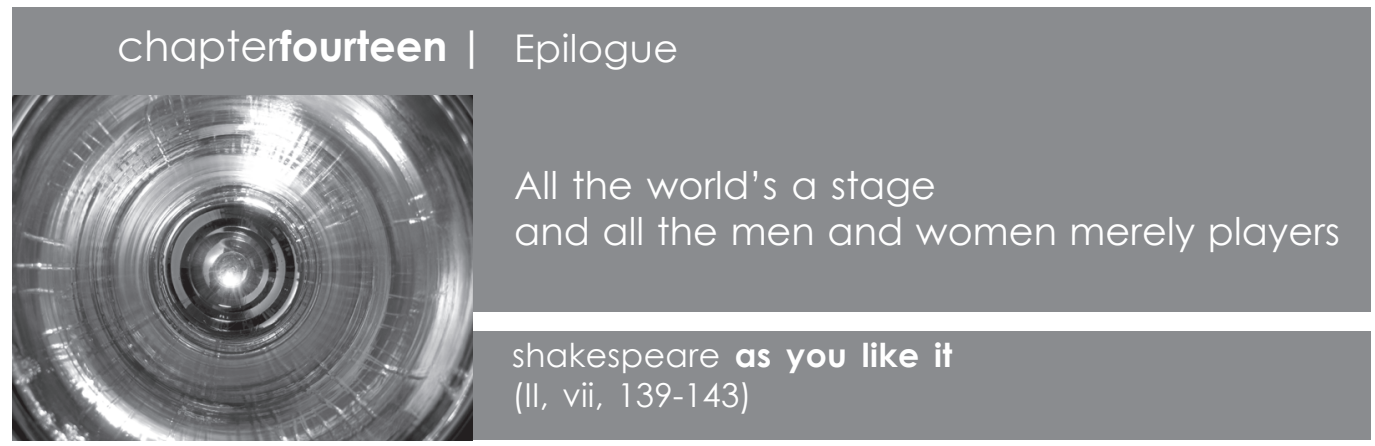

regie |

Mick Deutz

Maarten von Meyenfeldt

souffleurs |

Kees Dejong

Yvette Luiking

understudy Yvonne |

Gabrie ten Have

techniek |

Hans van Eijk

Jean Scheijen

Dennis Haagen

Dennis Suylen

décor |

kamer 5.348

requisieten |

CPV

RNL

Josep Argilés

Mike Tisdale

gastoptredens |

José Maessen

Miranda Hendrix

Trudy Jeunhomme

Jessica ter Steege

mammacare azM

Marielle Engelen

Kirsten Cosemans

Valeria Bender Braulio

Marion Jourdan

script |

mental coach

Jean Scheijen

Dannick Ritt 


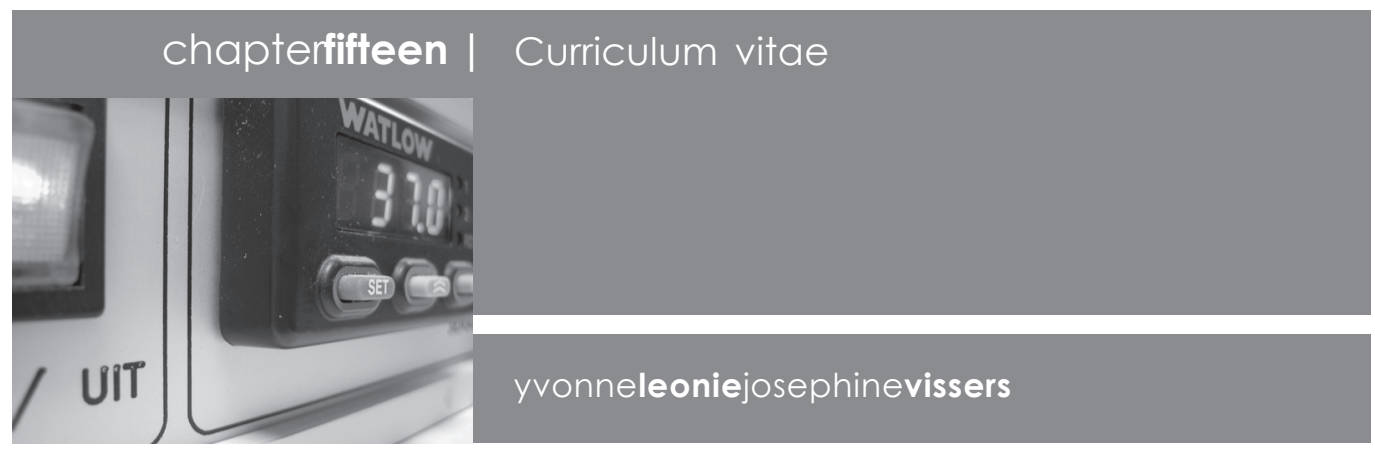

personalia

$10 \cdot 07 \cdot 2007$ geboorte zoon Max

$22 \cdot 04 \cdot 2006$ gehuwd met Dannick Ritt

24.05.1975 geboren te Heerlen

\section{opleiding}

2007 - heden arts in opleiding tot specialist Algemene Heelkunde, Maaslandziekenhuis Sittard (opleider AGM Hoofwijk)

2005 - 2006 arts in opleiding tot specialist Algemene Heelkunde, Academisch Ziekenhuis Maastricht (opleider JWM Greve)

2001 - 2004 arts-onderzoeker project "Arginine: peri-operative depletion en repletion in cancer", afdeling Algemene Heelkunde, Academisch Ziekenhuis Maastricht (projectleiders MF von Meyenfeldt en NEP Deutz)

2001 stage "Ontwikkeling van nieuwe technieken voor het bepalen van de activiteit van het ATP-ubiquitine-afhankelijk systeem", afdeling Biochemie en Moleculaire Biologie, Universiteit van Barcelona, Spanje (begeleider JM Argilés)

1999 - $2001 \quad$ student-arts in opleiding project "Regulation protein breakdown in cancer", afdeling Algemene Heelkunde, Academisch

Ziekenhuis Maastricht (projectleiders MF von Meyenfeldt en NEP Deutz)

1996 - 1999 studentassistent project "Developmental characteristics ADHD in pre-school children", afdeling Neurologie, Academisch Ziekenhuis Maastricht (projectleider JSH Vles)

1993 - 2001 studie Geneeskunde aan de Universiteit Maastricht 1987 - 1993 Gymnasium-ß aan het Jeanne d'Arc College, Maastricht 
prijzen |

2005 Young Investigator Award, European Society of Parenteral and Enteral Nutrition. Post-operative arginine metabolism is disturbed in cachectic and non-cachectic tumor-bearing mice.

2002 AGIKO-stipendium, ZonMw. Arginine: peri-operatieve depletie en repletie in kanker.

2002 Research Fellowship, European Society of Parenteral and Enteral Nutrition. Regulation of protein breakdown in cancer.

2001 Travel Award, European Society of Parenteral and Enteral Nutrition. $\mathrm{N}$-tau-methylhistidine production rate in male mice is increased after brief and prolonged starvation.

2001 Young Investigator Award, Federation of American Societies for Experimental Biology. Measuring actin/myosin protein breakdown in mice using a primed constant infusion protocol. 
partfive | chapterfifteen 




